\title{
Die Süsswasserfauna
}

Deutschlands

Herausgegeben von

A. BR AUER

HEFT 8:

EPHEMERIDA, PLECOPTERA,

LEPIDOPTERA

bearbeitet von

F. KLÁPALEK, K. GRÜNBERG

Jena, Verlag von Gustay Fischer 



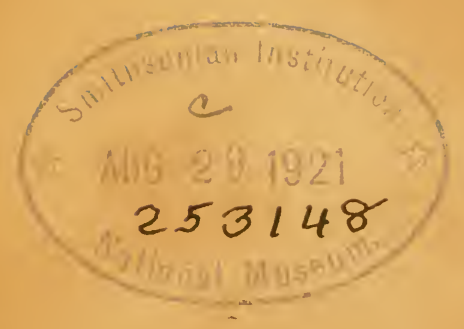





\section{DIE}

\section{SÜSSWASSERFAUNA DEUTSCHLANDS}

\section{EINE EXKURSIONSFAUNA}

\section{BEARBEITET VON}

Prof. Dr. Böhmig (Graz), Prof. Dr. Brauer (Berlin), Prof. Dr. Colutin (Berlin), Prof. Dr. Dahl (Berlin), C. van Douwe (München), Prof. Dr. von Graff (Graz), Dr. Grünberg (Berlin), Dr. Hartmeyer (Berlin), Prof. Dr. R. u. H. Heymons (Berlin), Prof. Dr. JäGERSKIöld (Göteborg), Dr. Johansson (Göteborg), Dr. KeILhack (Berlin), Prof. Dr. Ḱ,apálek (Karlin bei Prag), F. Koenike (Bremen), Dr. Kuhrgatz (Danzig), Dr. v. Linstow (Göttingen), Dr. Lühe (Königsberg), Prof. Matschie (Berlin), Prof. Dr. MichaeiSen (Hamburg), Dr. Neresheimer (Wien), Dr. Pa ppenheim (Berlin), Prof. Dr. Reichenow (Berlin), E. Reitter (Paskau), Dr. Ris (Rheinau), Dr. Thiele (Berlin), Prof. Dr. Tornier (Berlin), G. Ulmer (Hamburg), Dr. VÁvra (Prag), Prof. Dr. Weltwer (Berlin)

UND HERAUSGEGEBEN

VON

Prof. Dr. Brauer (Berlin).

HEFT 8:

EPHEMERIDA, PLECOPTERA, LEPIDOPTERA

BEARBEITET VON

FR. KLAPÁLEK, K. GRÜNBERG.

MIT 260 FIGUREN IM TEXT.

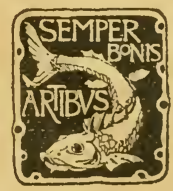

VERLAG VON GUSTAV FISCHER, JENA 1909. 
ALLE RECHTE VORBEHALTEN.

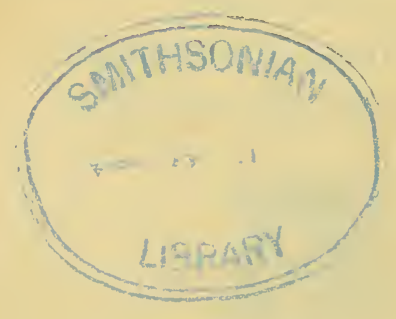




\section{Vorwort.}

In den letzten beiden Jahrzehnten ist die große Bedeutung, welche die Süßwasserfauna in wissenschaftlicher und wirtschaftlicher Hinsicht verdient, mehr und mehr wie in anderen Ländern so auch in Deutschland erkannt worden, und der Staat, Vereine und Private sind durch Bewilligung von Mitteln, durch Gründung von Stationen und Instituten bemüht gewesen, die Erforschung der Süßwasserfauna zu fördern. Neben praktischen Fragen wie der Kenntnis der Lebensweise und Lebensbedingungen der wirtschaftlich wichtigen Krebse und Fische, dem Nahrungswert der kleinen Tiere u. a. bilden rein wissenschaftliche, wie die Feststellung der Variabilität der Tiere unter verschiedenen Bedingungen, der Verbreitung der Glazialrelikte u. a. den Inhalt der Forschung. Welche Fragen man aber auch in Angriff nehmen mag, und ob man intensiver oder nur vorübergehend, um zu forschen oder um sich und andere zu unterrichten, der Süßwasserfauna sein Interesse zuwenden mag, immer wird sich die Notwendigkeit ergeben, die systematische Stellung der untersuchten Formen zu ermitteln. Hierfür fehlte bisher jegliches, die ganze Süßwasserfauna zusammenfassende Werk. Wohl behand eln einige dieselbe, ich erinnere besonders an das Werk Lamperts „Das Leben der Binnengewässer", aber alle behandeln die Tiere nur mit Auswahl und berücksichtigen besonder's die biologischen Verhältnisse der auffallenderen und bekannteren Formen. Diese Lücke soll dieses Werk auszufüllen suchen. Es soll ein wissenschaftliches Bestimmungsbuch für die Süßwasserfauna Deutschlands sein. Es sind deshalb keine längeren anatomischen oder biologischen Beschreibungen gegeben, sondern Bestimmungstabellen und kurze, aber gut durchgearbeitete Diagnosen, die alle wichtigen morphologischen Charaktere, ferner wichtige biologische und faunistische Notizen enthalten. Zur Unterstützung des Textes sind möglichst viele Figuren gegeben, die zwar einfach gehalten sind, aber die für die Bestimmung in Betracht kommenden Merkmale zeigen. Neben der knappen Form, die den praktischen Gebranch und die Übersichtlichkeit des Werkes erleichtern soll, wurde als Hauptaufgabe angesehen, dem gegenwärtigen Stande der Kenntnisse soweit als möglich gerecht $\mathrm{zu}$ werden und eine vollständige Zusammenstellung aller bisher beschriebenen deutschen Süßwassertiere zu geben. Die Durcharbeitung hat gezeigt, wie lückenhaft auf diesem Gebiete unsere Kenntnisse zum Teil noch sind, wieviel noch übrig bleibt, namentlich zur Erforschung der Larven und Jugendstadien. Diese Iü̈cken auszufüllen überschreitet die Kräfte Einzelner.

Hier müssen viele mit helfen, und es würde als ein großer Erfolg des Werkes betrachtet und von den Bearbeitern mit großem Dank begrüßt werden, wenn die Benutzer den Heransgeber oder die einzelnen Bearbeiter der Gruppen auf Lücken aufmerksam machten und besonders durch Mitteilung eigener Beobachtungen oder durch Einsenden des Materials an der Verbesserung und Vervollständigung des Werkes mithelfen würden. 
Schwierig war die Frage, was unter ,Süßwasserfauna" zu verstehen sei. Es sind in dem Werk zu ihr sowohl die Tiere, welche in und auf dem Süßwasser leben, als auch diejenigen, welche an den Rändern der Teiche, Seen, Flüsse u. a. leben, aber nur solche welche zum Wasser in engster Beziehung stehen, gerechnet worden; dagegen sind solche, welche nur vorübergehend das Wasser oder seine Ränder aufsuchen, ausgeschlossen worden. In manchen Gruppen sind vielleicht Tiere mit behandelt worden, welche besser als Landtiere $\mathrm{zu}$ bewerten sind, aber ein Zuviel dürfte hier weniger schaden als ein Zuwenig. Lediglich praktische Gesichtspunkte sind måßgebend gewesen, wenn das hier behandelte Faunengebiet einstweilen auf das politische Deutschland beschränkt wurde. So wünschenswert es gewiß gewesen wäre, die Grenzen weiter zu stecken und die Süßwasserfauna mindestens von ganz Mitteleuropa zusammenzufassen, so mußte doch vorläufig von diesem Ziel Abstand genommen werden, um das Werk in absehbarer Zeit überhaupt zum AbschluB bringen zu können und um vor allem eine wesentliche Verschiedenheit und Ungleichartigkeit in der Bearbeitung zu vermeiden, die wegen der zum Teil noch sehr ungenügenden Kenntnis der Süßwasserfauna der nichtdeutschen Länder die unausbleibliche Folge gewesen wäre. Der dadurch erzielte Gewinn hätte in keinem Verhältnis zu dem großen Mehraufwand von Arbeit und Zeit gestanden. Es versteht sich von selbst, daß Formen, welche außerhalb Deutschlands, aber nahe seinen Grenzen gefunden sind und deren Vorkommen auch in Deutschland wahrscheinlich ist, mit berïcksichtigt wurden.

Unberücksichtigt ist vorläufig auch die Abteilung der Protozoen geblieben. Der Grund liegt darin, daß gute systematische Werke, Z. B. diejenigen von $\mathrm{Blochmann}$ und $\mathrm{B}$ ütschli, bereits vorliegen, und weiter, daß von anderer Seite eine gründliche neue Durcharbeitung in den nächsten Jahren zu erwarten ist. Später soll diese Lücke ausgefüllt werden.

Zum Schluß drängt es mich, allen Mitarbeitern an diesem Werk meinen besten Dank zu sagen. Sie haben sich alle bemüht, rechtzeitig das zum Teil riesige Material zu bearbeiten und in meinem Sinne die große Aufgabe zu lösen.

Nicht weniger danke ich aber dem Verleger. Er hat nicht nur alles getan, was zur Ausstattung des Werkes dienen konnte, sondern ist auch stets auf jeden Wunsch eingegangen und hat in jeder Weise mitgeholfen, das Zustandekommen des Werkes zu sichern, obwohl der Umfang weit über den Anschlag hinausgewachsen ist

Berlin 1909.

A. Braner. 


\title{
I. Ephemerida, Eintagsfliegen.
}

Vol1

\author{
Prof. Fr. Klapálek (Karliu).
}

Mit 53 Abbildungen im Text.

\section{Ordnung Ephemerida, Eintagsfliegen.}

Kiopf verhältnismäßig klein, mit rerkïmmerten MIundwerkzeugen, 3 Punktaugen, 2 zusammengesetzten Augen und 2 ahlförmigen Fühlern. Diese hestehen aus 2 kurzen, aber starken Grundgliedern und einer vielgliedrigen feinen Borste. Die Augen sind bei den Männchen immer viel größer als hei den Weibchen und bei vielen Gattungen in 2 Abschnitte geteilt. Der obere Teil zeigt gröbere Facettierung und ist öfters anders gefärbt als der untere. Wenn die Furche zwischen beiden Teilen tief ist. nimmt der obere eine zylindrische Form an und ist nur auf seiner oberen Fläclıe facettiert; der untere bleibt dagegen eiförmig und ist auf seiner ganzen Oberfläche mit Facetten bedeckt.

Thorax ist stark, aber sein erster Ring steht, was seine Größe anbelangt, auffallend hinter den beiden anderen Ringen und ist ziemlich fest mit dem zweiten verbunden. Am stärksten ist der Mesothorax entwickelt. Beine sind immer schwach, manchmal ganz gebrauchsunfähig. Beim Männchen sind die Vorderfüße immer länger als beim Weibchen. In der Regel sind die Torderfüße länger als die Mittel- und Hinterfüße. Die Füße sind 4-5gliedrig, auf verkümmerten Beinen aber auch nur '2 gliedrig oder' ganz ungegliedert. Die Zahl der Glieder ist entweder auf allen Füßen gleich, nämlich 5, oder es sind die Vorderfüße 5-, die übrigen nur 4 gliedrig. Die Klauen sind entweder gleich oder ungleich, spitzig oder stumpf.

Die Torderflügel sind in der Regel dreickig, an den Fcken abgerundet. Hinterflügel, wenn sie ïberhaupt entwickelt sind, bleiben immer viel kleiner als das erste Paar, manchmal sind sie schmal pfriemenförmig mit stark reduzierter Nervatur. Gewöhnlich sind sie eiförmig oder länglich eiförmig und öfters ist ilır Vorderrand winklig vorgezogen.

Die Flügelmembran ist in d^r Regel zart, stark glänzend, selır oft irisierend, selten gefleckt, manchmal aher graulich oder weißlich getrübt. Nervatur fein, in der Regel dicht, mit vielen Längs- und Queradern. An dem Außenrande der Flügel finden wir oft kurze Adern einzeln oder zu zwei, welche ganz frei zwischen den Ästen der Längsadern verlaufen und welche wir Zwischenraumadern 
nennen. Von den Längsadern bildet die Costa den Vorderrand des Flïgels, Subcosta ist gerade und mit dem Rande fast parallel, und bleibt lis zu ihrer Einmündung in die Costa einfach; Radius läuft parallel mit der Subcosta und entsendet schon am Grunde den Sector radii, welcher mehrere Äste bildet; Media ist etwa in der Flügelmitte, Cubitus nahe am Grunde gegabelt und zwischen
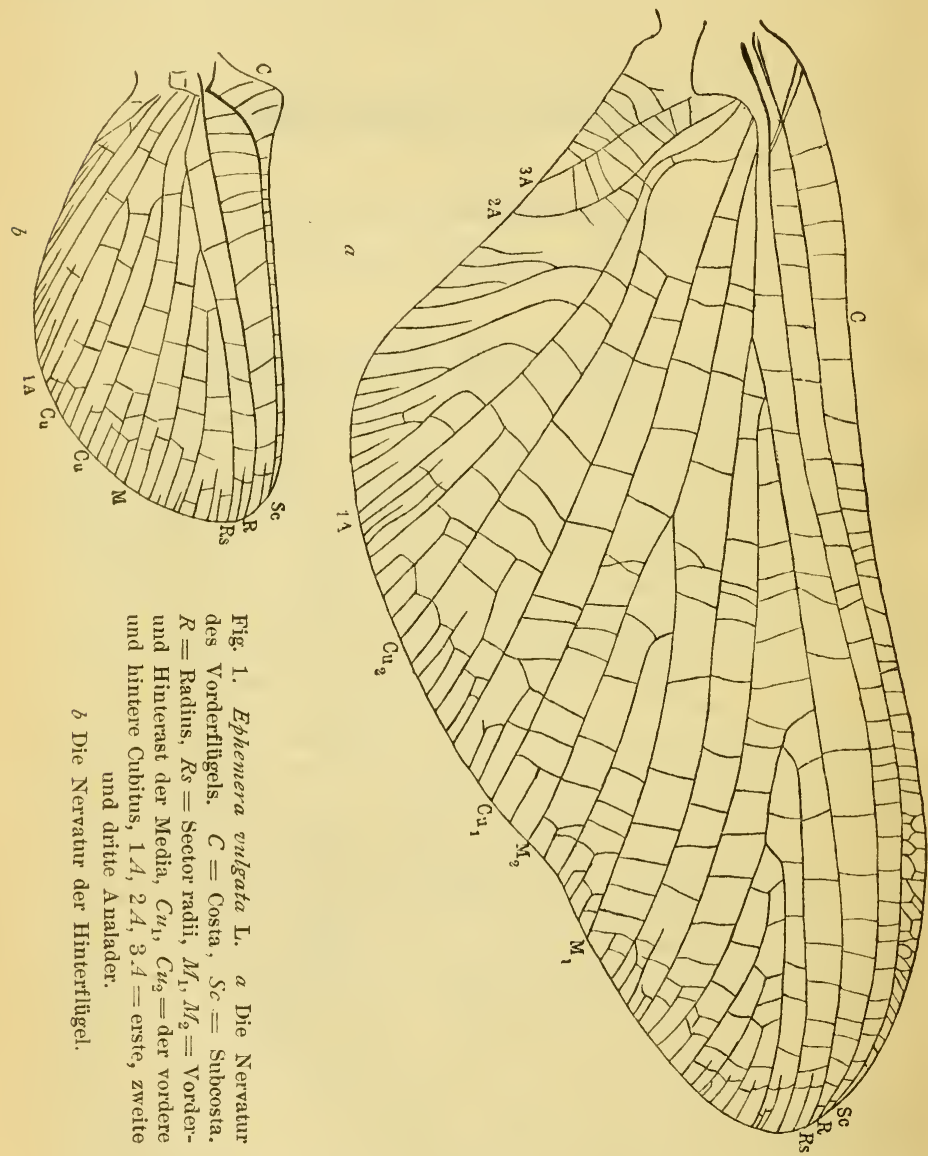

2 Hauptästen des letzteren sehen wir mehrere eingeschaltenęLängsadern; von den Analadern mündet die erste in den Außenrand des Flügels in der Nähe des analen Winkels desselben, die zwei übrigen überschreiten selten die Mitte des Imnenrandes. Für die Systematik ist hesonders das gegenseitige Verhältnis des Cubitus und der vorderen zwei Analadern wichtig. Es ist anffallend, wie die Nervatur trotz ihrer Kompliziertheit konstant ist. 
Der Itinterleih zeigt 10 dentliche Ringe, die ziemlich gleichmäßig gebildet sind. Beim o ist die 9. Ventralplatte ausgeschnitten oder bildet eine mehr oder weniger deutliche Subgenitalplatte, an welche sich die starken Genitalfüße stïtzen; diese sind gewöhnlich 3-4 gliedrig und bilden Greiforgane, mit welchen das Männchen seine Partnerin erfaßt. Über und zwischen den Genitalfüßen ragt meist deutlich die Rute vor, welche chitinisiert und immer aus 2 Röhrchen oder "Hörnern" besteht, von welchen jedes eine selbstständige Öffnung zeigt. Nanchmal gesellen sich zu der Rute noch dornartige Fortsätze, welche wir Titillatoren nennen wollen. Üher der Rite ist das 10. Segment, aus welchem die langen vielgliedrigen Schwanzfäden herausragen; diese sind entweder nur 2 und stellen uns die Anhänge des 11. Ringes dar, sog. Cerci, oder es ist noch eine Mittelborste vorhanden, welche die gegliederte Verlängerung des Supraanallobus bildet.

Beim Weilochen befindet sich die Genitalöffnung am Grunde des 8. Ringes und ist öfters durch eine kleine Verlängerung der 7. Ventralplatte - die Subgenitalplatte - verdeckt. Auch die 9. Ventralplatte ist vorgezogen und bildet die Supragenitalplatte. Dann folgt das 10. Segment und die Schwanzborsten.

Die Eintagsfliegen halten sich meist in der Nähe von fließenden Gewässern auf, obwohl einige Arten auch in den Teichen und Seen sich entwickeln. Auch die während des Tages fliegenden Arten vermeiden die Mittagssonne und jagen sich bei schönem Wetter am liebsten im Sonnenscheine etwa bis zur 10. Stunde und vor dem Sonnenuntergange. Manche Arten sind ausgesprochene Nachttiere und werden wie diese durch das Licht und helle, beleuchtete Flächen angelockt. Der Flug von Ephemeriden ist sehr charakteristisch und besteht aus einem tanzenden Auf- und Absteigen in einer fast vertikalen Richtıng. Bei schlechtem Wetter oder während der Mittagshitze können wir sie durch Ḱlopfen auf die Gebüsche aufschenchen.

Die Weibchen legen ihre in einem Klumpen hervorquellenden Eier in das Wasser, über demselben fliegend oder seltener in dasselbe hinabsteigend; das letztere unternehmen merkwürdigerweise die zarten Arten der Gattung Baëtis. Die Daner des Eierstadiums ist besonders nach der Temperatur verschieden, ist aber wahrscheinlich immer recht lang; hei Polymitarcis ist in dem Laboratorium heobachtet worden, daß die Jungen erst nach 6-7 Monaten aus den Eiern schlüpften.

Die Nymphe ist dem vollkommenen Insekte ziemlich ähnlich, hat aber selbstverständlich keine Flügel, deren Scheiden allmählich nach den zahlreichen Häutungen auf dem Thorax sich entwickehn, besitzt vollkommen ausgebildete beißende Mundteile und atmet durch die auf dem Hinterleibe befindlichen Kiemen. Auf dem Kopfe sind 2 mäßig große Augen, 3 Punktaugen und ahlförmige oder horstenförmige Fühler. Die Mandibeln sind stark, entweder als einfache, nach vorn gerichtete Fangzähne entwickelt, oder auf ihrer Innenseite mit einer starken Kaufläche versehen, oder stark und kurz mit starken Zähnen bewehrt. Auf der Maxilla sehen wir nur eine einzige Lade, welche in ihrer Form der Lacinia entspricht und den 2-4 gliedrigen Taster; die Form der Lade und die rela- 
tive Länge des letzten Tastergliedes sind systematisch wichtig. Labium kurz mit deutlichen 4 Laden und 2-3 gliedrigen Tastern.

Die Beine sind der Lebensweise der Nymphe angepaft; bei den im Schlamme lebenden Arten sind die vorderen zu starken Grabbeinen umgestaltet, bei anderen sind es Laufbeine, welche besonders bei den in rasch fließenden Wässern lebenden Arten sehr flach sind, seitwärts abstehen und zu dem Klettern auf den Steinen gut geeignet sind. Der FuB ist eingliedrig, mit starker Klaue.

Der Hinterleib trägt auf den ersten 4-7 Ringen die Tracheenkiemen in der Form von Blättchen oder Faden, welch letztere in Büschel verbunden sind. Die Kiemen sind seitlich an den Ringen befestigt, entweder einzeln oder zu zwei am Grunde verbunden und zwar entweder 2 Blättchen oder 1 Blättchen mit einem Fadenbüschel. Manchmal ist eins von den vorderen Paaren stärker und größer und bedeckt flügeldeckenartig die übrigen Kiemen. Die Zahl und die Form der Kiemen ist für die Systematik sehr wichtig.

Das Ende des Hinterleibes trägt meistens 3 Schwanzborsten; manchmal ist die mittlere von ihnen verkümmert oder wird bei der vorletzten Häutung verloren.

Wie lange das Nymphenstadium dauert, ist nicht bekannt; bei Palingenia soll dasselbe 3 Jahre dauern und nach John Lubbock macht Cloëon 23 Häntungen durch. Nachdem aber die Nymphe reif geworden ist, trachtet sie eine ruhige Stelle des Wasserspiegels zu erreichen, läutet sich und verwandelt sich in das Subimago. Dieses ist dem vollkommenen Insekt ganz ähnlich, nur die Beine und Schwanzborsten sind kürzer und die Flügel trübe, manchmal mit auffallender, dunkler Zeichnung. Das Subimago häutet sich in einer Entfermung rom Wasser, welche es fliegend erreicht hat, noch einmal - bei einigen Arten nicht auf dem ganzen Körper -- und wird zum vollkommenen Insekt, welches keine Nahrung aufnehmen kann und nur so lange am Leben bleibt, bis es die ihm auferlegte Aufgabe der Fortpflanzung erfüllt hat. Es danert 12 Stunden bis einige wenige Tage.

\section{Bestimmungstabelle der Gattungen.}

1. Hinterflügel fehlen.

- Hinterflügel vorhanden, wenn auch manchmal sehr klein. 4.

2. Flügel milchig getrübt, am Hinterrande gewimpert; Zwischenraumadern fehlen; 3 Schwanzhorsten.

Caenis S t.

- Flügel glashell, am Hinterrande nicht gewimpert; Zwischenraumadern einzeln; 2 Schwanzborsten. Cloëon Leach.

3. Flïgel milchig oder graulich getrültt.

- Flïgel glashell.

4. Hinterflügel ohne Queradern und in den Vorderflügeln nur die 2-4 vordersten Felder mit einigen Queradern. Oligoneuria P i c t.

- Beide Flïgelpaare mit zahlreichen Queradern.

5. Körper zart, wie die Flügel weißlich; Hinterbeine sehr kurz und schwach.

Polymitarcis Eat.

- Körper stark, wie die Flügel hraun; Hinterbeine normal.

6. Hinterflügel bloß mit $2-3$ Längsadern.

Palingenia $\mathrm{B} u \mathrm{rm}$.

- Hinterflügel mit vielen durch Queradern verbundenen Längsadern. 
7. Hinterflügel länglich eiförmig, stumpf; Zwischenraumadern zu 2.

Baëtis Leach.

- Hinterflügel sehr schmal, bandförmig, zugespitzt; Zwischenraumadern einzeln.

Centroptilum Eat.

8. 3 Schwanzhorsten.

- 2 Schwanzborsten; Augen des od und ㅇ einfach; \%wischenraumadern mit den Längsadern verbunden.

14.

9. Torderflïgel mehr oder weniger braun gefleckt; Augen des d einfach.

- Vorderflügel ungefleckt.

Ephemera L.

10. Vorderflügel mit gelb gefärbtem Costalfelde.

10.

Potamanthus Pict.

- Das Costalfeld nicht gelb gefärbt.

11.

11. Die 2. Analader am Grunde gerade, der $I A$ weit mehr genähert als der $3 A$, linter der ersten, sie mit der $I A$ verbindenden Querader im stumpfen Winkel gebrochen und nur im sanften Bogen zum Hinterrande laufend, so daß der Raum zwischen $I A$ und $2 A$ dreieckig ist. Ephemerella $\mathrm{W}$ als h.

- Die 2. Analader geschwungen. am Grunde der $3 A$ eher etwas näher als der $I A$ oder von heiden genamnten Adern gleich entfernt und an dem äußersten Grunde nach vorn gehogen und der Raum zwischen $I A$ und $2 A$ hat den Umriß eines Schinkens.

$1 \%$.

12. Zwischenraumadern fehlen. Habrophlebia Eat.

- Zwischenraumadern mit den Längsadern verbunden. $\mathbf{1 3 .}$

13. Der Costalstreif der Vorderfliigel hyalin. Ieptophlebia Eat.

- Der Costalstreif der Vorderflügel dunkelbraun gefärbt.

Choroterpes Eat.

14. Zwischen den 2 normalen Schwanzhorsten ein gegliederter Ansatz einer Mittelborste.

15 .

- 2 Schwanzborsten; Ansatz einer Mittelborste fehlt; Genitalfüße des of 3 gliellrig, das 1. Glied am längsten.

17.

15. Der Hinterfuß kürzer als die Schiene; die Genitalfüße 3 gliedrig, 1. Glied am längsten.

16.

- Der Hinterfuß länger als die Schiene; die Genitalfüße 4 gliedrig, ihr 2. Glied am längsten.

Siphlurus Eat.

16. 1. Glied der Hinterfüße deutlich kürzer als das 2.; die Vorderklaue in eine kleine Schuppe endend, die außen gekielt, innen ausgehöhlt ist; die Hinterklauen schmal, normal, beide gleich.

Chirotonetes Eat.

- 1. Glied der Hinterfüße kaum sichtbar kürzer als das 2..; auf allen Füßen eine Klane stumpf, die andere spitzig.

Ameletus Eat.

17. 1. Glied der Hinterfüße länger als das 2., dieses länger als das 3.

Ł. Glied der Hinterfïße so lang wie das ¿2.

19.

1. Glied der Hinterfüße külzer als das 2 .

20 .

18. 1. Glied der Vorderfüße so lang wie das 2.; die Hörner der Rute stark, durch einen dreieckigen Finschnitt voneinander gesondert und an der Spitze quer nach außen erweitert.

Epeorus Eat.

- 1. Glied der Vorderfüße kürzer als das 2.; die Hörner der Rute stark, gewöhnlich quer erweitert, manchmal aber eiförmig.

Eedyurus Eat. 
19. Die Hörner der Rute schmal, stähıhenförmig, an der Spitze etwas erweitert: Schenkel meist mit einem dunkelhraunen Punkte oder Striche in der Mitte der AuBenseite; 1. Glied der Vorderfüße beim ơ etwa $1 / 5$ so lang wie die Schiene.

Rhitrogena Eat.

- Die Hörner der Rute stark, an der Spitze stark erweitert oder eiförmig; Schenkel geringelt, aber ohne den auffallenden P'unkt in der Mitte; 1. Glied der Vorderfüße beim $\delta$ hat wenigstens $1 / 3$ der Länge der Vorderschienen.

Eedyurus Eat.

20. Die Außenseite der Schenkel mit einem dunklen Punkte oder Striche in der Mitte; die Hörner der Rute schmal, stäbchenartig, an der Spitze etwas erweitert und weit voneinander abstehend.

Rhitrogena Eat.

- Die Außenseite der Schenkel ohne dunkle Zeichnung; die Hörner der Rute kurz, breit, flach erweitert und durch einen dreieckigen Einschnitt voneinander gesondert.

Heptagenia Walsh.

\section{Familie Palingeniidae.}

Subcosta in den Vorderflügeln fehlt oder ist in einer Falte der Nembran unter dem Radius verborgen; $C u$, länft am Grunde des Flügels mit $I A$ und, wenn die übrigen Analadern vorhanden sind, auch mit der $2 A$ zusammen; die Beine des $q$ kurz und schwach oder gar verkümmert und die Hinterbeine länger als die Vorderbeine; die Hinterfüße 4 glıedrig; beim ơ die Augen einfach.

\section{Gattung Palingenia Burm.}

Media hinter der Nitte des Flügels gegabelt; die Analadern vorhanden; in allen Feldern zahlreiche Queradern. Vorderfüße des Männchens ełwa 2,5 mal so lang wie die Schenkel; Schwanzborsten ¿, beim of etwa 3 mal länger, beim $\bigcirc$ gleich lang wie der Körper.

Kopf pechschwarz, Thorax gelb, Mesonotum bräunlich, Hinterleib erdbrann, die Unterseite, Beine und Schwanzborsten bleiclıgell, Flügel rehbraun mit schmutzig braunen Adern. Länge des ơ 23 bis $25 \mathrm{~mm}$, des † $27-29 \mathrm{~mm}$, Flügellänge des ठ $24-26$, des $q$ $32 \mathrm{~mm}$, der Schwanzborsten des ơ 70-74, des f 26-27,5 $\mathrm{mm}$. An großen Flüssen, Juli August. Elbing, Westfalen.

longicanda Oliv.

\section{Gattung Oligoneuria Pict.}

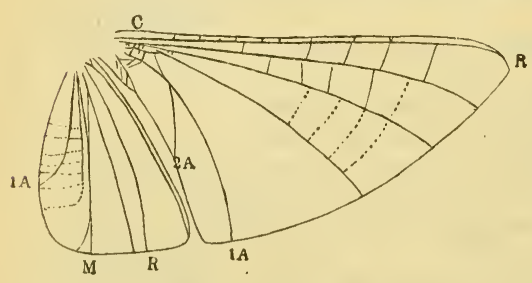

Fig. 2. Oligoneuria rhenana Imh. $q$ Die Nervatur. (Nach È a ton.)
Media ungegahelt; 11 r die 1. Analader entwickelt; nur in den Feldern bis zur Media einige Queradern; Vorderfüße des ó viel kürzer als die Schenkel; Schwanzborsten 3 , die mittlere etwas kürzer, beim of etwa $1 \frac{1}{2}$ mal so lang wie der Körper, beim of haben sie nur $1 / 4-\%$ der Länge desselben; die 
hinteren Hinterleibsringe sind an der Seite dornartig vorgezogen (Fig. 2).

Kopf und Thorax ockergelb, Hinterleib weißlich in der vorderen Hälfte der Ringe beim ơ durchscheinend, beim $q$ bräunlich. Vorderbeine und Hinterschenkel des of licht gelbbrann, sonst die Beine weiß; heim $q$ sind die Beine gelbhraun. Schwanzborsten und Genitalfüße weiß. Körperlänge des of $9-13,5$, des $912-15 \mathrm{~mm}$, Flügellänge des of $11-14,5$, des o $14-16 \mathrm{~mm}$, Schwanzborsten des б 12-13 mm, des $+3-4 \mathrm{~mm}$. - An gröBeren Flïssen of massenhaft; fliegt an die Straßenlampen, Angust.

rhenana $\mathrm{Iml}$.

\section{Familie Polymitarcidae.}

Von der vorigen durch die wohl entwickelte und dentlich sichtbare Subcosta verschieden; Nervatur vollkommen, mit zahlreichen Queradern.

\section{Gattung Polymitarcis Eat.}

Vorderbeine des $\delta$ so lang wie der ganze Köruer und die Vorderfüße 3-5 mal so lang wie die Schenkel, welche kaum $1 / 4$ der Länge der Schienen haben; die Mittel- und Hinterheine knrz. Schwanzborsten heim of 2, da die mittlere verkümmert ist, beim o 3 und gleich lang. Flïgel trübe.

Kopf weißlich, unter der Stirn schwarz, Thorax licht gelbbram, Hinterleil, gelblichweiß, Flügel milchig getrübt, Costa, Subcosta und Radius gran, Beine weißlich, Vorderschenkel mul Schienen oben schwärzlich. Beim 9 ist der Körper mehr bräunlich. Körperlänge les of $10-11$, des o $16-17 \mathrm{~mm}$, Flügellänge des oc 11-12,5 des o $16 \mathrm{~mm}$, Schwanzhorsten des $\delta 30-33,5$ des ㅇ $13 \mathrm{~mm}$. - An größeren Flüssen, stellenweise massenhaft. August. virgo Oliv.

\section{Familie Ephemeridae.}

Am Grunde lles Vorderflügels laufen $C u_{1}, I A$ und $2 A$ zusammen; heim $\delta$ sind die Beine wohl entwickelt und die vorderen wenigstens so lang wie die hinteren. Augen des o einfach. Der Grund der Genitalfüße stark entwickelt und das o ohne Supragenitalplatte.

\section{Gattung Ephemera L.}

Flïgel glashell mit zahlreichen (quer- und Längsadern, mehr oder weniger braun gefleckt. Beim $\sigma^{c}$ ist der Vorderfuß etwa 4 mal so lang wie der Schenkel, beim o etwa gleich lang wie derselhe. Schwanzhorsten 3, von gleicher Länge. Hinterfüße 4 gliedrig, die ersten 3 Glieder fast gleich lang; Klauen ungleich. Genitalfüße 4 gliedrig, das 2. Glied am längsten.

1. Meso- und Metanotum schwarz; Längsadern und Queradem schwarz und meist angeraucht; Schwanzborsten undentlich geringelt.

- Thorax oben hei dem ó lederbraun, beim $q$ lichter bis gelb: Längsadern wenigstens teilweise gelbbraun; Schwanzhorsten deutlich geringelt.

2. Hinterleib dunkel- bis rötlichlurann, die Segmente auf lem Rücken jederseits mit einem starken, schwarzen, kommaartigen 
Striche, welcher auf den rorderen Ringen dreieckg erweitert ist; auf dem 7.-9. Ringe ist zwischen denselben ein Paar von feinen kurzen Linien; auf der Bauchseite zieht sich auf den Segmenten jederseits ein feiner schwarzer Strich. Vorderflügel bräunlich, beim d viel stärker als beim o angeraucht, mit nehreren dunkien Flecken und dunkler gesäumten Queradern. Hinterflügel am Rande breit braun gesäumt, beim $\delta$ mit dunklem Mittelflecke. Vorderbeine schwarz, Schwanz-

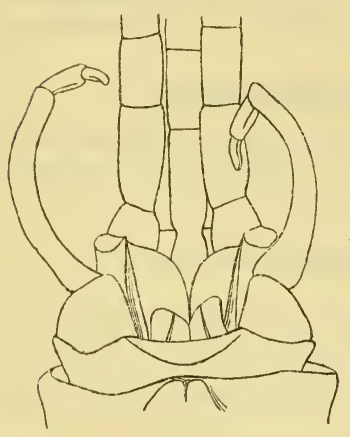

Fig. 3. Ephemera rulgata L. Das of Hinterleibsende von unten. horsten rotbram, kaum dunkler geringelt. Länge des Körpers 14-22 $\mathrm{mm}$, der Flügel beim $\delta$ 16-17, beim ㅇ 18-24 $\mathrm{mm}$, der Schwanzhorsten heim of 32 bis $36 \mathrm{~mm}$, des ㅇ 22-26 mm (Fig. 3). - Vom Mai bis Juli gemein.

vulgata $\mathrm{L}$.

- Hinterleib elfenbeinweiß, nur an der Spitze etwas bram angelaufen, oben jederseits mit einem starken, keilförmigen, beim 우 dreieckig erweiterten und den Hinterrand des Ringes weit nicht erreichenden Flecke; auf dem 6.-9. Ringe ist zwischen denselben ein Iaar von feinen, kurzen Linien; beim 오 bleiben aber die ersten 5 Rückensegmente oben ungezeichnet. An den Seiten sind 2 die Seitenlinie begrenzende feine, krimme Striche. Auf der Bauchseite zieht sich jederseits eine Reihe von feinen, schwarzen Linien. Sonst sind die Farben wie bei vulgata, Körperlänge des ơ $16-17$, des $q$ q $16-23 \mathrm{~mm}$, Flügel des of 16-17, des $914-22 \mathrm{~mm}$, Schwanzborsten des o $30-41 \mathrm{~mm}$, des f $14-25 \mathrm{~mm}$. - Gemein, aler an kälteren und schneller fließenden Gewässern. Mai bis Juli.

danica M ̈̈ll.

3. Die Ilinterleibsringe $\dot{b--9}$ auf dem Rücken jederseits mit 3 fast gleich starken, schwarzen Linien, von welchen die innerste auf den vorderen liingen verschwindet, die 2 äußeren mehr verwaschen werden. An den Seiten üher der Seitenlinie und unter derselben eine feine, krumme Linie; auf dem Bauche ist jederseits auf allen Ringen eine schwarze Linie. Körper beim ơ licht lederbraun, am Grunde des Hinterleibes und dem Bauche etwas lichter; beim of licht gelbbraun. Vorderbeine des o mit dem Körper fast gleichfarlig, an den Gelenken schwarzbraun; die hinteren bedeutend lichter, gelblich. Beim of sind die Vorderbeine mit der Brust gleichfarbig, beide Enden von den Schienen und die Spitzen der Fußglieder schwarz, die mittleren und hinteren Beine sind schwach gelblich mit schwarzen Klauen. Schwanzfïden lichtbraun, dentlich schwarz geringelt. Flügel beim ơ stark glänzend, schwach bräunlich getriilt, wenig gefleckt, an den Queradern schnal braun gesäumt. die IIinterflügel ohne den Mittelfleck. Beim $q$ sind die Flügel fast glashell, mit wenigen punktförmigen braunen Flecken, mit gelbem Sub- 
costalfelde und ungesäumten (Mneradern. Länge des Körpers beim or $15-20$, beim ㅇ $21-25 \mathrm{~mm}$, der Flügel beim 016 , beim o 20-21 mm, der Schwanzborsten beim of 30-36, heim Q 24-26 mm. - An der Ellse, Juni, Juli. lineata Eat.

- Die Hinterleibsringe 7-9 auf dem Rücken jederseits mit 2 parallelen, schwarzen Linien, die auf dem 10 . in einen länglichen Fleck, auf den vorderen $(2-6$; zu einer Linie zusammenfließen. An der Seitenlinie ist an ihrem unteren Rande vorn ein schwarzer Punkt und an dem oberen liande hinter ihm eine krumme, auf den 2 vorletzten Linien eine gerade, schwarze Linie. Die Unterseite der Ringe ist mit 2 nach hinten divergierenden, schwarzen Linien geziert. Beine wie bei lineata. Flügel mit rostgelben Längsadern und schwarzen Queradern, fast ungefleckt, die hinteren ohne den lraunen Mittelfleck. Schwanzborsten gelblich, braun geringelt. Die Genitalfüße entweder mit dem Hinterleibe gleichfarbig und an der Spitze der Glieder schwarz oder schwarzbraun, oder mit dunkelbraunem ersten und den 2 letzten Gliedern. Länge des Körpers $11-17 \mathrm{~mm}$, der Flïgel beim c $10-15$, heim of $10-16 \mathrm{~mm}$, der Schwanzborsten beim $\delta$ 15--23, beim f 11-14 mm. - Lausitz, Juli, August.

glaucops Pict.

\section{Familie Potamanthidae.}

In den Vorderflügeln lanfen $C u_{1}, I A$ und $2 A$ am Grunde zusammen; Augen des. ò einfach; Genitalfüße 3 gliedrig, 1. Glied am längsten; beim q die Supragenitalplatte wohl entwickelt.

\section{Gattung Potamanthus Pict.}

Beim of der Vordertarsus etwas länger als die Schiene, f) gliedrig, das 1 . Glied sehr kurz, das 2 . hat etwa ${ }^{2} / 5$ der länge der Schiene, die ülırigen stufenweise kürzer. Mittel- und Hinterfüße 4 gliedrig. Beim of hat der Vorderfulo fast $3 / 4$ der Länge von der Schiene. Schwanzfäden 3, fast gleich lang.

Ǩ̈rper hellgell, ïber den Rïcken des Hinterleibes zieht sich ein breiter branner Streifen, an der Seite des 2. -10 . Ringes nahe dem $\mathrm{Vor}$ derrande an der Sei-

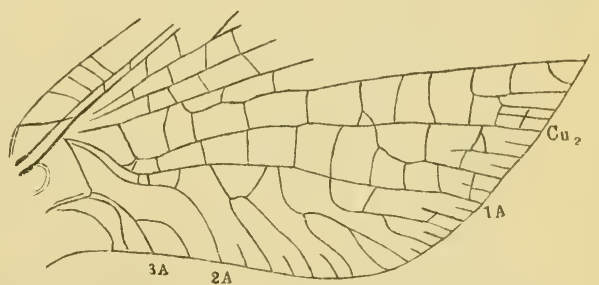

Fig. 4. Potamanthus luteus L. I Iie kubitale und anale Gegend der Vorderflügel. tenlinie ist ein schwarzer P'unkt, und ein anderer dunkelbrauner ist mehr gegen den Rücken gerïckt vor dem Hinterrande des 2. his 8. Ringes (Fig. 4). Vorderbeine etwas dunkler, an der Spitze der Schienen und der Fußglieder mit schwarzem Punkte, die Mittelund Hinterbeine dunkler, mit schwärzlichen Klauen. Schwanzborsten lichthraun, dunkelbraun geringelt. Flïgel hyalin oder sehr schwach gelblich, die vorderen mit gelben Längsadern und braunen 
Queradern, die aher gegen den Anßen- und Hinterrand lichter werden; Hinterflügel ganz mit hellgeller Nervatur. Länge des Körper's $9-13 \mathrm{~mm}$, die der Flügel beim ơ $12-13$, heim of $15 \mathrm{~mm}$, der Schwanzhorsten beim o 15-19, beim o $12 \mathrm{~mm}$. - An Flüssen und größeren Bächen, Juni, August.

luteus L.

\section{Familie Leptophlebiidae.}

Am Grunde der Vorderflügel ist $I A$ von dem $C u$ ganz getrennt und umsehreiht mit der $3 A$ einen Raum in der Form eines Schinkens. $2 A$ ist am Grunde nach vorn gebogen und der $I A$ näher als der $3 A$ und in ihrem Verlauf stark geschwungen. Wurzel der Genitalfüße und die $q$ Supraanalklappe wohl entwickelt. Angen des or geteilt.

\section{Gattung Leptophlebia Westw.}

Vorderrand der Hinterflügel ungleichmäßig flach bogenförmig, wobei die Subcosta fast parallel mit demselben und Radius gerade

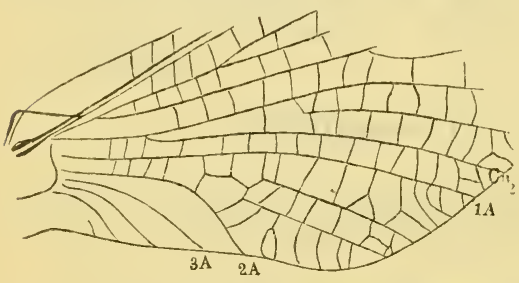

Fig. 5. Leptophlebia marginata L. Die kubitale und anale Gegend der Vorderflügel. verläuft (Fig. 5). Die Zwischenraumadern mit den Längsadern verbunden; in dem 1. Analfelde sind 2 untereinander und mit den Längsadem durch Queradern verbundene Zwischenraumadern. Vorderfuß des 0 etwas länger als die Schiene, sein 1. Glied am kïrzesten, das 2 . am längsten und die übrigen stufenweise kürzer. Hinterfuß 3 gliedrig, aber das 1. Glied undeutlich getrennt. Beim $O$ sind die letzten 4 Glieder des Vorderfußes etwa halb so lang wie die Schiene. Schwanzborsten 3, fast gleich. Genitalfüße 3 gliedrig (Fïg. 6).

1. Vorderflügel bräunlich angeraucht, besonders nach der Spitze zu; der Costalstreif nach der Spitze zu bräunlich gefärbt, gegen die Wurzel zu hyalin; Längsadern bräunlichgelb. Thorax schwarz, Hinterleib dunkelbramn, Vorderbeine schwarzhraun, die hinteren heller, Schwanzborsten dunkellbrann, Genitalfüße lichter als der 9. Ring. Beim $q$ sind die Vorderschienen licht rötlichgelb. Länge des Körpers $6-12 \mathrm{~mm}$, des Flïgels 6-11 mm, der Schwanzborsten des $\delta 12-20 \mathrm{~mm}$, des ㅇ 8-16 mm. - An Flüssen und Bächen häufig, Mai bis Oktoher; weit verbreitet.

marginata $\mathrm{L}$.

- Vorderflïgel glashell, nicht bräunlich angeraucht; der Costalstreif nicht dunkler.

2. Schwanzfäden eifarbig weiß. Thorax oben schwarz, an den Seiten bram, Hinterleib pechbram, in der Regel auf dem 2.-7. Ringe vorn weiflich durchscheinend. Beine weißlich, die Schenkel und Schienen der vorderen an der Spitze dunkler. Genitalfüße weißlich, gegen den Grund zu schwärzlich grau. Die Hörner der Rute divergierend, mit einem 
scharfen Vorsprunge vor der Spitze anf der Aukenseite. Beim ㅇ ist der Ilinterleib dunkelbraun, gelblieh geringelt. - An Bächen weit verbreitet, Juli, Angust. Lïnge des

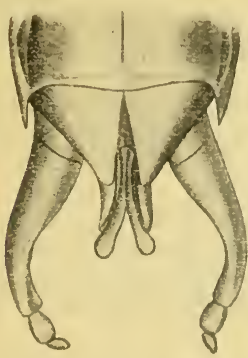

Fig. 6 .

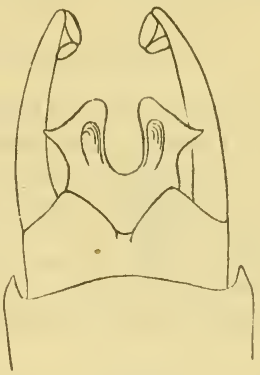

Fig. 7 .

Fig. 6. Leptophlebia marginata L. $ठ َ$ Das Hinterleilsende von unten.

Fig. 7. Leptophlebia cincta Retz. o Jas Hinterleibsende von unten.

Körpers 7-8, der Flügel 8-9, der Schwanzhorsten des ठ 8-11, des f 7-11 mm (Fig. 7). - Lansitz, Juli, August. cincta Retz.

- Schwanzfäden dentlich geringelt. 3.

3. Schwanzfäden lichtbraun, dunkler geringelt. Thorax oben schwarz, Hinterleib pechbraun oben, lichter unten und an dem Vorderrande der mittleren Ringe weißlich. Vorderbeine schwarz oder schwarzhraun, die hinteren lichthraun. Länge

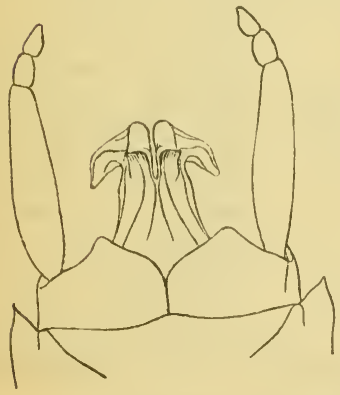

Fig. 8.

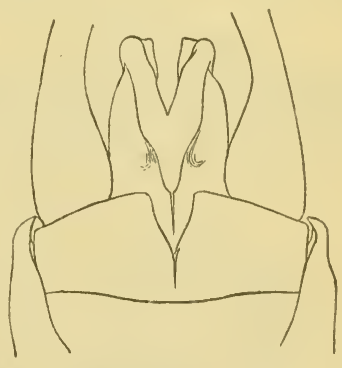

Fig. 9 .

Fig. 8. Leptophlebia submarginata St. ठे Das Hinterleibsende von unten.

Fig. 9. Leptophlebia Meyeri Eat. o Das Hinterleibsende von unten.

des Körpers 8-11, der Flügel 10-13, der Schwanzborsten des o 12-14, des 9 9-12 mm. - An clen Bächen häufig. Mai bis August (Fig. 8).

submarginata $\mathrm{S} \mathrm{t}$.

- Schwanzfüden weißlich, schwarzloram geringelt. Thorax oben tiefschwarz, Hinterleib pechbraun, an dem 3.-6. oder 7 . Ringe durchscheinend, Beine schwarzbraun. Genitalfüße weißlich (Fig. 9). Die Hörner der liute stark divergierend, an der 
Spitze mit einem klauenartigen, nach außen gekrïmmten Zahne versehen. Länge des Körpers $6-9$, der Flügel 7 bis () mm. - An Gebirgsbächen im Juli, Böhmerwald.

Meyeri Eat.

\section{Gattung Choroterpes Eat.}

Vorderrand der Hinterflügel in stumpfem Winkel gebrochen, so daf der durch den Radius und den Vorderrand umschriebene Teil der Flïgelfläche einen dreieckigen Unriß hat; Subcosta verläuft etwa in gleicher Entfernung von Costa und Radius. Nur in der apikalen Partie sind mehr zahlreiche Queradern; sonst sind sie sehr spärlich. Die kurzen Zwischenraumadern am Hinterrande des Flügels fehlen. In dem 1. Analfelde verlaufen alternierend 2 kurze und 2 längere Zwischenraumadern. Genitalfüße 4 gliedrig. Schwanzfäden 3 .

Thorax schwarzloraun, Hinterleib und Vorderbeine dunkellıraun, Hinterleib am Vorderrande der mittleren Ringe und auf dem Bauche lichter und etwas durchscheinend. Genitalfüße am Grunde dunkelbraun, rötlichbraun nach der Spitze zu. Hinterbeine und Schwanzhorsten bräunlich. die letzteren dunkel geringelt. Flügel hyalin, Costal- und Subcostalfeld der vorderen braun. Länge des Körpers und Flügels $10 \mathrm{~mm}$, und der Schwanzborsten $12 \mathrm{~mm}$. - Heidelberg, Dresden. August bis Oktober.

Picteti Eat.

\section{Gattung Habrophlebia Eat.}

Der Vorderrand der Hinterflügel bildet etwa in der Mitte einen rechtwinkligen Vorsprung, der durch einen tiefen Einschnitt gebildet wird. Sulicosta meistens mit dem Radius parallel und in

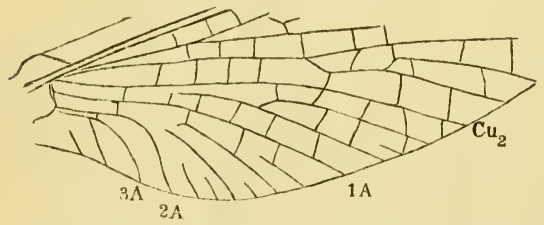

Fig. 10. Habrophlebia fusca Curt. Die kubitale und anale Gegend der Vorderflügel. gleicher Entfernung wie von der Costa laufend. Queradern mäßig zahlreich, öfters nach dem

Hinterrande zu verschwindend. Zwischenraumadern fehlen mit Ausnahme des ersten Analfeldes, wo 2-5 vorkommen können. Genitalfüße 3 gliedrig.

Schwanzfäden 3, untereinander fast gleich. Die ㅇ Supragenitalplatte scharf ausgeschnitten (Fig. 10).

1. Hinterleib braun, am Vorderrande der mittleren Ringe etwas lichter und durchscheinend. Thorax oben schwarz. Vorderbeine schwarzbraun (Fig. 11), Hinterbeine lichthraun. Schwanzfäden lichtbraun, dunkel geringelt. Flügel hyalin, mit blaßbrauner Nervatur; die Queradern bis zum Hinterrande des Flïgels entwickelt. Länge des Körpers 5-7, des Flügels $6-7$, der Schwanzhorsten beim of 8-12,5, beim o $6-9 \mathrm{~mm}$. - An Bächen und Flüssen häufig, Juni, Juli. fusca Ct. Der 2.-7. Hinterleibsring durchscheinend weiß; die Queradern gehen nicht bis zu dem Hinterrande des Flügels und lassen eine ziemlich breite Randzone frei. 
2. Vorderbeine graulichweiß, Mittel- und Hinterbeine weiß, durchscheinend. Thorax oben schwarz, Schwanzfäden weiß, Flügel hyalin mit weißlicher Nerratur, nur Sulocosta und Radius in Vorlerflügel braun. Länge des Körpers 5, des Flügels 6 und der Schwanzfäden des \& $7 \mathrm{~mm}$. - Nach Rostock in Sachsen.

mesolenca Brauer.

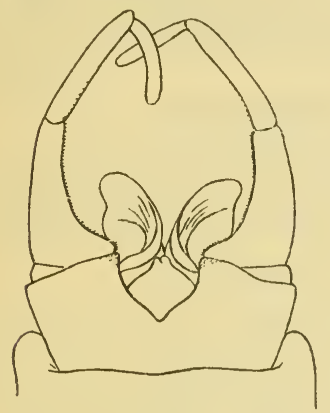

Fig. 11.

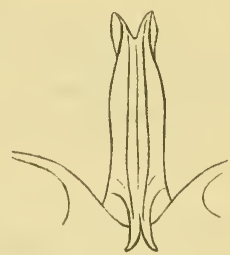

Fig. 12.

Fig. 11. Habrophlebia fusca Eat. $\delta$ Das Hintelleibsende von unten.

Fig. 12. Habrophlebia lauta Mc. Lach. Die Rute von unten.

- Auf den Vorderbeinen ist der Trochanter, Femur und beide Enden der Schienen dunkel- bis schwarzhraun. Sonst wie die vorige. An Bächen sehr häufig. Länge des Körpers $5-6$, des Flügels $6-\overline{7}$, der Schwanzfäden beim ơ $8-11$, beim of 6,5-7 mm (Fig. 12).

\section{Familie Ephemerellidae.}

In den Vorderflügeln laufen die 1. und 2. Analader am Grunde zusammen, die letztere ist am Grunde fast gerade und biegt hinter der 1. Querader im stumpfen Winkel gegen den Hinterrand des Flügels ab. Die-1. und 3. Analader umschreiben ein etwa drei-

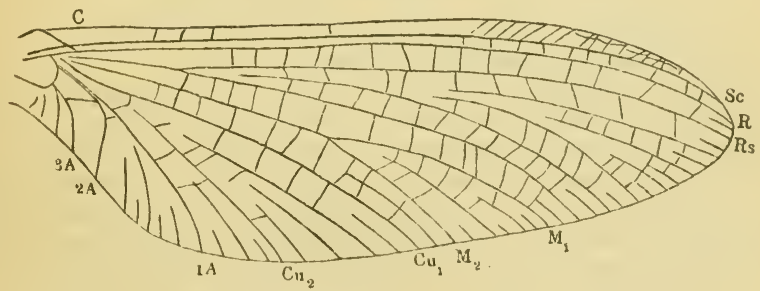

Fig. 13. Ephemerella ignita Poda. Der Vorderflügel.

eckiges Feld. Die Zwischenraumadern frei oder mit den Längsadern verbunden. Der Yorderrand der Hinterflügel hogenförmig geschwungen mit einem muldenartigen Ausschnitte in der Mitte (Fig. 13). Genitalfüße 3 gliedrig, mit langem 2. Gliede. Schwanzfäden 3 . 


\section{Gattung Ephemerella Walsh.}

Körper rötlichgell, bis rotbraun, Beine gelb bis gelbbraum mit dunkleren Gelenken, Schwanzborsten gelblich, schwarzbraun geringelt. F'lügel hyalin, die stärkeren Adern bräunlich. Länge des Kïrrpers bein of $6-9,5$, beim of $6-10$, der Flügel beim o $7-9$, beim of 7,5-11 mm, der Schwanzhorsten beim of 7-11, beim o 7-9 mm. \n Bächen stellenweise sehr häufig, Juni his September.

iguita Poda.

\section{Familie Caenidae.}

In den Vorderflügeln ist am Grunde $I A$ sehr nahe der $C_{n} u_{2}$ und weit entfernt von der $2 A$. Media ist gegabelt und die 1 . mit der 3. Analader umschreihen ein dreieckiges Feld. Hinterflügel fehlen.

\section{Gattung Caenis st.}

Queradern in eine Reihe geordnet; die Hinterleibssegmente 7-9 an den Seiten hinten ahlförmig vorgezogen. Schwanzfäden 3, gleich. Füße 4 gliedrig, nur die Vorderfüße des o 5 gliedrig. Genitalfüiße kurz, ungegliedert. Flïgel trübe. weißlich, olne Zwischenraumadern, am Hinterrande gewimpert (Fig. 14).

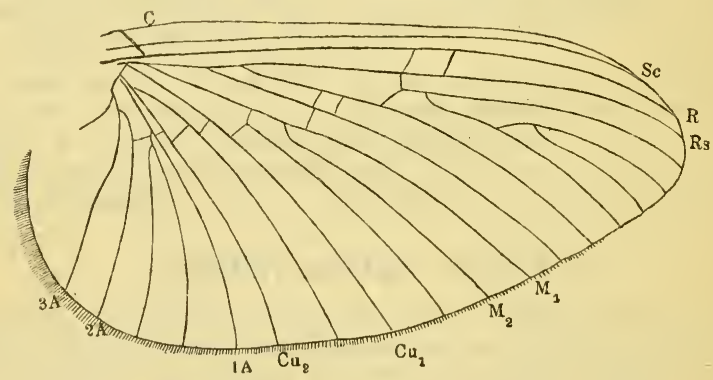

Fig. 14. Caenis dimidiata St. (Nach Eaton.)

1. Schwanzfäden weiß, weißlich oder mit gelblichem Anflug. 2

- Schwanzfäden grau oder schwärzlich grau.

2. Thorax pechbraun; Hinterleib weißlich mit graner Zeichnung auf dem Rïcken und grauen Punkten an den Seiten; Vorderbeine weißlich mit graubraunen Schenkeln, Hinterbeine grauweiß mit einem schwarzen Punkte auf der oberen Kante der Schenkel vor dem Kínie. Flügel am Vorderrande leicht graulich und die 3 ersten Längsadern sepiabraun. Länge des Körpers 3-5, der Flügel beim of 4, beim $q 5$, der Schwanzhorsten beim o $13-18$, beim $q 3 \mathrm{~mm}$. -- An größeren Flïssen weit verbreitet, Juni bis Oktober. dimidiata St.

- Thorax gelbbraun, Hinterleib weißlich gelbbraun, an der Spitze dunkler, Beine weißlich oder ganz licht fahlgelb; Flügel hyalin. Subcosta und Radius schwarz, übrige Adern gelblich, heim $ᄋ$ farblos. Länge des Körpers beim ot 3 , beim $q 4$, der Flïgel beim o 3,5 , beim of $4 \mathrm{~mm}$, der Schwanzborsten des o $11 \mathrm{~mm}$. - Preußen, August.

lacteella Eat. 
3. Beine pechschwarz, Schienen, Füße und die untere Kante der Schenkel licht schwïrzlichgrau und durchscheinend, Thorax pechbraun; Hinterleih graulich; Schwanzhorsten grau, dunkler geringelt; Flïgel graulichweiß, Costa, Subcosta und Radius pechschwarz. Iänge des Körpers heim ơ $4-5$, beim f $6 \mathrm{~mm}$, der Flügel beim o $4-5$, beim $q 7 \mathrm{~mm}$, der Schwanzfäden beim o $14-16$, beim $q 2-3 \mathrm{~mm}$. - An Teichen und Flüssen; Mai his September. Lausitz (Diehmen, Ḱlix, Bautzeli).

halterata $\mathrm{F}$.

- Vorderfüße hell sepiabraun, Hinterfüße licht schwärzlichgrau mit schwarzen Gelenken; Thorax pechschwarz, Hinterleib lichtbraun; Schwanzlıorsten grau oder licht schwärzlichgrau. Flügel weißlich mit grauen Adern bis anf die pechschwarze Subcosta und Radius. Länge des Kö̈pers beim o 6,5 , beim q 5-7, der Flügel 5,5-6, der Schwanzborsten bein c $25 \mathrm{~mm}$. - Berlin. August.

harrisella Ct.

\section{Familie Baëtillae.}

Die $I A$ ist am Grunde der Vorderflügel von der $C u$ und der $2 A$ vollkonmen getrennt; $2 A$ ist nur schwach bogenförmig und Media einfach. Der Hinterfuß hat $1 / 2-3 / 4$ der Länge von Tibia, ist 4 gliedrig mit langem ersten Gliede.

\section{Gattung Baëtis Leach.}

Hinterflügel vorhanden, elliptisch oder lïnglich eiförmig, am Vorderrande nahe der Wurzel in der Regel in einen dreieckigen,

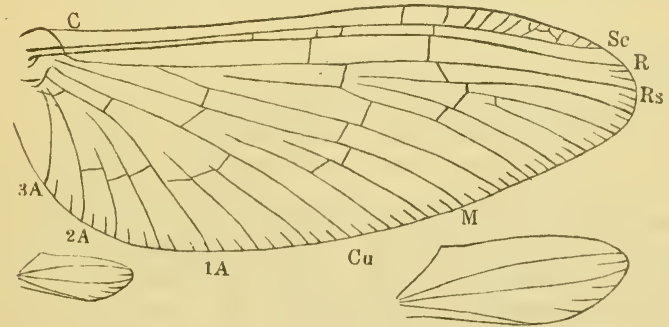

Fig. 15. Bä̈tis tenax Eat. Flügel: rechts der Hinterflügel stärker vergrößert.

spitzigen Zipfel auslaufend, mit 2-3 Längsadern mit sehr spärlichen oder gar keinen Queradern. In den Vorderflïgeln sind die Queradern in 3 Reihen geordnet; Zwischenraumadern zu zwei. Genitalfüße 4 gliedrig; '2 Schwanzhorsten. Beim o' Augen geteilt.

1. Schwanzfäden rein weiß.

- Schwanzfäden grau. 2. 9.

- Schwanzfäden geringelt.

2. Hinterflügel mit 2 Längsaderı.

- Hinterflügel mit 3 Hängsadern.

3. Zweite Ader der Hinterflügel gegabelt. Thorax oben pechschwarz, Hinterleih des $\delta$ auf dem $2 .-7$. Ringe durchscheinend weiß oder licht aschgran, auf dem 8.-10 pechbraun, rötlichbraun oder gelblichbraun auf dem Rücken, weißlich grünlichgrau, 
oder braun auf dem Bauche; die Bauchringe haben meist 2 divergierende kurze dunkle Linien nahe dem Vorderrande und hinter jeder einen Punkt. Beim ㅇ ist der Rücken des Hinterleibes kastanienbraun, die Hinterränder der Ringe $2-6$ und 3 kurze Linien vorn ockergelb. Schwanzfäden des of weiß oder grauweiß, oft dunkler, oder am Grunde rötlich geringelt; beim $q$ einfarbig grauweiß oder rötlich geringelt. Vorderbeine des ơ grauweiß oder gelblichgrün, mit rötlichbrauner Spitze der Schienen; Hinterfüße weißlich, am Grunde der Schenkel weiß und mit schwarzen Spitzen der Fußglieder und bramen Klauen; beim $q$ die Beine grünlich gelbbraun mit rauchbraunen Gelenken der Fußglieder. Genitalfüße am Grunde dunkelgrau, damn licht grünlichweiß. Länge des Körpers 5-7,5, des Flügels $6-8$, der Schwanzfäden des o 9-11, des 우 6-8,5 mm. - England. Mai, Juni und September (Fig. 16).

niger $L$.

Zweite Längsader der Hinterflügel einfach.

4. Erstes Glied der Genitalfüße schwarz. Thorax oben kohlenschwarz, Hinterleib oben kastanienbraun, etwas lichter an den Nähten und meist aschgrau auf dem Bauche. Schwanzfäden weiß oder aschgrau mit dunkleren Nähten am Grunde, beim $O$ dunkler. Beim ó sind die Vorderschenkel grünlichgrau, Vorderschienen und Füße schwärzlich; Hinterschenkel

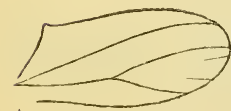

Fig. 16.

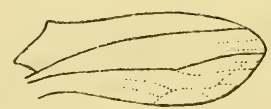

Fig. 17 .

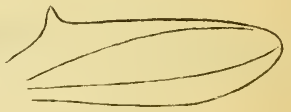

Fig. 18.

Fig. 16. Bä̈tis niger L. Der Hinterflügel. (Nach Eaton.) Fig. 17. Bä̈tis alpinus Pict. Der Hinterflügel. (Nach Eaton.) Fig. 18. Baёtis scambus Eat. Der Hinterflügel, (Nach Eaton.)

mehr ockergelb mit einem rötlichen Strich am Kñe, Schienen gewöhnlich licht rehbraun. Füße schwärzlich mit schwarzen Nähten. Beim $O$ sind die Beine grünlichgrau, Schienen und Füße schwärzlich. Genitalfüße am Grunde schwarz, nach der Spitze zu lichter. Länge des Körpers 7-8,5, des Flügels 8-10, der Schwanzfäden vom ơ 16 , vom t $13 \mathrm{~mm}$. Alpen. Juli, August (Fig. 17).

alpinus Pict.

- Genitalfüße weiß. Beim of Thorax oben kohlen- oder pechschwarz, der 2.-6. Hinterleihsring durchscheinend weif oder grïnlich, die übrigen nußbraun; beim o 올 der Kiörper grïnlichbraun. Schwanzfäden des $\delta$ weiß, einige untere Glieder dunkler; beim of rauchgran, an den Nähten der Glieder dunkler, Schenkel des ò kreideweiß oder grünlichgrau, Vorderfuß rauchgran, hintere Schienen und Füße grïnlichweiß; beim $q$ sind die Schenkel grünlichbraun, Schienen und Füße dunkel ranchgrau. Länge des Körpers 6-6,5, des Flügels 6-7; der Schwanzfäden beim o 12 , beim $q$ 9-10 mm. England. Juni, September (Fig. 18). 
5. 2. Längsader der Hinterflïgel gegabelt. Thorax oben pechschwarz bis pechbraun; Hinterleib heim of auf dem 2. bis 7. Ringe durchscheinend weiß, sonst oben gell,lich pechbraun, unten braun wie Umbra; beim o rötlich pechbraun mit gelbbrammen Nähten und hellerem Bauche. Schwanzfäden des ơ weiß, des + sehr licht rötlich braungrau. Beine des $\sigma$ weiß, Vorderschenkel, Füße und die Spitzen der Schienen sind licht schwarzgrau; beim $\circ$ sind sie entweder einfarbig blaßgrau oder grünlichgrau mit sepiagrauen Füßen. Genitalfüße weiß. Länge des Körpers $5-\overline{7}$, des Flügels beim o 4-6. beim o $_{11}-13 \mathrm{~mm}$, der Schwanzfäden beim ó $11-13$, beim 우 7,5 bis $10 \mathrm{~mm}$. - In Europa weit verbreitet. Mai bis Oktober (Fig. 19).

pumilus $\mathrm{Burm}$.

-_ 2. Längsader in den Hinterflügeln einfach.

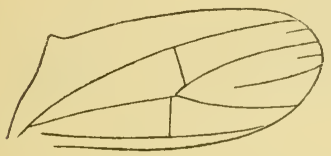

Fig. 19.

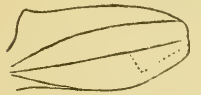

Fig. 21.

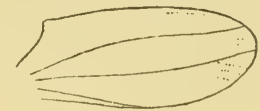

Fig. 20.

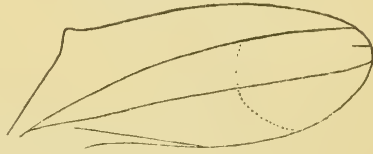

Fig. 22.

Fig. 19. Baëtis pumilus Burm. Der Hinterflügel. (Nach Eaton.) Fig. 20. Baëtis zernus Ct. Hinterflügel. (Nach Eaton.)

Fig. 21. Baëtis buceratus Eat. Der Hinterflügel. (Nach Eaton.) Fig. 22. Baëtis binoculatus I. Der Hinterflügel.

6. Genitalfüße weiß.

- Genitalfüße graulichweiß, gegen den Grund zu etwas dunkler und mit ganz weißen 2 letzten Gliedern. Thorax oben pechschwarz, Hinterleib hraun oder grünlichgran, mit helleren Nähten oder an den 2.-7. Ringe durchscheinend; Schwanzfäden weiß oder rauchgrau. Schenkel grünlichgrau, Schienen und Füße weißlich, nur die Vorderfüße dunkelgrau. Länge des Körpers 5,5-8, des Flügels beim o $5-7$, beim $q 7$ bis $9 \mathrm{~mm}$; der Schwanzfäden beim o $12-16,5$, beim o $10-12 \mathrm{~mm}$ (Fig. 20). - England und Finland. Mai, Juni, September und Oktober. vermus Curt.

7. Genitalfüße knieartig gekrïmmt, da die ersten 2 Glieder stark divergieren, die ibrigen wieder konvergieren und die ganze Gliedmaße unten stark bogenförmig ist. Sonst wie vernus oder tenax. Länge des fírpers des q 8-9, des Flügels 8-9, der Schwanzfäden 10-16 mm (Fig. 21). England. April, Mai.

buceratus Eat.

- Genitalfüße einfach bogenförmig.

S.

8. Hinterleib ohen auf dem 2.-6. oder 7 . Ringe durchscheinend weiß oder schwach gelblich, auf den übrigen Ringen siennabis dunkelbraun; beim 우 ist der Hinterleib grünlich nuß- 
braun, an den Nähten mehr oder minder lichtgelb. Thorax oben nußbraun bis pechschwarz. Beine beim on weißlich, beim ㅇ licht olivenbraum. Länge des Körpers $4-8$, der Flügel $6-8$, der Schwanzfäden beim ơ $10-13$, beim 우 8-10 mm (Fig. 22). - Europa und Nordamerika. Mai bis Oktober.

binoculatus $\mathrm{L}$.

- Hinterleib oben hell olivenbraun, durchscheinend auf dem 2.-6. Ringe, licht aschgrau auf dem Bauche. Thorax pechschwarz. Schenkel olivenbraun, Schienen und Füße aschgrau, Hinterfüße an den Nähten dunkler oder mit schmalen, schwarzen Ringen. Länge des Kiörpers 6-8, der Flingel 7-8,5, der Schwanzborsten beim ơ 14-16 mm. - England. Juni.

9. Hinterflügel mit 2 Längsadern.

tenax Eat.

Hinterflügel mit 3 Längsadern.

10.

10. 2. Längsader der Hinterflïgel einfach, Genitalfüße am Grunde schwarz (s. oben).

- 2. Längsader der Hinterflügel gegabelt, Genitalfüße weiß (s. oben).

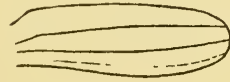

Fig. 23.

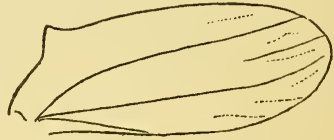

Fig. 24.

Fig. 23. Baëtis atrebatinus Eat. Der Hinterflügel. (Nach Eaton.)

Fig. 24. Baëtis Rhodani Piet. (Nach Eaton.)

11. Länge des Flügels beim of $5-7$, heim o $7-9 \mathrm{~mm}$, Thorax oben pechschwarz (s. oben).

vernus $\mathrm{Curt.}$

- Länge des Flügels beim of 4,5, beim $+5 \mathrm{~mm}$, Thorax oben grünlich nußbraun, Hinterleib beim ot auf dem 2.-6. Ringe durchscheinend weiß, auf dem 7.-9. oben dunkel olivenliraun mit ockergelben Nähten, unten ockergelb; beim $ᄋ$ ist der Körper grünlich nußbraun. Schenkel weiß, Schienen und Füße des ơ weißlich, des of dunkel ranchgrau. Länge des Körpers 4-4,5, der Schwanzborsten beim ơ 9 , beim o $6,5 \mathrm{~mm}$. - Schweiz. August.

venustulus Eat.

12. Hinterflügel ohne den zahnförnigen Zipfel am Grunde des Vorderrandes (Fig. 23). Sonst wie Baëtis Rhodani. Länge des Körpers 7-8, der Flügel 6-8, der Schwanzfäden des $\sigma^{\circ}$ $11-13$, des ㅇ $8-10 \mathrm{~mm}$. - England. Oktober.

atrebatimus Eat.

- Hinterflügel mit deutlichem Zipfel am Grunde.

13.

13. Hinterflïgel nur mit 2 Längsadern.

s. 10.

- Hinterflügel mit 3 Längsadern, Thorax oben pechschwarz, Hinterleib nußbraun, beim ot auf den Segmenten 2-6 oder 7 durchscheinend. Schwanzfäden grïnlichgran mit sepiabraunen oder rötlichen Nähten. Beine grünlichgrau oder lichtgrau. Genitalfüße grünlichgrau, das 3. und 4. Glied mehr oder minder weißlich. Länge des Körpers 5,5-9, der Flügel beim ơ 5,5-9, beim 0 bis 12 , der Schwanzfäden beim $\delta$ $13-19$, beim o $16 \mathrm{~mm}$ (Fig. 24). - Weit verbreitet. Mai bis Oktober. 


\section{Gattung Centroptilum Eat.}

Hinterflïgel schmal, bandförmig, zugespitzt, gewöhnlich mit einem spitzigen Zipfel am Grunde des Torderrandes und bloß mit 2 Längsadern. Im Vorderflügel sind die Queradern in 3 Reihen geordnet und Zwischenadern einzeln.

Hinterflïgel scharf zugespitzt und ihr Vorderrand von dem Zipfel nach der Spitze zu gerade oder eher etwas konkav, so daß die Flïgelspitze nach vorn gerichtet ist. Thorax oben pechbraun bis schwarz, Hinterleib des ot auf dem 2.-7. Pinge durchscheinend weiß, auf den ührigen Segmenten ockergelb bis nußbraun; Schwanzfäden und Genitalfüße weiß. Beim $q$ ist der Thorax oben nußbis olivenbraun, Hinterleib (Fig. 25) oben gelbbraun oder olivenbraun, unten lichter; Schwanzfäden weiß oder graulichweiß. Beim o sind die Schenkel kreideweiß, Schienen und Fïße graulich oder bräunlichweiß. Länge des Kï̈rpers $5-7$, des Flügels $6-7,5$, der Schwanzfäden beim ơ 10-14, des ㅇ $8-9 \mathrm{~mm}$. -- Häufig an Flüßen und Bächen. Im Nai, Juni und Oktober.

\section{luteolum II üll.}

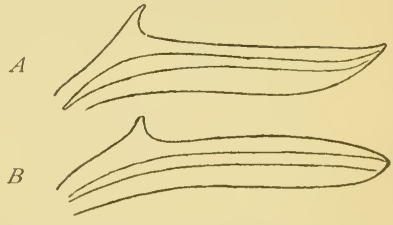

Fig. 25. Die Hinterflügel $A$ ron Centroptilum luteolum Müll.; $B$ C. pennulatum Eat. (Nach Eaton.)

Hinterflügel stumpf zugespitzt mit bogenförmigem Vorderrande. Thorax oben gelbbraun bis nuBbraun, 1. Hinterleibssegment oben pechbraun, 2.-6. weißlich durchscheinend, an den Nähten gelblich, 7.-10. rotbraun; Schwanzfäden und Genitalfüße weiß; Beine weiß, die Spitzen der Schenkel gelblich und die Endglieder der F'üße lräunlich. Beim 0 ist der Thorax oben bräunlich bis braungrau, Hinterleib oben braungrau, gegen die Spitze zu licht rötlichbraun, längs des Rückens mit breiter dunkler Mittellinie, unten lichter, mehr gelb. Schwanzfäden weiß; Schenkel weißlichgelh, Schienen weißlichgrau. Länge des Körpers und Flügels 8-9, der Schwanzfäden beim o 14-17, beim o $11 \mathrm{~mm}$. - Lausitz. September, Oktober.

penulatum Eat.

\section{Gattung Cloëon Leach.}

Hinterflügel fehlen. Vorderflügel häufig im Costal- und Subcostalfelde gefärbt, mit spärlichen Queradern, welche in 3 Reihen geordnet sind; Zwischenraumadern einzeln. Genitalfüße 4 gliedrig. ihr 3. Glied am längsten, Schwanzhorsten 2.

1. Costalfeld beim 오 gelbbraun bis nußbraun gefärlot, beim in dem apikalen Teile des Costalfeldes nur wenige (3-5) Queradern; die 1. Querader zwischen dem Radius und seinem Sektor ist wenigstens $\mathrm{mm}$ ihre eigene Länge von der nächsten Querader der 2. Reihe entfernt und nach imen geschoben. Thorax oben gelbbraun his pechbraun, Hinterleib rötlichbraun, gelbbraun bis pechbraun, leim o auf dem 2.-7. Ringe mehr oder weniger durchscheinend bis weiß. Schwanzfäden weiß oder rötlichweiß, manchnal am Grunde rötlich oder schwärzlich geringelt. Yorderbeine des o grauweiß oder graugelb mit dunkleren Schienen und Füßen und einem rötlichen 
Punkte oder pechbraunem Ringe vor der Spitze der Schenkel; Hinterfüße weißlich, Fußglieder an der Spitze šchwarz oder dunkelgrau. Beim $O$ sind die Beine rotgelb, die Vorderschenkel mit lichten Ringen. länge des Körpers beim ơ $5-10$, heim 우 8-11, der Flügel beim o $6-11$, heim 우 9-12, der Schwanzborsten beim of 13-20, beim 오 12 bis $15 \mathrm{~mm}$ (Fig. 26). - An Tümpeln und Teichen. August, September.

dipterum L.

Beim $O$ ist der Costalstreif hyalin, beim or sind in dem apikalen Teile des Costalfeldes 6-11 Queradern.

2.

2. Im apikalen Teile des Kostalfeldes 6 - 8 schiefe, selten nach der Subcosta zu gegabelte Queradern. Thorax oben pechschwarz, pechbraun, lraumgelb his ockergelb. Hinterleib des co durchscheinend weiß, die 3-4 letzten Ringe pechbraun bis rotgelb. Genitalfüße und Schwanzfäden weib, letztere öfters entfernt schmal schwarz geringelt. Hinterleib beim 우 braun lis ockergelb, auf dem 2.-7. Ringe lichter. Beine weiß bis grünlichgrau. Länge des Körpers 5-9, der Flügel

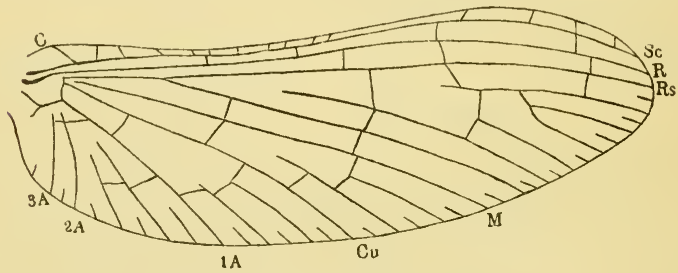

Fig. 26. Cloeon dipterum L.

6-10, der Schwanzfäden beim ô 13-15, beim $q 10-12 \mathrm{~mm}$. - Sachsen. Juli, August.

rufulum II üll.

- Im apikalen Teile des Costalfeldes 9-11 Queradern, welche unregelmäßig gekrümmt, gegen die Subcosta zu öfters gegabelt und hie und da untereinander verbunden sind. Thorax oben pech- oder kastanienbraun; Hinterleib beim of oben pechbraun, unten aschgrau, beim gelbbraun. Schwanzfäden rötlichweiß, rot geringelt. Genitalfüße grünlichweiß. Beine grïnlichgrau oder grünlichbraun mit dunkleren Füßen. Länge des Körpers 9-10, der Flügel beim of 8 , beim $ᄋ 10 \mathrm{~mm}$, der Schwanzfäden beim ơ $14-15$, beim o $10-1+\mathrm{mm}$. England, Frankreich, Schweiz. September, Oktober.

simile Eat.

\section{Familie Siphluridae.}

Die $I A$ am Grunde des Flügels von $C u$ weit entfernt und der $2 A$ genähert oder mit derselhen zusammenlaufend; sie ist mit dem Innenrande des Flügels parallel. $2 A$ trifft den Innenrand des Flïgels etwa in seiner Mitte. Zwischenraumadern mit den Längsadern verbunden und in dem 1. Analfelde Äste der $1 A$ bildend. Hintertarsi 5 gliedrig. Schwanzhorsten 2 mit kurzem Pudimente der dritten. 


\section{Gattung Chirotonetes Eat.}

Hinterfüße kürzer als die Schienen, ihr 1. Gilied kürzer als das 2.; in den Vorderfïßen des o ist das 1. Glied, in jenen des 우 das 5. am längsten. Ḱlanen gleich, schmal, hakenförmig. Die Erweiterung des Costalfeldes stumpf. Genitalfüße 3 gliedrig. Supragenitalplatte des ㅇ stumpfwinklig ausgeschnitten.

Thorax oben rotbraun, Hinterleib kastanienbram, beim $q$ etwas lichter; Vorderbeine schwarzhraun, die Wurzehn der FuBglieder und die Klaten lichter. IInterbeine strohgelb, letztes Fußglied und Klauen schwärzlich. Genitalfüße schwärzlich, an den Gelenken lichter. Schwanzfäden weißlich, am Grunde bräınlich, beim of gelblichweiß, an der Wurzel rötlich. Flïgel hyalin, mit fast durchsichtigen Adern. Länge des Körpers und der Filügel 12-13, der Schwanzfäden heim o 27, heim of $20 \mathrm{~mm}$. - Sachsen, Lausitz. Juli. iguotus Walker.

\section{Gattung Ameletus Eat.}

Hinterfüfe etwas kürzer als die Schienen und ihr 1. Glied etwa so lang wie das 2.; in den Vorderfüien ist das 2. Glied länger

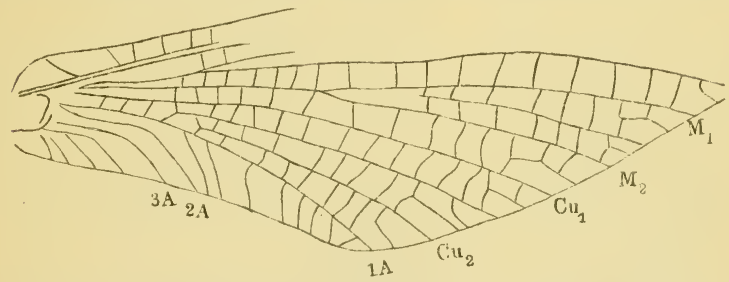

Fig. 27. Ameletus impinatus Eat. Die kubitale und auale Gegend der Vorderflügel.

als das 1.; Genitalfüße 4 gliedrig. Die + Supragenitalplatte subtriangulär, mit algestumpfter Spitze (Fig. 27 u. 2S).

Körper und Beine pechbraun, Flïgel glashell mit rotbramen Adern. Beine und Schwanzfäden gelblıraun, letztere schwach dunkler geringelt. Länge des Körpers und der Flügel $10 \mathrm{~mm}$. -- Schwarzwald. Juli. Vogesen. (Nehstdem nur aus dem Tatragebirge bekannt.)

inopinatus Eat.

\section{Gattung Siphlurus Eat.}

Hinterfüße bedentend länger als die Schienen, ihr J. Glied am längsten, die übrigen stufenweise kürzer. Vorderfüße etwa $11 / 2$ mal so lang wie die Schienen und ihr 1. Glied ehenfalls am längsten. Alle Klanen gleich, schmal und hakenförmig. Genitalfüße 4 gliedrig; ihr 2. Glied am längsten. Dje o Supragenitalplatte kurz, parabolisch oder stumpf dreieckig (Fig. 29). 
Thorax olen braun, Hinterleib oben dunkelbraun mit helleren Nähten nach den Seiten zu, unten gelhlich oder ockergelh mit Uförmigen

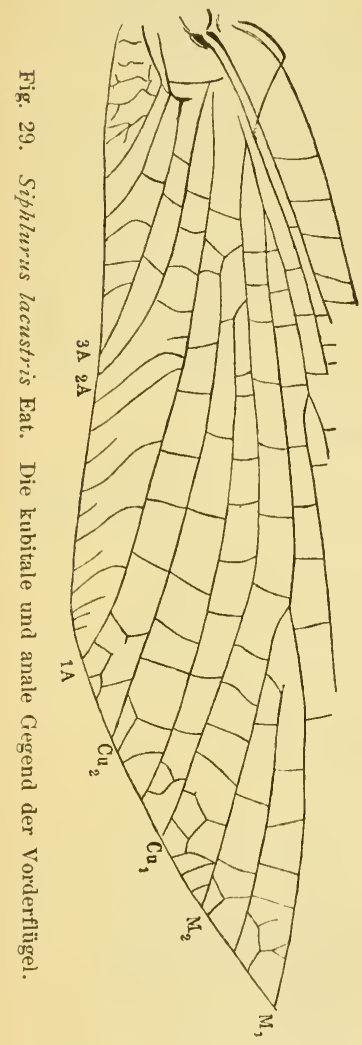
dunkleren Flecken auf den hinteren Segmenten. Genitalfüße dunkelbram. Schwanzfäden sehr licht braungrau, dunkelbraun geringelt. Vorderbeine pechbraun, die hinteren gelblich. Flügel glashell, grünlichgran gefärbt mit dunkelbrauner Nervatur. Länge des Körpers 14-15, der Flügel 15-16, der Schwanzfäden beim $0 \div 24-25 \mathrm{~mm}$ (Fig. 30 u. 31). - Bisher nur aus England bekannt, aber wahrscheinlich auch in Deutschland vorkommend. Juli. armatus Eat.

Thorax oben pechschwarz oder pechbraun. Hinterleib oben dunkel pechbraun mit ockergelben Nähten, auf den letzten 3 Ringen ins Gelbe übergehend, auf den vorderen Ringen mit 2 schiefen, dunklen Strichen, welche sich auf den hinteren zu U förmiger Zeichnung verbinden. Genitalfüße nußbraun, Schwanzfäden sepiabraun auf der Wurzel, grünlichgrau nach hinten mit dunkleren Ringen. Beine gelbbraun mit dunkleren Schenkeln, Flügel glashell, mit pechbraunen Adern. Länge des Körpers und der Flügel 12-15, der Schwanzfäden des o $17-20$, beim of $16-18 \mathrm{~mm}$. England, Savoi, Italien, Dänemark und Steiermark. August, September.

lacustris Eat.

\section{Familie Ecdyuridae.}

Die 1. Analader an Grunde der Vorderfliigel von $C u$ entfernt und mehr der $2 A$ genähert, welche ihrerseits von der $3 A$ entfernt ist und in mäßigem Bogen nicht weit von dem hinteren Winkel in den Hinterrand einmündet. Zwischenraumadern mit den Iängsadern verbunden; in dem 1. Analfelde sind 4 lange $Z$ wischenranmadern, welche zu 2 und 2 genähert sind, hie und da die $I A$ erreichen und untereinander durch Queradern verbunden sind. Hintertarsi kürzer als die Schienen, immer 5 gliedrig (Fig. 32).

\section{Gattung Epeorus Eat.}

1. Glied der Hinterfüße dentlich länger als das 2., und das 1. Glied der Vorderfüße etwa so lang wie das 2. Die Hörner der Rute stark, durch einen dreieckigen Einschnitt voneinander geschieden und an der Spitze nach außen erweitert. 
Thorax oben pechschwarz oder pechlrann, Hinterleib isabellabraun, der Hinterrand der Segmente ist breit Van Dyck-bram und dieser Streifen (Fig. 33) biegt an den Seiten nach vorne ab; anf

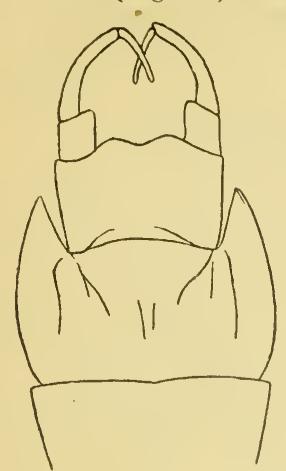

Fig. 30. Siphlurus armatus Eat. б. Das Hinterleibsende von unten.

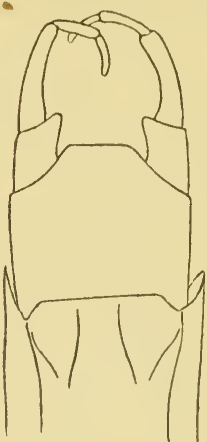

Fig. 31. Siphlurus lacustris Eat. $ð$ Das Hinterleibsende von unten.

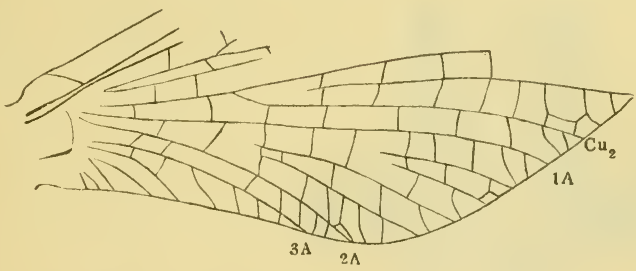

Fig. 32. Ecdyurus forcipula Kollar. Die kubitale und anale Gegend der Vorderflügel.

den Ventralringen ist je ein großer dreieckiger Van Dyck-braumer Makel, welcher von dem Hinterrande nach vorn sich verschmälert, aber den Vorderrand nicht erreicht. Vorderbeine schwarzbraun,

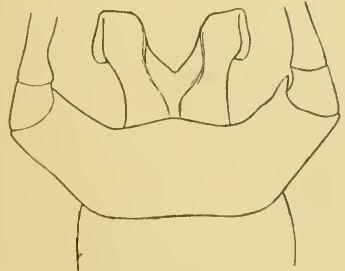

Fig. 33. Epeorus assimilis Eat. Die Rute von unten.

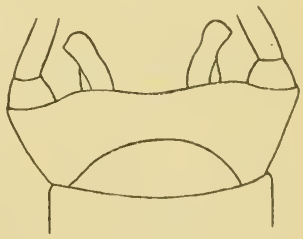

Fig. 34. Rhitrogena semicolorata Curt. Dic Rute von unten.

Ilinterschenkel nufbraun, Schienen und Füße etwas lichter. Schwanzfäden am Grunde sepiabraun, gegen die Spitze zu lichter, fahlgelb, nicht geringelt. Flügel glashell, nach der Wurzel zu grünlich ge- 
färbt: Adern pechschwarz; die äußere Hälfte des Costalfeldes gebräunt und die (queradern daselbst hie und da durch (Queräste verbunden. Länge des Körpers 14, der Flügel beim ơ 15-16, beim Weibchen 17-19 mm. Schwanzfäden des o 35-45, des ㅇ $34 \mathrm{~mm}$. - Schwarzwald, Baden, Böhmerwald. Juli, September.

assimilis Eat.

\section{Gattung Rhitrogena Eat.}

Das 1. Glied der Hinterfüße etwa so lang wie das 2., jenes der Vorderfüße heim o hat nur etwa $1 / 5$ der Länge des 2. Gliedes. Auch beim $q$ ist das 1. Glied viel kürzer als das 2. Die Hörner des Penis durch einen breiten und tiefen Einschnitt voneinander getremnt, schmal, stäbchenförmig und an der Spitze erweitert oder lanzettlich. Schenkel in der Regel in dèr Mitte der Außenseite mit einem dunklen Punkte oder breiten Striche (Fig. 34).

1. Vorderflügel in der inneren Hälfte hräunlich gefärbt. Körper rötlichbraun, auf dem Thorax oben ins Kastanienbraue übergehend. Beine und Schwanzfäden licht braun, letzte am Grunde sepiabraun, nicht geringelt. Nervatur sepiabraun nur Subcosta und Radius in der unteren Hälfte rostgelb. Queradern in dem apicalen Teile des Subcostalfeldes einfach.

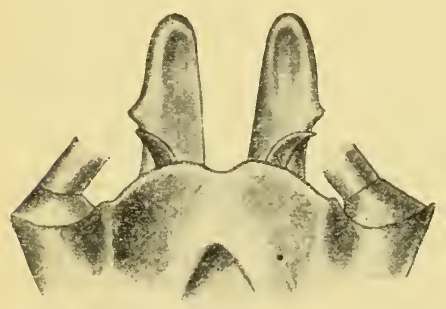

Fig. 35. Rhitrogena germanica Eat. Die Rute.

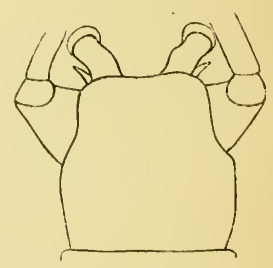

Fig. 36. Khitrogena anrantiaca Burm. Die Rute von unten.

Länge des Körpers 7-11, der Flügel 7-12, der Schwanzfäden beim ơ $23-28$, beim 우 $14 \mathrm{~mm}$. - An rasch fließenden Bächen mit reinem Wasser häufig. Mai bis Septenber. semicolorata Cırt.

Flügel glashell, höchstens nur an Grunde bräunlich gefärht. ‘.

2. Gröfere Art. Körper dunkel rotbraun, Thorax oben kastanienbraun, Hinterleib an den Nähten lichter an dem Ende sepiabraun. Beine dunkelbraun, die hinteren lichter, Knie und die Schienenspitze dunkler. Schwanzfäden lram, schmal dunkler geringelt. Flügel hyalin, am Grunde rostbräunlich, mit rotbrauner Nervatur; Subcosta und Radius erscheinen bei gewisser Stellung gelbbraun, die (Queradern sind auffallend stärker als die Längsadern und schmal bräunlich gesäumt. Länge des Körpers oder der Flügel 14, der Schwanzfäden beim ơ $28 \mathrm{~mm}$. - Rhein bei Lauffenlourg (Fig. 35).

- Kleinere Art. Thorax oben gell oder gelbbraun, Metanotum schwarz oder pechlraun, Hinterleib bräunlich, die Segmente 
vor dem helleren Hinterrande kastanienbraun, an den Seiten mit einem starken schwarzen schrägen Striche. Vorderheine des scherbengelb, an den Gelenken dunkler, Hinterschenkel grünlichweiß, ins licht Olivengrïne ühergehend, Schienen lichter, Füße schwärzlich, dunkler als die Vorderfüße. Genitalfüße schwarz oder grünlich schwarz, nach der Spitze zu lichter. Schwanzfäden sepiagrau, nach der Spitze zu weißlich, an der Wurzel schwarz geringelt. Flügel hyalin. Länge des Kö̈rpers 6, $5-9$, der Flügel $\overline{7}-10$, der Schwanzfäden beim $\delta 11-15$, beim $99-10 \mathrm{~mm}$. - Dresden, Halle, Schwarzwald. Juli, August (Fig. 36).

aurantiaca Bur.

\section{Gattung Heptagenia Walsh.}

Das 1. Glied der Hinterfüße kürzer als das 2., welches wieder gleich, oder etwas länger ist als das 3.; das 1. Glied der Vorderfüße ist viel kürzer, heim of nur ${ }^{1 / 5}$ so lang, wie das 2., welches etwa so lang ist wie das 3., hein to etwas länger. Die dunklen Punkte oder Striche in der Mitte der Schenkel fehlen. Hörner der Rute breit, unten abgeflacht, durch einen dreieckigen Einschnitt voneinander geschieden.

1. Der Costalstreif glashell, ungefärbt oder höchstens am Spitzenrande schwach gelblich. Thorax gelbbraun, hinten dunkler; Hinterleib oben bramn, an den Segmentenden dunkler, an den Seiten und unten weißgelh, die 3 Endsegmente schwach orange. Vorderbeine scherbengelb mit dumkleren Gelenken. Genitalfüße bräunlich. Schwanzfäden schmutzigweiß und bis zur Spitze dunkler geringelt. Vorderflügel bläulich schimmernd nit dunkel gelbliraunen Queradern; Costa gell). klügelspanmung 21, Länge der Schwanzborsten beim of $25 \mathrm{~mm}$. An der Weißeritz bei Dresden. August.

- Der Costalstreif deutlich gelb gefärbt. Costa gelb. Vorderbeine gelh oder scherbengelb.

coerulaus Rost. mentenden dunkler, in der Mitte mit einem braunen, lreiten Längsstreif. Thorax bräunlichgelb, Prothorax lieiderseits mit einem großen, dunkel violettbramen Fleck. Läıgsadern im Vorderflügel schwarz, mit Ausnahme der 3 ersten, welche gell, sind; der Costalstreif stellenweise rötlich gefärlıt und mit schwarzen Nodalpunkten. Der ganze Flügel melır oder weniger gelb gefärbt. Schwanzborsten weiß oder schwach rötlich, dunkler rot geringelt. Länge des Körpers 9-12, der Flügel beim $\widehat{c} 10-12$, beim $011-15$, der Schwanzfäden beim ó 24, beim $+15-25 \mathrm{~mm}$. - Lausitz. Juli. Septemlier.

flava Rost. Hinterleib in der Mitte ohne dunklen Längsstreif, nicht rötlich getuscht, blaßgelb oder schwach bräunlich, an den Segmentenden dunkler.

3. Beine isabellfarbig, die Schenkel, wenigstens dic vorderen, mit 2 fleischroten Ringen. Thorax gelblich, P'ronotum in der Mitte mit dunklerem F'leck, Metanotum ïber der Einlenkung der Hinterhüften mit dunklerem I'unkte; die Hintelleibssegmente 2-7 beim ơ durchscheinend weißlich mit nuß- 
braunen Hinterrändern, 8-10 licht gelbbraun. Schwanzborsten gelblich, dunkler geringelt. Flügel hyalin, gegen den Vorderrand zu grünlichgelb gefärbt mit sclıärzlicher Nervatur. Länge des Kïrpers 12-14, der Flïgel beim ó 14-15, beim ㅇ 17. der Schwanzborsten des of 20-33, des 우 $21 \mathrm{~mm}$. Sachsen. Juni bis August (Fig. 37). flavipennis Duf.

- Beine grünlichgelb, die Schenkel ohne dunklere Ringe. Thorax gelblich. Metathorax an den Seiten lichter als anderswo. Die

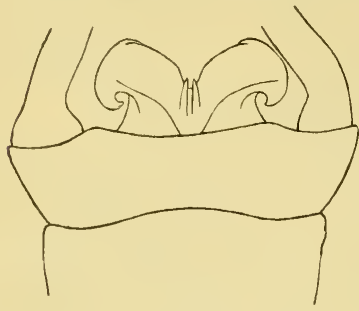

Fig. 37. Heptagenia flavipennis Duf. Die Rute von unten. Hinterleibssegmente $1-7$ beim o licht grïnlichbraun oder olivengrau durchscheinend, schmal dumkler an den Hinterrändern der Segmente; 8-10 licht gelbbraun. Schwanzborsten graulichweiß, schwärzlich oder rotbraun geringelt. Flügel hyalin mit pechbrauner Nervatur. Länge des Körpers beim ơ 7-10, beim $9-11$, der Flügel des $\delta$ 8, $5-12$, beim o $11-13$, der Schwanzborsten beim o $16-23$, beim ㅇ 14-19 mm. - Weit verbreitet in Europa. Mai bis September. sulphurea Mïll.

\section{Gattung Eclyurus Eat.}

An den Vorderfüfen sind meistens die 4 ersten Glieder stufenweise kürzer, nur die ersten 2 können manchmal etwa gleich lang sein; in den Vorderfüßen des $\delta$ ist das 1 . Glied wenigstens $1 / 3$ so lang wie das 2 ., welches etwa so lang ist wie das 3 , beim 0 ist das 1. kürzer als das 2. und dieses länger als das 3. Die Hörner der Rute meist nach außen erweitert, durch einen mäßigen Einschnitt voneinander getrennt; seltener sind sie flach, eiförmig.

1. Hinterleil nicht mit Punkten geziert.

2.

- Hinterleib des o auf dem 2.-7. Ringe durchscheinend weißlichgelb, bei dem 우 fahlgelb, auf dem Rücken etwas dunkler, bei beiden Geschlechtern mit schwarzbraunem Streifen an dem Hinterrande, welcher schräg nach vorn abbiegt und in den Winkel zwischen dem Vorderrande des Segmentes und der Seitenlinie sich zieht; anf dem Banche des 2.- . Ringes ist in der Mittellinie ein bis in die Mitte reichender Strich und 4 hinter ihm im Bogen gestellte Punkte, von welchen die 2 äußeren strichartig gegen die Mitte des Vorderrandes des Segmentes verlängert sind und so eine fächerförmige Zeichnung bilden. Thorax beim ơ dunkel, beim o lichter braun. Torderbeine schwarzbraun, Mittel- und Hinterbeine licht gelbbraun, Knie und die Füße gegen die Spitze zu dunkelbraun. Schwanzfäden dunkel sepiabraun, gegen die Spitze zn kaum lichter. Flügel hyalin mit grober schwarzbrauner Nervatur, in dem apikalen Teile des Costal- und Subcostalfeldes gebräunt. Die Queradern im apikalen Teile des Costalfeldes netzartig verbunden. Länge des Körpers $10-14$, der Flügel beim or $10-12$, beim $q 12-15$, der Schwanzfäden heim ơ $32-34$. beim $q 22-25 \mathrm{~mm}$. - An Gebirgsbächen von Mai bis August (Fig. 38 u. 39). insignis Eat. 
2. Die Hörner der Rute algerundet, eiförmig, eng aneinander gepreft. Thorax oben pechloraun, beim of etwas lichter, Hinterleıb van Dyck-braun, etwas rötlich, mit schmalem, schwarzbrannem Hinterrande der Segmente, mit 3 lichten, parallelen Strichen auf dem Rücken, einem durchscheinenden lichten Flecke an der Seite; leim $Q$ ist der Hinterleib etwas dunkler und die Zeichnung undentlich (Fig. 40). Vorderbeine schwarzbraun, mit ein wenig lichterem Fuße. Nittelund Hinterbeine mit den Brustseiten gleichfarbig, mit dunkleren Knien und Fußspitzen. Schwanzborsten licht nußbraun, kaum kenntlich geringelt. Flïgel hyalin, stark irisierend mit van Dyck-branner, feiner Nervatur; Queradern in dem apicalen Teile des Costalfeldes einfach. Länge des Köropers

Fig. 38. Ecdyurus insignis Eat. Die Zeichnung der Ventralsegmento.

Fig. 39. Ecdvurus insignis Eat. Die Rute.

Fig. 40. Ecdyurus lateralis Eat. Das Hinterleibsende von unten.

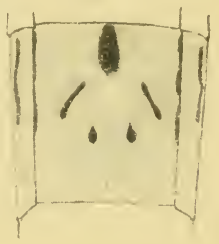

Fig. 38.

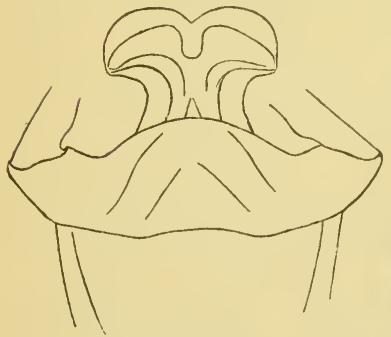

Fig. 39 .

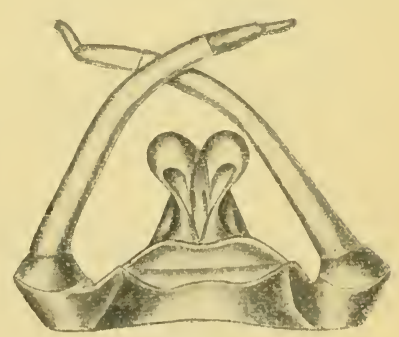

Fig. 40 .

$5-9$, der Flügel beim $\delta 6-10$, beim $q 7-10$, der Schwanzfäiden beim of 19, beim $\& 15 \mathrm{~mm}$. - An Gebirgshächen. Mai bis Angust.

lateralis $\mathrm{Ct}$.

- Die Hörner der Rute flach, stumpf dreieckig, quer erweitert. 4 .

4. Vorderfüße des $\delta$ deutlich lichter als die dunkel- bis schwarzbraunen Schenkel und Schienen; ihr 1. Glied etwa hall so lang wie das 2. Schwanzfäden am Grunde sepiabraun, in der distalen Hälfte ganz licht, dunkler geringelt. Thorax oben rötlichbraun, dunkler entlang der Mittellinie, Hinterleib beim o lichtbraun mit einem sepiabramnen Streifen an dem Hinterrande der Ringe, welcher an den Seiten dreieckig erweitert und nach vorn verlängert ist; vorne an der Seitenlinie ist ein durchschenend weißlicher Fleck. Beim o ist der Hinterleih rötlichbraun mit ähnlicher, aber weniger dentlicher Zeichnung. Genitalfüße dunkel sepiabraun. Flügel hyalin, in dem apicalen Teile des Costal- und Subcostal- 
feldes gebräunt. Länge des Körpers beim ơ 8-11, beim 9 $9-12$, der Flügel beim of $9-12$, beim $q 9-14$, der Schwanzfäden beim ơ 19-23, bein o 15-22 mm (Fig. 41). - An Gebirgsbächen weit verbreitet, aber nicht häufig. Juli bis September.

fluminum Pict. Die ganzen Vorderbeine des $\delta$ schwarzbraun bis schwarz.

5. Schwanzhorsten schmutzig weiß, nach dem Grunde zu dunkler, deutlich dunkelbraun geringelt; erstes Glied der Vorderfüße $0.674 \mathrm{mal}$ so lang wie die Schiene. Beim $\delta$ ist der Körper braun, auf der hinteren Partie des Mesonotums, anf dem Metanotum und den Hinterrändern der Abdominalringe schwarzbraun. Die Beine ebenfalls braun, die vorderen etwas dunkler, Schenkel mit '2 verwaschenen dunkleren Querbändern und die Füße gegen die Spitze zu schwarzbraun. Flügel stark glänzend, hyalin, mit schwarzbrauner ziemlich scharf ausgeprägter Nervatur. Das $q$ ist bedentend lichter, so daß der Körper licht lederbraun, auf dem Meso-, Netanotum und den Hinterrändern der Abdominalringe dunkelbram ist. Auch die Nervatur ist etwas lichter. Die Queradern im apicalen Teile des Subcostalfeldes stark ver-

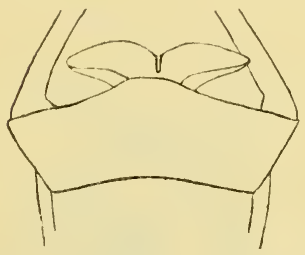

Fig. 41. Ecdyurus fluminum Pict. Die Rute.

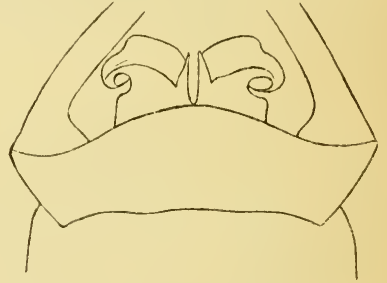

Fig. 42. Ecdyurus volitans Eat. Die Rute.

zweigt und netzartig verbunden. Länge des Körpers 12 bis $15 \mathrm{~mm}$. der Flügel beim of $13-14$, bein $q 14 \mathrm{~mm}$, der Scliwanzhorsten beim of 25-28, beim of $20 \mathrm{~mm}$ (Fig. 42). - Mai, Juni. Oberwiesental? volitans Eat.

- Schwanzborsten am Grunde sepiahraun, nicht geringelt. 6.

6. Erstes Glied der Vorderfüfe beim of $0.54-0,58$ mal so lang wie die Schiene. Körper licht gelbbraun, Thorax oben dunkelbraun, die Hinterränder der Abdominalringe oben schwarzhraun und an der Seite in einen schiefen breiten Strich nach vorn vorgezogen. Vorderbeine dunkelbraun, etwas rötlich, die Mittel- und Hinterbeine gelbbraun. Flügel meist mit einem düstergrünlichen Anfluge, das Costal- und Subcostalfeld, besonders gegen die Spitze zu bräunlich; Nervatur dunkel sepiabraun, die Queradern in dem apicalen Teile des Subcostelfeldes rerzweigt und mäßig netzartig verbunden. Länge des Körpers 9-12, der Flïgel 10-13, der Schwanzhorsten beim of $22-31$, beim o $21 \mathrm{~mm}$. - Im Sommer an reinen Bächen weit verbreitet (Fig. 43). 
- Erstes Glied der Vorderfüße heim ơ etwa 0,72 mal so lang wie die Schiene. Die Farbe des liörpers etwas dunkler, mehr rotbraun, sonst aber dem vorigen ähnlich. Flügel hyalin, mit starker, schwarzbramer Nervatur; der apicale Teil des Costal- und Subcostalfeldes deutlich braun gefärbt

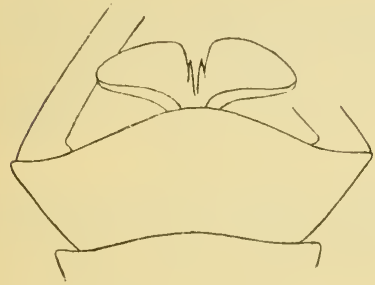

Fig. 43. Ecdyurus forcipula Kollar. Die Rute.

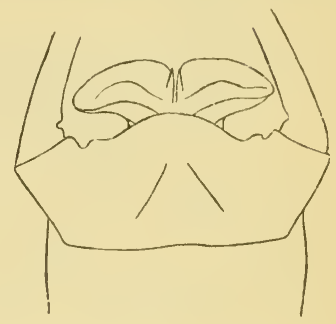

Fig. 44. Ecdyurus venosus F. Die Rute.

und die Queradern im Costalfelde daselhst verzweigt und netzartig verbunden. Länge des Körper's 15, der Flügel 15-16, der Schwanzborsten beim o $31-40$, beim 우 $25 \mathrm{~mm}$. -. Vom Mai bis September an klaren Bächen. Lausitz, Schwarzwald (Fig. 44).

venosus Fab.

Bestimmungstabelle der Gattungen ller Ephemeridennymphen*).

1. Labialtaster 2 gliedrig.

- Labialtaster 3 gliedrig.

2. Das Grundglied der Labialtaster kürzer als das 2. Gliecl. Maxillartaster ebenfalls 2 gliedrig.

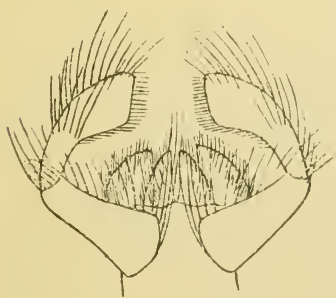

Fig. 45. Ephemera rulgata I. Die Unterlippe der Nymphe. (Nach Eaton.)

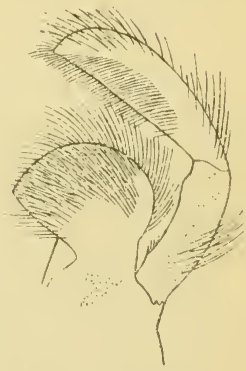

Fig. 46. Polymitarcys rirgo L. Rechte Hailft: vom Labium der Nymphe. (Nach Eaton.)

- Das Grundglied der Lahialtaster etwa so lang wie das 2.; Maxillartaster 3 gliedrig. $\Lambda$ uf dem Hinterleibe 7 Paare ron schmalen 2 ästigen, an den Rändern befransten Kiemen, von

*) Nach Eaton, A revisional monograph of recent Ephemeridae, pag. 307 . 
welchen das 1. Paar rudimentär und unbefranst ist; nit 2 spitzig konischen Vorsprüngen vorn auf der Stirn (Fig. 45).

Ephemera.

- Das Grundglied der Lippentaster länger als das 2. Glied; Maxillartaster ebenfalls 2 gliedrig; 7 Paare von Hinterleibskiemen.

3. Die Kiemen bestehen aus einer kleinen, dicken, eiförmigen Schuppe und einem Büschel voll feinen Fäden, welcher am Grunde der Unterseite mit derselben verbunden ist; das 1. Kiemenpar ist anf der Unterseite des 1. Ringes.

Oligonenria.

- Kiemen schmal, 2 ästig, am Rande befranst.

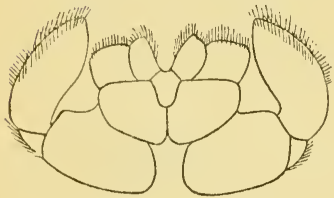

Fig. 47.

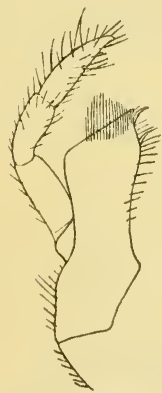

Fig. 48 .

Fig. 47. Rhitrogena aurantiaca Burm. lie Unterlippe der Nymphe. (Nach Faton.)

Fig. 48. Potamanthus luteus L. Maxilla der Nymphe. (Nach Eaton.)

Fig. 49. Die Kiemen der Nymphe von Choroterpes Pictetii. Eat. (Nach Eaton.)

Fig. 50. Caenis halterata F. Maxilla der Nymphe. (Nach Eaton.)

4. Sechs Paare von gleich gebildeten Kiemen; der Mittellobus der Unterlippe zugespitzt; Mandibeln stark und kurz.

Palingenia.

- Sieben Paare von Tracheenkiemen, von welchen aber das 1. rudimentär, klein, einfach und schuppenförmig ist; der Mittellobus der Unterlippe stumpf; Mandibeln stark verlängert (Fig. 46).

Polynitarcys.

5. Das vorderste Kiemenblättchenpaar unterhalb der Hinterbrust lionvergierend nnd einander berührend; die Kiemenfäden in Büscheln (Fig. 47).

Rhitrogena.

- Die vordersten Kiemenblächen weit voneinander entfernt. 6.

6. Die mittlere Schwanzborste fehlt den älteren Nymphen; Kiemenfäden in Büscheln verbunden.

Epeorus.

- Alle 3 Schwanzborsten vollkommen entwickelt.

7.

7. Kiemenblättchen schmal lanzettförmig.

Heptagenia. 
Die vorderen Kiemenblättchen ellipsoid, die hinteren von länglich eiförmigen in eiförmige ïbergehend; bei jüngeren Stiicken sind sie schmäler und eher dreieckig. Eedyurns.

8. Maxille schief abgestutzt und anf dieser Abstutzung unter der Spitze eine Bürste ron dichten Haaren tragend; Taster länger als die Maxilla.

- Maxilla zugespitzt mit bogenförmiger oder schwach winklig gebrochener äußeren Kontur, an der Spitze und auf der Innenkante mit starken Zähnen versehen.

12.

9. Hinterleib mit 6 Paaren von gleichartigen Kiemen; jede Kieme besteht ans zwei am Grunde verwachsenen eiförnigen, aber federartig geteilten Blättchen (Fig. 48).

- Hinterleib mit 7 Paaren von Kiemen.

Potamantlıus.

10.

10. Die vordersten Kiemen einfach, schmal lanzettlich; die übrigen bestehen aus je 2 durch ihre Stiele verbundenen etwas un-

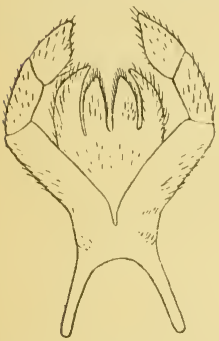

Fig. 51. Cleёоn simile. Pict. Labium der Nymphe. (Nach Eaton.)

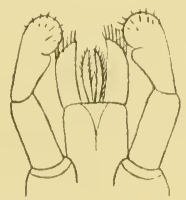

phe. (Nach Eaton.)

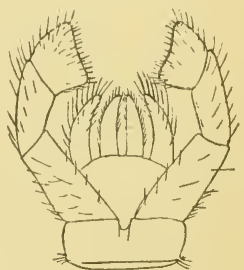

Fig. 53. Centroptitum Inteolnm I. Labium der Nymphe. (Nach Eaton.)

gleichen und assymetrischen Blättchen, deren Endteil durch zwei tiefe Einschnitte ron der übrigen Fläche gesondert ist (Fig. 49).

Choroterpes.

- Alle Kiemenpaare gleichförmig.

11.

11. Jede Kieme besteht aus 2 dünnen ahlförmigen Teilen.

Leptophlebia.

- Kiemen zweiteilig und jeder Teil wieder in mehrere fadenförmige Abschnitte geschlitzt.

Habrophlebia.

12. 4-5 Kiemenpaare; Maxillartaster kürzer als die Maxillen.

Ephemerella.

- 6 Kiemenpaare; Maxillartaster länger als die Maxilla; das vorderste Kiemenpaar ist rudimentär, das nächste grol und nach der Art von Flügeldecken die übrigen 4 Paare deckend; diese sind am Rande gefranst (Fig. 50).

Caenis.

- 7 Kiemenpare; Maxillartaster so lang oder länger als die Maxillen.

13. Die Kieferteile der Unterlippe kaum länger als breit, stumpf; die mittleren Hinterleibsringe mehr oder weniger erweitert und an der Seite vorgezogen.

- Die Kieferteile der Unterlippe dentlich länger als breit, zugespitzt und sichelförmig; die mittleren IInterleibsringe nicht erweitert und nicht rorgezogen. 
14. Alle Kiemenblätter einzeln und eiförmig; Maxillartaster den Kieferteil der Maxilla kaum ïberragend.

Chirotonetes?

- Auf den ersten 2 Ringen sind jederseits ¿2 Kiemenblätter paarweis verbunden, auf den übrigen sind die Kiemenblätter einzeln; Maxillartaster länger als die Naxilla. Siphlurus.

15. Alle Kiemenblätter einzelı.

16.

- Die Kiemenblätter meistens oder durchweg doppelt, aus ungleichen Teilen zusammengesetzt. Letztes Glied der Lippentaster abgestutzt, spitzig; letztes Glied der Maxillartaster lang, dünn (Fig. 51).

Clö̈on.

16. Kiemenblätter breit eiförmig, stumpf; letztes Glied der Labialtaster kugelig, mit dem -vorletzten zu einer Keule eng verbunden; letztes Glied der Maxillarsaster lang (Fig. 52).

Baëtis.

- Kiemenblätter schmal eiförmig bis lanzettlich, zugespitzt; letztes Glied der Labialtaster viereckig an der Spitze al)gestutzt; letztes Glied der Maxillartaster lang und dünn. (Fig. 53).

Centroptilum. 


\title{
II. Plecoptera, Steinfliegen.
}

\author{
Von
}

\author{
Prof. Fr. Klapálek (Karlin).
}

Mit 124 Abbildungen im Text.

\section{Ordnung Plecoptera, Steinfliegen.}

Kopf prognath, oben flach, meist gleich hinter den Augen abgerundet olme dentliche Schläfen zu bilden. Mundteile beißend, mit ahlförmigen oder fadenförmigen Tastern, von welchen die maxillaren 5, die labialen 3 gliedrig sind; die Unterlippe zeigt 4, wenigstens durch runde Lobi angedeutete Laden und auf der Innenseite einen kurzzungenförmigen Hypopharynx. Fühler lang, borstenförmig. Nebst den zusammengesetzten Augen sind bei den europäischen Arten 3 Punktaugen entwickelt. Hinter den hinteren Punktangen zieht sich die bogenförmige Scheitelnaht, welche den Scheitel gegen das Hinterhaupt begrenzt; vor und nach außen von denselben sind 2 Schwielen, welche wir Stirnschwielen nennen und die für die Systematik gute Charaktere bieten. Der Kopfschild ist von der Stirn durch eine M-förmig gewundene schmale Schwiele geschieden; diese werden wir als die $\mathbf{M}$-Linie bezeichnen. Bei der Beschreibung der Arten werden wir als ein Merkmal öfters den gegenseitigen Abstand der Punktaugen und die Entfermung der hinteren von dem Immenrande der Augen benützen (Fig. 54); dabei messen wir die Entfermungen vom Mittelpunkte der Punktangen und ron dem nächsten Punkte des Imnenrandes der Augen; es ist zu diesem Zweck am besten den Kopf der Fliege unter dem Mikroskop genau horizontal zn stellen, so daß alle 3 Punktaugen gleichzeitig scharf zu sehen sind, und eine einfache Zeichnung der Augen, Punktaugen und der Stirnschwielen zu machen.

Pronotum querelliptisch, aber seine Seitenteile sind meist nach unten umgeschlagen, wodurch dasselbe eine querviereckige, oder trapezoide Form erhält. Am Vorder- und Hinterrande entlang zieht sich die Vorder- und Hinterrandsfurche, in der Mittellinie die Mittelfurche; die seitlichen Partien sind meist erhöht, mit wurmförmigen Schwielen geziert und gegen das Mittelfeld scharf begrenzt. Dieses Mittelfeld ist selten gleichmäßig breit; gewöhnlich ist dasselbe vor der Mitte am schmälsten und nach vorn und hinten erweitert, wobei die Ränder gerade oder bogenförmig sein können. Wir werden öfters das Verhältnis der Breite des Mittelfeldes zu der Breite des ganzen Pronotums auf der Stelle, wo das Mittelfeld 
am schmälsten ist, als ein Merkmal benützen; auch das Verhältnis der Breite am Vorderrande zu jener am Hinterende und zur Länge ist für die Bestimmung wichtig.

Meso- und Metathorax sind einander sehr ähnlich gebildet. Wir unterscheiden anf ihrer dorsalen Fläche 4 flachhügelartige Erhöhungen, die kreuzweise gestellt sind. Die vorderste ist das Praescutum, die 2 seitlichen, welche der Flügelwurzel genähert sind, bilden das Scutum und die eiförmige, in der Nittellinie liegende

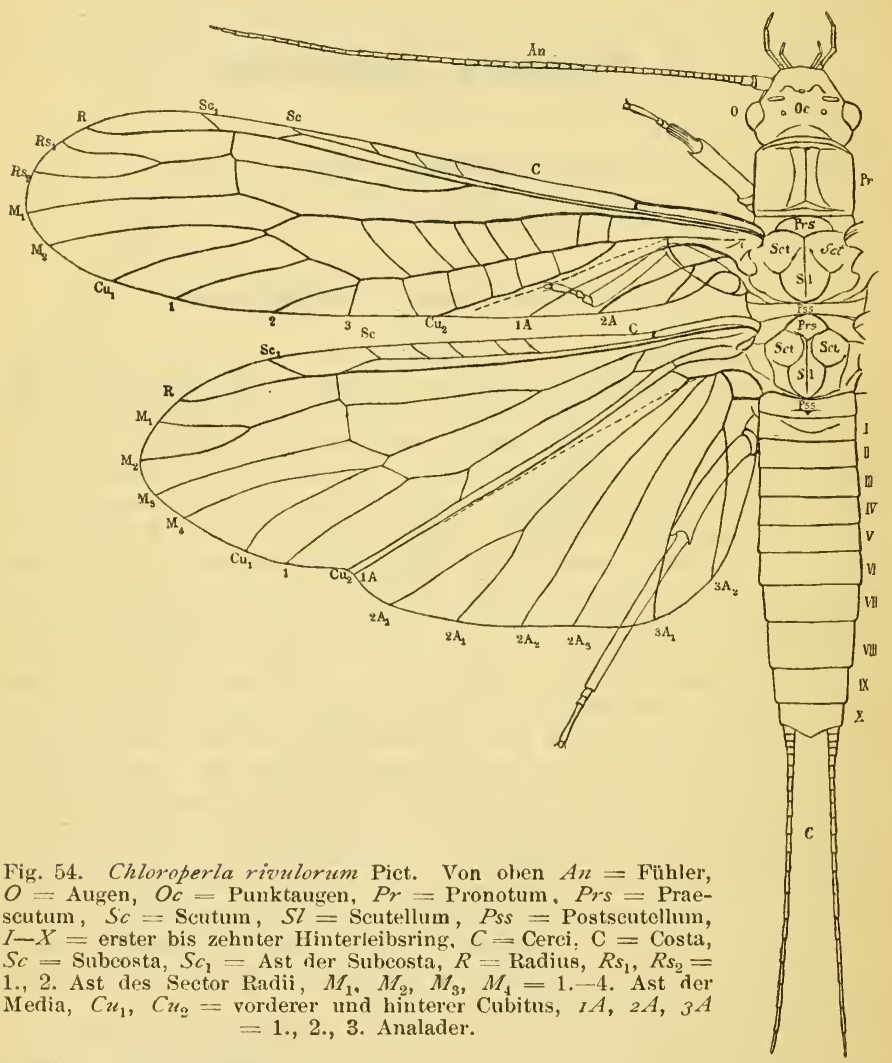

hintere ist das Scutellum; die hinterste quere Partie von den 2 Ringen ist das Postscutellum. Die Bruststïcke (Sterna) der Thorakalringe sind durch eine deutliche Naht in 2 Teile geschieden: einen breiten queren vorderen und ein kleines, zwischen den Hüften gelegenes eiförmiges oder herzförmiges hinteres Stück.

Die Laufbeine sind schlank, mit dreigliedrigen Füßen, deren Glieder entweder alle 3 fast gleich lang sind, oder die 2 ersten sehr kurz, das dritte viel länger ist als beide zusammen, oder zuletzt das 2. Glied am kürzesten ist. 
Flügel meist vollkommen entwickelt, seltener beim Männchen verkürzt. Gewöhnlich sind die Hinterflügel bedeutend breiter, da sie einen wohl entwickelten analen Teil haben. Die Membran ist glasartig oder mehr oder minder braun angeraucht, seltener grünlich. Die Nervatur ist ziemlich primitiv. Die Randader (Costa, C') bildet wirklich den Vorderrand, die Unterrandader (Subcosta, Sc) mündet ziemlich weit vor der Flügelspitze in den Vorderrand ein. Die Radialader (Radius, $R$ ) ist fast gerade und mündet ebenfalls vor der Spitze in den Rand; in den Vorderflügeln bildet sie einen Ast, welcher vor der Mitte der Flügellänge abgeht und öfters noch weitere mehr oder minder parallele Äste gegen den Außenrand abgibt; das ist der Sector radii $(R s)$. In den Hinterflügeln fehlt anscheinend diese Ader. Die nächste Längsader ist die Media $(M)$. In den Vorderflügeln ist sie nur einmal gegabelt, in den Hinterflügeln ist sie zweimal gegalelt, aber die vordere Zinke bei der ersten Gabelung entspricht in ihrem weiteren Verlauf vollkommen dem Sector radii; wir müssen demnach trotz dem verschiedenen Verlauf beide Adern für homolog halten. Den 5. Hauptstamm bildet die Cubitalader $(C \iota)$, welche in beiden Flïgelpaaren sehr nahe der Wurzel in 2 starke Äste geteilt ist; der vordere Cubitus

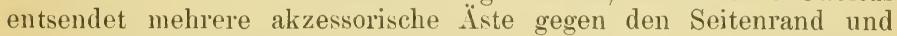
zwar in der Unterordnung Setipalpia nach hinten, in der Unterordnung Filipalpia nach vorn. Die Aualadern sind in den Vorderflïgeln schwach entwickelt, in den Hinterflügeln meist wohl entwickelt und verästelt. Die erste von ihnen bleibt immer einfach, die übrigen 2 haben meist je 3 Äste. Der Vorderast der 2. Analader entsendet meist nach hinten einige parallele akzessorische İste, von welchen der längste mit dem Mittelaste durch eine Querader verbunden sein kann, was für die Systematik, wichtig ist. Der anale Teil des Flügels ist von dem vorderen durch eine Längsfalte geschieden.

Zwischen den Längsadern finden wir Queradern, von welchen einige regelmäßig vorkommen, die anderen aber fehlen können. Zwischen der Costa und Subcosta in dem sog. Costalfelde finden wir immer am Grunde eine starke Querader, welche wir die humerale nennen, nach außen von derselben sehen wir eine variable Zahl von Queradern, welche auch gänzlich fehlen können. Zwischen der Subcosta und dem Radius, in dem Subcostalfelde finden wir mit Ausnahme einer einzigen vor dem Ende der Subcosta selten einige Queradern; in der änßeren Partie des Subcostalfeldes, zwischen dem Radius und der Costa, sind öfters einige Queradern, von welchen die erste mit der früher erwähnten Querader einen teilweise mit dem Radius verbundenen Ast der Subcosta vorstellt. Zwischen den apicalen Ästen sind bei den emopäischen Arten selten einige Queradern, dafür finden wir dieselben regelmäßig zwischen der Media und Cubitus anticus in den Vorderflügeln und zwischen den beiden Ästen des Cubitus, in beiden Flügelpaaren. Der apicale Teil der Flïgel ist durch eine zusammenhängende Reihe von Queradern begrenzt, welche wir die Mnastomose nemnen. Die einzelnen, durch die Längs- und Queradern begrenzten Felder und Zellen werden nach der ihren vorderen Rand bildenden Längsader oder ihrem Aste benannt und bezeichnet. Öfters wird die interradiale Zelle $(I R I)$ des Vorderflügels und die Intramediale (IIIL) des Hinterflügels erwähnt. Die erstere liegt zwischen dem Radius und seinem Sector 
und ist nach außen durch die Qnerader $r-s$ begrenzt, die letztere liegt zwischen beiden Zinken der Media und ist ebenfalls durch eine Querader $(m)$ geschlossen. Bei diesen Zellen ist das Verhältnis ihrer Länge zur Länge des Stiels, welche von der basalen Querader (am Grunde zwischen der $M$ und $C u$ ) gemessen wird, für die Systematik gut zu verwerten.

Der Hinterleib zeigt eine ziemlich homonome Gliederung und wir können in der Regel wenigstens auf dem Rücken sehr deutlich 10 Segmente zählen. Das 11. Segment ist nur auf der Bauchseite entwickelt und in 2 dreieckige Teile gespalten, welche wir als Subanalklappen bezeichnen; der 12., den After tragende Ring ist auf seiner Rückenseite deutlicher und bildet den sog. Supraanallobus. Der 11. Ring trägt gegliederte, fühlerförmige Anlıänge, die aber in vielen Fällen bis auf ihr Grundglied reduziert sein können; wir nennen dieselben Cerci. Der Hinterleib zeigt die Geschlechtsunterschiede. Beim Männchen ist in der Regel der Ventralbogen des 9. Ringes vorgezogen und bildet so eine Subgenitalplatte, welche oft durch eine Längsfalte jederseits gegen die Seitenteile begrenzt ist. Nebstdem können die Subanalklappen. Cerci, der Supraanallobus, sowie die Dorsalfläche der Hinterleibsringe zum Zwecke der Erleichterung von Kopulation modifiziert werden. Beim Weibchen sind die Sexualcharaktere einfacher mo beschränken sich meist auf die Bildung einer Subgenitalplatte, welche durch die Verlängerung der 8. Ventralplatte entsteht.

Die Steinfliegen halten sich meist an fließenden Gewässern anf; nur die Gebirgsseen machen von der Regel Ausnahme und werden von einigen, für solche Lokalitäten typischen Arten aufgesucht. Wir können sie von den auf den Ufern wachsenden Bäumen und Gebïsch herabklopfen, in den Ritzen der Rinde oder unter den Steinen (besonders die größeren Frühjahrsformen) finden oder auch im hellen Sonnenscheine fliegend fangen. Die Weibchen tragen oft recht große Eierballen an der Unterseite der Hinterleibsspitze und lassen dieselben über dem Wasserspiegel fliegend in das für die Nymphen unentbehrliche Element fallen.

Die Nymphen erinnern in ihrer Form schon an das vollkommene Insekt, von welchem sie sich durch den Mangel von Flïgeln unterscheiden. Sie halten sich auf und unter den Steinen auf Wasserpflanzen auf. Die größeren Arten haben faden-oder büschelförmige Tracheenkiemen, welche meistenteils anf der Brust sitzen. Das Hinterleibsende trägt immer 2 fühlerartige Schwanzfäden (Cerci), wonach sie leicht kenntlich sind.

\section{Bestimmungstabelle für die Gattungen.}

1. Alle 3 Fußglieder fast gleich lang; Schwanzfäden stark verkürzt.

- 2. Fußglied an kürzesten, 1. und 3. fast gleich. $\mathbf{5}$.

- 3. Fußglied am längsten, viel länger als das sehr kurze 2. und 1. zusammen; Schwanzfäden lang, fülılerartig. $\mathbf{S}$.

2. Der vordere Cubitus entsendet 2--3 akzessorische Äste nach vorn gegen den Außenrand; die Subgenitalplatte des ơ lang, 
am Grunde mit Anhang; das 9. Sternit des 0 in eine Supragenitalplatte vorgezogen.

Taeniopteryx.

- Der vordere Cubitus hat nur einen akzessorischen Ast. 3.

3. Zwischen der Costa und Subcosta 2-3 Queradern; die d Sulogenitalplatte lang, ohne Anhang am Grunde; das 9. 우 Sternit nur in der Mitte des Hinterrandes zungenförmig verlängert.

Rliabdiopteryx.

- Zwischen der Costa und Subcosta keine Queradern.

4.

4. Die Subcosta endigt vor dem 2. Drittel der Flügellänge; Sector radii dreimal gegabelt; die ơ Subgenitalplatte lang, olne Anhang; das 9. Sternit des $q$ in eine Platte verlängert.

Oemopteryx.

- Die Subcosta endigt hinter dem 2. Drittel der Flügellänge; Sector radii uur eimmal gegabelt; die or Subgenitalplatte kurz, kaum verlängert; das 9. Sternit des o ebenfalls nur schwach rundlich erweitert.

Nephelopteryx.

5. Schwanzfäden eingliedrig, oft verschiedenartig modifiziert. 6 .

- Schwanzfäden immer mehrgliedrig, wenn auch manchmal verkürzt.

7.

6. Am Anfange der Anastomose bilden die Adern eine $\mathbf{X}$ förmige Kreuzung; die Flügel in der Ruhe flach auf den Hinterleib zusammengelegt.

Nemura.

- Der Anfang der Anastomose bildet keine X-förmige Kreuzung; die Flügel in der Ruhe röhrchenartig um den Hinterleib zusammengerollt.

Leuctra.

7. Der anale Teil der Hinterflügel ist nicht abgesondert und der Hinterrand des Flügels ist einfach bogenföımig; Schwanzfäden verkïrzt.

Capnopsis.

- Der anale Teil der Hinterflügel normal entwickelt; Cerci lang.

Capnia.

8. Der anale Teil der Hinterflügel schwach entwickelt, durch einen sehr seichten Einschnitt des Hinterrandes angedeutet, alle drei anale Adern einfach; Pronotum querelliptisch.

Isopteryx.

- Der anale Teil der Hinterflïgel dentlich entwickelt; die 2 hinteren Analadern Aste bildend und der Vorderast der 2. Analader gegabelt.

9. Zwischen dem Radius und seinem Sector mehrere Queradern, welche oft ein umregelmäBiges Netzwerk bilden.

Perlodes.

-- Zwischen dem Radius und seinem Sector außerhalb der Auastomose höchstens ganz vor dem Ende eine Querader. 10.

10. Zwischen der Costa und dem Radius auBerhalb der Subcosta höchstens 2 Queradern. meist jedoch nur eine; der Vorderast der 2. Analader nicht mit dem Mittelaste durch eine Querader verbunden.

Chloroperla.

- In dem Subcostalfelde außerhall der Subcosta wenigstens 3 (Queradern.

11.

11. Der 1. Ast des Sector radii ist in der Regel mit seiner W Wurzel an der Bildung der Anastomose beteiligt orler, wemn er außerhalb der Anastomose verläuft, entsteht er wenigstens nahe derselben; der Vorderast ler 2. Analader ist meistens durch eine Querader mit dem Mittelaste verbunden; Pronotum zwar 
nicht stark, aber doch deutlich nach hinten verschmälert ohne einen gelben Mittelstreifen.

Perla.

- Die Ïste des Sector radii verlaufen alle auferhalb der Anastomose und zwar ziemlich von derselben entfernt; der Torderast der 2. Analader ist nicht durch eine Querader mit dem Mittelast verbunden; Pronotum parallelseitig oder eher nach rorn verschmälert mit einem gelben Mittelstreifen.

12.

12. Das Nännchen kurzflügelig, mit zapfenartig vorragenden und den Hinterrand des 10. Dorsalringes überragenden Subanalklappen; die weibliche Subgenitalplatte nimmt kaum etwas mehr als die Hälfte der Breite des 2. Ringes ein.

Perlodes.

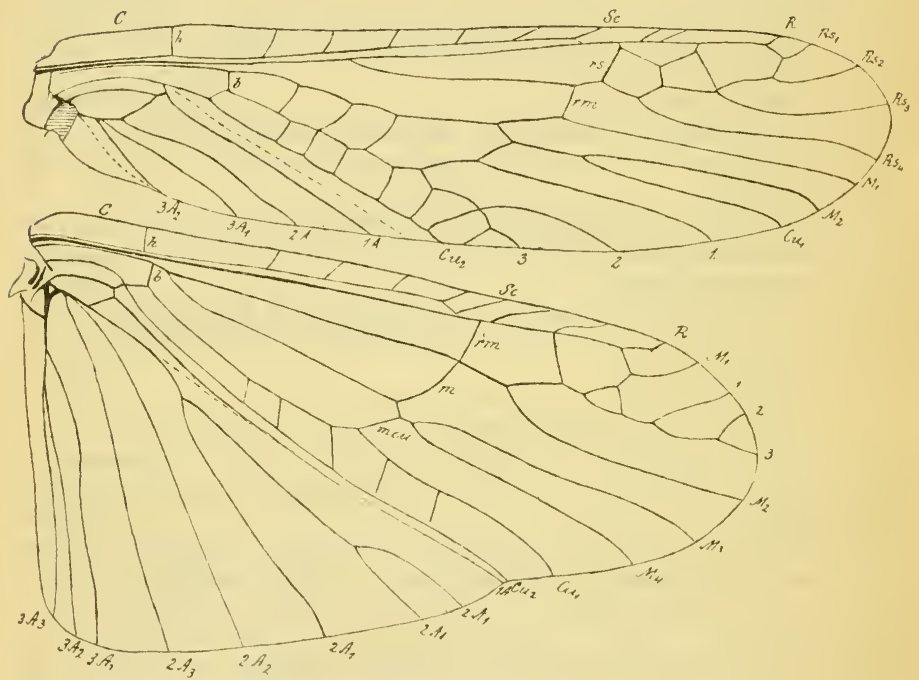

Fig. 55. Perlodes dispar Rmb. O. Die Flügelnervatux. $C=$ Costa, $S c=$ Subcosta, $R=$ Radius, $R s_{1}, R s_{2}, R s_{3}, R s_{4}=1 ., 2 ., 3 ., 4$. Ast des Sectoris radii, $M_{1}, M_{2}=1$. und 2. Ast der Media, $C u_{1}=$ vorderer, $C u_{2}$ binterer Cubitus, $I A$, $2 A, 3 A=1 ., 2 ., 3$. Analader, $h=$ die humerale, $b=$ basale, $r s$ radiosectorale, $r m=$ radiomediale, $m=$ mediale, $m c u=$ mediocubitale Querader.

- Das Männchen vollflïgelig mit kurzen kahnförmigen an den Supraanallobus gepreRten und den 10. Dorsalring nicht überragenden Subanalklappen; die weibliche Sulgenitalplatte grof, fast die ganze Ventralfläche des 9. Ringes bedeckend.

Isogenus.

Bestimmungstabelle der kurzflügeligen Männchen.

1. Zweites Fußglied am kürzesten, 1. und 3. fast gleich lang; der Supraanallobus auffallend groß, penisartig und nach oben gekrümmt.

Capuia.

- Drittes Fußglied am längsten, viel länger als die 2 ersten zusammen; Supraanallobus nie penisartig. 
2. Hinterrand des 8. Ventralringes in der Mitte mit einem al)gerundet viereckigen, stärker chitinisierten Anhang.

Chloroperla.

- Hinterrand des 8. Ringes ohne einen Anhang.

3.

3. Pronotum nach hinten deutlich schmäler, ohne einen gelhen Mittelstreifen; die Subanalklappen dreieckig oder kahnförmig.

Perla.

- Pronotum parallelseitig oder eher nach vorn schmäler, mit einem gelben Mittelstreifen; die Subanalklappen aneinandergepreßt, zusammen zapfenförmig.

Perlodes.

\section{A. Unterordnung Plecoptera setipalpia.}

- Die Glieder der Taster nehmen an Stärke stufenweise ab, so daß sie ahlförmig oder bei größerer Länge borstenförmig erscheinen. Die akzessorischen Ïste des Cubitus anticus gehen alle nach hinten ab, die Ader selhst ist aher vorgebogen. Die Schwanzfäden wohl entwickelt, fühlerartig.

\section{Familie Perlodidae.}

Pronotum parallelseitig oder eher nach vorn schmäler, meist mit einem gelben Mittelstreifen. Die Ïste des Sector radii verlaufen alle außerhalb der Anastomose und beginnen ziemlich weit von derselben. Der Vorderast der 2. Analader 1-2 akzessorische Äste bildend, ohne Querader. Die Subanalklappen, der Supraanallobus und öfters auch das 10. Dorsalsegment zu Kopulationszwecken modifiziert. Häufig finden wir zwischen dem Radius und seinem Sector zahlreiche Queradern, welche ein unregelmäßiges Netzwerk bilden können (Fig. 55).

\section{Gattung Perlodes Banks (Dictyopteryx Pict.).}

Beim Männchen sind die Subanalklappen halbwalzenförmig, aneinandergepreßt, so daß sie einen Zapfen bilden. Der 10. Dorsalbogen ist ganz, nicht geschlitzt. Beim Weibchen ist die Sulggenitalplatte entweder groß, quer elliptisch oder kleiner halbkreisförmig oder abgerundet dreieckig.

a) Zwischen dem Radius und seinem Sector ein unregelmäßiges Netzwerk; die Subanalklappen des Männchens den Hinterrand des 10. Dorsalringes in der Ansicht von oben nicht ïberragend; die weibliche Subgenitalplatte groß, querelliptisch.

Perlodes s. str

1. Nur der Kopfschild vor der $M$-Linie schwach glänzend der Kopf sonst, besonders zwischen den Punktangen, matt. Der helle Nakel auf dem Kopfschilde fehlend oder kaum angedeutet; die seitlichen Hinterhauptsflecke klein. Pronotum vorn fast so breit wie der Kopf samt Augen. Fühler düinn. Das ơ mit kurzen Flügelrudimenten. Körperlänge des of $7-11 \mathrm{~mm}$, des $99-16 \mathrm{~mm}$, Flügelspannung des ? 27-37 mm. Unter Steinen und Rinde an größeren Flüssen. April, Nai. Dresden, Hamburg (Fig. 56 и. 57). 
2. Der Kopf auch zwischen den Punktaugen glänzend. Der Kopfschild mit einem deutlichen dottergelben Makel vor der $M$-Linie. Pronotum vorn kaum so breit wie das Hinterhaupt. Fühler stark. Das ơ vollflügelig. Körperlänge des of $8-11 \mathrm{~mm}$, des 우 $15-17 \mathrm{~mm}$, Flügelspannung des of 20-30 $\mathrm{mm}$, des o

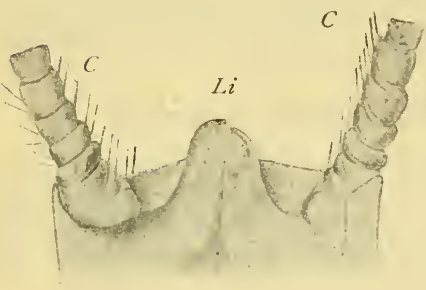

Fig. 56. Perlodes dispar Rmb. ठ․ Die Subanalklappen $(L i)$ und der nntere Teil der Cerci $(C)$. Die 10. Ventralplatte abgeschnitten.

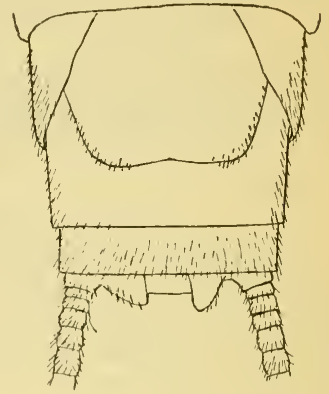

Fig. 57. Perlodes dispar. Rmb. 9 . Hinterleibsende von unten.

$38-40 \mathrm{~mm}$. Wie die vorige, aber etwas später, auch an größeren Bächen, in Wäldern. Gotha, Schandan.

microcephala Pict.

b) Zwischen dem Radius und seinem Sector kein unregelmäBiges Netzwerk von Queradern; die Subanalklappen des ơ verlängert

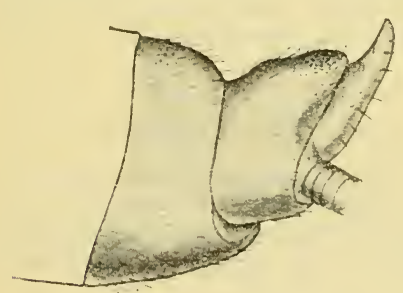

Fig. $58 a$.

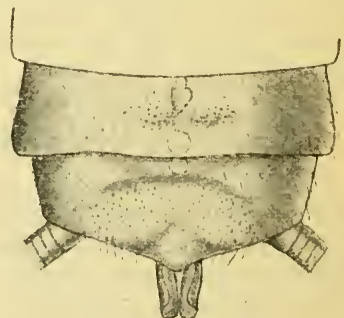

Figr. 58; $b$.

Fig. 58. Dictvopterygella recta Kny. 3. Das Hinterleibsende. $a$ von der Seite, $b$ von oben gesehen.

Fig. 59. Dictyopterygella recta Kuy. ㅇ. Das Hinterleibsende von unten.

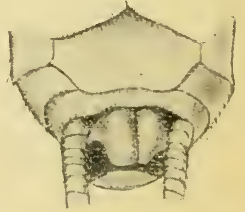

Fig. 59 .

und in der Ansicht von oben den Hinterrand des 10. Ringes deutlich ïberragend; die weibliche Subgenitalplatte kaum etwas mehr als die Hälfte der Breite des S. Ringes einnehmend. 
1. Die seitlichen Hinterhauptsflecke wenig dentlich, die Körperlänge beim o $7-10 \mathrm{~mm}$, heim o 9-13 $\mathrm{mm}$, Flïgelspannung des q $10-16 \mathrm{~mm}$. Schwarzbraun, schwach glänzend, mit sehr breitem, fast abgerundet dreieckigen Scheitelflecke, breit dreieckigem mittleren Hinterhauptsmakel und am Innenrande gelb gesäumten Augen. Die Hochgebirgsseen des Riesengebirges im Juni, Flinsberg, Juli (Fig. 58 u. 59). recta $\mathrm{Kmpy}$.

2. Die seitlichen Hinterhauptsflecke deutlich ınd der Kopfschild größtenteils gelb; Körperlänge des ơ 10-12 mm, des 우 10-14 mm, Flügelspannung des of $26-32 \mathrm{~mm}$, sonst wie vorige. Der große Teich im Riesengebirge. Juni

septentrionis.

\section{Gattumg Isogenus Newm.}

Beim $\delta$ ist der 10. Dorsalring geschlitzt, an den Enden der Abschnitte abgerundet, verdickt und beborstet; die Subanalklappen kahnförmig und an dens stark modifizierten Supraanallobus gepreßt;

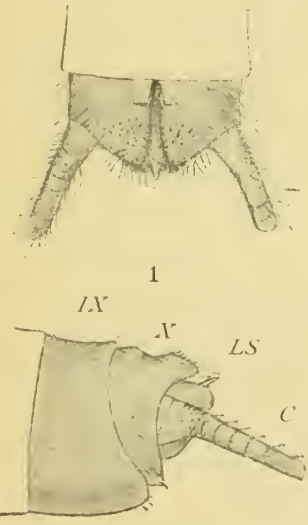

2

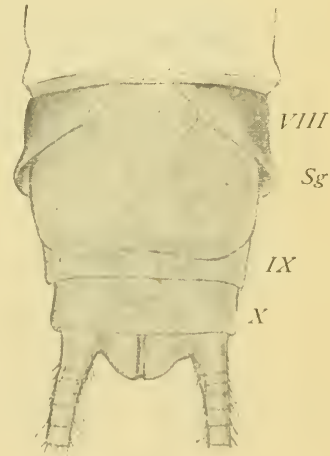

3

Fig. 60. Isogenus nubecula Nwm. 1. Das o Hinterleibsende vou oben; 2. dasselbe von der Seite gesehen; 3 . das f Hinterleibsende von unten.

dieser besteht aus einem scheidenartigen Teile, zwei Titillatoren und einem Mittelhöcker, welcher auf dem Rüicken mit einem chitinisierten, an der Spitze schnabelartig vorspringenden Längsstreifen versehen ist. Die weibliche Subgenitalplatte nimmt bei der einzigen dentschen Art fast die ganze Breite des 9. Ventrahringes ein. An der Querader $r$-rs ein dunkler, runder Fleck, Körper schwarzbraun, auf dem Meso- und Metanotım stark, an der Hinterleibsspitze schwach glänzend, sonst matt und nur die Schwielen und der Raum zwischen den Punktaugen glänzend. Der gelhe Scheitelfleck länglich eiförmig, vorn breiter und mit dem dreieckigen Hinterhauptsmakel fast zusammenhängend. Der Mittelstreifen auf dem Pronotum ziemlich schmal, die ganze Breite des Mittelfeldes nicht einnehmend. 
Der 9. Ring an den Seiten, der 10. ganz gelb. Die Unterseite des Hinterleibes gelbbramn. Fühler und Taster schwarzbraun, Beine gelbbraun bis braun, Schenkel und Schienen gegen die Spitze zu schwärzlich, Füße schwarzbraun, Cerci olivenbraun, schwärzlich geringelt. Körperlänge $12-16 \mathrm{~mm}$, Flügelspannıng $30-38 \mathrm{~mm}$. Langsam fließende Gewässer in Mittel- und Nordenropa. März, April (Fig. (i0).

nubecula Newm.

\section{Familie Perlidae.}

Beim $\sigma$ ist die 9. Ventralplatte meist in eine parabolische Subgenitalplatte verlängert; die Subanalklappen sind normal, dreieckig, schmal kahnförmig, öhrchenartig, selten klauenartig; der Supraanallobus ist klein. kaum vorragend, oder unter dem Hinterrande des 10. Dorsalbogens halbkugelig gewölbt. Sonst sind die Hinterleibsringe meist normal, seltener ist der 5. Dorsalring schildchenartig vorgezogen und stärker gewölbt; der 8. Ventralring in der Mitte seines Hinterrandes oft mit einem viereckigen oder trapezoiden
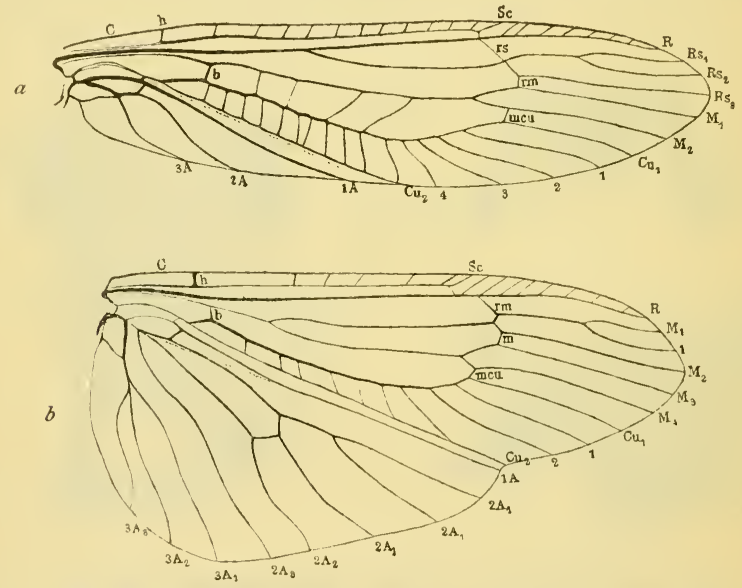

Fig. 61. Perla abdominalis Burm. Nervatur; Erklärung wie Fig. 54.

Anhange versehen, der 10 . Dorsalring ist entweder ganz oder in der Mitte geschlitzt und anf jedem Abschnitte mit einem nach vorn gerichteten Fortsatze versehen oder einen nach vorn gekrümmten starken Chitinzalın tragend. Der of Hinterleib normal, die Subgenitalplatte deutlich oder fehlend. Flügel meist vollkommen entwickelt, seltener beim ơ verkïrzt. Sector radii entweder nur einmal gegabelt oder mit melıreren hinten zum Außenrande parallel abgehenden Ïsten versehen; hei europäischen Arten sind zwischen diesen Apicalästen keine Queradern entwickelt. Der vordere Cubitus ist entweder ganz einfach oder biegt sein Ende nach vorn ab und sendet nach hinten mehrere parallele Äste zum Außenrande ab. 


\section{Gattung. Perla Ge offr.}

Kopf breit, ziemlich flach; Pronotum vorn schmäler als der Kopf samt den Augen, nach hinten dentlich verschmälert Im Subcostalfelde außerhalb der Subcosta wenigstens 3 Queradern, Sector radii mit wenigstens 2 Ästen, Cubitus anticus einige akzessorische Äste zum Anßenrande abgebend, der anale Teil des Hinterflügels wohl entwickelt, der Vorderast der 2. Analader wenigstens mit 2 Ästen und mit dem Mittelaste durch eine Querader verbunden oder nicht. Beim o sind die Hinterleibsringe normal oder der 5. Dorsalring dreieckig vorgezogen und stärker gewölbt. Der 9. Ventralring bildet eine kurze Subgenitalplatte, der 10. in der Regel geschlitzt und in 2 nach vorn gerichtete Fortsätze vorgezogen. Subanalklappen normal, Supraanallobus klein, kaum sichtl)ar. Bein o fehlt meistens eine Subgenitalplatte gänzlich, seltener ist eine stumpf dreieckige oder parabolische Subgenitalplatte vorhanden. Große, meist braun gefärbte Arten (Fig. 61).

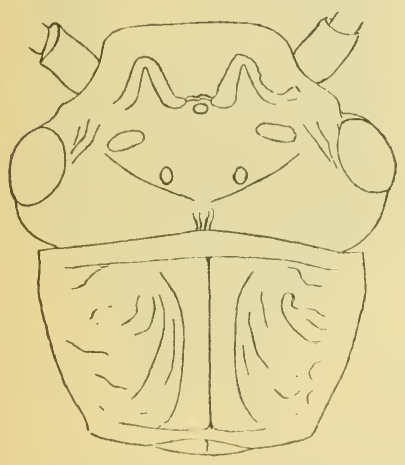

$a$

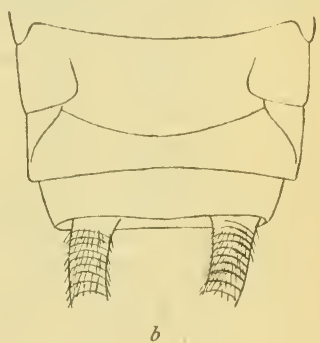

$b$

Fig. 62. Perla cephalotes Curt. a Kopf mit Pronotum, $b$ \& Hinterleibsende von inten.

A. Der Vorlerast der 2. Analader mit dem Mittelaste durch eine Qnerader verbunden.

a) Die Punktaugen in ein schmales, gleichschenkliges Dreieck gestellt und der Alıstand der hinteren kaum gleich $2 / 3$ der Entfermung derselben vom Innenrande der Angen. Pronotum stark trapezoid, vorn deutlich schmäler als das Hinterhaupt. In dem medialen Felde der Hinterflügel 1-3 Queradern. Der 10. Dorsalring heim o hinten nur ausgeschnitten und in dornartige Fortsätze nicht vorgezogen. Die $q$ Subgenitalplatte kur\%, stumpfwinklig dreieckig (Fig. 62).

1. Untergattung Dinocras $\mathrm{K} l \mathrm{l}$.

Kopf mäßig glänzend, dunkel ockergelb, vor der M-I linie und in einem von der Insertion der Fühler über die hinteren Punktaugen gehenden Bogen dunkelbraun; Thorax oben braun, der Vorder- und Ilinterrand des Pronotums dunkler, Hinterleib am Grunde dunkel ockergelb, gegen dic Spitze 
zu allmählich braun. Fühler und Taster dunkelbraun, Cerci braun. Beine braun, Schenkel und Schienen an den Knien dunkler. Das Verhältnis des Abstandes zu deren Entfernung rom Innenrande der Augen und vom vorderen Punktange: 20:27-29:22. Das ơ kurzflügelig. Kürperlänge des ơ $11-15 \mathrm{~mm}$, des 우 $15-18 \mathrm{~mm}$. Flügelspannung des 우 43 bis $54 \mathrm{~mm}$. An Gebirgsbächen. Juni. cephalotes Curt.

b) Die Punktaugen in ein fast gleichseitiges Dreieck gestellt und der Abstand der hinteren etwa so groß wie die Entfernung vom Innenrande der Augen. Pronotum weniger stark nach hinten verschmälert. In dem medialen Felde der Hinterflügel keine Queradern. Der 10. Dorsalring beim $\delta$ in der Mittellinie geschlitzt und jeder Abschnitt in einen dornartigen, nach vorn gerichteten Fortsatz vorgezogen. Der Hinterrand des 8. Ventralbogens beim o nicht vorgezogen, gerade. Perla s. str. 1. Der Kopf meistenteils - auch unten auf der Kehle schwarz, nur das Hinterhaupt lichter und die M-Linie sowie auch die Stirnschwielen rötlich; der 10. Dorsalring des 9 in der Mitte dreieckig vorgezogen und die Schwanzfäden die zusammengelegten Flügel deutlich überragend. Pronotum beim ơ schwarz, heim $q$ jederseits entlang des Mittelfeldes etwas rotbraun, welche Farbe sich öfters bedeutend verbreitert, Meso- und Metanotum glänzend schwarz, heim $ᄋ$ ins Braune übergehend. Der Hinterleib des $\delta$ rotgelb, beim o licht rotbram bis bram. Fülıler schwarz, Taster schwarzbraun, Beine braun, an den Knien dunkler, Schienen lichter als die Schenkel, Schwanzfäden braun bis schwarzbraun. Flügel stark glänzend, nur schwach getrübt, ohne den gelben Anflug entlang dem Vorderrande, Nervatur stark, braun, Costa und Subcosta in den hinteren, lichter als die ülrigen Adern, in der Regel gelb. Körperlänge des ơ $13-15 \mathrm{~mm}$, des +19 bis $23 \mathrm{~mm}$, Flïgelspannung des o $32-38 \mathrm{~mm}$, des 우 $50-58 \mathrm{~mm}$. In den niederen Lagen an größeren Flüssen überall verbreitert. Juni.

abdominalis $\mathrm{Burm}$.

- Der Kopf größtenteils, besonders unten licht, oben wenigstens der Kopfschild vor der M-Linie mit einem rotbraunen Makel.

2.

2. Pronotum gelbbraun bis rotbraun mit einem deutlichen, dunklen Mittelstreifen sowie Vorder- und Hinterrande; der Seitenrand von der übrigen Fläche in der Farbe nicht verschieden. Flügel dentlich gelb oder graugrün getrübt, mit wenig auffallender, gelbbrauner Nervatur, das Costalund Subcostalfeld nicht selten grüngelb gefärbt. Schwanzfäden kurz, die zusammengelegten Flügel nicht überragend. Die Körperfarbe bedeutend veränderlich. Kopf ockergelb bis rotbraun, Punktaugen schwarzbraun gesäumt bis mit einem schwarzbraunen $V$ förmigen Flecke verbunden. Fühler rot- bis schwarzbraun, Beine gelbbraun mit schwarzem Knierande bis braun. Körperlänge des ðे $12-16 \mathrm{~mm}$, des $018-25 \mathrm{~mm}$; Flügelspannung des oे $32-42 \mathrm{~mm}$, des o 50-60 mm. - An Gebirgsbächen. Juni, Juli. 
- Körper ockergelb, auf dem Pronotum das schmale Mittelfeld und alle vier Ränder schwarzhraun. Flügel schwach getrübt und entlang dem Radius gelblich. Nervatur braun, in den linteren Subcosta größtenteils und Radius im unteren Drittel gelb. Schwanzfäden die zusammengelegten Flügel deutlich überragend. Scutum und Scutellum der Mittel- und Hinterbrust kastanienbraun, die Seiten des Thorax braun und die Unterseite des Hinterleibes etwas dunkler als der Rücken. Fühler und Taster schwarzbraun, Beine lichtbraun mit schwarzbraunen Knien und Füßen. Schwanzfäden mit dem Hinterleibe gleichfarbig. Körperlänge $17-22 \mathrm{~mm}$, Flïgelspannung $43-64 \mathrm{~mm}$. - An größeren Flüssen. Juni.

maxima Scop.

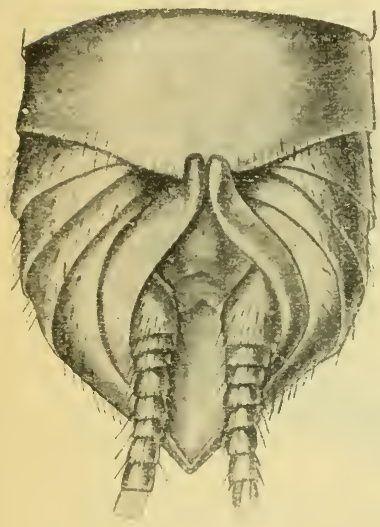

Fig. $63 a$.

Fig. 63. Perla vitripennis Burm. ठ. a das Hinterleibsende von oben; $b$ der Fortsatz des 10. Dorsaluinges von der Seite.

Fig. 64. Perla vitripennis Burm. ․ Hinterleibsende von unten.

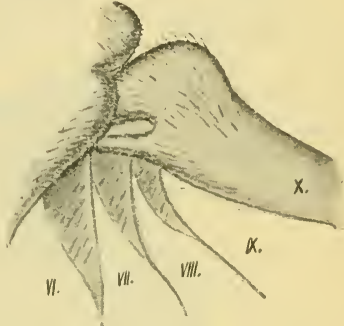

Fig. 63 b.

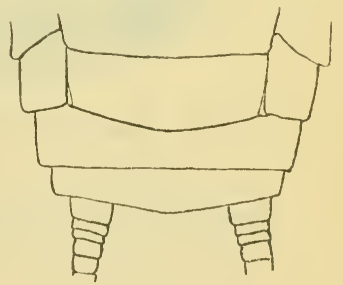

Fig. 64.

B. Keine Querader zwischen der längsten akzessorischen Ader des Vorderastes der 2. Analader und dem Mittelaste derselben. Das o voll- oder kurzflügelig; sein 5. Dorsalring dreieckig vorgezogen und die Fortsätze des 10. Ringes zweiteilig. Beim 우 ist der 8. Bauchring hinten stumpfwinklig vorgezogen.

Untergattung Narthamea $\mathrm{Klp}$.

1. Beim $q$ ist der Kopf entlang des Augeninnenrandes und auf den Schläfen auffallend gelb; Fühler schwarzbraun bis schwarz, gegen den Grund zu lichter, gelb; Praescutum des Mesound besonders des Metanotums lichter, gelb; Schwanzfäden gelbbraun; der Mittellappen der of Subgenitalplatte nimmt etwa $1 / 3$ der Breite des 8 . Ringes ein. Beim $\delta$ ist der größere Teil des Kopfes und alle 3 Thorakalringe schwarzbraun; Flügel voll entwickelt. Beim $\sigma^{*}$ ist der größte Teil des Kopfes und das Pronotum schwarzbraun, nur der Kopf- 
schild, Wangen und die Seiten des Hinterhauptes ockergelb, Meso- und Metanotum glänzend, fast schwarz, Hinterleib rothraun; beim of sind die Farben lichter, hesonders auf dem Kopfe hat die lichte Farbe einen größeren Unfang. Beine gelbbraun, die Rückenkante der Schenkel, die Schienen unter den Kinnien und Füßen schwarzbraun. Schwanzfäden gelbbraun, die letzten 4-5 Glieder schwarz. Flügel glashell, entlang dem Vorderrande deutlich gelb. Nervatur fein, schwarzbraun, nur Costa und Subcosta mit den costalen Queradern zitrongelb. Körperlänge des $\delta 10 \mathrm{~mm}$, des o 11 bis $15 \mathrm{~mm}$, Flügelspannung des of $30 \mathrm{~mm}$, des ㅇ $34-40 \mathrm{~mm}$. An größeren Flüßen. Juni (Fig. 63 u. 64).

vitripennis $\mathrm{Burm}$. Beim $q$ der Kopf gleichmäßig braun, nur zwischen den Punktaugen etwas dunkler; Fühlerbasis schwarzbraun; Prae-

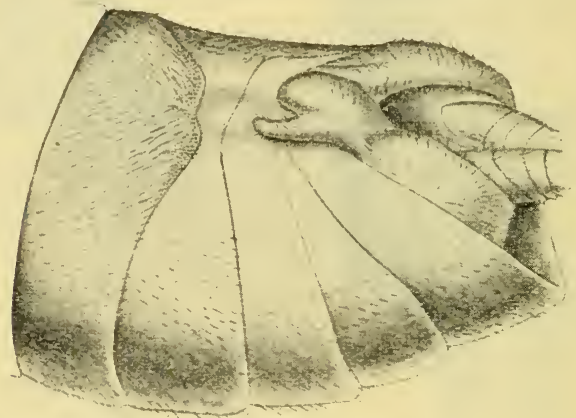

Fig. 65. Perla Selysii Pict. $\delta$ Hinterleibsende von der Seite.

scutum der Mittel- und Hinterbrust schwarzbraun, eher etwas dunkler als die übrige Fläche; der Mittellobus der 오 Subgenitalplatte nimmt nur etwa $1 / 5$ der Breite des 8 . Ringes ein;

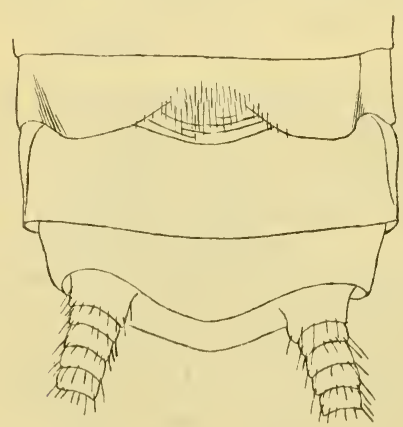

Fig. 66. Perla Selysii Pict. Hinterleibsende von unten. der Kiörper des ơ einfarbig braun und die f'lügel verkürzt. Körper des $O$ braun mit einem Stich ins Olivengrüne, die Mittel- und Hinterbrust oben schwarzbraun, unten gelblich. Fülıler und Taster braun, Schwanzfäden licht olivbram. Flïgel etwas getrübt, entlang dem Vorderrande gelblich, Nervatur braun, Costa und Subcosta mit ihren Queradern gelb. Körperlänge $13 \mathrm{~mm}$; Flügelspannung des o $38 \mathrm{~mm}$. An der Mosa. Juni, Juli (Fig. 65 u. 66).

Selysii Pict. 
- Körper des $\delta$ überwiegend gelb, der Kopf oben mit erhabenen schwarzen Linien und Makeln, Pronotum mit starken schwarzen Rändern und einem. Mittelstreifen. Schwanzfäden am Grunde gelblich, Beine fast ganz gelblich, nur die Spitzen der Schenkel und Schienen und die Füße schwärzlich. Beim $O$ ist der Körper schlanker, oben schwarz, auf dem Hinterleibe graulich; Unterseite des Kopfes gelblich mit einem großen schwarzen Makel, jene des Hinterleibes mit einem breiten gelben Mittelstreifen. Beine graulich, Füße schwärzlich, Schwanzfäden grauschwarz, deutlich geringelt. - Mosellaufer bei Alf 31./7.-1./8. (Mc. Lachl.).

var. Mosellae Mc. Lach.

\section{Gattung Chloroperla Nwm.}

Mittelgroße bis kleine Arten meistens von gelbgrüner oder dunkel graugrüner Farhe. Pronotum vorn etwas breiter als das Hinterhaupt, parallelseitig, quer viereckig mit breitem logenförmig nach voln und hinten erweiterten Mittelfelde. Im Subcostalfelde außerhalb der Subcosta höchstens nur 2, meistens aber nur eine Querader. Sector radii meist nur einmal außerhalb der Anastomose

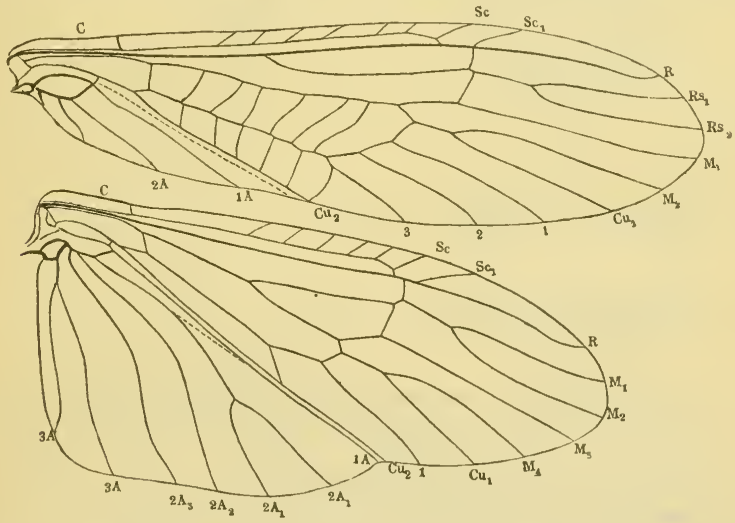

Fig. 67. Chloroperla rivulorum Pict. Nervatur. Erklärung siehe Fig. 54.

gegabelt, Cubitus anticus im Vorderflügel nur mit 2-3, im Hinterflügel mit einer akzessorischen Ader; der Vorderast der 2. Analader bei größeren Arten einmal gegabelt, bei kleineren überhaupt ungegabelt, aber immer ohne die ihn mit dem Mittelaste verbindende Querader; der anale Teil der Hinterflügel wohl entwickelt. Beim ơ trägt der Hinterrand des 8. Bauchringes in einem Ausschnitte den abgerundet trapezoiden oder quer viereckigen, stärker chitinisierten Anhang. Die 9. Ventralplatte bildet eine parabolische Subgenitalplatte. In dem Ausführungsgang der Genitalien befindet sich ein röhrchenartiger, am Ende geschlitzter Titillator. Die Subanalklappen schmal, klauenartig, Supraanallobus halbkugelig. Beim o bildet der 8. Ring eine querelliptische oder dreieckige Subgenitalplatte (Fig. 67). 
1. Schwanzfäden dünn, lang (fast so lang wie die Fühler), licht und dentlich geringelt; die weibliche Subgenitalplatte dreieckig.

- Schwanzfäden stark, dentlich kürzer als die Fühler, ganz dunkel oder nur am Grunde lichter, nur selten undeutlich geringelt.

2. Kopf und Pronotum gelbbraun bis braun mit verwasch en em hufeisenförmigen oder hinten ganz geschlossenen Makel. Auf dem Pronotum sind die Seitenfelder, nach anßen allmählich lichter. Der übrige Körper van Dyck-braun, nur das Praescutum und Scutum des Mesonotums und das Praescutum des Metanotums lichthraum. Die ganze Unterseite licht ockergelb. Fühler am Grunde gelbbraun, gegen die Spitze zu dunkler. Beine mit der Unterseite gleichfarlig, die Rückenkanten dunkler, Füße braun. Schwanzfäden ockergelb, dunkelbraun geringelt, an der Spitze ganz dunkelbraun.

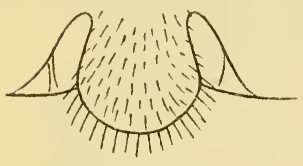

Fig. 68.

Fig. 68. Chloroperla venosa St. ơ Anhang der VIII. Ventralplatte.

Fig. 69. Chloroperla venosa St. †. Das Hinterleibsende von unten.

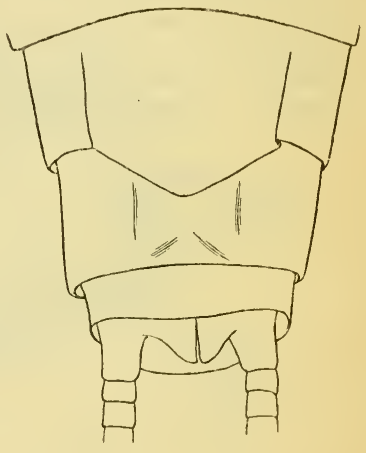

Fig. 69.

Flügel fast hyalin, mit auffallender, feiner, brauner Nervatur; nur die Subcosta grünlichgelb. Das Subcostalfeld am Grunde und an der Spitze deutlich gellgrün. Das Verhältnis des Abstandes der hinteren Punktangen zur Entfernung vom Innenrande der Aıgen ist 28-30:10. Beim o ist der Anhang des 8. Bauchringes so lireit wie lang, hinten abgerundet. Flügelspannung 21-22 mm. -- Mai. Nach Pictet in Deutschland vorkommend, mir aus Österreich bekannt (Fig. 68 u. 69).

venosa $\mathrm{St}$.

- Die Punktaugen durch einen scharf begrenzten hufeisenförmigen Fleck verbunden.

3. Das Verhältnis des Abstandes der hinteren Punktaugen zur Entfernung derselben vom Innenrande der Augen ist 37: 10; die $\{$ Subgenitalplatte nimmt fast die ganze Breite des 9 . Ringes ein; 10. Dorsalring nur mäßig bogenförmig erweitert; die Subanalklappen normal. Körper relativ schmal, oben mit Ausnahme des ockergelben Kopfes dunkelbraun, unten gelbbraun. Auf dem Pronotum ist das Mittelfeld und die schmalen Seitenründer ockergelb, die wurmförmigen Schwielen dunkelbraun. Flïgel schmal hyalin, das Costal- und Subcostalfeld 
nur in gewisser Stellung am Grunde und an der Spitze grünlich. Adern nicht auffallend, in den Vorderflügeln ist die Subcosta bis auf die schwach bräunliche Mitte, Costa bis auf die Spitze, Radius, Sector radii und Media am Grunde und die Analadern ganz gelb; in den Hinterflügeln ist nur das Ende des Radius und die Gabel seines Sectors bräunlich, sonst Adern gell. Der Anhang des 8. o Ventralringes etwa um $1 / 4$ breiter als lang, mit ganz abgerundeten Hinterecken. Flügelspannung $17-21 \mathrm{~mm}$. - An größeren Flüssen im Juni und Juli häufig (Fig. 70). griseipennis Pict.

- Das Verhältnis des Abstandes der hinteren Punktaugen zu deren Entferuming vom Innenrande der Augen ist 22:10; die 오 Subgenitalplatte nimmt etwa $3 / 4$ der Breite des 9 . Ringes ein; der 10. Dorsalring stark parabolisch vorgezogen; die Subanalklappen spitzig, beim ơ klawenartig. Kopf und Pronotum licht ockergelb, das letztere an den Seiten dunkler

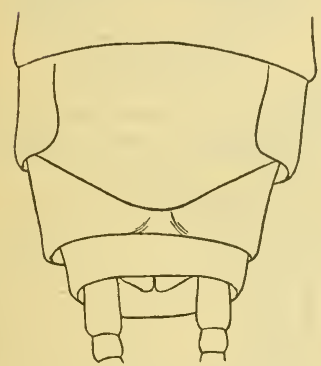

Fig. 70.

Fig. 70. Chloroperla griseipennis Pict.

․ Das Hinterleibsende von unten.

Fig. 71. Chloroper-la rufescens St. $\delta$. Anhang der VIII. Ventralplatte.

Fig. 72. Chloroperla rufescens St. +. Das Hinterleibsende von unten.

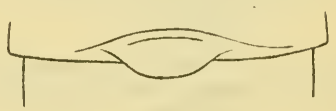

Fig. 71 .

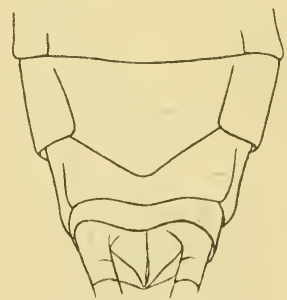

Fig. 72.

mit fast schwarzen, kleinen Schwielen, Meso- und Metanotum braun bis schwarzbraun mit gelben Praescutum, der Hinterleib dunkelbraun, gegen die Spitze zu lichter. Flügel hyalin, im Subcostalfelde an Grunde und an der Spitze grïnlich. Adern fein, gelbbraun, in den Vorderflïgeln Costa, die Spitze des Radius, die Gabel des Sector radii, die Spitze der Media und der vordere Cubitus etwas dunkler und stärker; in den hinteren nur die Adern der Flügelspitze dunkler. Der Anhang des of am 8. Ventralringe sehr kurz, trapezoid, stark nach hinten verschmälert und am Grunde etwa $1 / 3$ der ganzen Breite des Ringes einnehmend. Flügelspannung $20-22 \mathrm{~mm}$. - Juni, Juli an größeren Flüssen (Fig. 71 ı. 72).

rufescens $\mathrm{St}$.

4. Kopf gelb, mit scharf begrenztem, hufeisenförmigem Makel; Sector radii größtenteils gelb; die 오 Subgenitalplatte bogenförmig. Pronotum gelb, die Seitenfelder schwach bräunlich, Meso- und Metanotum glänzend kastanienbraun mit einem 
grünlichen Anfluge, Hinterleib olivbraun, gegen die Spitze $\mathrm{zu}$ lichter, die ganze Unterseite gelbbraun. Beine gelbbraun, mit einem sehr deutlichen dunkelbraunen Rückenstreifen auf den Schenkeln. Cerci olivbraun, am Grunde gelbbraun. Flügel grünlich, im Costal- und Subcostalfelde deutlich gelbgrün. Adern gelbgrün, in den Vorderflügeln ist die Costa bis auf die Wurzel, die äußere Hälfte der Subcosta, das Ende von Sector radii und Media nach außen von der Anastomose, diese und die äußeren Queradern, sowie auch öfters ein Teil des vorderen Cubitus auffallend stärker und braun; in den Hinterflügeln sind nur die Apicaläste braun. Beim $\sigma$ ist der Anhang des 8. Ventralringes stark quer, etwa zweimal so breit wie lang, etwas nach hinten verschmälert mit abgerundeten Hinterecken. Beim o ist der 10. Dorsalring

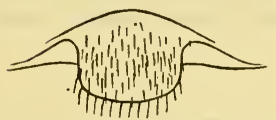

Fig. 73. Chloroperla grammatica Scop. o'. Anhang der VilI. Ventralplatte.

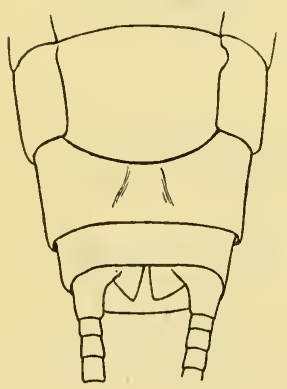

Fig. 74. Chloroperla grammatica Scop. ㅇ. Das Hinterleibsende von unten.

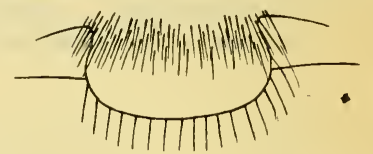

Fig. 75. Chloroperla difformis Klp. б. Anhang der VIII. Ventralplatte.

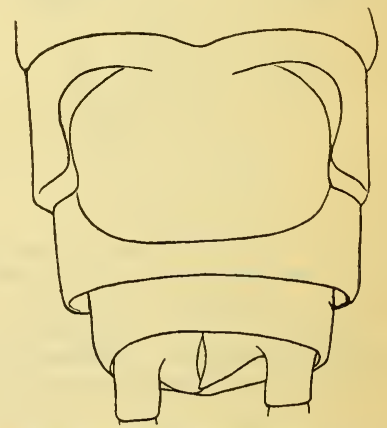

Fig. 76. Chloroperla difformis Klp. ․ Das Hinterleibsende von unten.

stumpf winklig vorgezogen. Flügelspannung $22-27 \mathrm{~mm}$. - Von Mai bis August an Bächen und Flüssen häufig (Fig. 73 u. 74).

grammatica Scop.

- Kopf zwischen den Punktaugen mit einem verwaschenen, den Raum zwischen ihnen ausfüllenden oder die gelbe Mitte des Scheitels kreisförmig umschließenden Makel; in letzterem Falle ist die $ᄋ$ Subgenitalplatte stumpf dreieckig.

5.

5. Das $\delta$ kurzflügelig und der Anhang seines 8. Ringes wenig breiter als lang; die $ᄋ$ Subgenitalplatte groß, $3 / 4$ der Länge des 9. Ringes bedeckend; der Abstand der hinteren Punktaugen größer als die doppelte Entfernung vom Innenrande der Augen. K̈̈̈rper schwarzbraun, mattglänzend, nur die Kopfseiten und das Mittelfeld des Pronotums lichter, gelblich; Flügel grau, schwach grünlich, die vorderen mit brauner, 
die hinteren mit gelblicher und nur in der Spitze lräunlicher Nervatur. Körperlänge des $\delta$ 6--.7 mm, Flügelspannung des of 20-24 mm. - April, Mai. Dresden. (Schiller) Böhmen, Dänemark (Fig. 75 ‥ 76).

difformis Krlp.

- Das ơ vollflügelig und die $q$ Subgenitalplatte einfach bogenförmig und den Hinterrand des 8. Ringes wenig überragend oder stumpf dreieckig.

6.

6. Der Anhang der 8. Ventralplatte des ơ deutlich weniger als zweinal so breit wie lang. Kopf olivgrün gelb, zwischen den Punktaugen mit einem braunen Makel, welcher in der Regel den Raum zwischen denselben ganz ausfüllt, seltener eine gelbe Mitte zeigt und dann verwaschen hufeifenförmig

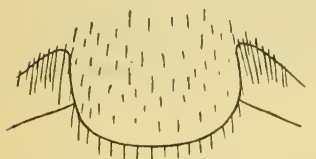

Fig. 77. Chloroperla Strandi Kny. ठ. Anhang der VIII. Ventralplatte.

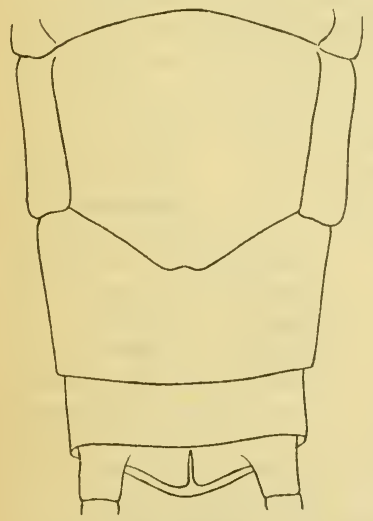

Fig. 78 .

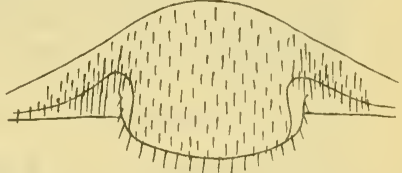

Fig. 79. Chloroperla rivulorum Pict. ठ์. Anhang der VIII. Ventralplatte.

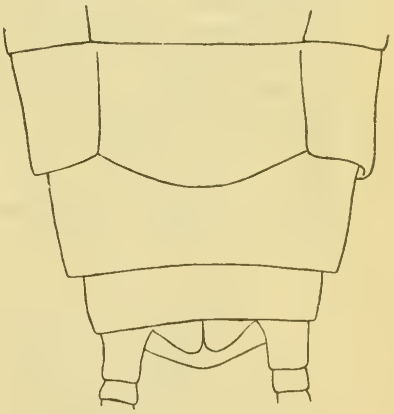

Fig. 80. Chloroperla riv'ulorum Pict. ․ Das Hinterleibsende von unten.

Fig. 78. Chloroperla Strandi Kny. ․ Das Hinterleibsende von unten.

erscheint. Die Grundfarbe des Pronotums jener des Kopfes gleich; die Seitenfelder mit mehr oder minder dunkelbraunen Schwielen. Meso- und Metanotum glänzend schwarzbraun, das erstere mit gelbgrïnem Praescutum, welche Farbe sich manchmal als ein Streifen zwischen beiden Hügeln des Scutums nach hinten zieht; Beine gelboliv mit schwarzbramen Füßen und auffallendem Streifen auf beiden Kanten der Schenkel. Die Längsadern der Torderflügel mit Ausnahme von Subcosta und der Flügelwurzel auffallend dunkelbraun, jene der Hinterflïgel gelb nur in der Spitze braun. Die weibliche Subgenitalplatte stumpf dreieckig und in der Regel an der Spitze etwas ausgekerbt. Flügelspannung des 
o $21-22 \mathrm{~mm}$, des $q 23-28 \mathrm{~mm}$. - Juni bis September. Riesengebirge, Norwegen (Fig. 77, 78). Strandi Kmpny.

- Der Anhang der 8. Ventralplatte deutlich mehr als zweimal so breit wie lang.

7. Die 오 Subgenitalplatte einfach hogenförmig, den Hinterrand des 8. Ringes kaum üherragend. Die Grundfarbe des Kiopfes und des Pronotums deutlich gelbgrïn, welche Farle auch die Flügel zeigen; die wurmförmigen Schwielen des Pronotums braun; Hinterleib oben schwarzbraun, unten braun; die vordere Hälfte des Körpers matt; Fühler schwarzbraun, am Grunde der Geißel lichter, rötlichbraun; Beine gelbbraun, die Rückenkante der Schenkel und die Füße dunkellıraun; die Adern der Vorderflügel dunkelbraun, nur die Subcosta und die Wurzel der starken Längsadern gell, jene der Hinterflügel ganz gelb und nur in der Spitze dunkler. Flügelspannung 23-29 mm. - August. Gebirgsbäche (Fig. 79 u. 80).

rivulorum Pict.

- Die o S Subgenitalplatte dreieckig, an der Spitze öfters ausgekerbt.

8. Die Grundfarbe des Körpers grünlichgelb, Vorderast des Sectoris radii meist gegabelt. Punktaugen durch einen hufeisenförmigen, verwaschenen Makel verbunden, welcher aber sich öfters so verbreitert, daß er den Raum zwischen den Punktaugen ganz ausfüllt; Praescutum und Scutum des Mesonotums meist deutlich lichter als die schwarzbraune glänzende hintere Hälfte. Nervatur der Vorderflügel bis auf die Subcosta und die gelbgrïne Flügelwurzel braun, jene der Hinterflügel grünlichgelb, in der Spitze bräunlich. Flügelspannung des of 24-25 mm, des o 28-29 mm. - Juli, August. Riesengebirge, Karpathen.

sudetica $\mathrm{Kol}$. Die Grundfarbe des Kopfes und Pronotums gelbgrau, ähnlich

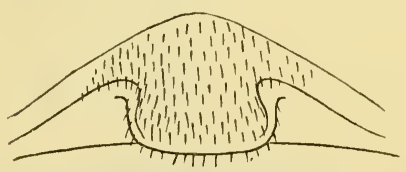

Fig. 81. Chloroperla helretica Schoch. б. Anhang der VIII. Subgenitalplatte. gelspannung 24-26 mm. - April, Mai. Schweiz (Fig. 81). helvetica Sch och.

\section{Gattung Isopteryx P ict.}

Pronotum quer elliptisch, weil seine Seitenteile nicht nach unten umgebogen sind. Subcosta endigt nahe der Mitte der Flügellänge, im Costalfelde spärliche, im Subcostalfelde nur eine Querader; Sector radii nur einmal gegabelt, und zwar weit nach außen von der Anastomose; der vordere Cubitus hat im Vorderflügel nur eine, im Hinterflügel keine akzessorische Ader und der hintere ist stark, besonders im Vorderflügel verkürzt; der anale Teil ist sehr klein und alle 3 Analadern einfach; Media im Hinterflügel ist stark gebogen und die intramediale Zelle etwa so lang wie ihr Stiel. 
Beim of ist der 9. Bauchring in eine etwa paraholische Subgenitalplatte vorgezogen, auf deren Spitze die Genitalöffnung sich befindet; in dem Ausfiilhrungsgange ist ein in 2 Borsten gespaltener Titillator. Der 10. Dorsalring in der Mitte verdickt und in der Seitenansicht zahnförmig nach oben vorspringend. Sonst sind die Segmente und ihre Anhänge normal. Beim o bildet die 8. Ventralplatte eine kurze Subgenitalplatte. - Kkleine, gelbgrïne oder weifliche Arten (Fig. 82).

1. Fühler gesägt, im unteren Drittel grünlichgelb, sonst schwarzbraun. Pronotum halbmondförmig mit deutlichen Vorderecken, breitem, fast $1 / 3$ der ganzen Breite eimnehmendem Mittelfelde und entlang demselben mit einem verwaschenen braunen Streifen, welcher in der Vorderrandsfurche erweitert und fast schwarz ist; dasselbe ist stark quer, mehr als zweimal so breit wie lang. Flügelspannung $19-25 \mathrm{~mm}$. - An größeren Flüssen im Juni.

serricornis Pict.

- Fühler einfach borstenförmig, nicht gesägt.
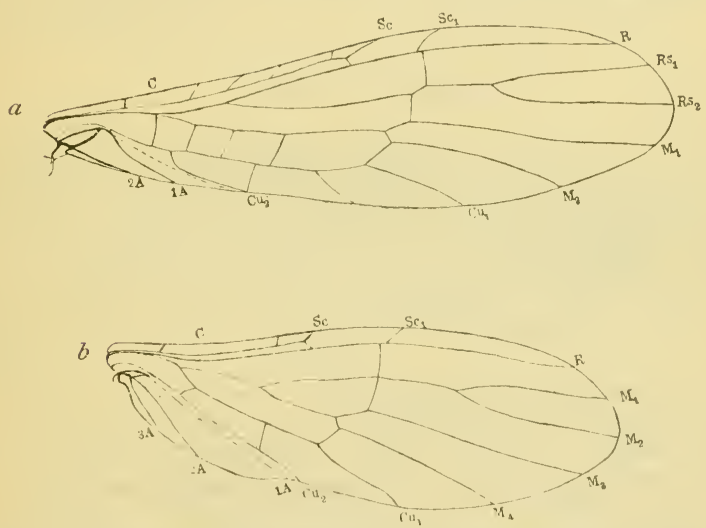

Fig. 82. isopteryx tripunctata Pict. Erklärung wie Fig. 54.

2. Die Nittelfurche des I'ronotums schwarz sowie auch die Vorder- und Hinterrandsfurche. Punktangen durch einen verwaschenen V förmigen Fleck verbunden und der Kopfschild schwärzlich. Fühler schwarz, nur die untersten 4-5 Glieder der Geißel grünlichgelb. Nervatur dunkelbrann, nur die Adern im basalen Flügeldrittel, die Subcosta und Radius sowie sein Sector fast bis zur Anastomose gelb; im Hinterflügel sind nur die Apicaläste und der größte Teil der Costa dunkelbraun. Schwanzfäden größtenteils grünlichgelb, fein schwarzbraun geringelt. nur die Spitze schwarzbraun. Flügelspanmung 15-18 $\mathrm{mm}$. - Weit verbreitet und die erste Art im Frïhlinge, Mai.

Burmeisteri Pict.

Die Mittelfurche des Pronotums nicht schwarz.

3. Schwanzfäden lang, deutlich lïnger als der Ilinterleib und an der Spitze schwarz. 
- Schwanzfäden kurz, kaum so lang wie der Hinterleib, ganz gelb; Punktaugen nicht durch einen $\mathbf{V}$ förmigen Fleck verbunden.

4. Der Seitenrand des Pronotums auffallend schwarz, die Vorderrandsfurche mit einer feinen, schwarzen Linie und die Seitenfelder in ihrem äußeren Drittel mit einem krummen, schwarzen Striche. Flügelspannung $12-17 \mathrm{~mm}$. - An Bächen im Vorgebirge von Nitte Mai bis Juli sehr häufig.

torrentium Pict. Pronotum ganz gelb, ohne schwarze Seitenränder und mit sehr feiner, schwarzer Linie in der Vorderrandsfurche. Flügel grünlichgelb mit deutlicher grüngelber Nervatur; das Sub-
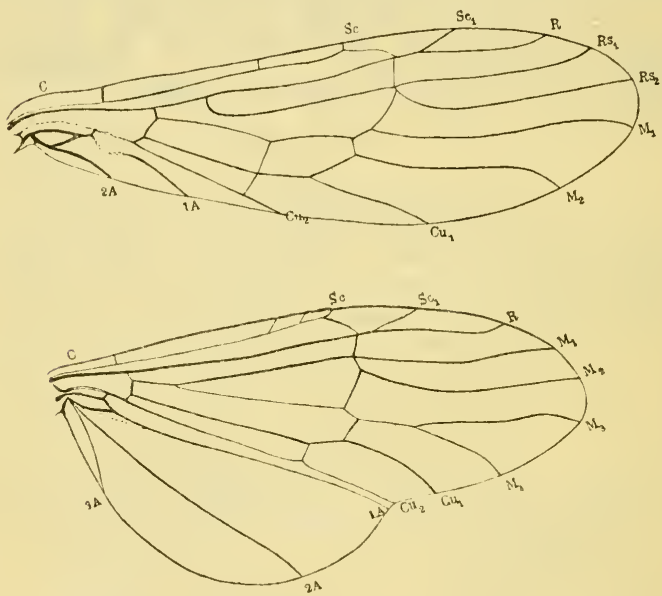

Fig. 83. Capnia nigra Piet. Nervatur. Erklärung wie Fig. 54.

costalfeld am Grunde und der Spitze stärker gefärbt. Flügelspannung 16-18 mm. - Erzgebirge und Riesengebirge. Juli, August.

neglecta Rost,

5. Pronotum gelb, schwarz gerandet, ohne jede andere Zeichnung. Körper gelb, das Scutellum des Meso- und Metanotums mit schwarzer Mittellinie und schwarzem Umrisse hinten. Flügel blafgell, mit gelber Nervatur. Fühler im unteren Drittel gelb, sonst schwarz. Flügelspannung 16-20 mm. An größeren Bächen und Flüssen. Mai bis Juli.

tripunctata Scop.

- Pronotum ganz gelb, ohne jede schwarze Zeichnung. Körper, Flügel und Nervatur noch blasser als bei der vorigen, das Scutellum des Meso- und Metanotums nie mit einer schwarzen Vittellinie und der schwarze hintere Saum desselben fehlend oder kaum angedeutet. Pronotum dentlich länger. Flügelspannung 12-15 mm. - An größeren Flüssen oder Bächen in niederen Lagen. Mai bis Juli. apicalis Newm. 


\section{B. Unterordnung Plecoptera filipalpia.}

Die Tasterglieder gleichmäßig stark und die Taster fadenförmig. Die akzessorischen Äste des Cubitus anticus gehen alle nach vorn al, die Ader selbst nicht vorgebogen. Cerci entweder vorhanden, fühlerartig oder verkürzt, eingliedrig, oder zu Zwecken der Kopulation modifiziert.

\section{Familie Capniidae.}

Der vordere Cubitus einfach, ohne akzessorische Äste; das Costalfeld mit wenigen oder ganz ohne Queradern; im Subcostalfeld die Querader vorhanden oder fehlend. Sector radii einmal gegabelt. Beim đo ist der 9. Bauchring kaum verlängert oder eine ziemlich deutliche Subgenitalplatte bildend. Der Supraanallobus in einen langen nach oben und vorn gekrümmten penisartigen Fortsatz verwandelt. Schwanzfäden entweder lang, fühlerartig oder stark verkürzt (Fig. 83).

\section{Gattung Capnia Pict.}

Im Costalfeld neben der humeralen wenigstens eine Querader. Die Querader im Subcostalfeld vorhanden. Die Querader rs mündet in den Sector radii auf derselben Stelle ein, wo er seinen Ast abgibt Zwischen der Media und dem vorderen Cubitus 3 Queradern. Der anale Teil der Hinterflügel deutlich entwickelt, die Analadern einfach. Cerci lang. Das 9. Ventralsegment bildet beim of keine Subgenitalplatte. Beim 우 fehlt die Subgenitalplatte oder ist kurz dreieckig.

Die durch den unteren Teil der beiden Cubiti und die zwischen ihnen liegende Querader gebildete Zelle viereckig, gegen den Grund zu mäßig verschmälert. Körper schwarz, Flügel bräunlich angeraucht mit starker schwarzbrauner Nervatur. Beim ó Flügel stark verkrümmt. Flügelspannung des q $16-18 \mathrm{~mm}$. nigra Pict.

Die durch den unteren Teil der Cubiti und die zwischen ihnen liegende Querader gebildete Zelle dreieckig, gegen den Grund zu stark verschmälert. Der Körper schlanker, Flügel feiner und mehr hyalin. $\delta$ vollflüglig. Flügelspannung $12-17 \mathrm{~mm}$. atra Mort.

\section{Gattung Capnopsis Rost. (Mort.).}

Im Costalfelde neben der humeralen keine Querader. Die Querader im Subcostalfelde fehlend. Die Querader $r s$ trifft den Sector radii an der Abzweigung seines Astes. Zwischen der Media und dem vorderen Cubitus nur 2 Queradern. Der anale Teil der Hinterflügel verkümmert. Beim ơ bildet das 9. Segment eine deutliche Subgenitalplatte. Cerci stark verkürzt. Beide Geschlechter vollflïgelig (Fig. 84).

Körper schwarz, Flügel schwach bräunlich getrübt mit dunkelbrauner, deutlicher Nervatur. Flügelspannung $12 \mathrm{~mm}$. - Nai. Dresdener Heide, an der Prießnitz (Schiller). pygmaea Zett. 


\section{Familie Taeniopterygidae.}

Sector radii einmal bis dreimal gegabelt und der erste Ast ist öfters an der Bildung der Anastomose beteiligt; der vordere Cubitus entsendet im Vorderflügel $1-3$ parallele akzessorische Äste: im Hinterflügel bleibt derselbe ganz einfach. Der Analteil der Hinterflügel wohl entwickelt, 2. Analader dreiästig, der Vorderast einmal

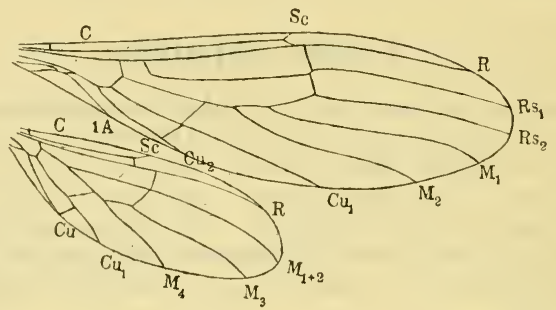

Fig. 84. Capnopsis pygmaea Zett. Nervatur. Erklärung wie Fig. 54.

gegabelt und mit dem Mittelaste durch eine Querader nicht verbunden. In dem medialen und vorderen Cubitalfelde der Vorderflügel zahlreiche Queradern. Bei dem ơ bildet gewöhnlich der 9. Ventralring eine Subgenitalplatte, welche nahe dem Grunde auf ihrer Außenseite öfters mit einem tränenförmigen Anhange versehen ist. Die Subanalklappen und der Supraanallobus zu Kopu-

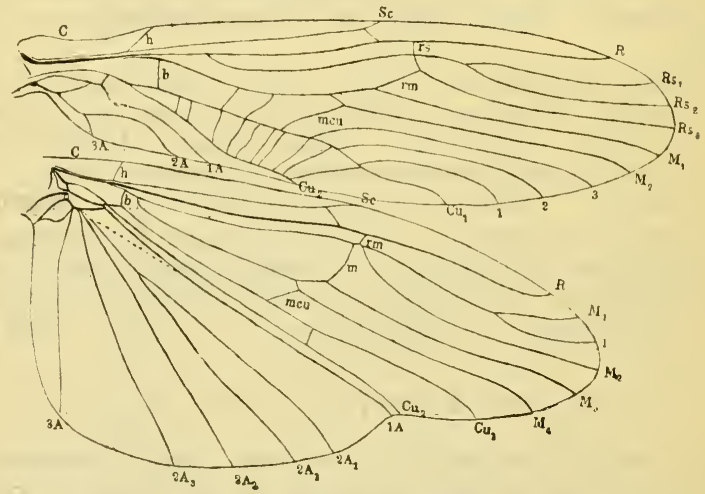

Fig. 85. Taeniopteryx Braueri Klp. Nervatur. Erklärung wie Fig. 54.

lationszzwecken modifiziert. Schwanzfäden stark verkürzt, aus wenigen Gliedern bestehend oder bloß eingliedrig. Beim $q$ ist die Genitalöffnung oft bis auf die Fläche des 8. Ventralringes verschohen, welche nicht vorgezogen ist. Dafür ist die 9. Ventralplate ausgehöhlt und mehr oder weniger plattenartig vorgezogen. Flügel bei den $\sigma$ einiger Arten rudimentär (Fig. 85). 


\section{Gattung Taeniopteryx Pict.}

Der vordere Cubitus mit $2-3$ akzessorischen $\mathrm{A}$ sten, im Costalfelde sowie zwischen Radius und seinem Sector außerhalb der Anastomose keine Queradern, im Sulscostalfelde außerhalb der Subcosta nur eine Querader, welche noch fehlen kann. Beim o die Subgenitalplatte lang mit dem Anhange an dem Grunde; Cerci eingliedrig, öhrchenförmig, mit knopfartigem 2. Gliede. Die Subanalklappen asymmetrisch, stark modifiziert, in spiralige Chitingräten auslaufend; Supraanallobus ebenfalls stark modifiziert, in 2 Teile differenziert: einen halbkugeligen, dorsalen und röhrenartigen, ventralen, aus dessen Innern grätenartige Titillatoren herausragen; die Form der Spitze dieses Röhrchens ist für die Unterscheidung der Arten wichtig. Beim $q$ ist die 9. Ventralplatte nach der Art einer Subgenitalplatte verlängert. Sclıwarzbraune, schlanke Arten, die wir auf Mauern, unter Steinen und in den Ritzen der Rinde sammeln können.

1. Fühler stark, in der unteren Hälfte lichtbraun, deutlich perlschnurförmig.

- Fühler schwach, borstenförmig, aber in dem unteren Fünftel sind ihre Glieder kurz, breiter als lang, manchmal schwach perlschnurförmig. Sector radii nur einmal gegabelt.

- Fühler fein, borstenförmig, alle ihre Glieder walzenförmig, länger als breit.

2. Das $\delta$ kurzflügelig (das $ᄋ$ mit borstenförmigen, unten kurzgliedrigen Fühlern), s. 3 .

trifasciata Pict.

- Beide Geschlechter vollflügelig. Körper relativ stark, schwarz, nur der Kopf dunkel rotbraun, mit einem schwarzen Flecke zwischen den Punktaugen; Meso- und Metanotum glänzend. Flügel schwach braun getrübt mit graulnauner Spitze und 3 bogenförmigen, nach außen kionkaven Querstreifen, welche aber manchmal nur ganz schwach angedeutet sind. Sector radii 1-2 mal gegabelt. Beine gelb- bis dunkelbraun. Die Form mit stark perlschnurförmigen Fühlern ohne Querstreifen auf den Flügeln ist moniticornis Pict. Körperlänge 5-81/2 mm. Flügelspannung 20-31 mm (Fig. 86 u. 87). Braueri Klp.

3. Das of vollflügelig, die unteren Fühlerglieder lichter und ziemlich deutlich perlschnurförmig. Körper ziemlich schlank, Kopf und Brust schwarz, Hinterleib, Abdomen schwarzbraun oder dunkel rotbraun. Flügel schwach glänzend mit graubrauner Spitze und 3 bogenförmigen, nach außen konkaven Querstreifen; der vordere Cubitus mit 3 oder 2 Ïsten. Beine braun, Schenkel unter der Spitze dunkler bis schwarzbraun, Schienen immer mit einem dunklen Ringe unter dem línie.

Kempnyi Klp.

-- Das ठ̊ kurzflügelig. Alle Fühlerglieder walzenförmig. Körper beim ơ ziemlich stark, stärker als beim o, dunkelbraun, beim of etwas lichter als beim $q$, in der Mitte des Kiopfes schwarzbraun. Die Vorderflügel des $\delta$ kaum halb so lang wie die Hinterflügel, beide Paare braun, mit starker Nervatur. Beim $q$ die Flügel mattgrau, die Spitze und 3 fast gerade Querstreifen dunkler. Vorderer Cubitus mit 3 akzessorischen Adern. Beine braun, die Schenkel unter der 
Spitze und ein Ring auf den Schienen unter den Knien dunkler (Fig. 88).

trifasciata $\mathrm{Pict}$.

4. Sector radii zweimal gegabelt und sein erster Ast meistens zur Anastomose beitragend und mit derselben weit verbunden;
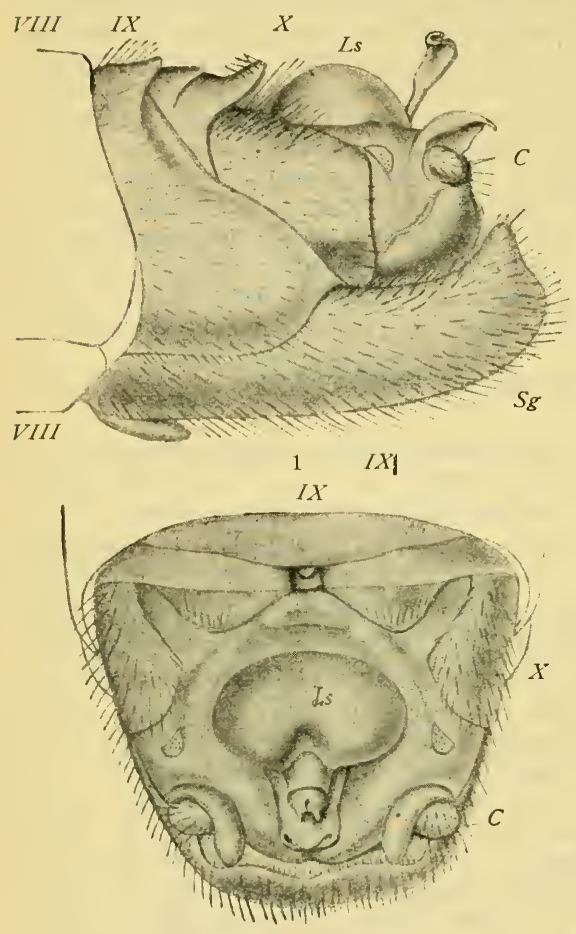

$S g \quad 2$

Fig. 86 .

Nervatur auffallend stark, schwarzbraun, nur der Radius manchmal lichter. Körper schwarzbraun, nur der Kopf und das Pronotum etwas lichter, das letztere gelbbraun gerandet. Flügel schwach getrübt mit sehr deut-

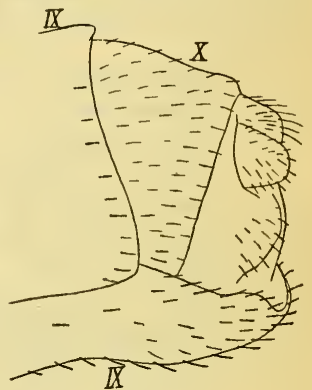

Fig. 87.;

Fig. 86. Taeniopteryy

Braueri Klp. O'. 1 das Hinterleibsende von der Seite; 2 von oben. $S g=$ Subgenitalplatte, Ls = Supraanallobus, $C=$ Cerci.

Fig. 87. Taenioptery $x$ Braueri Klp. + . Das Hinterleibsende von der Seite.
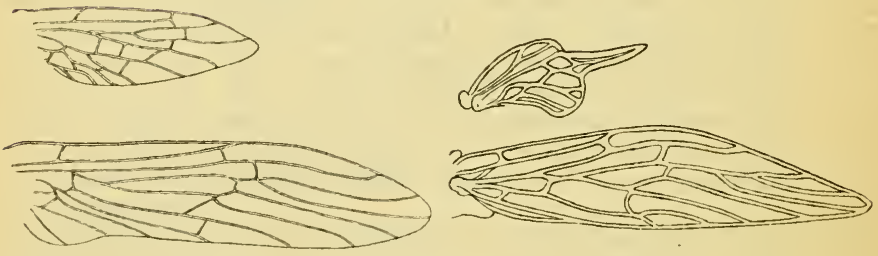

Fig. 88.

Fig. 89.

Fig. 88. Taeniopteryx trifasciata Pict. ठे. Flügel.

Fig. 89. Flügel des $q$ von Oemopteryx Loewii Alb.

lichen bogenförmigen Querstreifen, aber die Spitze kaum dunkler. Beine braun, die Rückenkante der Schenkel und die Schienen gegen die Spitze zu schwarzbraun. Körperlänge 
6-7 mm, Flügelspannung 20-26 mm. - Böhmerwald, Riesengebirge, Erzgebirge, Harz. Juni, Juli; die späteste von unseren Taenioptery $x$-Arten.

seticoruis $\mathrm{Klp}$.

- Sector radii nur einmal gegabelt und sein Ast die Anastomose nur in einem Punkte berïhrend oder ganz außerhalb derselben verlaufend. Nervatur fein, lichtbraun bis braun. Flügel fast hyalin, mit schwach angedeuteter Zeichnung, von welcher nur der halbmondförmige Querstreifen über der Anastomose deutlicher hervortritt. Sonst wie die vorige, von welcher sie sich durch den zarteren Bau im allgemeinen unterscheidet. Körperlänge $6-7 \mathrm{~mm}$, Flügelspannung 22 bis $25 \mathrm{~mm}$.

Risi Mort.

\section{Gattung Oemopteryx Klp.}

Der vordere Cubitus mit einem akzessorischen Aste; im Costalfelde keine Queradern, aber zwischen dem Radius und seinem Sector 2-3 Queradern; die Querader im Subcostalfelde außerhalb der

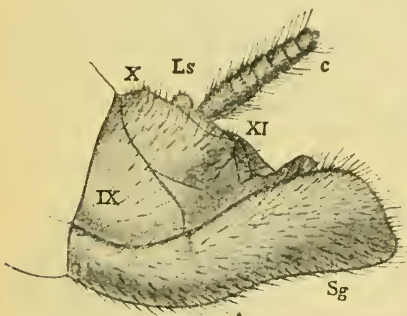

A.

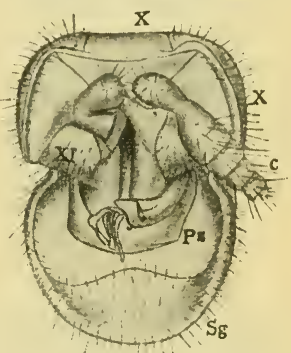

B.

Fig. 90. Oemopteryx Loewii Alb. $\delta$. $A$ das Hinterleibsende von der Seite; $B$ von oben und von hinten. $S g=$ Subgenitalplatte, $L s=$ Supraanallobus, $C=$ Cerei.

Subcosta vorhanden. Sector radii mit $2-3$ Ästen. Beim ơ ist die 9. Bauchplatte lang, eine Subgenitalplatte ohne Anhang am Grunde bildend; die Subanalklappen stark moiitıziert und spiralig gewundene Chitingräten bildend; der Supraanallobus bildet 2 Abschnitte, voll welchen der dorsale stark chitinisiert, kugelig verdickt und unten in ein Chitinröhrchen verlängert ist, der ventrale, schwächer chitinisierte ist mit Spitzen und Häkchen besetzt, an der Spitze dreilappig und mit einem grätenartigen Titillator versehen, der aus dem inneren des mittleren röhrchenartigen Teiles hervortritt. Cerci stark verkürzt, aber mehrgliedrig. Beim $q$ ist die 9 . Bauchplatte in eine sphärische dreieckige Supraanalplatte vorgezogen (Fig. 89,90 u. 91 ).

Schwarzlraun, Pronotum ringsum

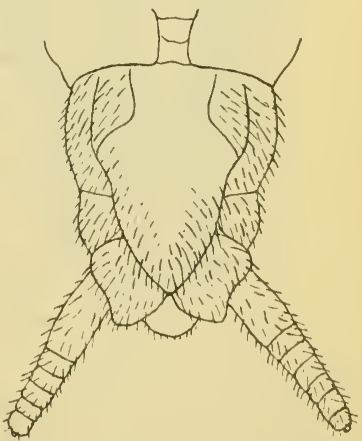

Fig. 91. Oemoptery.x Loewii Alb. ․ Hinterleibsende von unten. 
gelbbraun gerandet, Beine gelbbraun mit schwarzbraunen Knien und Füßen. Flügel graubraun getrïbt mit starker, brauner Nervatur. Das of stark hrachypter, und zwar sind die Vorderflügel bedeutend kürzer als die Hinterflügel. Flügelspannung des $q 27-29 \mathrm{~mm}$. Rheinprovinz, Bonn; März, April.

Loewii Alb.

\section{Gattung Rhabdiopteryx Klp.}

Der vordere Cubitus mit einem akzessorischen Aste; im Costalfelde 1-3 Queradern; zwischen dem Radius und seinem Sektor anßerhalb der Anastomose nur ansnahmsweise eine Querader. Beim $\delta$ ist die 9. Bauchplatte in eine lange Subgenitalplatte umgebildet, welche keinen Anhang an ihrem Grunde besitzt. Die Subanalklappen stark, etwas unsymmetrisch modifiziert. Der 10. Dorsalring in 2 dreieckige, oft dornartig verlängerte Teile gespalten. Der Supraanallobus kleiner als bei den vorhergehenden Gattungen, aber ähnlich modifiziert. Cerci kurz, aber doch aus mehreren Gliedern zusammengesetzt. Das 9. Sternit beim $q$ in der Mitte des Hinterrandes in eine zungenförmige Platte verlängert (Fig. 92).

Sector radii nur einmal gegabelt; die of Subgenitalplatte groß, an dem Ende abgestutzt; die Abschnitte der 10. Rückenplatte dornartig verlängert. Dunkelbraun, Kopf, Meso- und Metanotum schwarzbraun. Flügel fast hyalin, nur der Streifen über die Anastomose deutlicher. Körperlänge $7-8 \mathrm{~mm}$, Flügelspannung $22-25 \mathrm{~mm}$. Bayern (Würzburg), Glogau in Schlesien. Juni-August.

neglecta Alb.

\section{Gattung Nephelopteryx Klp.}

Der vordere Cubitus mit einem akzessorischen Aste; im Costalfelde keine Queradern. Sector radii nur einmal gegabelt und zwischen ihm und dem Radius keine Queradern. Beim ơ ist die Subgenitalplatte sehr kurz, am Grunde mit einem Anhange. Die Subanalklappen symmetrisch in einen Dorn auslaufend. Lobus supraanalis kurz, zapfenförmig, einfach. Beim $q$ ist der 9. Bauchring nur kurz, rundlich verlängert. Cerci beim ơ eingliedrig, beim ㅇ mehrgliedrig.

1. Das ơ vollflïgelig, die Querader in dem Subcostalfelde vorhanden. Körper dunkelbraun, der Hinterleib des $\sigma$ fast schwarz. Flïgel bräunlich getrüibt ohne dunklere Querstreifen. Beine braun. Flügelspanuung des ơ $22-25 \mathrm{~mm}$, des $+30-35 \mathrm{~mm}$. - Hannover, Dresden, Westfalen. Februar, März (Fig. 93 и. 94).

nebulosa L.

- Das ơ kurzflügelig; die Querader im Subcostalfelde fehlend, oder, wenn vorhanden, ist sie sehr kurz und dem Ende von Radius sehr nahe. Auf den Schenkeln dentlichere dunkle Längsstreifen. Sonst wie vorige. Flügelspannung des 오 25 bis $32 \mathrm{~mm}$. - Dresden 30./3. und 30./4. (leg. C. Schiller); erscheint etwas später als die vorige (Fig. 95 u. 96).

araneoides $K l p$.

\section{Fam. Leuctridae.}

Sector radii nur einmal gegabelt und der erste Ast an der Bildung der Anastomose beteiligt oder nicht; der vordere Cubitus 
olne akzessorische Adern, der hintere Cubitus, die 1. und 2. Analader im Vorderflügel stark geschwungen. Die Längsadern in der

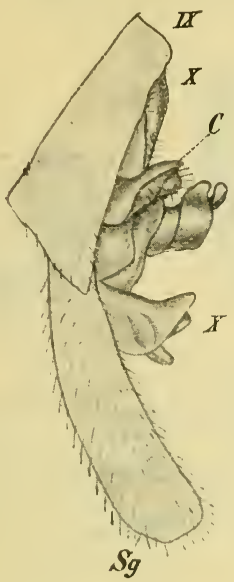

Fig. $92 A$.

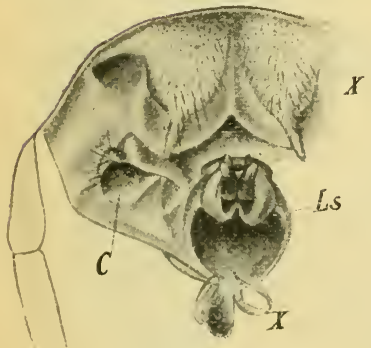

Fig. $92 B$.

Fig. 92. Rhabdiopteryx neglecta Alb. б. $A$ das Hinterleibsende von der Seite; $B$ der 10. Ring und der Lobus supraanalis von oben und hinten.

Fig. 93. Nephelopteryx nebulosa $\mathbf{L}$. ठ․ $A$ das Hinterleibsende von unten; $B$ von der Sejte. $S_{g}=$ Subgenitalplatte, $L s=$ Supraanallobus, $C^{\circ}=$ Cerci.

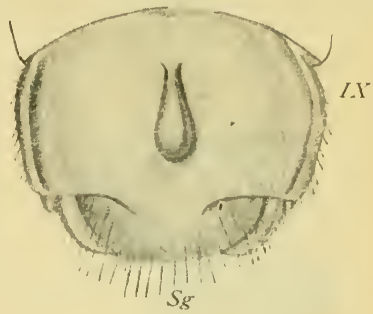

Fig. $93 A$.

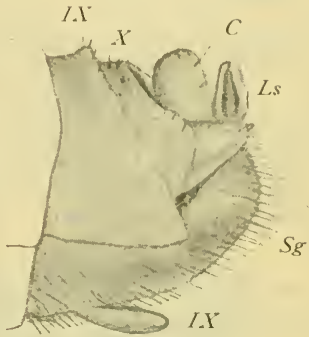

Fig. 93 B.

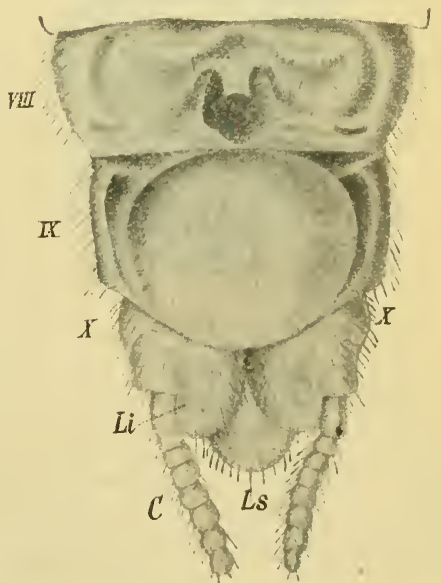

Fig. 94.

Fig. 94. Nephelopteryx nebulosa I. T. Das Iinterleibsende ron unten. IIII. $1 \mathcal{Y}, Y=9 .-10$. Ring, $L i=$ Subanalklappen, $L s=$ Supratuallobus, $C=$ Cerei. äußeren Hälfte parallel laufend. In dem medialen und vorderen Cubitalfelde zalilreiche Queradern. Der anale Teil der Hinter- 
flügel klein oder ganz fehlend; die Analadern einfach. Beim ơ ist der 9. Bauchring in eine kurze Subgenitalplatte vorgezogen und ist am Grunde meist mit einem lappenförmigen Anhange versehen.

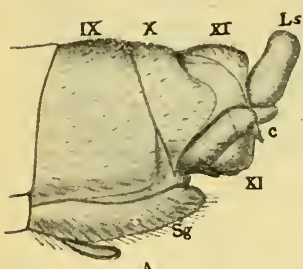

A

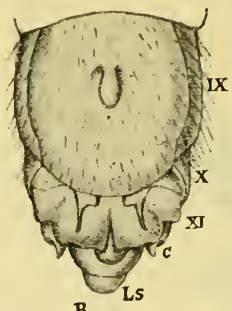

B.

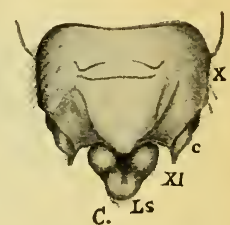

C.

Fig. 95. Nephelopteryx araneoides Klp. đ. A Das Hinterleibsende von der Seite; $B$ von unten: $C$ von oben. $I X, X, X I=9 ., 10 ., 11$. Segment, $S g=$ Subgenitalplatte, $C=$ Cerci, $L s=$ Lobus supraanalis.

Die Subanalklappen sind in dornartige Fortsätze umgestaltet, welche den 2 an der Genitalöffnung vorragenden Tilillatoren anliegen; der Supraanallobus bei unserer Gattung klein, hügelartig. Cerci eingliedrig, zapfenförmig, öfters an der Spitze mit dem Rudimente

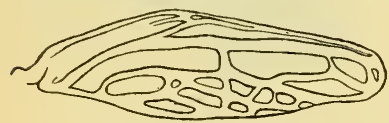

Fig. 96 .
Fig. 96. Der Flügel des O' Nephelopteryx araneoides Klp.

Fig. 97. Leuctra hippopus Kpny. Nervatur. Erklärung wie Fig. 54 .
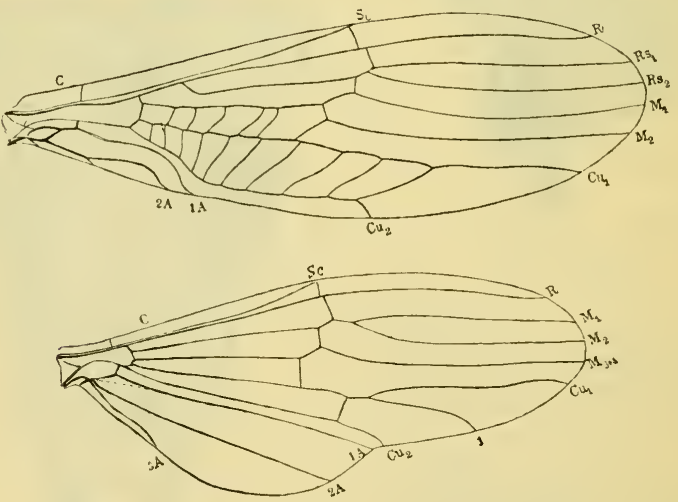

Fig. 97.

eines weiteren Gliedes. Der 6.-8. Dorsalring tragen oft dornartige, zahn- oder lappenförmige Anhänge, deren Form für die Unterscheidung von einzelnen Arten wichtig ist. Beim $q$ ist der 8. Ventralring meist in eine deutliche Subgenitalplatte vorgezogen. Die Flügel in der Ruhe um den Hinterleib walzenförmig gerollt (Fig. 97). 


\section{Gattung Leuctra St.}

Der anale Teil der IIinterflügel kleiner als üblich, aber doch dentlich. Beim ơ der Supraanallobus klein, hügelartig. Schlanke, gewöhnlich schwarzbraune bis schwarze Arten, die wir oft massenhaft von Gebüschen an den Bachufern herabklopfen können.

1. Beine lang abstehend behaart.

- Beine nur kurz und fein behaart.

2. Pronotum fast $\mathrm{mm} 1 /$ länger als breit: Flügelspannung des o $20-22 \mathrm{~mm}$, des $q 23-26 \mathrm{~mm}$. Kopf und Pronotum schwarzbraun, Meso- und Metanotum dunkel gelbbraun, Hinter-

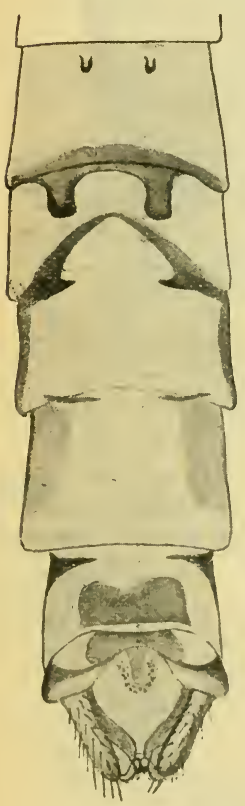

Fig. 98. leib des ơ oben vorn dunkel bräunlich, vom 6. Ringe weich, gelblichweiß. Nahe dem Vorderrande des 6 . Ringes entspringen 2 von oben rechteckige, von der Seite langelliptische Höcker; das 7. Dorsalsegment trägt nahe dem Vorderrande 2 schmälere, in ilırer Mitte rechtwinklig gebrochene Haken, deren scharfe Spitze nach innen gerichtet ist. Die Subanalklappen und Titillatoren etwa gleich lang. Der o Hinterleib oben

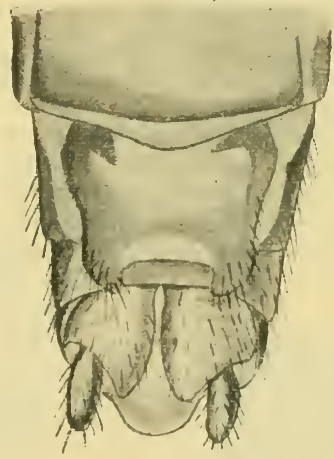

Fig. 99.

Fig. 98. Leuctra cylindrica De Geer. O'. Der Hinterleib von oben.

Fig. 99. Leuctra cylindrica De Geer. ㅇ. Der Hinterleib von unten.

fahlgelb mit je 4 schwarzen Punkten auf jedem Segmente; 10. Ring und der Supraanallobus ganz schwarz. O Subgenitalplatte lang, hinten sattelartig ausgeschnitten. Fühler schwarz, erste 2 Glieder gelbbraun, Beine gelbbraun, Schienen und Füße dunkler. Flügel bräunlich. - Im Vorgebirge; August bis November (Fig. 98 u. 99).

cylindrica De Geer.

- Pronotum deutlich breiter als lang. Flügelspannung des $\delta$ $15-17,5 \mathrm{~mm}$, des 우 $16-19 \mathrm{~mm}$. Körper braun, der $\bigcirc$ Hinterleib oben fahlgelb. Fühler gegen die Spitze dunkler. Flügel braun gefärbt. Beim to trägt das 7. Rückensegment 
einen rom Vorderrande entspringenden, anfgerichteten, bandförmigen Anhang, der in 2 dreieckige, scharfe Zacken ausgezogen ist; in der Seitenansicht stehen diese Zacken zahnartig ab. Die Subanalklappen etwas kürzer. Beim o läuft die 8. Bauchplatte in 2 drehrunde Fortsätze aus, deren Abstand etwa ihrer Breite gleich ist. - An Waldbächen stellenweise massenhaft. Juli bis September (Fig. 100). Brameri Kny.

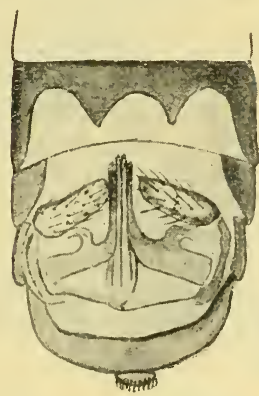

A

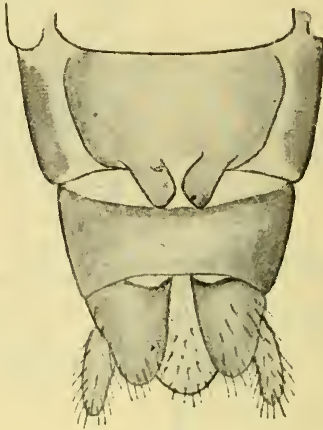

$B$

Fig. 100. Leuctra Braueri Kpny. $A$ das $\delta$ Hinterleibsende von oben: $B$ das $q$ Hinterleibsende von unten.

3. Fühler lichtbraun, knotig, stark, abstehend, quirlartig behaart; Körper dunkelbraun, Beine lichthraun, Schenkel gegen die Spitze zu etwas dunkler, Flügel hräunlich getrübt, glänzend, mit starker Nervatur. Eine sehr leicht kenntliche, an die L. Braueri erinnernde, aher viel größere Art. Flügelspannung

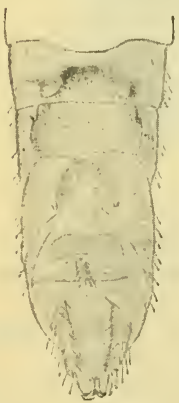

Fig. $101 \mathrm{~A}$.

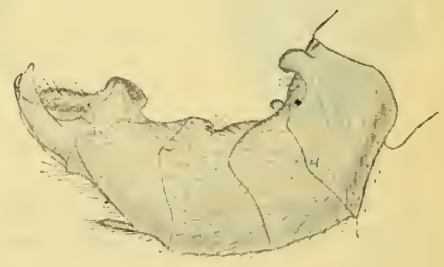

Fig. $101 B$.

Fig. 101. Lenctra cingulata Kny. б. Das Hinterleibsende, $A$ von oben, $B$ von der Seite.

19-23 mm. - England, Holland, Umgebung von Bonn (leg. Dr. le Roi).

geniculata $\mathrm{St}$.

- Fühler einfach, borstenförmig, kurz, nicht quirlartig behaart. 4.

4. Pronotum wenigstens so lang wie breit. Braun, Flïgel bräunlich angerancht mit gelbbraunen Adem. Beim đo die vordere Hälfte und die Seitenfläche des 6. Dorsalringes 
stärker chitinisiert; in der Mitte der Dorsalfläche entspringen 2 etwa um ihre eigene Breite voneinander entfernte parallele, kurz rechteckige Fortsätze. Auf dem 7. und 8. Dorsalringe tragen die stärker chitinisierten Seitenflächen an ihrer inneren Grenze je ein kleines Zähnchen. Die Subanalklappen breit, etwas länger als die Titillatoren. Beim $O$ ist die Subanalklappe (bei trockenen Stücken) durch einen tiefen, dreieckigen Einschnitt in 2 stumpf konische Teile gespalten.

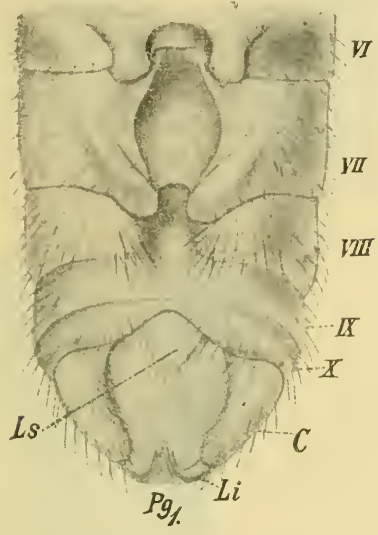

Fig. $103 \mathrm{~A}$.

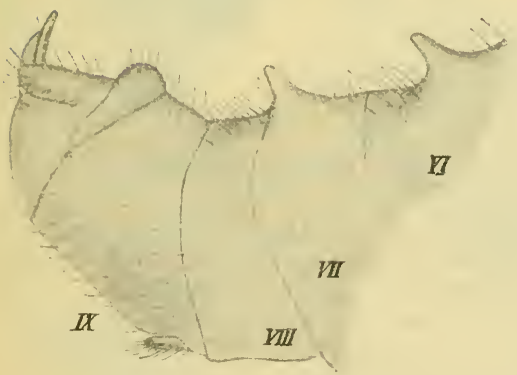

Fig. $103 \mathrm{~B}$.

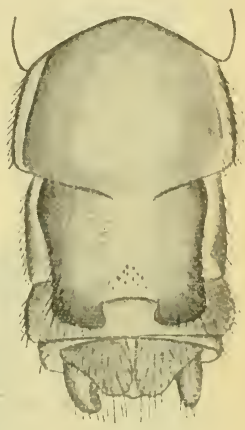

Fig. 102. Leuctra cingulata Kny. ㅇ. Das Hinterleibende von unten.

Fig. 103. Leuctra Klapáleki Kny. ฮ. Das Hinterleibsende, $A$ von oben, $B$ von der Seite.

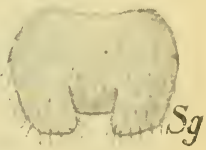

Fig. 104. Leuctra Klapáleki Kny. Die + Subgenitalplatte.

Flïgelspannung des of $12-14 \mathrm{~mm}$, des 우 14--16 mm. An Gebirgsbächen; August, September (Fig. 101 u. 102).

cingulata $\mathrm{K} \mathrm{m} \mathrm{n} \mathrm{y}$.

- Pronotum deutlich breiter als lang.

5. Die o Subgenitalplatte am Grunde olne Anhang oder derselbe sehr klein; die O Subgenitalplatte in der Mitte ansgeschnitten, hinten 2 Abschnitte bildend, die breiter als lang sind.

- Die of Subgenitalplatte am Grunde mit einem deutlichen, länglich eiförmigen Anhange. 
6. Die Fortsätze des 7. Dorsalringes des $\delta$ sehr stark und schief nach hinten und innen gerichtet, so daß sie eine muldenartige Stelle hegrenzen; beim $q$ ist $z$ wischen beiden Endabschnitten eine viereckige Ausbuchtung. Körper samt allen Gliedmaßen schwarz; Flügel beim ơ graulich, beim $q$ bräunlich. Der Abstand der Fortsätze des 6. Dorsalringes beim $\delta$ kaum größer als die Breite eines jeden von ihnen. Flügelspannung des of 14-16 mm, des 우 16-19 $\mathrm{mm}$. - Im Hügellande vom September bis zum Winter häufig (Fig. 103, 104).

Klapáleki $\mathrm{K} m \mathrm{pny}$.

- Die Fortsätze des 7. Dorsalringes beim ơ schwächer und quergestellt; beim $q$ ist die Sulgenitalplatte in der Mittellinie schwächer chitinisiert und infolgedessen bei trockenen Exemplaren in 2 bis zum Grunde getrennte länglich viereckige, an der Spitze schief abgestutzte Abschnitte geteilt. Die Fortsätze des 6. Dorsalringes beim ơ schmal lang und so

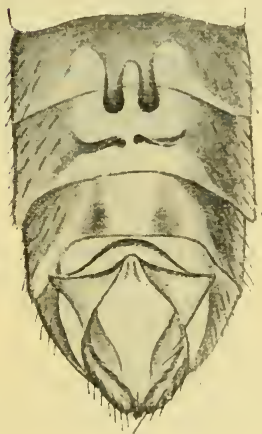

A

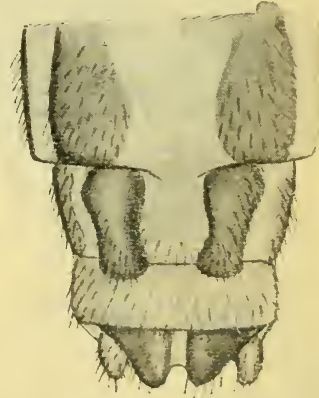

$B$

Fig. 105. Lenctra digitata Kny. $A$ das $\delta$ Hinterleibsende von oben; $B$ das $q$ Hinterleibsende von unten.

nahe einander gestellt, daß ihr Abstand kaum so groß ist wie ihre Breite. Körper dunkel, kastanienbraun bis schwarzbraun; Fühler schwarzbraun, Beine etwas heller. Flügelspannung des o $14-16 \mathrm{~mm}$, des ㅇ $15-19 \mathrm{~mm}$. - Im Vorgebirge, September-November (Fig. 105). digitata K pny.

7. Der 6. Dorsalring des ơ mit Höckern versehen.

- Der ó Hinterleil nur auf dem 8. Ringe mit Höckern versehen oder ganz unbewehrt.

8. Der ơ Hinterleib auf dem 6. und 7. Ringe mit Höckern versehen, die in der Ansicht von oben kurz rechteckig, in der Seitenansicht abgerundet erscheinen. Die o Subgenitalplatte hinten einfach abgerundet. Körper lichter oder dunkler bram, Beine etwas lichter. Fühler fein gran getrübt, mit licht gelbbraunem Geäder. Flügelspannung des o $12-14 \mathrm{~mm}$, des o 15-17 mm. - In Vorgebirge, Juli-September (Fig. 106, 107).

albida K p n y.

- Der 6. und 8. Hinterleibsring beim of bewehrt; die Fortsätze stark, in der Seitenansicht zugespitzt, von oben ab- 
gerundet, das vordere Paar deutlich kleiner als das hintere, aber das vordere viel weiter voneinander entfernt als das hintere. Die $q$ Subgenitalplatte hinten mit einem stumpfwinkligen Ausschnitte und in der Mitte desselben mit einem

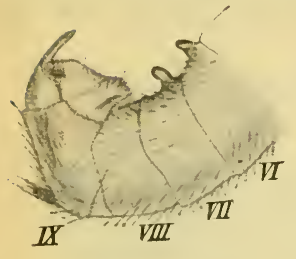

A

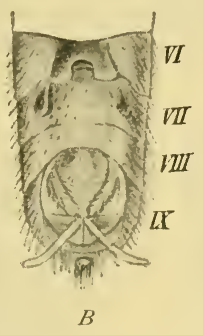

Fig. 106. Leuctra albida Kny. б. A der Hinterleib von der Seite, $B$ von oben.

Fig. 107. Leuctra albida Kny. †. Der Hinterleib vou unten.

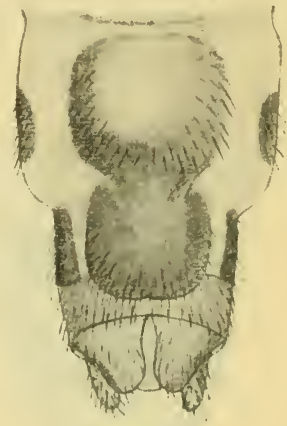

Fig. 107.

runden Zipfel. Körper samt seinen Gliedmaßen schwarzbraun. Flügel stark braun angeraucht. Flügelspannung des ơ 10-14 mm, des o 15-18 mm. - Im Vorgebirge häufig, April, Mai (Fig. 108, 109). nigra Pict.

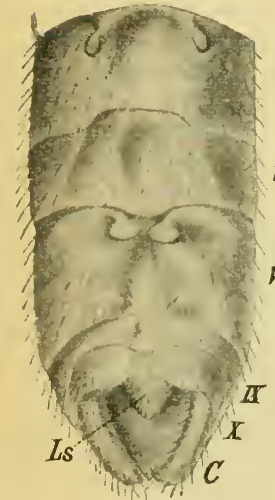

Fig. 108 A.

VT

VII

VIII

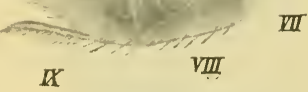

Fig. 108 B.

Fig. 108. Leuctra nigra Pict. $\sigma$. $A$ das Hinterleibsende von oben, $B$ von der Seite.

Fig. 109. Leuctra nigra Pict. ․ Das Hinterleibsende von unten.

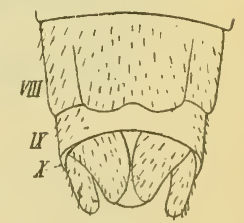

Fig. 109.

- Der ơ Hinterleib auf dem Rücken unbewehrt, die Subanalklappen kurz, stark, kaum über das 2. Drittel der Titillatoren reichend, die $ᄋ$ Subgenitalplatte seicht, stumpfwinklig ausgeschnitten. Kopf und Pronotum schwarzbraun, der übrige 
Körper samt Fühlern und Beinen hraun. Flügel grau, getrübt. Flügelspanuung des o $11-12 \mathrm{~mm}$, des $+13-15 \mathrm{~mm}$. - Im Vorgebirge, Mai-Juli (Fig. 110, 111).

inermis K pny.

- Der 8. Hinterleibsring des ơ bewehrt. Die of Subgenitalplatte entweder jederseits in ein dicht bewimpertes Läppchen auslaufend oder in der Mitte schwach ausgerandet.

10.
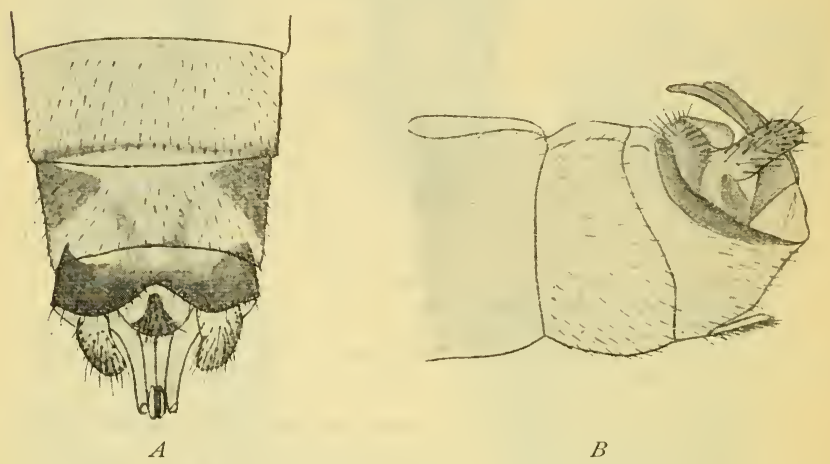

Fig. 110. Leuctra inermis Kny. ठ․ $A$ das Hinterleibsende von unten, $B$ von der Seite.

10. Der 9. Dorsalring des ơ oben größtenteils häutig, aber in jedem Dritteile seiner Breite mit einem schmalen Chitin-

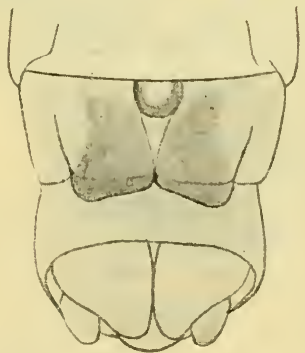

Fig. 111. Leuctra inermis Kny.

†. Das Hinterleibsende von streifen, dessen Ende als ein rundliches oder viereckiges Köpfchen erhoben und stärker chitinisiert ist. Auf dem 9. Dorsalringe ein trapezförmiger dunkler Fleck mit winklig ausgeschnittenem Vorderrande. Die o Subgenitalplatte hinten in der Mitte breit ausgeschnitten, wodurch 2 tatzenförmige. stark beborstete Seitenlappen entstehen. Körper samt Fühlern und Beinen dunkel schwarzbraun. Flügelspannung des o $14-15 \mathrm{~mm}$, des f 16-17 mm. - Im Hügellande, März bis Mai (Fig. 112). unten.

hippopus K pny.

- Der 9. Dorsalring mit deutlichen, in der Seitenansicht dornartig abstehenden, schwärzlichen Höckern, welche aber zu einem parallelseitigen, hinten winklig ausgeschnittenen Plättchen verbunden sind. Der chitinisierte hintere Teil des 9. Dorsalringes bildet in der Mitte einen zweilappig nach vorn auslaufenden braunen Fleck. Die o Subgenitalplatte hat einen fast vollkommen runden, durch eine stärker chitinisierte Linie bezeichneten Hinterrand. Körper samt Fühlern und Beinen dunkel schwarzbraun. Flügelspannung des ơ $14-15 \mathrm{~mm}$, des $q$ 17-19 mm. - Im Hügellande die erste Art im 
Frühlinge, März, April, an Gebirgsbächen im Herbst, September bis November (Fig. 113).

prima Kpny.

\section{Familie Nemuridae.}

Sector radii nur eimmal gegabelt und sein Ast mit dem Ende des Subcostalastes und der Querader $r-m$ eine $\mathbf{X}$-förmige Figur

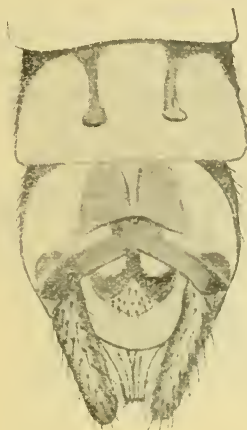

A

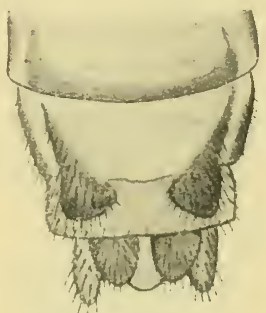

$B$

Fig. 112. Leuctra hippopus Kny. $A$ das $\delta$ Hinterleibsende von oben; $B$ das $O$ Hinterleibsende von unten.

bildend; der vordere Cubitus keine akzessorische Adern entsendend; in dem medialen und vorderen cubitalen Felde mehrere Queradern; der anale Teil der Hinterflügel deutlich; die Analadern dasselbe strahlenförmig durchlaufend; zweite von ihnen dreiästig. Beim ठ ist der 9. Ventralring durch 2 Längsfalten in 3 Felder geteilt, von

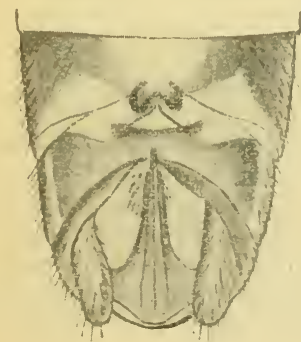

$A$

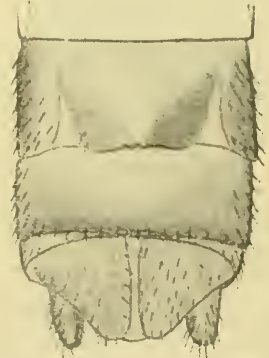

$B$

Fig. 113. Leuctra prima Kny. $A$ das $\delta$ Hinterleibsende von oben; $B$ das $q$ Hinterleibsende von unten.

welchen das mittlere mehr oder weniger dreieckig vorgezogen und demzufolge von einem symmetrisch fünfeckigen Umrisse ist; seine Spitze ist nach oben gebogen, legt sich an den basalen Teil des Supraanallobus an und trägt die Geschlechtsöffnung: es ist die Subgenitalplatte. Die Basis ihrer Außenseite trägt einen im frischen 
Zustande blasenartig gewölbten, vertrocknet aber löffel- oder schaufelförmig ausgehöhlten Anhang. Cerci sind entweder wie bei den $q$ eingliedrig, zapfen- oder kegelförmig oder zu Kopulationszwecken in haken- oder beilförmige Gebilde umgestaltet. Ebenso die Subanalklappen sind entweder wie im weiblichen Geschlechte normal, stumpf dreieckig oder stark modifiziert. In diesem Falle können wir in der Regel einen medialen, einen lateralen und einen dorsalen Teil unterscheiden. Der Supraanallobus ist in ein mächtiges, penisartiges Kopulationsorgan umgebildet; dasselbe entspringt über den Subanalklappen aus einer breiten, kegelartig sich verjüngenden Basis und ist nach oben und vorn gekrümmt; seine dorsale, infolge der Krümmung nach unten umgeschlagene Seite ist meist mit Widerhaken besetzt. Beim $ᄋ$ befindet sich die Genitalöffnung auf der Fläche des 8. Ringes mehr oder minder weit nach vorn geschoben. Der 7. Ring ist entweder normal, höchstens etwas stärker gewölbt, oder in eine dreieckige oder halbkreisförmige Subgenital-
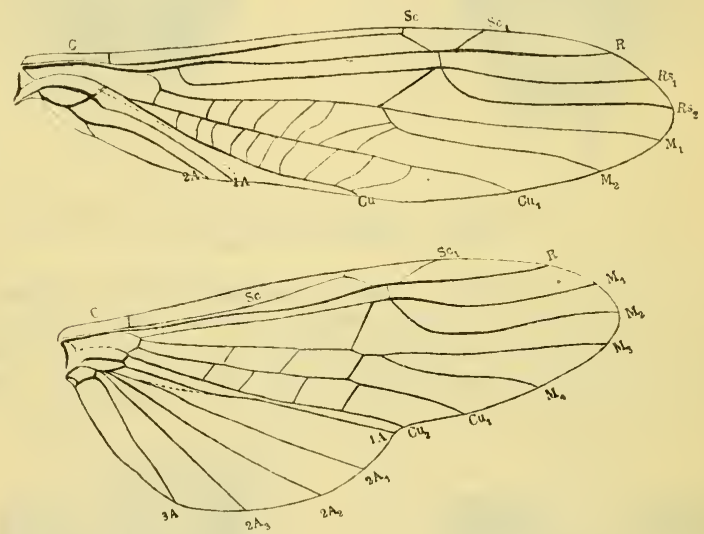

Fig. 114. Nemura variegata Oliv. Nervatur. Erklärung wie Fig. 64.

platte vorgezogen. In diesem Falle ist der 8. Ring in der Mittellinie vertieft und an den Seiten der Genitalöffnung höckerartig erhoben; im ersteren Falle ist der vordere Teil seiner Fläche plattenartig erhoben und unter dem Hinterrande dieser Platte erheben sich 2 quere oder dreieckige Höcker, welche wir kurzweg Scheidenklappen nennen wollen. Flügel in der Ruhe dem Hinterleibe flach aufliegend. Diese Familie ist durch die einzige, die Merkmale der Familie tragende

\section{Gattung Nemura Latr.}

vertreten (Fig. 114).

a) Cerci der ơ einfach zapfenförmig; der Anhang der Subgenitalplatte mäßig bis sehr breit; die Subanalklappen stark modifiziert; Supraanallobus mäßig breit; Flügel schmal und die Adern meist grau oder graubraun gesäumt.

Untergattung Protonemura Kmpny. 
1. Bei vollkommen ausgefärbten Stïcken sind die Flügel gleichmäßig braun getrübt, nur das Subcostalfeld im 1. Dritteile nach außen von der humeralen Querader und an der Anastomose dunkler und die Flïgelbasis auffallend hell, gelbbraun; Radius am Grunde bis zur humeralen Querader gelb, sonst aber schwarzbraun und besonders nach außen von der Anastomose sehr stark; das apicale Feld $S c_{1}$ lang, so daß sein Vorderrand gleich lang ist wie der Abstand zwischen dem Ende der $\mathrm{Sc}_{2}$ und dem $R$.-Beine, lichtbraun, die Schenkel gegen das Ende zu kaum dunkler. Bei den nicht vollkommen ausgefärbten Stïcken sind die Flügel gleichmäßig

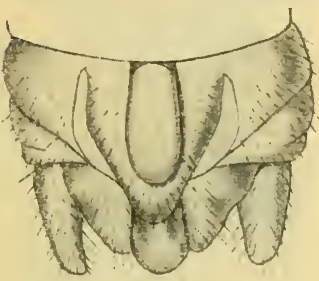

$A$

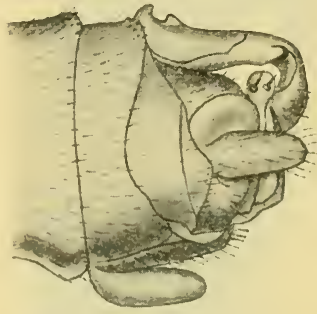

$B$

Fig. 115. Nemura humeralis Pict. o. A das Hinterleibsende von unten; $B$ von der Seite; $C$ von oben.

gran getrübt. Der mediale Teil der Subanalklappen im rechten Winkel nach außen in eine ziemlich lange und starke Chitingräte verlängert. Flïgelspammung des $\sigma^{\circ} 15 \mathrm{~mm}$, des 17 mm. - Im Gebirge (Fig. 115). humeralis Pict.

- Die Adern grau oder graubraun gesäumt, oder wenn die Flügel in größerem Maße graugefärbt sind, so zeigen doch die Felder in der Mitte hellere, weißliche Streifen; Schenkel gegen die Spitze zu auffallend dunkler.

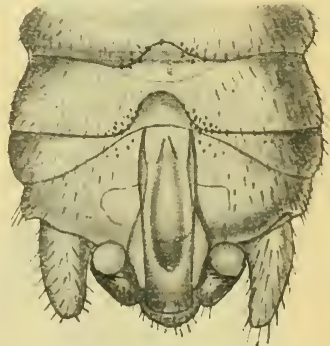

C

2. Der Ast des Sector radii stark geschweift und infolgedessen auch der Vorderast der Media deutlich wellenartig gekrümmt; Kiopf und Pronotum mit langen und feinen Härchen besetzt und nur matt glänzend; das erstere mäßig, aber deutlich trapezoid; Kopf schwarz, aber hinter der Scheitelsutur mit einem queren, bogenförmigen, verwaschenen rotbraunen Querstreifen; auch das Praescutum auf dem Mesonotum rotbraun; Flügel stark glänzend, hyalin, mit schwarzhraunen, graubraun gesäumten Adern, was besonders am Anfange der Anastomose deutlich hervortritt. Beine lichtbraun im distalen Drittel der Schenkel schwarzbraun und nebst dem mit einem großen schwarzbraunen Makel in der Mitte der Dorsalkante, was den Eindruck macht, als ob die Schenkel mit einem Ringe 
geziert wären. Der mediale Teil der Subanalklappen in eine schmale, dünne Lamelle ausgezogen, die sich spiralig um die laterale Kante nach oben umschlägt und am Ende

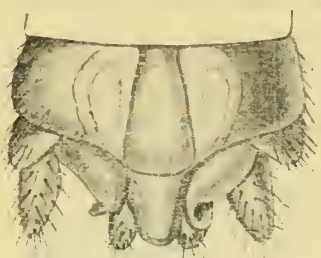

$A$

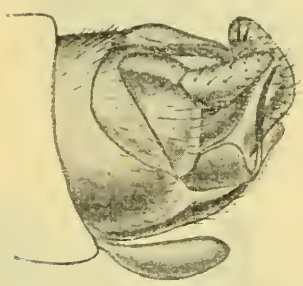

$B$

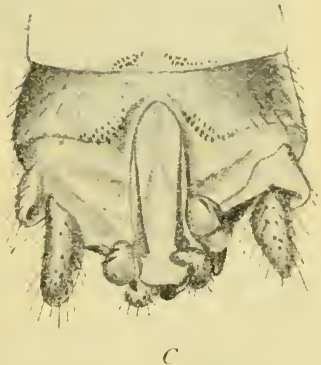

Fig. 116. Nemura Meyeri Pict. 6. A das Hinterleibsende von unten; $B$ von der Seite: $C$ von obell.

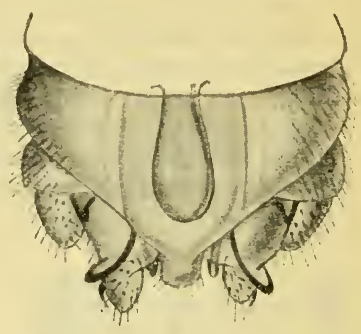

4
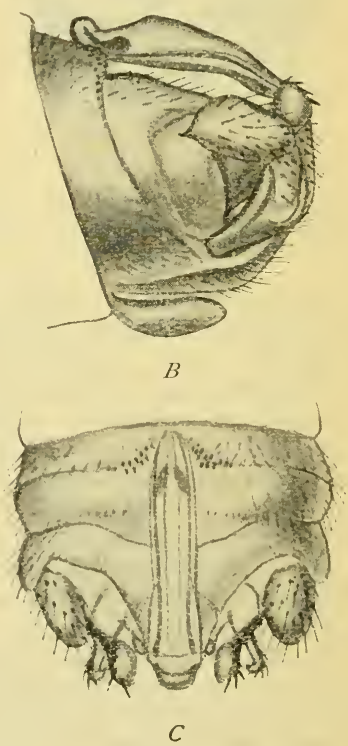

Fig. 117. Nemura lateralis Piet. б. $A$ das Hinterleibsende von unten; $B$ von der Seite; $C$ ron oben.

einen scharfen Dorn trägt. Flïgelspannung des o $15 \mathrm{~mm}$, des o 19-25 mm. - Im Gebirge, Mai, Juni (Fig. 116).

Meyeri Pict.

- Der Vorderast der Media höchstens nur schwach gebogen, in der Regel ganz gerade. Kein Makel in der Mitte der dorsalen Kante der Schenkel. 
3. Der dorsale Teil der đo Subanalklappen lang, an den Seiten des Supraanallobus nach hinten vorragend, der ventrale in eine lange Chitingräte auslaufend.

- Der dorsale Teil der Subanalklappen ist kurz, stumpf kegelförmig, den ventralen nicht weit überragend; dieser nur in eine kurze Spitze, selten in eine etwas längere Gräte auslaufend.

4. Der dorsale Teil der Subanalklappen kopfartig aufgeschwollen und unten in eine Spitze auslaufend; die Chitingräte des ventralen Teiles nach außen gekehrt. Anhang der Subgenital-

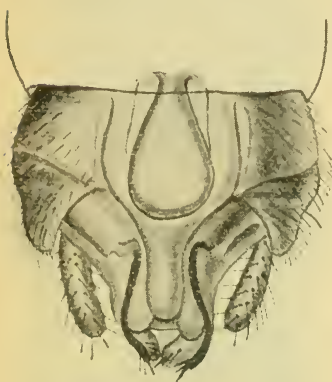

$A$

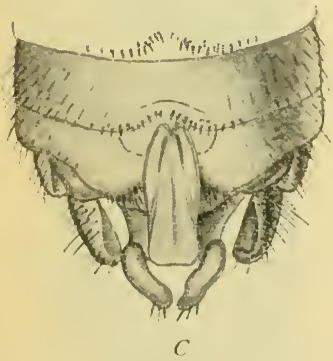

Fig. 118. Nemura nimborum Ris $\delta$. $A$ das Hinterleibsende von unten, $B$ von der Seite, $C$ von oben.

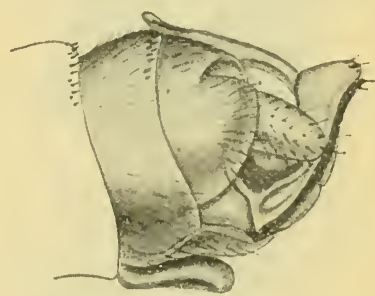

$B$

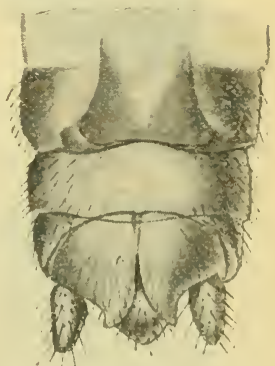

Fig. 119. Nemura nimborum Ris ?. Das Hinterleibsende von unten.

platte breit. Kopf und Pronotum glänzend schwarz. Adern schwach grau gerandet. Flügelspannung des o $13-15 \mathrm{~mm}$, des +16 mm. - Im Gebirge, Juli, August (Fig. 117).

lateralis Pict.

- Der dorsale Teil der Subanalklappen an dem Ende erweitert und gerade abgestutzt, also im ganzen dreieckigen Umrisses; die Chitingräten des ventralen Teiles lang, gewöhnlich unter dem Supraanallobus gekreuzt. Kopf und Pronotum glänzend dunkelbraun. Anhang der Subgenitalplatte breit. Adern stark grau gerandet. Flügelspannung des oc 15-18 mm, des $q$ 19-22 mm. - Im Gebirge. Juli, August (Fig. 118, 119). nimborum $\mathrm{Ris}$. 
5. Anlıang der Subgenitalplatte sehr breit, sein vertiefter Endteil etwa so breit wie lang, dreieckigen Umrisses; Kopf und Pronotum schwarz, schwach glänzend, das letztere breit, parallelseitig. Flügel mit stark graı gesäımten Adern. Der dorsale und ventrale Teil der Subanalklappen kurz, kegelförmig, in eine kurze Spitze auslaufend, die Cerci nicht überragend. Flügelspannung des o $18 \mathrm{~mm}$, des o $22 \mathrm{~mm}$. - Im Hügelland, Mai (Fig. 120).

praecox Mort.

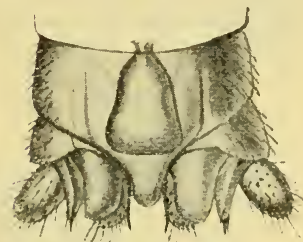

$A$

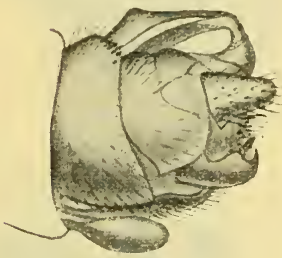

$B$

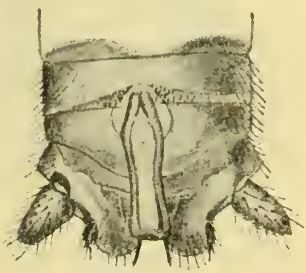

C

Fig. 120, Vemura praecox Mort. o. $A$ das Hinterleibsende von unten; $B$ von der Seite; $C$ von oben.

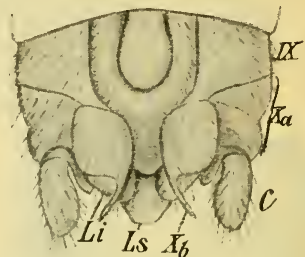

A

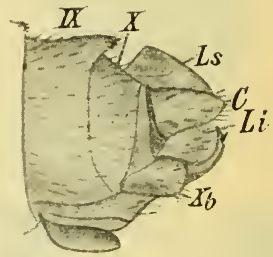

B

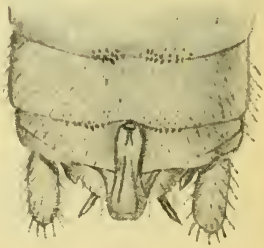

C

Fig. 121. Nemura fumosa Ris c. $A$ das Hinterleibsende von unten; $B$ von der Seite; $C$ von oben.

- Der Anhang der Subgenitalplatte länglich, eiförmigen Unrisses.

6.

6. Der dorsale Teil der Subanalklappen von dem ventralen fast ganz verdeckt; der letztere breit, rhomboid, an der inneren Endecke in eine an dem Rande in 2 kurze Spitzen auslaufende Chitingräte vorgezogen. Flügel bei stark ausgefärbtem Exemplaren braun, am Grunde gelblich, aber immer mit helleren Streifen in der Mitte der Zellen. Flügel- 
spannung des o $15-18 \mathrm{~mm}$, des ๆ $19-21 \mathrm{~mm}$. - Gebirge. Mai bis August (Fig. 121, 122).

fumosa Ris.

- Der dorsale Teil der Subanalklappen länger als der ventrale, diesen ïberragend.

7. Der ventrale Teil der Subanalklappen in eine kurze, nach außen gerichtete Chitingräte auslaufend. Flügelspannung des o $18-20 \mathrm{~mm}$, des + $22-29 \mathrm{~mm}$. - Vorgebirge und Gebirge. August bis November (Fig. 123).

nitida Pict.

- Der ventrale Teil der Subanalklappen kurz kegelförmig, in eine kurze Spitze auslaufend. Flügelspannung des o $16 \mathrm{~mm}$.

- Gebirge. August (Fig. 124).

brevistyla $\mathrm{Ris}$.

b) Cerci stumpf konisch, kurz; der Anhang der Subgenitalplatte sehr schmal, parallelseitig; die Subanalklappen stark modifiziert.
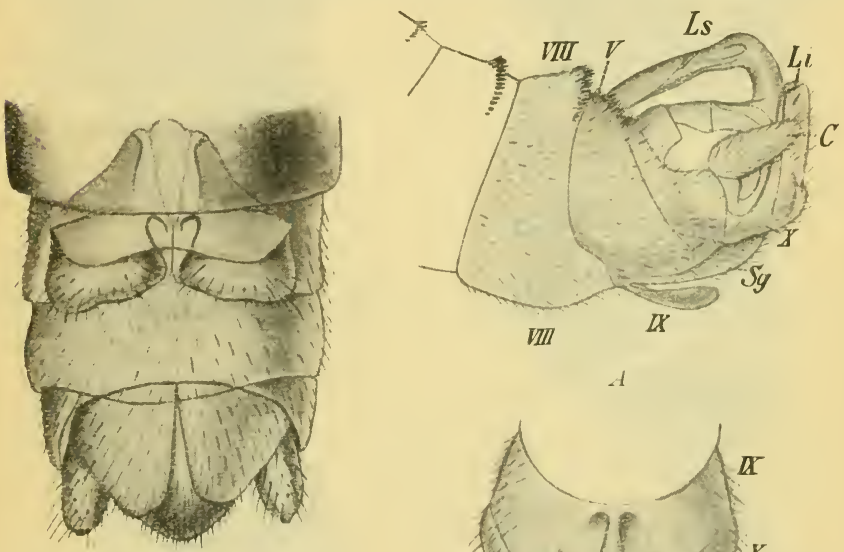

Fig. 122. Nemura fumosa Ris + . Das Hinterleibsende von unten.

Fig. 123. Nemura nitida Piet. $\delta$. $A$ das Hinterleibsende von der Seite; $B$ von unten.

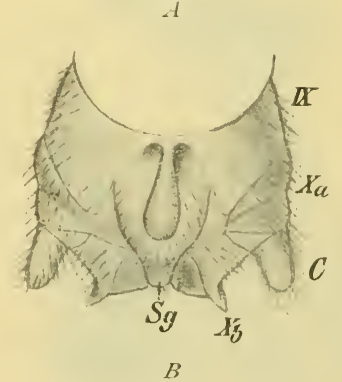

Fig. 123.

Supraanallobus ziemlich schmal; beim $q$ bildet der 7 . Ring eine kleine, halbkreisförmige Subgenitalplatte und unter ihrem Hinterrande befinden sich auf dem 8 . Ringe '2 Vaginalklappen. Kleine Arten.

Untergattung Amphinemura Ris.

1. Die Subanalklappen einen stark chitinisierten Fortsatz bildend; der Supraanallobus am Ende schmal.

- Die Subanalklappen nur mäßig chitinisiert, ihr lateraler Teil wie ein gekrümmter Finger den Grund der Cerci umfassend, auf seiner Außenseite mit feinen Widerspitzen besetzt und am Ende mit einer Reihe von steifen Borsten bewehrt; das Ende des Supraanallobus lanzettlich erweitert. Flügelspannung des o 12-14 mm, des 오 15-17 mm. - Im Hügellande. Juni bis September (Fig. 125, 126). 
2. Der chitinisierte Teil der Subanalklappen nach oben knieförmig gebogen, an der Spitze unbewehrt; Flügel öfters stark braun getrübt und mit deutlich ausgeprägter $\mathbf{X}$-Figur. Flïgelspannung des of $13^{1} / 2-14^{1} / 2 \mathrm{~mm}$, des o $17-18 \mathrm{~mm}$. Weit verbreitet von Mai bis September (Fig. 127). cinerea 0 liv.

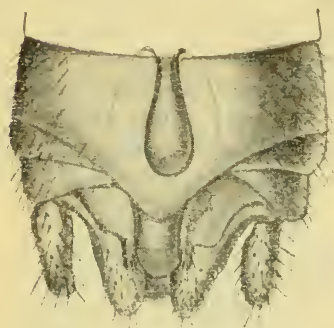

$A$
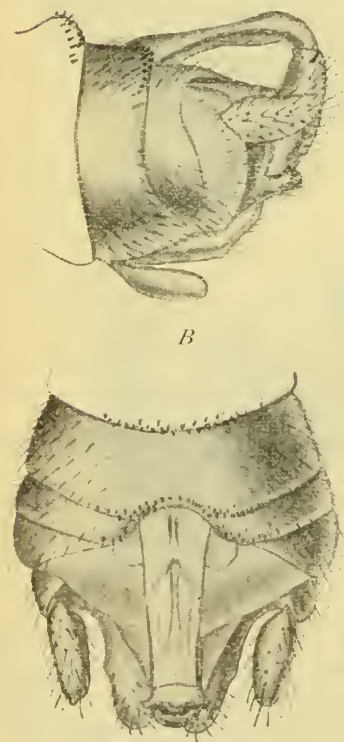

C

Fig. 124. Nemura brevistyla Ris $\delta$. $A$ das Hinterleibsende von unten; $B$ von der Seite; $C$ von oben.

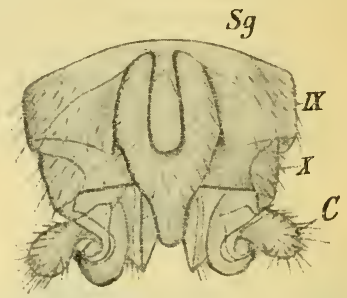

$A$
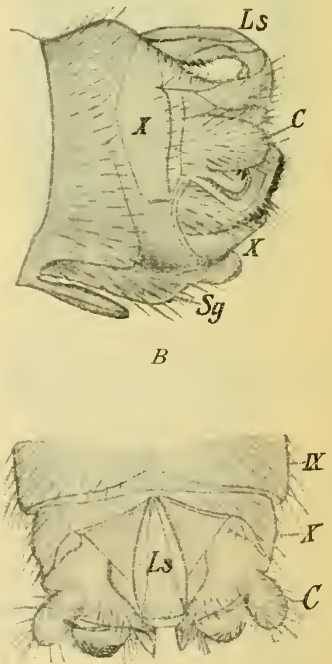

C

Fig. 125. Nemura Standfussi Ris $\delta$. $A$ das Hinterleibsende von unten; $B$ von der Seite; $C$ von oben.

- Der chitinisierte Teil der Subanalklappen kürzer, bogenförmig nach oben gekrümmt, an der Spitze erweitert und nach der Art eines Zahnrades am Rande mit starken Zähnen besetzt; Flügel sehr fein und schwach grau getrübt, besonder's 
die Adern am Anfange der Anastomose zeigen nicht die auffallende Verdickung wie bei den 2 anderen Arten; auch scheinen die Flügel schmäler zu sein, mit einem schärfer parabolischen Apex. Farbe dunkelbraun, Beine blaßbraun, die Schenkel an der Spitze kaum dunkler. Flügelspannung des of $15-16 \mathrm{~mm}$, des $q 16 \mathrm{~mm}$. - In torfigen Gegenden der Vorgebirge und Gebirge. In meiner Sammlung sind Exemplare, die ich im Mai, Juli und September gesammelt habe (Fig. 12S).

borealis Nort.

c) Cerci zu Kopulationszwecken verschiedenartig modifiziert, hakenoder beilförmig; der Anhang der Sulgenitalplatte, mäßig breit, länglich eiförmig; die Subanalklappen fast normal, stumpf drei-

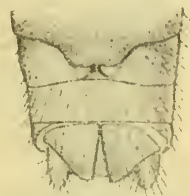

Fig. :126. Nemura Standfussi Ris +. ¿Das Hinterleibsende von unten.

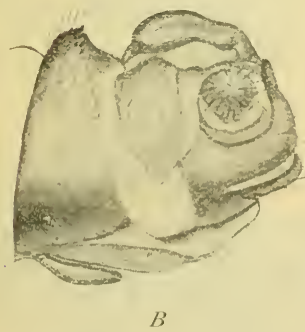

Fig. 127. Nemura cinerea Oliv. ठ․ A das Hinterleibsende von unten; $B$ voll der Seite; $C$ von oben.

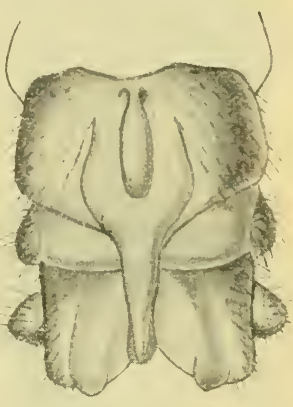

A

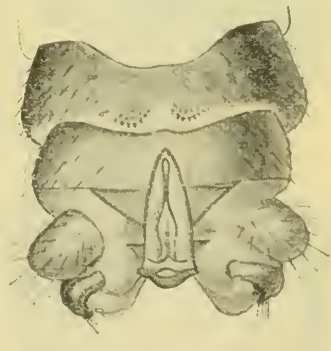

C

eckig, einfach; beim 올 bildet das 7. Segment eine halbkreisförmige Subgenitalplatte, welche einer Mulde des S. Ringes aufliegt. Meist breitflügelige Arten mit hyalinen Flügeln.

Nemura s. str.

1. Pronotum mit abgerundeten Ecken, stark chagriniert und matt, heller oder dunkler braun; Cerci in der Ansicht von oben gerade und an der Spitze 2 starke Zähne bildend, in der Seitenansicht ebenfalls gerade und an der Spitze stark klauenartig nach unten gekrümmt. Beine gelbbraun, die Schenkel vor den Knien etwas dunkler. Flügel gewöhnlich an der Basis bräunlich mit stark vortretender X-Figur; es kommen aber Exemplare vor, deren basale Hälfte der Hinter- 
flügel stark braun gefärbt ist und die Querader $r-s$ in allen 4 Flügeln dunkelbraunen Fleck trägt. Flügelspannung
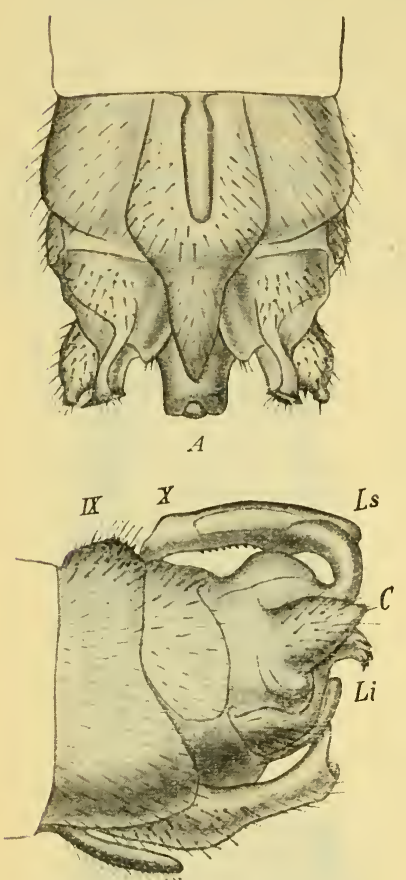

B

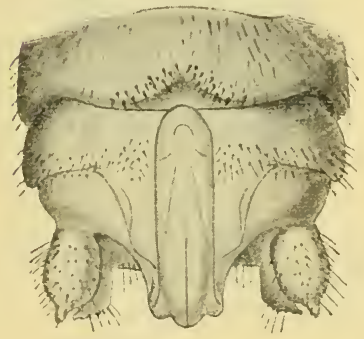

C

Fig. 128. Nemura borealis Mort. б. $A$ das Hinterleibsende von unten; $B$ von der Seite; $C$ von oben.
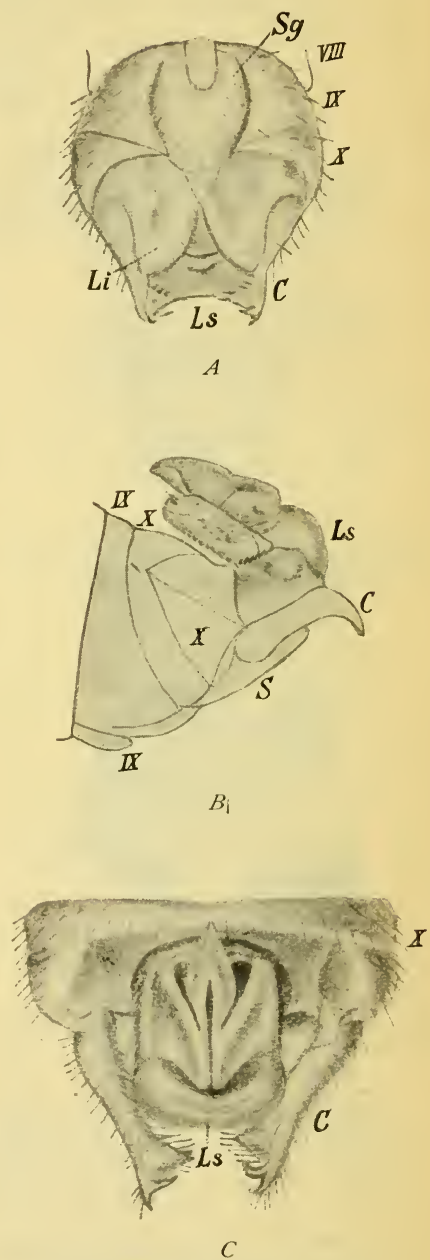

Fig. 129. Nemura variegata Oliv. $\widehat{~}$. $A$ das Hinterleibsende von unten; $B$ von der Seite; $C$ von oben. des o $15-20 \mathrm{~mm}$, des $q 16-27 \mathrm{~mm}$. - Überall gemein.
(Fig. 129 u. 130). 
- Die Cerci in der Seitenansicht nach oben gekrümmt und an der Spitze klauenartig nach unten gebogen, von oben an der Spitze nach außen fußartig erweitert. Ich kenne bisher keine sicheren Merkmale, nach welchen man die Weibchen der letzten 2 Arten unterscheiden könnte; die cambrica dürfte

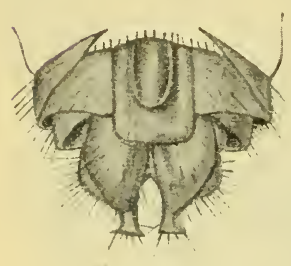

$A$

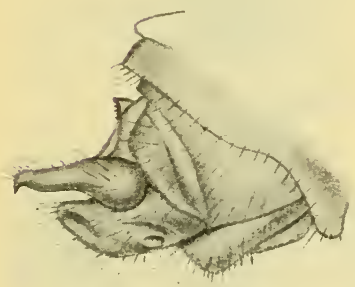

B

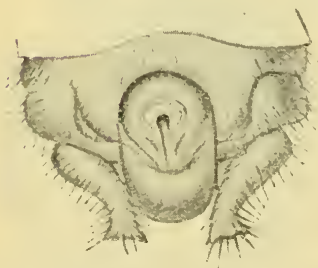

C

Fig. 132. Nemura marginata Pict. 万. $A$ das Hinterleibsende von unten; $B$ von der Seite; $C$ von oben.

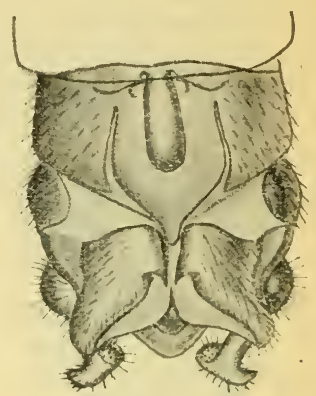

$A$

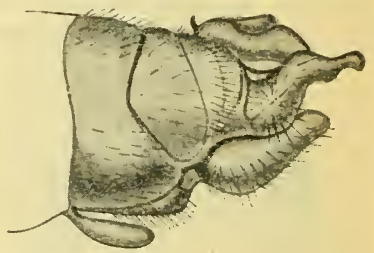

$B$

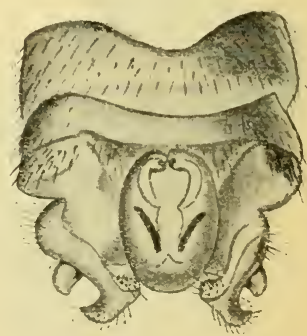

C

Fig. 133. Nemura cambrica St. $\delta$. $A$ das Hinterleibsende von unten; $B$ von der Seite; $C$ von oben.

durchschnittlich kleiner sein und ihre Flügel schmäler als bei marginata. Flügelspannung des $\delta 15 \mathrm{~mm}$, des $q 16$ bis 19 mm. - In höheren Lagen. Mai. (Fig. 133.) cambrica St.

d) Beim ơ Cerci aus einem kugetig verdicktem Grunde walzenförmig verlängert, lang; der Anhang der Subgenitalplatte ziem- 
lich schmal. Die Subanalklappen lang, schmal, kegelförmig und an der Innenseite ihres Grundes entspringt eine lange, schmal säbelförmige Chitingräte; der Supraanallobus kırz, nach linten dreieckig verschmälert. Beim of bildet fler 7 . Ring eine dreieckige Sulgenitalplatte, welche in eine muldenförmige Vertiefung des S. Ringes hineinpaßt (Fig. 134 แ. 135).

Untergatt. Nemurella K $\mathrm{mpny}$.

Dunkelbraun mit ziemlich schmalen Flügeln, welche meist eine feine Nervatur zeigen, die an der Anastomose nur wenig
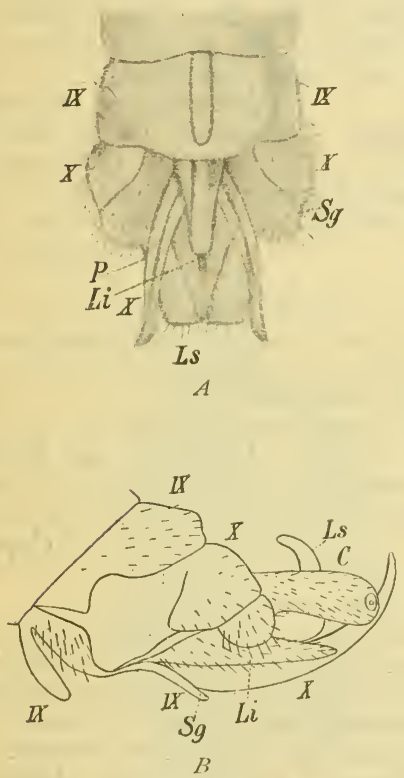

Fig. 134. Nemura Pictetii KIp. $\delta$. A das IIinterleibsende von unten; $B$ von der Seite; $C$ von oben.

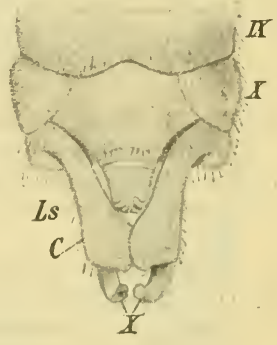

C

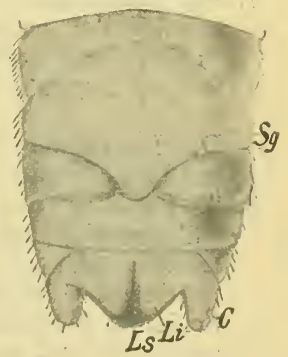

Fig. 135. Nemura Pictetii KIp. . Das Hinterleibsende von unten.

verdickt ist. Pronotum besonders beim of sehr breit. Flïgelspannung des of $13-19 \mathrm{~mm}$, des $q$ 19-27 mm. - - In den Ebenen bis in die Vorgebirge weit rerbreitet. Von Mai bis September.

Pictetii Kllp.

\section{Bestimmungstabelle der Gattungen von Plecopterenumphen.}

1. Taster ahlförmig; die Innenladen der Unterlippe rudimentär, erste 2 Fußglieder sehr kurz, zusammen kürzer als das 3." 2.

- Taster gleichmäßig stark; kurz fadenförmig; die Unterlippe trägt 4 zwar weit verwachsene, aber durch fast gleich große Lobi angedeutete Laden. 
2. Die Tasterglieder bis zum vorletzten gleichmäßig stark, das letzte aber auffallend dünner, stumpf; Unterlippe bis zum Submentum geschlitzt; Körper schmal länglich. Isopteryx.

- Tasterglieder stufenweise an Stärke abnehmend, das letzte nicht auffallend dünner als das vorletzte und die Taster vollkommen ahlförmig.

3.

3. Körper flach, breit, auf der Brust mit Kiemenbüscheln, Hypopharynx dreieckig zugespitzt.

Perla.

- Körper nicht auffallend flach, ohne Kiemen auf der Brust; Hypopharynx abgerundet.

4. Das 3. Glied der Maxillartaster so lang oder etwas länger als das 4.; letztes Tasterglied deutlich dünner als das vorletzte, aber fast gleichmäßig stark und nicht zugespitzt.

Perlodes und Isogenus.

- Das 3. Glied der Maxillartaster kürzer als das 4. und das letzte ahlförmig zugespitzt.

Chloroperla.

5. Die Hüften mit dreigliedrigen Anhängen; die ersten 2 Fußglieder untereinander fast gleich lang, zusammen so lang wie das 3.

- Hüften ohne Anhänge.

Nephelopteryx.

6. Die Fußglieder stufenweise länger; beide Taster und die Laden der Unterlippe dicht kurz bewimpert. Taeniopteryx.

- 2. Fußglied am kürzesten oder die Füße anscheinend zweigliedrig; Taster nur spärlich beborstet.

7.

7. Die Laden der Unterlippe durch tiefe Einschnitte deutlich voneinander getrennt; die ersten 2 Fußglieder der Hinterfüße wenig voneinander verschieden, das 3 . wenigstens zweimal so lang wie die 2 ersten zusammen; Sporne sehr klein.

Capnia.

- Die Laden der Unterlippe durch seichte Einschnitte nur als runde Lobi angedeutet; Sporne stark.

8. 2. Fubglied undeutlich, mit dem 1. verschmolzen und die Füße anscheinend zweigliedrig; das letzte Glied der Maxillartaster am längsten; Labium quer viereckig, breiter als lang; das letzte Glied der Labialtaster kegelförmig; Schenkel und Schienen überwiegend mit langen, abstehenden Borsten besetzt, nur mit spärlichen Dornen; Körper schmal. Leuctra.

- 2. Fußglied am kürzesten, aber deutlich, das 3. an längsten; die letzten 3 Glieder der Maxillartaster fast gleich lang; Labium länger als breit und das letzte Glied der Labialtaster eiförmig; auf den Schenkeln und Schienen überwiegend in Reihen geordnete Spitzen, abstehende Borsten nur spärlich; Körper ziemlich stark.

Nemura.

\section{Perlodes Pict.}

Körper stark, nur mäßig flach, Kopf deutlich, etwas breiter als das Pronotum, welches schmal quer elliptisch ist und ganz abgerundete Seitenränder hat. Die Punktaugen in ein gleichschenkliges Dreieck gestellt und der Abstand der hinteren etwa um die Hälfte größer als die Entfernung vom Innenrande der Augen und vom vorderen Punktauge. Beine mäßig stark, an der Innenkante mit kurzen, nicht dichten Spitzen, auf der Außenkante bis zur Spitze mit einer Franse von langen, feinen Haaren besetzt; die Schienen 
mit 2 ungleichen Endspornen. Bei der 9 Nymphe ist der 8. Bauchring etwas läinger als der 7. und 9.; der 10. Ring ist auf der Rückenseite stumpf dreieckig vorgezogen. Die Subanalklappen sind bei beiden Geschlechtern sphärisch dreieckig und divergierend, beim $\delta$ länger als beim $Q$, an der Außenseite nicht mit Spitzen besetzt (Fig. 136, 137, 138).

Kopf und Pronotum graubraun mit gelber Zeichnung, sonst aber ist der Körper gelb mit graubramer Zeichnung. Auf dem Kopfe ist ein dreieckiger his zum vorderen Punktange reichender Fleck auf dem Kopfschilde, ein eiförmiger zwischen den Punktaugen und ein anderer jederseits auf dem Hinterhaupte; kleine Punkte finden wir zwischen den Punktangen und der Fühlerbasis. Auf dem Prono-

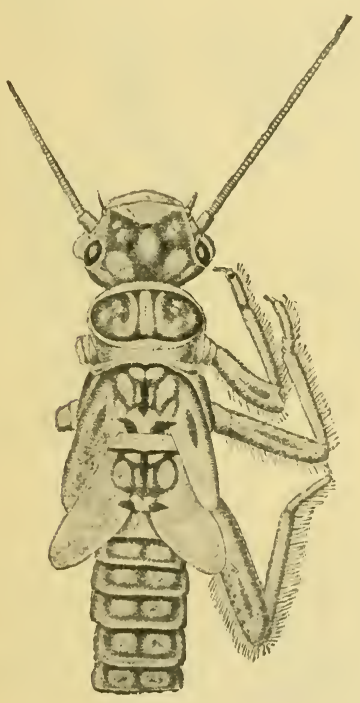

Fig. 136.

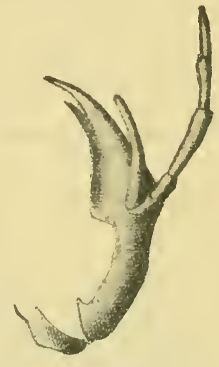

Fig. 137 .

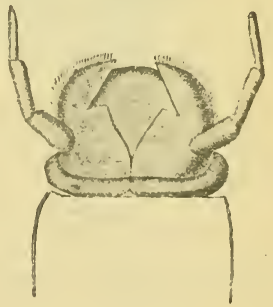

Fig. 138.

Fig. 136-138. Perlodes dispar Rmbr. Fig. 136 Vorderkörper der Nymphe; Fig. 137 Maxilla; Fig. 138 Unterlippe.

tum ist ein heller Mittelstreifen und jederseits von demselben ein bogenförmiger nach außen konkaver Streifen; die Randfurche ist auffallend dunkler.

dispar $\mathrm{Rmb}$.

\section{Isogenus $\mathrm{New}$.}

Der vorigen Gattung sehr ähnlich. Beim $q$ ist der 8. Bauchring in der Mitte an Hinterrande kaum merklich logenförmig vorgezogen, wohei zwei stärker chitinisierte Linien einen kleinen Einschnitt andeuten und die Dornenreihe unterbrochen ist; der 10. Dorsalring ist in seiner ganzen Breite stumpfwinklig vorgezogen; die Subanalklappen sind fast parallelseitig, hinten vollkommen abgerundet, reichen bis zum Hinterrande des ebenfalls runden Supraanallobus 
und sind auf ihrer Außenseite mit kurzen Spitzen besetzt. Beim $\delta$ ist der 9. Ring nicht vorgezogen und nicht länger âls der S. mnd der Supraanallobus überragt als ein kurzer Kegel den Hinterrand des 10. Ringes. Das Pronotum ist nach hinten etwas erweitert und zeigt dentliche obwohl etwas gerundete Seiten (Fig. 139).

Körper weißlich olivengrün, oben braun gefleckt. Auf dem Kopfe ist die vordere Partie his zur M-Linie licht, der übrige Teil braun, nur zwischen den Punktangen ist ein lichter Fleck und das Hinterhaupt ist auch etwas heller. Auf dem Pronotum ist der Rand, der Mittelstreifen und je ein bogenförmiger, nach anßen konvexer Fleck auf den Seitenfeldern lichter. Anf dem Meso. und Metanotum sind vier krenzweiß gewellte eiförmige lichte Flecke.

nubecula New m.
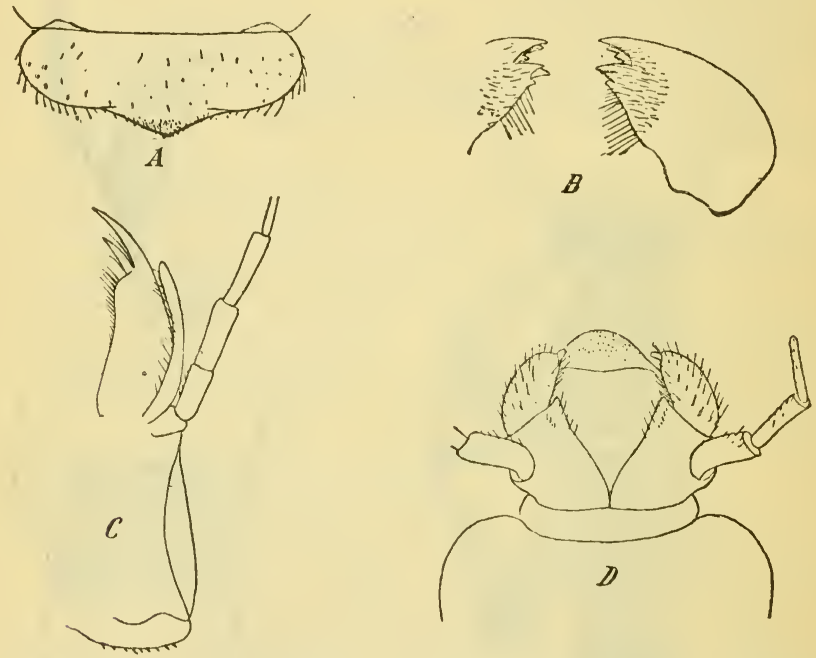

Fig. 139. Isogenus nubecula Newm. Nymphe. A Oberlippe, $B$ Mandibeln, $C$ Maxilla, $D$ Unterlippe.

Perla Ge offr.

Körper breit, flach, insbesondere unten ganz eben; Kopf von parabolischem Umrisse mit winkelig hinter den Angen vorspringenden Schläfen. Taster relativ ku'z, ihre Glieder von den dritten an Länge abnehmend. Beine breit und auf der änßeren Kante mit einer Franse von langen feinen Haaren versehen und mit kurzen Spitzen besetzt. Auf der Brust ist je ein starkes Doppelbüschel von feinen Kiemenfäden auf der weichen Haut hinter jeder Hüfte und nebstdem auf der Vorderbrust ein kleines vor der Hüfte. Bei einigen Arten tragen auch die Subanalklappen auf ihrer weichen Haut Kiemenbüschel. Die Hinterleibssegmente sind normal nur das 10. ist auf der Bauch- wie Rückenseite in der Mitte dreieckig vorgezogen, beim $\delta^{*}$ ist aber dieser Vorsprung in der Mitte etwas ausgekerbt und in der Nittellinie mit einer Furche versehen. Bei vollständig reifen weiblichen Nymphen ist in der Mitte des Hinterrandes des 8. Ventralringes ein weißlicher runder Fleck, der vorn 
von einer stärker chitinisierten Linie gesäumt ist. Die Subanalklappen sind kurz und klaffend, der Supraanallobus ist klein.

1. Die Subanalklappen Kiemenbüschel tragend; die Schwanzfäden nur mit Dornkränzchen, olne Haarfransen.

- Die Suhanalklappen ohne Kíiemenbüschel, dafür aber die Schwanzäden auf ihrer Rückseite mit einer dichten Haarfrause versehen. Körper gelb, braun gezeichnet: auf dem Kopfe ist eine braune Zickzacklinie zwischen den Augen und am Rande des Clypeus sind einige braune F'lecke so gestellt, daß auf dem Kopfschilde eine gelbe, sechsstrahlige, sternförmige Zeichnung entsteht. Auf dem Pronotum zieht sich von dem dunkelbraunen Randstreifen eine kurze den Randstreifen linten nicht erreichende Binde. Auf den Hinterleibsringen ist der Vorderrand braun gesäumt und dieser Saum verlängert sich nach hinten in 5 Zacken, von welchen

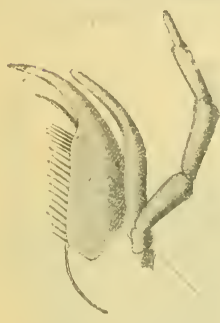

Fig. 140. die äußeren ałf den Körperseiten sich befinden, der innerste in der Mittellinie der Dorsalfläche; auf den vorderen Ringen sind diese Zacken nur kurz, auf den mittleren erreichen sie den Hinterrand und

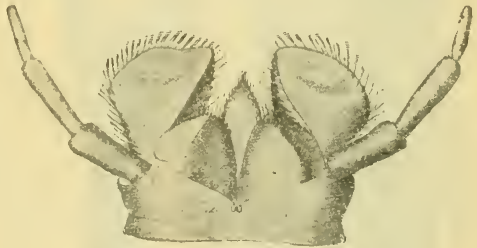

Fig. 141.

Fig. 140 u. 141. Perla abdominalis Burm. Nymphe. Fig. 140 Maxilla. Fig. 141 Unterlippe. schlieben damn 4 helle Makeln ein. Der 9 . Ring ist fast, der 10. ganz braun. In der Mitte der Außenfläche der Schenkel sind braune Flecke kaum angedentet.

maxima Scop.

2. Körper gell, braun gezeichnet; die Mitte des Kopfes nimmt ein trapezförmiger Fleck, welcher vorn vor der Fühlerbasis beginnt und hinten in der Mitte des Hinterhauptes endet, aber durch die gelbe M-Linie, die Stimschwielen und die l'unktaugen unterbrochen ist; manchmal dringt die helle Farbe des Kopfschildes in den mittleren Winkel der M-Linie ein. A.uf dem Pronotum reichen die dunklen Binden auf den Seitenfeldern bis zum hinteren Randstreifen und die Seitenfelder werden dadurch in zwei lichte Streifen geteilt. Auf den Hinterleibssegmenten erreichen die von dem Vorderrandssame alogehenden Zacken meist den Hinterrand und deshalb zeigen die Rückensegmente je 4 eiförmige, lichte Flecke in dem dunklen Grunde. Auf den Schenkeln ist der schwarzbraune Knierand und ein Fleck in der Mitte der AuBeuseite wohl entwickelt. Öfters ist auch die Kehle bräunlich. Der Abstand der hinteren Punktangen ist wenig kleiner als die Entfernung vom Immenrande der Augen und gleich 
der Entfernung vom vorderen Punktauge (11:13:11) (Fig. $140,141)$.

abdominalis $B$ urm.

- Körper fast gleichmäßig rotbraun, nur der Vorderrand des Kopfschildes, Fühler, Taster, Schienen, Füße und Schwanzfäden gelb. Der Abstand der hinteren Punktaugen fast zweimal kleiner als die Entfernung vom Innenrande der Augen und etwas kleiner als die Entfernung vom vorderen Punktauge $(12: 23: 14)$.

cephalotes Curt.

\section{Chloroperla Newm.}

Körper von ähnlicher Form wie bei Isogenus oder Perlodes, aber kleiner, ohne Kiemenbüschel. Taster ziemlich lang, ihr 4. Glied etwas länger als das 3. und das letzte ahlförmig zugespitzt. Auch die Form der äußeren Laden der Unterlippe ähnlich wie bei den genannten Gattungen. Die Fransen auf der Rückenkante der Beine nur auf den Schienen deutlicher entwickelt, sonst schwach, dafür

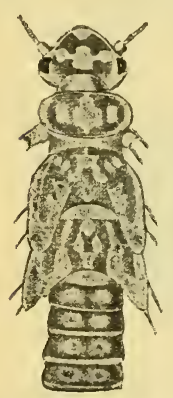

Fig. 142.

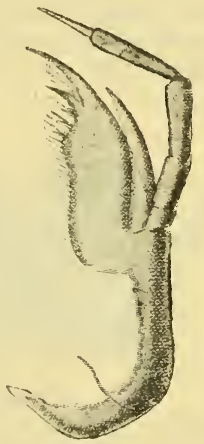

Fig. 143.

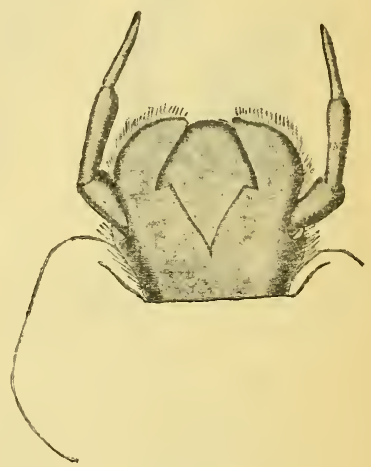

Fig. 144 .

Fig. 142-144. Chloroperla difformis Klp. Nymphe. Fig. 142 Vorderkörper. Fig. 143 Maxilla. Fig. 144 Unterlippe.

treten daselbst die kurzen Spitzen auf. Die Hinterleibssegmente zeigen keine Geschlechtsmerkmale, höchstens scheint der 9. Ventralring etwas verlängert zu sein. Der 10. Ring ist nur auf der Rückenseite rundlich dreieckig vorgezogen. Die Subanalklappen sind schmal dreieckig und klaffend.

1. Kopf braun, nur der Vorderrand des Kopfschildes, ein eiförmiger Fleck zwischen den Punktaugen und ein Punkt an jedem Punktange deutlich heller; auf dem Hinterhaupt sind 2 Paare von nur undeutlich vortretenden Makeln. Auch die Zeichnung auf dem Pronotum beschränkt sich nux auf 2 undeutliche hellere Streifen entlang der Mittellinie. Der Hinterleib ist unten einfarbig braun, hat oben einen breiteren helleren Mittelstreifen, welcher durch eine undentliche Mittellinie geteilt ist. Fühler und Schwanzborsten etwas lichter als der Körper, die ersteren gegen die Spitze zu dunkelbraun, die letzteren undentlich geringelt; Taster und Beine lichtgelb.

helvetica Schoch. 
- Körper gelb mit brauner Zeichnung.

2. Alustand der hinteren Punktaugen un die Hälfte größer als die Entfernung derselben vom Innenrande der Augen; die braune Zeichnung des Körpers tritt deutlich hervor und das Hinterhaupt, besonders hinter den Augen ist ebenfalls bräunlich; die Schwanzborsten schmal, aber deutlich braun geringelt; beim $\delta$ sind die Flügelscheiden nur als ganz kurze Lappen angedeutet (Fig. 142, 143, 144). difformis Klp.

- Abstand der linteren Punktaugen etwa so groß wie die Entfernung derselben von dem Innenrande der Augen; die braune Zeichnung des Körpers nicht so deutlich vortretend und das Hinterhaupt gelb; die Schwanzborsten nicht geringelt; die Flügelscheiden bei beiden Geschlechtern gleich entwickelt.

grammatica Scop.

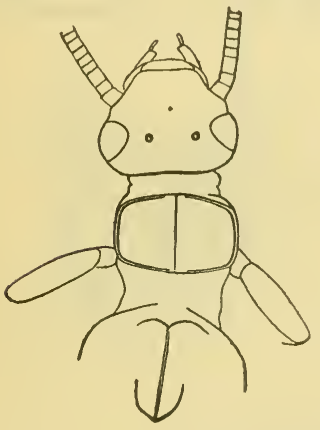

Fig. 145 .

Fig. 145. Isopteryx tripunctata Pict. Nymphe. Der Vorderkörper.

Fig. 146. Isopteryx Burmeisteri Pict. Nymphe. Vorderkörper.

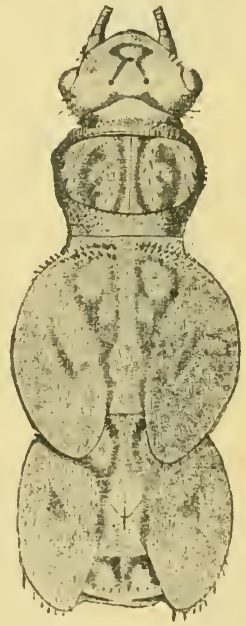

Fig. 146.

\section{Isopteryx Pict.}

Körper schlank, im Querschnitte elliptisch. Die Punktangen in ein gleichschenkliges Dreieck gestellt, der Abstand der hinteren noch etwas mehr als zweimal so groß wie die Entfernung vom Innenrande der Augen. Das wichtigste Merkmal bieten die Taster, welche im wahren Sinne des Wortes kaum ahlförmig zu nennen sind, da ihre Glieder bis zum vorletzten stärker werden und das dünne letzte auffallend schwach und klein erscheint. Pronotum nicht ganz so breit wie der Kopf samt Augen, meist quer elliptisch, seltener querlänglich mit abgerundeten Ecken; es ist an dem Rande mit steifen Borstenhaaren besetzt. Die Flügelscheiden haben eiförmigen Umriß. Beine kurz, schwach; die Fransen auf der änßeren Kante derselben sind schwach entwickelt, dafür treten kurze Spitzen und kurze steife Borsten in größerer Zahlı auf. Die 
Hinterleibsringe sind normal, nur das 10. ist auf dem Rücken stumpf dreieckig oder rundlich vorgezogen. Die Subanalklappen kurz dreieckig, auf der Anfenseite mit kurzen steifen Borsten hesetzt. Supraanallobus rundlich, wenig vorragend, mit kleinen Spitzen besetzt. Körperfarhe hellgelb oder licht rötlichbraun.

1. Pronotum dentlich schmäler als der Kopf samt Angen, querlänglich viereckig mit abgerundeten Ecken; das Verhältnis seiner Breite zur Länge ist 50:34. Schwanzborsten kurz, etwa so lang wie die 6 letzten Hinterleibssegmente, 16 gliedrig. Körper gelb ohne Zeichnung, nur bei reifen of Nymphen mit einem dunklen Streifen auf dem Rücken des Hinterleibes (Fig. 145).

tripunctata Scop.

- Pronotum an den Seiten yollkommen abgerundet, quer elliptisch und kürzer.

2. Körper gelb mit undeutlicher bramer Zeichnung; Pronotum sehr kurz, Breite zur Länge wie 50:26; Schwanzborsten etwa so lang wie die 6 letzten Hinterleibssegmente, 16 gliedrig (Fig. 146).

Burmeisteri Pict.

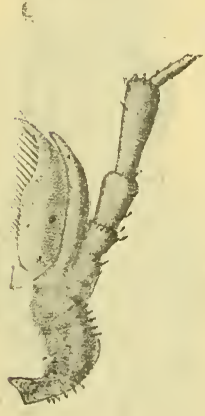

Fig. 147.

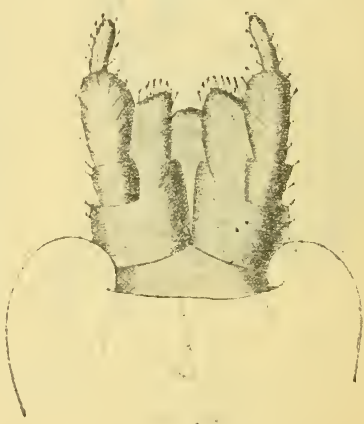

Fig. 148.

Fig. 147 u. 148. Isopteryx torrentium Piet. Nymphe. Fig. 147 Maxilla. Fig. 148 Unterlippe.

- Körper licht lederbraun olne Zeichnung; Pronotum kürzer als bei tripunctata, aber länger als bei Burmeisteri (50:30); Schwanzborsten länger als bei den genannten Arten 16 gliedrig etwa so lang wie die $S$ hinteren Segmente (Fig. 147, 148).

torrentium Pict.

\section{Capuia Pict.}

Körper schlank, fast walzenförmig. Kopf abgerundet dreieckig. Punktangen in ein gleichschenkliches Dreieck gestellt; Abstand der hinteren etwa zweimal so groß wie die Entfernung vom Innenrande der Augen. Pronotum quer viereckig, mit abgerundeten Ecken, vorn etwas schmäler als hinten. Flïgelscheiden der o Nymphe sehr klein, der $\not$ groß sackförmig. Beine kurz; von den Fußglieder'n ist das mittlere am kürzesten, das Endglied etwas länger als die zwei ersten zusammen. Auf der Rückenkante der Beine nur spärliche lange Haare. Die Hinterleibssegmente sind normal entwickelt, nur das 10. ist auf dem Pï̈cken samt dem mit ihm 
verwachsenen Lobus supraanalis heim ot lang dreieckig vorgezogen und an der Spitze algestutzt, heim $q$ parabolisch verlängert. Schwanzborsten fein, lang, fast die Länge des Hinterleiles erreichend. Die

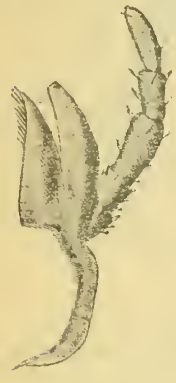

Fig. 149 .

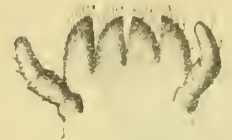

Fig. 150 .

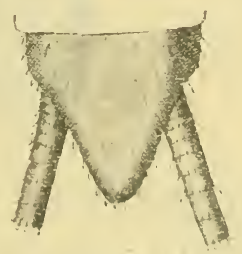

$A$

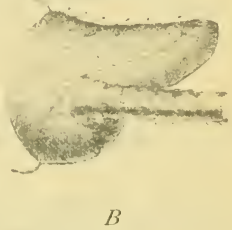

Fig. 151.

Fig. 149 u. 150. Capnia nigra Piet. Nymphe. Fig. 149 Maxilla.

Fig. 150 Unferlippe.

Fig. 151. Capnia nigra Piet. Nymphe. $A$ Hinterleibsende des $\delta$ von oben; $B$ von der Seite.

Subanalklappen kurz, abgerundet dreieckig und stark klaffend (Fig. $149,150,151 \mathrm{a}, \mathrm{b})$.

Kö̈rper licht gelb, ohne jede besondere Zeichnung, nur des Kiopf etwas dunkler.

nigra Pict.

\section{Nephelopteryx $K l_{p}$.}

Körper schlank, fast walzenförmig. Punktaugen in ein gleichschenkeliges Dreieck gestellt und der Abstand der hinteren etwa zweimal so groß wie ihre Entfernung vom Innenrande der Augen. Pronotum vorn etwa so breit wie das Hinterhaupt, nach hinten erweitert, also von trapezoidęr Form, aher mit etwas bogenförmigen Seiten. Die vorderen Flïgelscheiden lang eiförmig, die hinteren abgerundet dreieckig. Beine lang und ziemlich schlank; die Fußglieder stufenweise länger; das 3 . fast so lang wie die 2 ersten zusammen. Die Haarfranse auf der äußeren Kante der Schenkel und Schienen dümm, die Innenkante der Schenkel mit einigen starken Zähnen, die mit einer kurzen Spitze bewehrt sind. Die Hüften tragen einen einziehbaren, dreigliedrigen Anhang. Das 1. bis 7. Hinterleibssegment ist in der Mitte des Hinterrandes mit einem konischen Höcker bewehrt. Bei reifen Nymphen ist die Teilung des 9. Ventralbogens in 3 Felder angedentet. Der 10. Ring

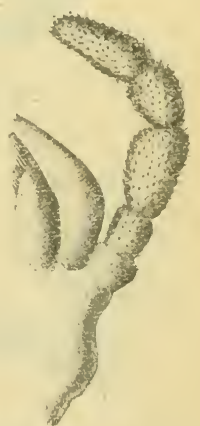

Fis. 152. Nepholeptery.r nebulosi 1 . Nymphe. Maxilla. ist auf der Bauchseite stark verkiurzt, auf der Rï̈ckenseite dreieckig vorgezogen. Die Subanalklappen breit dreieçkig, der Supraanallobus 
verlängert und den 10. Ring noch etwas überragend. Schwanzborsten dünn, länger als der Hinterleib (Fig. 152, 153, 154).

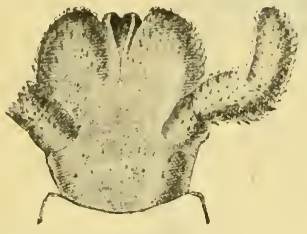

Fig. 153.

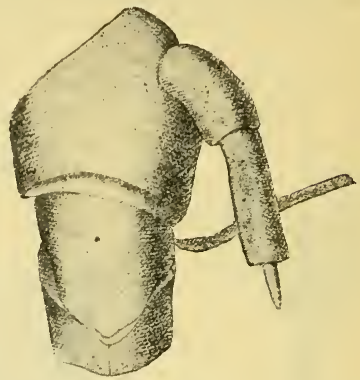

Fig. 154.

Fig. 153 u. 154. Nephelopteryx nebulosa L. Nymphe. Fig. 153 Unterlippe; Fig. 154 Hüfte mit Anhang.

Körper lichter oder dunkler braun, oben gewöhnlich etwas dunkler, die Kopfnähte und ein über den ganzen Körper sich ziehender Mittelstreifen lichter. nebulosa L.

\section{Taeniopteryx Pict.}

Mit der vorigen Gattung habituell übereinstimmend, aber ohne gegliederte Anhänge der Hüften und ohne konische Höcker in der

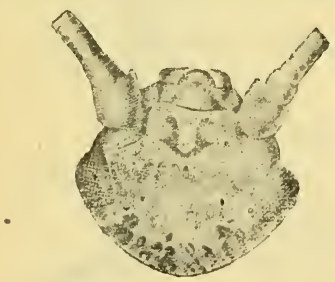

Fig : 155 .

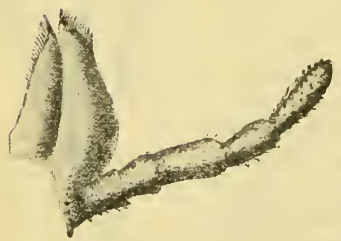

Fig. 157.

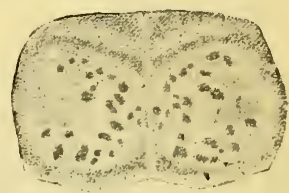

Fig. 156.

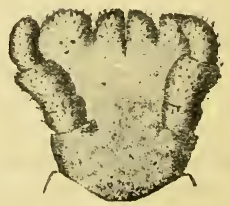

Fig. 158.

Fig. 155-158. Taeniopteryx Braueri Klp. Nymple. Fig. 155 Kopf;

Fig. 156 Ironotum; Fig. 157 Maxilla; Fig. 158 Unterlippe.

Mitte des Hinterrandes der Hinterleibssegmente. Der 9. Ring ist lei beiden Geschlechtern in eine parabolische, auf der Bauchseite 
stark und lang behaarte Platte verlängert. Der 10. Ring ist auf der Bauchseite ganz geteilt, auf der Rïckenseite dreieckig vorgezogen und unter ihm ist der runde Supraanallobus sichthar. Beim of sind in der Ansicht von unten unter der Platte des 9. Ringes die öhrchenartigen Subanalklappen sichtbar. Cerci so lang wie der Körper (Fig. 155-158).

Fühler stark, die Glieder erst über der Mitte so lang wie breit; Farbe ledergelb, mit undeutlicher, dunklerer Zeichnung; das 2. und 3. Fußglied auf seiner Rückenkante mit einem schwarzen Punkte am Grunde. Körper stärker und größer. Braneri Klp. Fühler fein, ihre Glieder schon über dem ersten Drittel so lang wie breit; Körper lederbraun, die Fußglieder am Grunde und den Endrande schwarzbraun gesäumt, öfters ist auch ihre Rückenkante schwarzbraun. Körper kleiner und zarter. seticornis Klp.

\section{Leuctra St.}

Körper sehr schlank, schmal walzenförmig; Kopf abgerundet dreieckig; Punktaugen in ein gleichschenkeliges Dreieck gestellt und der Abstand der hinteren etwa zweimal so groß wie die Entfernung derselben vom Innenrande der Augen; Taster fadenförmig,

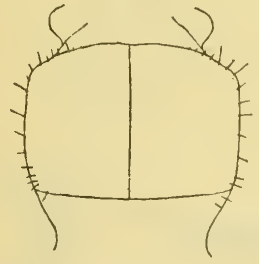

$A$

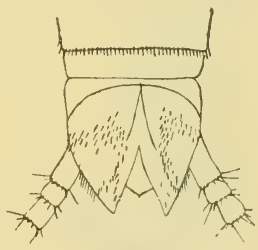

$B$

Fig. 159. Leuctra prima Kpny. Nymphe. $A$ das Hinterleibsende von unten; $B$ das Pronotum.

ihre Glieder stufenweise länger. Pronotum etwas schmäler als der Kopf samt Augen, quer viereckig; Flügelscheiden sackförmig; Beine relativ kurz, die hinteren stufenweise länger; das mittlere Fußglied am kürzesten, oft undeutlich. Der 10. Ring ist auf der Bauchseite tief rundlich ausgeschnitten, auf der Rückenseite abgerundet dreieckig vorgezogen und mit dem Supraanallobus fest verbunden. Die Subanalklappen sind beim ơ dreieckig, zugespitzt, aber nur teilweise auf einer runden Stelle etwas chitinisiert und an den Rändern dieses Schildchens mit feinen IBörstchen besetzt; die Klappen sind durch einen tiefen Einschnitt voneinander getrennt. Beim $q$ sind die Subanalklappen abgerundet, hinten mit einem Kranze von steifen, ziemlich langen Börstchen und berühren einander in der Mittellinie. Schwanzborsten kurz, fein, an den Enden der einzelnen Glieder mit langen Börstchen besetzt (Fig. 159).

Pronotum quer länglich viereckig, nach hinten kaum verschmälert, nur an den Seiten mit längeren Härchen besetzt, auf ihrer oberen Fläche ganz kahl; die Riïckenfläche des 3.-10. Hinterleibsringes nur mit zerstreuten steifen Börstchen und die Hinterränder der genannten Ringe mit einem Kŕranze von feinen Spitzen; die neue 
Gliederung der Fühler beginnt mit dem 7.-8. Gliede: Schenkel und Schienen nur mit spärlichen langen Haaren besetzt.

prima $\mathrm{K} p \mathrm{n}$.

l'ronotum trapezoid, nach hinten deutlich (etwa $11 \mathrm{~m} / 6$ ) verschmälert, mit alogermudeten Ecken, nicht nur an allen Rändern, sondern auch an den seitlichen Teilen der oberen Fläche behaart; die Rückenfläche des Hinterleibes dicht mit kurzen Börstchen besetzt, denen an den Seiten längere Härchen beigemengt sind; die Hinterränder der Segmente ohne besondere Borsten- oder Spitzenkränze (Fig. 160); die neue Gliederumg der Fühler beginnt mit dem 10. Gliede; Schenkel und Schienen mit zahlreichen langen Haaren besetzt (Fig. 161, 162).

nigra Pict.

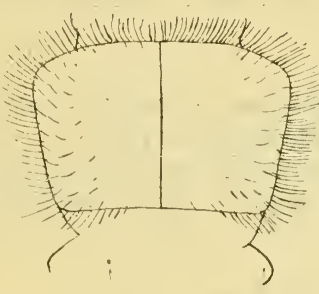

Fig. 160.

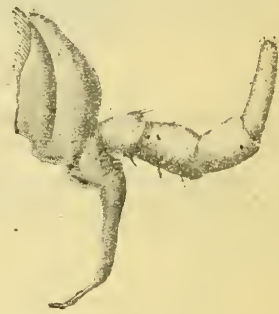

Fig. 161 .

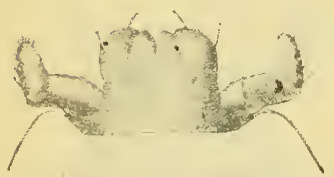

Fig. 162.

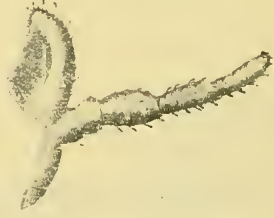

Fig. 163.

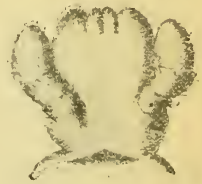

Fig. 161.

Fig. 160-162. Lenctra nigra Pict. Nymphe. Fig. 160 Pronotum; Fig. 161 Maxilla; Fig. 162 Unterlippe.

Fig. 163 11. 164. Nemura variegata Oliv. Nymphe. Fig. 16:3 Maxilla, Fig. 164 Unterlippe.

\section{Nemura Latr.}

Körper stärker als bei den 2 vorhergehenden Gattungen, besonders in der Brust. Die Tasterglieder stufenweise länger. Pronotum so breit oder etwas breiter als der Kopf samt Augen, mit trapezoidem Chitinschildchen, dessen Ecken mehr oder weniger abgerundet sind; es ist in der Mitte durch eine feine weißliche Linie geteilt und an den Rändern mit Spitzen oder Borsten besetzt. Die Flügelscheiden sackartig, die hinteren etwas breiter als die vorderen. Beine stark mit dreigliedrigen Füßen, deren mittleres Glied am kürzesten und das letzte etwas länger ist als die 2 vorhergehenden zusammen; die Beine tragen nur zerstreute längere Borsten, sind dafür ziemlich dicht mit kurzen Spitzen und steifen Börstchen besetzt. Beim oc ist der 9. Ventralring dreieckig vorgezogen, der 10. rollständig geteilt; die Subanalklappen klaffend, hinten abgerundet 
und anf den chitinisierten Flächen mit starken steifen Borsten oder dünnen Spitzen besetzt. Die 10. Rïickenplatte ist hinten vorgezogen und mit dem abgerundet kegelförmigen Supraanallobus verbunden. Beim $O$ ist die 7. Ventralplatte ofter's in der Mitte etwas vorgezogen, die S. mit einer chitinisierten kurzen (Querleiste versehen, aher am Hinterrande gerade, die 9. wieder etwas vorgezogen, die 10. nicht geteilt, die Subanalklappen und der Supraanallobus kür\%er,

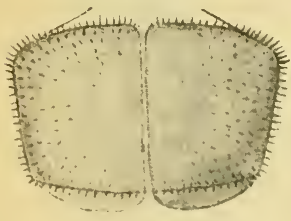

Fig. 165.

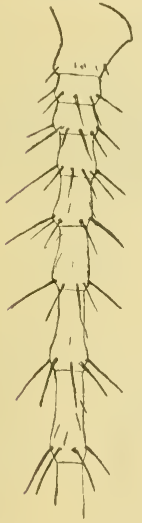

Fig. 168.

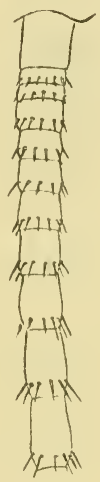

Fig. 166.

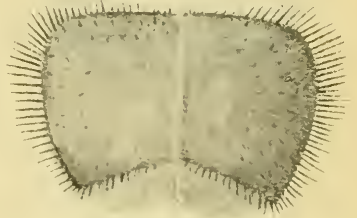

Fig. 167.

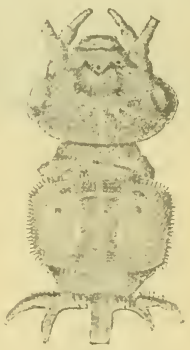

Fig. 169.

Fig. 165 u. 166. Nemura humeralis Pict Nymphe. Fig. 165 Pronotum;

Fig. 166 Sehwanzborste.

Fig. 167 и. 168. Nemura cinerea Oliv. Nymphe. Fig. 167 Pronotum; Fig. 168 unterer Teil der Schwanzborste.

Fig. 169. Nenurella Pictetii Klp. Kopf der Nymphe.

verhältnismäßig breiter. Schwanzborsten bei beiden Geschlechtern stark, etwas länger als der Hinterleib, ror dem Ende der Ǵlieder mit quirlartig gestellten Spitzen oder starken Borsten besetzt. Die Nymphen der Untergattungen Protonemura und Amphinemura tragen auf der Vorderbrust Kiemenfäden (Fig. 163, 164).

1. Die Vorderbrust mit jederseits drei kurz wurstförnigen, weißen Kiemenfäden; Pronotum trapezoid, mit geraden Seiten, bogenförmigem. Vorder- und Hinterrande, am ganzen Rande mit einem Kranze von kurzen, steifen borstenartigen spitzen; das Verhältnis der vorderen und hinteren Breite zur Länge ist 50:43:32. Schwanzborsten vor dem Ende der Glieder mit Quirlen von feinen Spitzen, welche külzer sind als die halbe Länge des Gliedes; erst das 8. Glied so lang wie breit. (Fig. 165, 166). 
- Die Vorderbrust mit 4 Büscheln von je 5-8 feinen langen weißen Kiemenfäden; Pronotum trapezoid, aber die Seiten

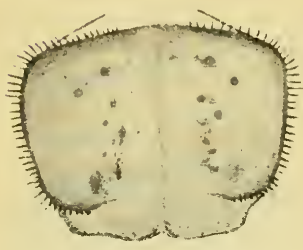

Fig. 170.

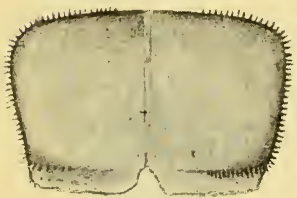

Fig. 173.

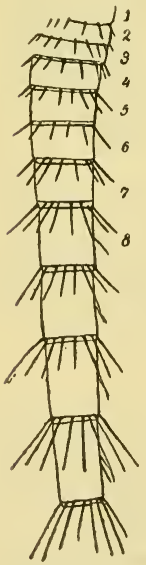

Fig. 175.

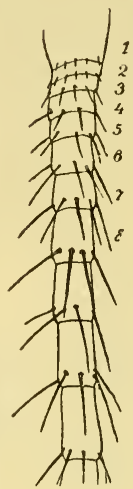

Fig. 171.

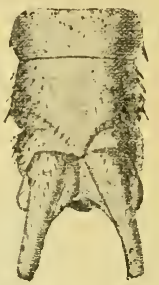

Fig. 172.

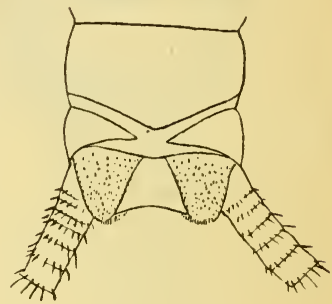

Fig. 174.

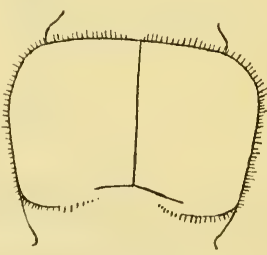

Fig. 176.

Fig. 170-172. Nemura Pictetii Klp. Nymphe. Fig. 170 Pronotum; Fig. 171 unterer Teil der Schwanzborste; Fig. 172 ठे Hinterleibsende von unten.

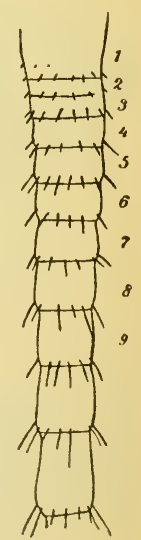

Fig. 177.

Fig. 173-175. Nemura marginata Pict. Nymphe. Fig. 173 Pronotum;

Fig. 174 Hinterende des $\sigma^{\top}$; Fig. 175 unterer Teil der Schwanzborste.

Fig. 176. Nemura variegata Oliv. Pronotum der Nymphe.

Fig. 177. Nemura variegata Oliv. Der untere Teil der Schwanzhorste.

sind stark bogenförmig gerundet, der Vorderrand fast gerade, die Vorderecken stark abgerundet und der Hinterrand stumpf- 
winklig ausgeschnitten; der Rand trägt einen Kranz von dichten, langen, steifen Borsten: das Verhältnis der vorderen und hinteren Breite zur Länge ist 50:37:27, wobei die vordere Breite etwa in ersten Drittel, wo das Schildchen am breitesten ist, gemessen wird. Die Glieder der Schwanzborsten an den Enden knotenartig verdickt und mit einem Quirl von starken Borsten versehen, die wenigstens $2 / 3$ der Lünge des Gliedes haben. Der ganze Körper ist überhaupt stark mit Borsten und Haaren besetzt (Fig. 167, 168).

Amphinemura cinerea 0 liv.

- Vorderbrust ohne Kiemen (Fig. 169).

2. Die Subanalklappen des ơ sehr lang, zapfenförmig, den Supraanallobus weit überragend, beim $q$ klaffend zugespitzt; das 1. Glied der Hinterfüße fast so lang wie das letzte; Pronotum trapezoid nit schwach bogenförmigen Rändern und abgerundeten Vorderecken, an den Rändern mit einem Kranze von feinen kurzen Börstchen; die Glieder der Schwanzborsten am Ende mit einem Kranze von steifen Borsten, die etwa im unteren Drittel der Cerci die Länge des Gliedes erreichen. (Fig. 170, 171, 172). Nemurella Pictetii Klp.

- Die Subanalklappen bei beiden Geschlechtern kurz und an der Spitze abgerundet; 1 . Glied der Hinterfüße kaum halb so lang wie das letzte.

(Nemura s. str.) 3

3. Die Borsten in den Quirlen an den Enden der Glieder von Schwanzfäden stark und lang, fast die Länge der Glieder erreichend, abstehend; Pronotum trapezoid mit abgerundeten Vorderecken, an den Rändern mit einem Kranze von kurzen Spitzen (Fig. 173, 174, 175).

marginata Pict.

- Die Borsten in den Quirlen an den Gliedern der Schwanzfäden feiner, die halbe Länge der Glieder nicht überschreitend und nicht so abstehend; Pronotum ähnlich aber auch der Rand mit feinen kurzen Börstchen besetzt (Fig. 176, 177). 


\title{
Lepidoptera, Schmetterlinge.
}

Von

\author{
Dr. K. Grünberg (Berlin).
}

Mit 83 Abbildungen im Text.

\section{Lepidoptera.}

Insekten mit vollkommener Verwandlung, saugenden Mundteilen und 4 gleichmäßig gebildeten, häutigen, beschuppten Flügeln.

Körper in ganzer Ausdehnung dicht beschuppt oder behaart. Kopf stets deutlich abgesetzt, Thoraxsegmente verschimolzen. Hinterleib mit 6 oder 7 sichtbaren Ringen.

Facettenaugen groß und gut entwickelt, 20 cellen vorhanden oder fehlend. Fïhler stets vielgliedrig, langgestreckt und ungebrochen, im speziellen Bau verschieden, einfach mit keulenförmig verdicktem Ende (Rhopaloceren oder Tagfalter) oder ohne Endverdickung, beborstet oder gefiedert usw. und meist bei $\delta$ und 우 dentlich verschieden (Heteroceren, alle übrigen Familien). Mandibeln und Maxillen rudimentär. Maxillartaster, wenn vorhanden, meist klein, zweigliedrig, selten groß und mehrgliedrig. Labium (2. Maxillen) einen langen, aus 2 Halbrohren bestehenden, spiralig einrollbaren Saugrïssel bildend, zuweilen rudimentär oder fehlend. Labialtaster kräftig, dreigliedrig, dicht behaart oder beschuppt, verschieden gebildet.

Flügel von sehr verschiedener Form, dicht mit oft lebhaft bunten, dachziegelförmig gelagerten Schuppen bedeckt, zuweilen behaart. Bezeichnung der Flïgelränder bei Vorder- und Hinterflügeln: Vorderrand, vorderer Rand von der Wurzel bis zur Spitze, Innenrand, der gegenüberliegende Rand, und AuBenrand, von der Spitze zum Innenrand reichend. Außenrand und häufig auch der Innenrand mit einem Saum mehr oder weniger langer Schuppen odler Haare (Saumschuppen bzw. - Haare). Geäder im Vorderund Hinterflügel in den Grundzïgen gleich (vergl. Fig. 180), im Vorderflügel meist 12 , im Hinterflügel 8 Adern, welche vom Innenland aus gezällt werden. Aus der Wurzel treten 4 Adern in den Flügel ein: die Innenrand-oder Dorsalader (Ader 1, häufig doppelt oder dreifach und dann mit $1 a, 1 b, 1 c$ bezeichnet), die vordere und hintere Mittelader oder Subcostal- und Subdorsalader und die Vorderrand-oder Costalader (Ader 12 bzw. Ader 8, stets einfach, nur zuweilen an der Wurzel mit einem 
kurzen Gabelast). Vordere und hintere Mittelader umschließen die Zelle, welche am Ende durcli eine Querader, die D iscocellularader, geschlossen wird, aher auch teilweise oder ganz offen sein kann. Sie kann ferner der Länge nach durch eine Ader oder aderartige Falte geteilt sein. Im Vorderflügel bilden die aus dem vorderen Zellenende entspringenden Adern zuweilen (z. B. bei den Noctuiden) ein kleines, geschlossenes, mit der Zelle zusammenhängendes Feld, die Anhangszelle. Das Geäder ist bei vielen Tineiden rudimentär. Bei den $q$ mancher Arten sind die ganzen Flügel verkümmert. Bei den meisten Heteroceren entspringt von der Wurzel des Hinterflügels eine steife, federnde Borste (oder ein Borstenbüschel), die Haftborste oder Frenulum, welche in eine riegeloder rinnenförmige Vorrichtung auf der Unterseite des Vorderflïgels (Retinaculum) eingreift und eine feste Verbindung zwischen beiden Flügeln herstellt.

Beine mit fünfgliedrigen Tarsen und verlängerten Metatarsen. Mittel- und Hinterschienen mit je 2 Endspornen, Hinterschienen vielfach auch mit Mittelspornen.

Larven (Raupen) mit beißenden Mundteilen, 12 ringelig, meist mit 8 Fußpaaren, den gegliederten Thorakalfüßen und 5 Paar ungegliederten Bauchfüßen am 6.-9. und 12. Segment (letztere als Nachschieber bezeichnet). Von den Bauchfüßen können einzelne Pare verkümmern oder ganz verschwinden. Bauchfüße entweder mit zweilappiger Sohle, deren äußere Hälfte mit einwärts gekrümmten Häkchen besetzt ist (Klammerfüße), oder ungeteilt und am Rande mit einem Kranz auswärts gerichteter Häkchen (Kranzfüße). 1. und letztes Segment auf dem Rücken gewöhnlich mit einer stärker chitinisierten Platte, dem Nacken- und Afterschild.

Die Raupen der am Wasser vorkommenden Arten leben meist im Innern von Pflanzen und sind daher ganz oder nahezu nackt and farblos oder wenigstens nie auffallend bunt und lebhaft gefärbt.

Puppen frei oder in einem gesponnenen Kokon, häufig auch in einer ausgeglätteten oder ausgesponnenen Erdhöhle.

Zur Süßwasserfauna ist unter den Lepidopteren nur die verhältnismäßig geringe Zahl der Arten zu rechnen, deren Raupen von den in und am Wasser wachsenden Pflanzen leben und deren Imagines daher ebenfalls in unmittelbarer Nähe von Gewässern zu finden sind. Sie bilden keine natürliche geschlossene Gruppe wie etwa die Wasserkäfer, sondern rekrutieren sich zusammenhanglos aus verschiedenen Famlien, den Noctuiden (Eulen), Cossiden (Holzbohrern), Pyralididen (Zünslern), Tortriciden (Wicklern) und Tineiden (Schaben oder Motten), welche teilweise nur einzelne Vertreter stellen. Nur bei den Noctuiden und Pyralididen kommen einige natïrliche Verwandtschaftsgruppen hinzu. Die Rhopaloceren (Tagfalter) sind überhaupt nicht vertreten, ebenso fehlen von den Heteroceren gänzlich die Geometriden (Spanner), Sphingiden (Schwärmer) and die Bombyciden (Spinner) in weitesten Sinne.

Die meisten der im folgenden behandelten Arten können nur als Wasserbewohner im weiteren Sinne oder als Wasseranwohner gelten. Wasserbewohner im engsten Sinne sind nur die Raupen der Hydrocampinen, einer kleinen Pyralididen-Gruppe, welche ganz ähnlich leben wie die Larven der Trichopteren und zum Teil sogar wie diese mit Fadenkiemen ausgestattet sind. Als direkte Wasser- 
bewohner können im allgemeinen auch nur Raupen in Betracht kommen, denn die entwickelten Schmetterlinge sind ja durch ihre ganze Organisation auf das Landleben angewiesen. Die einzige Ausnahme macht von allen deutschen Schmetterlingen nur das 오 von Acentropus niveus, ebenfalls einer Hydrocampine, welches auch als Imago im Wasser lebt.

Viele der am Wasser zwischen Rohr und Sumpfgräsern fliegenden Arten zeigen eine starke Anpassung an solche Örtlichkeiten durch ihre stumpfe, gelb- oder graubraune Färbung, welche der Farbe trockenen Rohres oder Schilfes gleicht. Diese ausgesprochene Schilffärbung besitzen z. B. alle Rohreulen (Leucaniinen), unter den Pyralididen die Schoenobiinen, ferner anch einige Tineiden.

\section{Übersicht über die am Wasser vorkommenden Familien.}

I. Hinterflügel mit zwei Dorsaladern.

Ader 5 im Hinterflügel schwach oder fehlend. Vorderflügel meist mit Anhangszelle. Ader 7 und 8 im Hinterflügel nur an der Wurzel verschmolzen. Maxillartaster meist fehlend. Labialtaster und Rüssel kräftig entwickelt.

Noctuidae.

II. Hinterflïgel mit drei Dorsaladern oder Geäder rudimentär.

1. Fühler kurz und dick, beim ot lang gefiedert. Labialtaster klein, Naxillartaster und Rüssel fehlen. Ader 7 und 8 im Hinterflügel getrennt. Schienensporne klein. Große robuste Arten.

Cossirlae.

2. Fühler lang und dünn. Maxillartaster vorhanden oder fehlend. Labialtaster und Rïissel meist gut entwickelt. Mittelgroße bis kleine, meist zarte Arten.

a) Vorderflügel dreieckig, seltener lang und schmal, mit 11 oder 12 Adern, Ader 7 und 8 oder 7,8 und 9 gestielt; Ader 7 und $8 \mathrm{im}$ Hinterflügel an der Wurzel eine strecke verschmolzen. Maxillartaster meist vorhanden. Labialtaster kräftig, zuweilen verlängert.

Pyralididae.

b) Vorderflügel lang und breit, trapezförmig, mit 12 meist getrennten Adern. Maxillartaster fehlen. Labialtaster kräftig, gedrungen, seltener verlängert, mit kurzem stummelförmigen Endglied.

Tortricidae.

c) Flügel meist schmal und spitz mit sehr langen Saumhaaren. Ader 7 und 8 im Hinterflügel getrennt; Geäder häufig rudimentär. Maxillartaster vorhanden oder fehlend. Labialtaster lang und dünn, aufgebogen, mit langem spitzen Endglied, selten kurz und hängend.

Tineidae.

\section{Noctuidae, Eulen.}

Sehr umfangreiche Familie von leicht kenntlichem, durchweg einheitlichem Körperbau, mit kräftigem gedrungenem oder auch schlankem, dichtbehaartem oder beschupptem Körper und dreieckigen Vorderflügeln, deren Zeichnung sich in ihren charakteristischen Grundzügen (Kreis- oder Ringfleck, Nierenfleck, Wellenlinie etc.) bei fast allen Gruppen wiederholt. Augen nackt oder behaart, zuweilen von einem Kranz langer dünner Haare umstellt. Stirn glatt gerundet, zu- 
weilen mit rundem, spitzem oder plattenförmigem hornigen Fortsatz. Fühler borstenförmig, hänfig gewimpert oder beborstet, zuweilen gezähnt, selten lang gefiedert. Tasten meist steil aufgebogen und dicht beschuppt, mit kurzem dünnen, zylindrischen oder stummelförmigen Endglied, bei einigen Gruppen stark verlängert. Rüssel kräftig entwickelt, selten fehlend. Thorax und Hinterleib oft mit Haarschöpfen. Beine kräftig und gedrungen, zuweilen stark verlängert oder mit besonderen Merkmalen (Haarpinseln, Chitindornen), Mittelund Hinterschienen gespornt. Vorderflügel (Fig. 180) gewöhnlich und mit 12, zuweilen mit 11 Adern, meist mit Anhangszelle; Hinterflügel mit Haftborste, Ader 5 schwach ausgebildet oder fehlend, 8 dicht hinter der Basis die vordere Mittelrippe berührend, selten eine längere Strecke mit ihr verschmolzen.

Raupen (Fig. 178) meist $16 \mathrm{füßig,} \mathrm{mit} \mathrm{Klammerfüßen} \mathrm{und}$ hornigem Nackenschild, nackt, nur selten und dümn behaart, sehr häufig mit feinen dunklen, meist borstentragenden Wärzchen, mit aus dunklen oder hellen Längsstriemen bestehender Zeichnung. Verpuppung meist in oder an der Erde in einem leichten Gespinst.

Außer einzelnen Vertretern verschiedener Unterfamilien stehen als einigermaßen geschlossene Gruppe nur die Leucaniinen, deren Raupen in oder an Rohr, Schilf oder Sumpfgräsern leben, zu dem Wasser in enger Beziehung. In ausgedehnten Sümpfen und an fließenden Gewässern mit reichlichem Rohrbestande gehören sie zu den charakteristischen Erscheinungen.

\section{Übersicht über die Unterfamilien.}

I. Taster kurz, aufgebogen. Beine mäßig lang.

1. Augenrand ohne Kranz von Wimperhaaren.

a) Körper dicht behaart.

a) Thorax und Hinterleib mit Haarschöpfen. Hadeninae.

ß) Thorax höchstens mit vorderem kleinen Haarschopf, Hinterleib stets ungeschopft.

Lencaniinae.

b) Körper beschuppt, Thorax und Hinterleib mit kleinen Schöpfen.

Erastriinae.

2. Augenrand mit einem Kranz feiner Wimperhaare, Thorax und Hinterleib dicht wollig behaart und geschopft. Plusiinae.

II. Taster stark verlängert, Beine sehr lang.

Hermininae.

\section{Hadeninae.}

Augen nackt. Fühler kurz gewimpert, beim $\delta$ zuweilen gezähnt. Taster steil aufgebogen, dicht beschuppt. Schienen ohne Dornen. Thorax und Hinterleib rauh wollig behaart, mit Haarschöpfen. Vorderflügel dreieckig, mit deutlicher typischer NoctuidenZeichnung.

Raupen 16 füßig. 


\section{Gattungsübersicht.}

1. Endglied der Taster deutlich sichtbar, dünn, zylindrisch, vorgestreckt, Haarschöpfe am Thorax und Hinterleib gut entwickelt. a) Fühler gleichmäßig kurz gewimpert, Körper rauh behaart.

b) Fühler unterbrochen gewimpert, mit einzelnen kurzen Haarbüscheln, Leib glatt behaart.

Helotropha.

2. Endglied der Taster sehr kurz, stummelförmig, in der Behaarung des 2. Gliedes versteckt, Hinterleib nur mit einem schwachen basalen Haarschopf.

Hydroecia.

Hadena Schrank (Fig. 179 u. 180).

Augen nackt. Fühler kurz gewimpert. Taster his zur Stirn aufgerichtet, dicht abstehend beschuppt, mit kurzem dünnen, rorwärts gerichteten Endglied. Rüssel kräftig. Thorax mit geteiltem mittleren und hinteren Haarschopf. Hinterleib mit dorsalen Haarschöpfen und seitlich vorstehen-

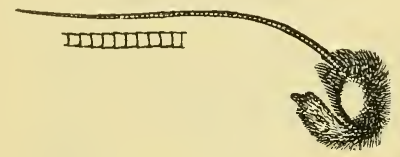

Fig. 179.

Fig. 179 u. 180. Hadena unanimis Tr. Kopf und Geäder.

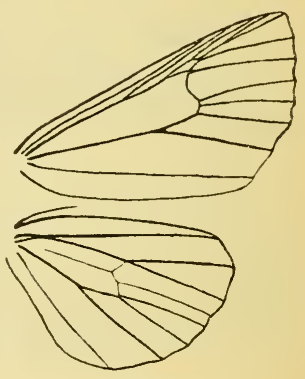

Fig. 180

den Haarbüscheln. Vorderflügel mit rechtwinkliger abgerundeter Spitze. Hinterflügel breit, gerundet, mit welligem Saum. Ader 3 und 4 aus dem unteren, 6 und 7 aus dem oberen Zellenende; 8 nahe der Basis die vordere Mittelrippe berührend.

Raupen mit feinen borstentragenden Wärzchen, an Gräsern. Verpuppung in der Erde.

Zahlreiche deutsche Arten, davon eine am Wasser.

\section{Hadena umanimis Tr. (Fig. 181).}

Fühler und Taster bram. Thorax oben dunkel rotbraun bis schwarzbraun. Hinterleib heller, graubraun, glänzend. Beine braun, mit schmalen hellen Tarsenringen. Oberseite der Vorderflügel von dunkelrot- oder graubrauner Grundfarbe mit dunkleren schwarzbraunen Flecken. Basalteil und äußerer Flïgelteil jenseits des Nierenfleckes etwas heller, so daß eine meist dentliche schwarzbraune breite Mittelquerbinde entsteht, welche innen schwarz, außen weißlich gesäumt ist und hinter dem undeutlichen Ringfleck einen unbestimmten schwarzen Schatten zeigt. Längs des Vorderrandes bis zum Nierenfleck eine Reihe schwarzbrauner, jenseits des Nierenfleckes 3 kleine weißliche Punkte. Nierenfleck weißlich, besonders scharf am Außenrand. Adern in dem hellen Feld hinter der Mitte schwarz und weiß gepunktet, aber unscharf. Wellenlinie deutlich, 
hellbraun, Saumteil hinter derselben mit Ausnahme der helleren Spitze schwarzbraun mit kleinen schwarzen winkeligen Saumflecken und hellbrauner Saumlinie. Saumschuppen dunkelbraun mit hellen Fleckchen an den Adermündungen. Hinterflügel oben dunkel graubraun mit heller Basis und undeutlichem Discocellularfleck, heller Saumlinie und weißlichgrauen Saumschuppen. Unterseite in beiden Flügeln dunkel graubraun, am Innenrand heller, Außenrandpartie im Vorderflügel weißlich, Hinterflügel mit scharfem, schwarzhraunem Discocellularfleck und dunkler discaler Bogenlinie. Flügelspannung $30-35 \mathrm{~mm}$. Mai-Juli. In Deutschland verbreitet, aber nicht häufig.

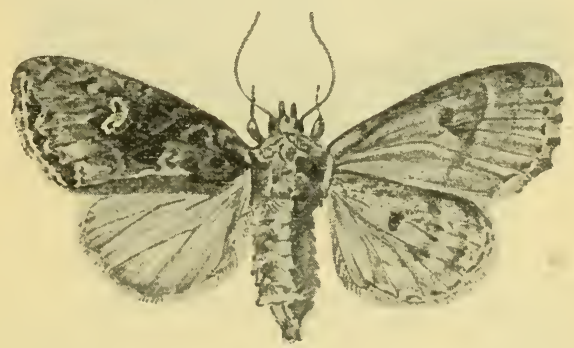

Fig. 181. Hadena unanimis Tr. Vergr. $1^{3 / 1}$.

Kaupe: Kopf und Nackenschild bräunlichgelb, auf dem letzteren 3 weißliche Längsstriche. Körper graugelb bis graubraun, oberseits mit 3 weißlichen Längsstriemen, zu beiden Seiten der mittleren eine Längsreihe schwärzlicher Warzenpunkte, je 2 auf jedem Segment. Stigmen weiß mit schwarzer Umrandung, in der breiten hellen Seitenstrieme. Unterseite hellgrau. Länge bis $40 \mathrm{~mm}$. Herbst--Mai an Sumpfgräsern, besonders an Glanzgras (Phalaris arundinacea L.), tagsüber zwischen einem zusammengesponnenen Blatt; verpuppt sich gern in Rohrstoppeln.

Puppe dunkelbraun.

\section{Miana Steph.}

Sehr nahe verwandt mit Hadena, von schlankerem Körperban, in den übrigen Nerkmalen mit ihr übereinstimmend.

5 deutsche Arten, davon eine am Wasser.

\section{Miana ophiogramma Esp. (Fig. 182).}

Kopf, Fühler, Taster und Beine dunkelbraun. Thorax und Hinterleib graubraun, Halskragen hinten mit schwarzem Querstrich. Flügeldecken mit einzelnen schwarzen Schuppen bestreut. Vorderflïgel oberseits hell graubraun mit großem, tief dunkelbraunem Fleck, welcher, vorn am breitesten, den Vorderrand von der Basis bis jenseits der Mitte einnimmt, außen bis über den Nierenfleck und hinten bis kurz vor die Ader 1 reicht; er ist hinten scharf gerandet und weißlich gesäımt, außen weniger scharf gerandet. Am Vorderrand eine Reihe dunkler, hinter der Nitte 3 oder 4 kleine, weißliche Punkte. Ringfleck unscharf, Nierenfleck scharf, hellhraun. Adern außerhalb des dunklen Fleckes weißlich, hinter der Mitte mit einer 
Querreihe feiner, schwarzer Doppelpunkte. Hinter der Ader 2 ein am Saum erweiterter schwarzer Längsstrich. Wellenlinie sehr undeutlich, innen von einem dunklen Schatten begleitet. Saum etwas dunkler, mit schwarzen, bogenförmigen Saumfleckchen und schmaler, heller Saumlinie. Saumschuppen dunkelbraun, an den Adermündungen etwas heller. Hinterflïgel oben einfarbig graubraun. Unterseite der Vorderflügel dunkel graubraun, hinten heller, mit sehr

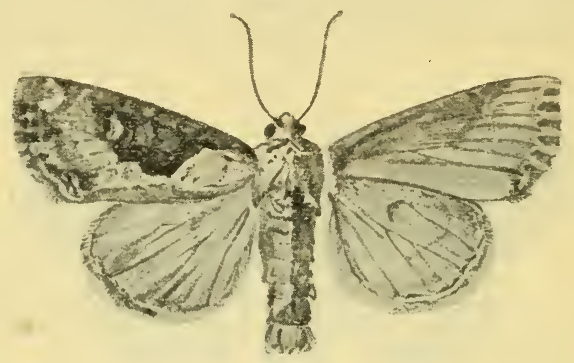

Fig. 182. Miana ophiogramma Esp. Vergr. $1^{3 / 4}$.

undeutlicher Bogenlinie rom Vorderrand bis zur Ader 4 und kleinen, schwärzlichen Saumfleckchen. Hinterflügel ebenfalls graubraun mit hellerem Innenrande, scharfem schwarzbraunen Discocellularfleck und undeutlicher, dunkler Bogenlinie hinter der Mitte. Flügelspannung $30 \mathrm{~mm}$. Juni, mehr in Norddeutschland, auch bei Frankfurt a. M., nicht häufig.

Raupe: Kopf glänzend hellbraun, Nacken- und Afterschild dunkelbraun. Körper schmutzig fleischfarben mit 2 dorsalen Längsreihen dunkler Warzenpunkte, je 4 auf jedem Segment und 3 bis 4 ebensolcher Punkte um die Stigmen. Unterseite weißlichgrau. Länge bis $40 \mathrm{~mm}$. Herbst - Frühjahr, im Mai in den Jungtrieben der Schwertlilie (Iris) und verschiedener Sumpfgräser, besonders in Schilf (Calamagrostis), Glanzgras (Phalaris), Süßgras (Glyceria), dicht über der Wurzelkrone, von außen bemerkbar durch die Bohröffnung. Verpuppung in einer Erdhöhlung.

Puppe hellbraun.

\section{II. ophiogr. var. maerens $\mathrm{Stgr}$.}

Dunkler als die Hauptform, Vorderflügel fast einfarbig schwarzbraun. Hauptsächlich in Süd- und Westleutschland, auch bei Hamburg.

\section{Helotropha Led.}

Augen nackt. Fühler unterbrochen gewimpert. Taster, Thorax und Hinterleib wie bei Hadena, die Beschuppung und Behaarung glatter; Hinterleib beim $\delta$ mit breitem Afterbüschel, beim $q$ spitz. Geäder wie bei Hadena.

Raupe fein behaart. Puppe mit 2 Dornen am Hinterende.

Nur eine Art. 
Helotropha lencostigma Hb. (Fig. 183).

Kopf, Thorax und Beine tief dunkelbraun, Fühler etwas heller, Hinterleib hell graubraun. Oberseite der Vorderflügel tief dunkelbraun mit undeutlicher, schwärzlicher Zeichnung und breiter, etwas hellerer Außenbinde. Vorderrand mit dunklen Punkten und 3 kleinen weifen Punkten hinter der Mitte. Ringfleck undeutlich, Nierenfleck

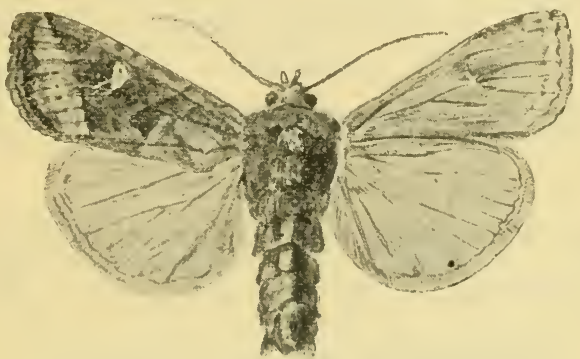

Fig. 183. Helotropha leucostigma Hb. Vergr. $1 \frac{1}{2}$.

sehr scharf, weiß mit schwärzlicher Innenseite. Außenrand schwärzlich mit zusammenfließenden, bogenförmigen, schwarzen Saumfleckchen und heller Saumlinie. Saumschuppen schwarzbraun. Hinterflügel graubraun mit hellerer Basis. Unterseite in beiden Flügeln dunkel graubraun mit hellerem Innenrand. Discocellularfleck und Bogenlinie in den Hinterflügeln undeutlich. Flügelspannung 35 bis $40 \mathrm{~mm}$. Juni-August, ganz Deutschland, nicht häufig.

Raupe: Kopf hellbraun, Nacken- und Afterschild schwarz. Körper schmutzig weißlich, Oberseite rot- oder schwarzbraun; 3 helle Rückenlängsstriemen umschließen 2 Längsreihen schwarzer Warzenpunkte, je 4 auf jedem Segment, deren jeder ein Haar trägt. Stigmen schwarz, mit 4 kleinen Warzenpunkten umstellt. Unterseite hell graubraun. Herbst-Juni oder Juli in der Wurzel und im unteren Stengel von Sumpfpflanzen, besonders in Schwertlilie (Iris), Schilf (Calamagrostis) und Igelkolben (Sparganium), auch im Wasser selbst zwischen den Herzblättern des Schilfrohrs gefunden. Verpuppung in einem dünnen Gespinst im Innern der Futterpflanze.

Puppe zuerst olivengrün mit bräunlichem Hinterende, dann olivenbraun.

\section{Hel. lencost. var. fibrosa II b.}

Vorderflügel heller, die scharfe, helle Außenbinde mit einer Querreihe schwarzer Doppelpunkte. Ringfleck deutlich, weißlich umrandet.

\section{Hydroecia Guen.}

Augen nackt. Fühler gewimpert. Taster mit kurzem. stummelförmigem, in der Beschuppung halb verstecktem Endglied. Vorderer Haarschopf des Thorax ungeteilt, schmal und scharf gekielt, Hinterleib nur an der Basis mit einem kleinen Haarschopf, beim ot mit wolligem Afterbüschel, beim $\subsetneq$ spitz. Vorderflügel mit ziemlich 
scharfer Spitze, ehenso wie die Hinterflügel mit gewelltem Saum. Geäder wie bei Hadena.

Raupen dick, walzig, mit feinen dunklen borstentragenden Wärzchen. Im Stengel und in der Wurzel von Gräsern und einigen anderen Pflanzen.

5 deutsche Arten, davon 2 am Wasser.

\section{Artenübersicht.}

Imagines.

Vorderflügel und Flügelunterseite hellrötlichbraun. H. micacea. Vorderflügel und Flïgelunterseite dunkelbraun.

H. petasitis.

Raupen.

Schmutzig grauweiß, in Schwertlilie, Schilf, Wasserampfer.

Hell fleischfarben, in Pestwurz. $\quad$ H. micacea.

\section{Hydroecia micacea Esp. (Fig. 184).}

Fühler hellbraun, an der Basis oben weißlich. Kopf, Thorax und Beine rötlichbraun, Hinterleib hell graubraun. Oberseite der

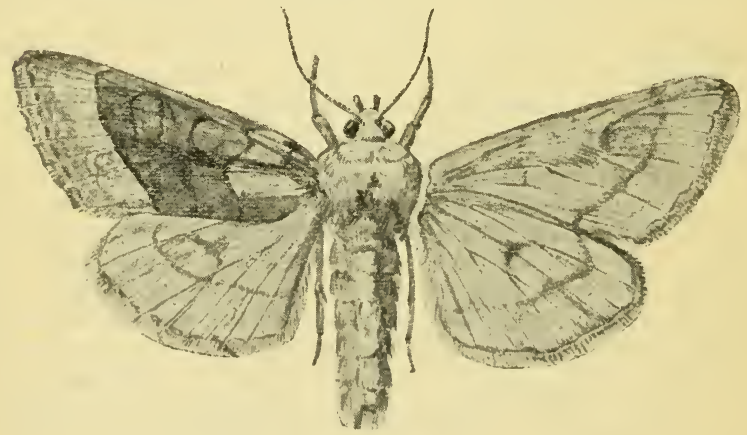

Fig. 184. Hydroecia micacea Esp. Vergr. $1^{3 / 4}$.

Vorderflügel rötlichbraun mit breitem dunklerem, hinten verschmälertem und scharf dunkel gerandetem Mittelfeld. Wurzel- und Außenrandpartie heller, mit Grau durchtränkt. Ring- und Nierenfleck etwas heller vom Mittelfeld abgehoben, mit scharfer dunkler Umrandung. Wellenlinie undeutlich, zuweilen kaum angedeutet, hat nur inneren dunklen Schatten. Saumlinie dunkel, Saumschuppen von der Farbe des Mittelfeldes. Hinterflügel oben ganz einfarbig, hell gelblichbraun mit sehr undeutlichem dunklen Discoidalfleck und dunkler Mittellinie. Unterseite in beiden Flügeln hell rötlichbraun, am Vorderrand leichter weiß durchtränkt, am Innenrand heller, besonders im Hinterflügel. Discocellularfleck und Bogenlinie mehr oder weniger deutlich, Saumlinie dunkel. Flügelspannung $35-43 \mathrm{~mm}$. August-September, in ganz Deutschland verbreitet, aber selten. 
Raupe: Kopf hell rotbraun, glänzend, Nacken- und Afterschild gelblich. Körper hell fleischfarben mit braunroter Rïckenlängslinie zwischen 2 Längsreihen schwarzer, je eine Borste tragender Warzenpunkte; gleiche Warzenpunkte seitlich über den ebenfalls schwarzen Stigmen. Unterseite weißlichgrau. Länge bis $50 \mathrm{~mm}$. Nai und Juni, an sumpfigen Stellen in der Wurzel von Schwertlilie (Iris), Riedgras (Carex), Schilf (Calamagrostis), auch in Wasserampfer (Rumex aquaticus L.). Erwachsen auf dem Boden zwischen Pflanzen oder in der Erde. Verpuppung in einer geleimten Erdhöhlung.

Puppe gelbbraun, verhältnismäßig klein, schlank.

\section{Hydroecia petasitis Doubld.}

Sehr ähnlich $H$. micacea, etwas größer. Flügel dunkler. Mittelbinde der Vorderflügel, besonders am Vorderrand, schmäler, mit steileren, wenig hervorgehobenen Rändern. Fühler wie bei micacea. Kopf und Thorax dunkel rötlichbraun, Hinterleib ebenso, mit hellerer Basis auf dem Rücken. Vorderflïgel dunkelbraun, VVurzel- und Außenrandpartie heller, Außenrand wieder etwas dunkler, mit heller Saumlinie. Ring- und Nierenfleck hell, scharf, die dunklen Ränder undeutlich. Adern hinter der Mitte weiß gesprenkelt. Wellenlinie undentlich, hell. $\Lambda$ dern hinter der Mitte weiß gesprenkelt. Wellenlinie undeutlich. Saumschuppen dunkelbraun. Hinterflügel dunkel graubraun, mit schwach angedeuteter Bogenlinie. Unterseite in beiden Flügeln dunkel graubraun, Discocellularflecke und Bogenlinie deutlich. Flügelspannung $40-45 \mathrm{~mm}$. Herbst, selten.

Raupe: Kopf, der längsgeteilte Rückenschild und Afterschild dunkelbraun. Körper schmutzig grauweiß, mit dunkel durchscheinendem Rückengefäß und schwarzen Warzenpunkten in 2 dorsalen Längsreihen, sowie je 4 um die weißen, schwarzgesäumten Stigmen. Länge bis $50 \mathrm{~mm}$. Mai - Juli. Auf sumpfigen Wiesen, an Bachund Uferrändern im Stengel, später in der Wurzelkrone der gebräuchlichen Pestwurz (Peiasites of finalis Moench). Verpuppung in der Nährpflanze oder in der Erde.

Puppe dunkel rotbraun.

\section{Lencaniinae.}

Augen nackt oder behaart. Fühler gewimpert, selten beim $\delta$ gezähnt. Taster aufgebogen, mit dichter Behaarung. Körper glatt, anliegend, fein wollig behaart oder beschuppt, Hinterleib olne Haarschöpfe. Schienen ungedornt. Vorderflügel dreieckig, mehr oder weniger lang gestreckt, mit abgerundeter oder scharfer Spitze. Färbung gleichmäßig und stumpf, gelblichgrau oder hell graubraun, rohr- oder schilffarben: Noctuiden-Zeichnung ganz zurücktretend oder nur der Nierenfleck scharf ausgeprägt. Geäder wesentlich wie bei den Hadeninen. Schmetterlinge am Wasser, in Rohrbeständen, auch in Gehölzen und trockenen Büschen.

Raupen 16 füßig, blaß gefärbt, schlank, meist mit feinen schwarzen Wärzchen oder mit Längsstriemen, fast alle im Innern von Pflanzen, im Stengel oder an der Wurzel. 
I. Augen nackt.

\section{Gattungsübersicht.}

1. Stirn mit hornigem Fortsatz.

a) Stirnfortsatz plattenförmig, viereckig.

b) Stirnfortsatz spitz.

Nonagria.

Coenobia.

2. Stirn ohne Fortsatz.

a) Körper wollig behaart.

a) Taster steil bis zur Stirn aufgebogen.

$\beta$ ) Taster vorgestreckt, nur ganz wenig aufgebogen.

b) Körper glatt anliegend beschuppt.

Tapinostola. Senta.

II. Augen behaart.

1. Vorderflügel lang und schmal mit sehr scharfer Spitze und stark abgeschrägtem Außenrand.

Meliana.

2. Vorderflügel mit rechtwinkeliger Spitze und steilem Außenrand.

Lencania.

Nonagria Ochsh., Schilfeulen (Fig. 185).

Kräftig gebaute, robuste Arten von teilweise beträchtlicher Körpergröße. Augen nackt. Stirn in eine durch dichte Beschuppung verdeckte, viereckige, hornige Platte ver-

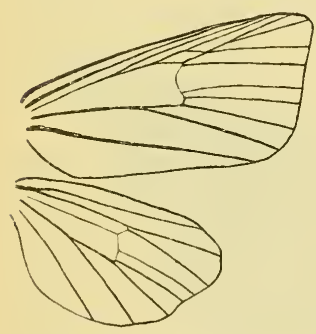

Fig. 185. Nonagria cannae Ochsh. Geäder. längert, daher stark vorstehend. Fühler dick, kräftig gewimpert, mit einer längeren Borste auf jeder Seite jedes Gliedes, beim oc von nexa stark gezähnt, mit pinselartiger Wimperung. Taster bis zur Stirn aufgebogen, mit kurzem stumpfen Endglied. Thorax glatt behaart, mit kleinem vorderen Haarschopf, der hintere fehlend, ebenso die Haarschöpfe auf dem Hinterleib. Vorderflügel ziemlich lang, mit rechtwinkeliger, scharfer oder abgerundeter Spitze und steilem glatten Saum. Saum der Hinterflügel ebenfalls glatt, an der Ader 5 leicht einspringend.

Schenkel mit langen abstehenden Haarfahnen.

Falter in Rohrbeständen oder in dürren Büschen, versteckt.

Raupen langgestreckt, nackt, hell gefärbt, mit hornigem Nackenund Afterschild, in Stengeln von Rohr und Sumpfgräsern. Ter-puppung in der Futterpflanze in einem leichten Gespinst. Puppen außer der von nexa mit einem hornigen Kopfvorsprung.

7 deutsche Arten.

Artenübersicht.

\section{Imagines.}

1. Nierenfleck auf dem Vorderflïgel scharf ausgeprägt, weiß. 2. Nierenfleck auf dem Vorderflïgel wenig hervortretend oder fehlend.

3.

2. Vorderflügel rötlichbraun mit dunklerer Mittelbinde, Nierenfleck am Hinterende nach innen umbiegend. N. nexa. Vorderflügel einfarbig graubraun ohne Mittelbinde, Nierenfleck in 2 Flecke aufgelöst. 
3. Vorderflügel kurz und breit.

4. Vorderflügel mit mehr oder weniger deutlicher schwärzlicher Längsstrieme und einigen weißlichen Flecken in der-selben.

Vorderflügel einfarbig ohne solche Zeichnung, nur mit einer ganz verschwommenen Verdunkelung auf der Mitte.

N. camnae.

5. Unterseite ohne Discocellularflecken, Vorderflügel weniger scharf gezeichnet.

N. neurica.

Unterseite mit scharfen dunklen Discocellularflecken, Zeichnung des Vorderflügels stärker ausgeprägt.

N. dissoluta var. arunclineta.

6. Unterseite der Hinterflügel mit scharfem Discocellularfleck.

Unterseite ohne Discocellularfleck.

N. typhae.

N. sparganii.

\section{Raupen.}

1. Rücken mit schmalen hellen oder dunklen Längslinien. 2.

Rücken ohne Längslinien.

2. Rï̈cken mit hellen Längslinien. Rücken mit dunklen Längslinien.

3. Schmutzig fleischfarben mit 3 hellen Längslinien, in Rohrkolben.

N. typhae. Schmutzig weiß mit 3 hellgrauen Längslinien, in Rohr.

$\mathrm{N}$. neurica.

4. Schmutzig weiß mit 2 braunroten Längslinien, in Wasserschwaden und Riedgras.

N. nexa.

Lichtgrün mit 4 dunklen Längslinien, in Rohrkolben, Igelkolben, Rohr.

N. sparganii.

5. Schmutzig weiß mit hellrötlichem Rücken, in Rohr.

N. dissoluta. var. arundineta.

Körper einfarbig.

6.

6. Schmutzig gelbgrün, in Rohrkolben, Igelkolben, Simse.

N. camnae. Schmutzig weiß, in Rohr.

N. geminipuncta.

Nonagria nexa Hb. (Fig. 186).

Fühler hellbraun. Kopf, Thorax und Beine rötlichbraun, Hinterleib etwas heller. Vorderflügel breit mit stark geschwungenem Außenrand und ziemlich scharfer Spitze, oberseits von der Farbe des Thorax, auf der Mitte dunkler, längs des Saumes weißlichgrau. Die dunklere, hinten verschmälerte Mittelbinde von $2 \mathrm{sehr}$ unscharfen hellen Linien eingefaßt, von denen meist nur die äußere deutlicher zu sehen ist. Am Vorderrand hinter der Nitte einige helle Punkte. Nierenfleck sehr scharf, weiß, am unteren Ende längs der hinteren Mittelader einwärts bis zur Wurzel ron Ader 2 verlängert. Dariiber in der Zelle ein kleiner weißer Fleck. In dem helleren Saumfeld auf den Adern eine Querreihe feiner schwarzer Punkte. Saumlinie dunkel, Saumschuppen rotbraun. Hinterflïgel einfarbig, dunkel oder heller graubraun. Unterseite in beiden Flügeln rötlich graubraun mit verschwommener ziemlich breiter Bogenlinie und 
schwärzlicher Saumlinie. Flügelspannung $22-28 \mathrm{~mm}$. August. Vorzugsweise in Norddeutschland, selten.

Raupe: Kopf braun mit weißlicher Winkelzeichnung; Nackenschild braungelb mit braunem Vorderrand und ebensolchen Seitenflecken. Afterschild glänzend gelb oder braun, hinten in 2 schwärzliche Zähnchen auslaufend. Körper schmutzig weiß mit 2 undeutlichen braunroten Rückenlängsstriemen und 4 schwarzen, ein feines

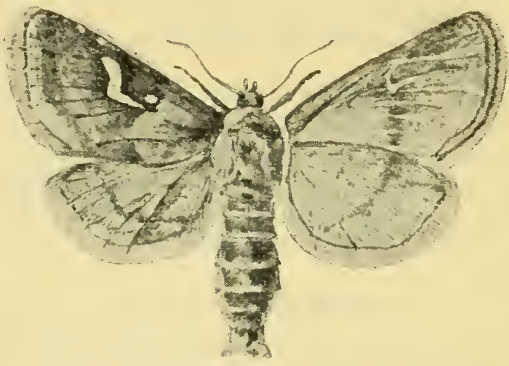

Fig. 186. Nonagria nexa Hb. Vergr. 2.

Härchen tragenden Warzenpunkten auf jedem Segment. Stigmen schwarz, über einer schwarzen unterbrochenen Seitenlinie. Länge bis $30 \mathrm{~mm}$. Herbst-Juli, in den Stengeln von Süßgras (Glyceria) und Riedgras (Carex), dicht über der Wurzel, erst im Juli weiter oben. fortsatz.

Puppe glänzend gelbbraun, aufrecht im Stengel, ohne Kopf-

Nonagria geminipuncta Hatch. (Fig. 18i).

Fühler hellbraun, oben weißlich. Vorderflügel kurz und breit,

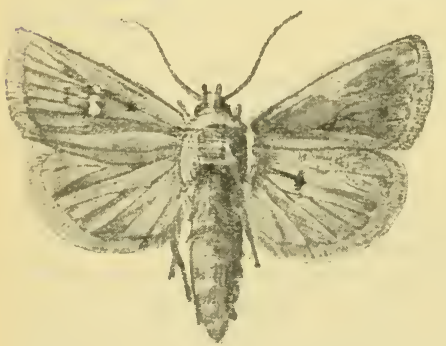

Fig. 187. Nonagria geminipuncta Hatch. Vergr. 11/2. mit gerundeter Spitze. Leib und Flügel einfarbig dunkelgrau oder rötlichbraun. Nieren fleck der Vorderflügel scharf, weiß mit mehr oder weniger deutlicher schwärzlicher Umrandung, meist in einen vorderen kleinen und einen hinteren größeren Fleck aufgelöst. Häufig einwärts vom Nierenfleck am Vorderrand der Zelle ein kleiner. runder, schwärzlicher Fleck. AuBerhalb des. Nierenfleckes meist eine undentliche schwärzliche Bogenlinie und jenseits derselben eine kaum angedentete hellere Querbinde. Adern vor dem Saum häufig weiß und schwarz gefleckt. Unterseite dunkel graubraun mit undeutlichem Discocellularfleck im Hinterflügel. Flügelspannung 25-33 mm. August, ganz Deutschland. Ei kugelig, dunkelbraun, einzeln an Rohrstengeln abgelegt.

Raupe: Kopf, Nacken- und Afterschild schwarzbraun. Körper schmutzig weiß oder gelblich, mit \& dorsalen Längsreihen kleiner, 
borstentragender, schwarzer Warzenpunkte, je 4 auf jedem Segment und ebensolchen seitlich üher den schwarzen Stigmen. Länge his $50 \mathrm{~mm}$. Herbst-Juni in den Stengeln des Rohrs (Phragmites communis Trin.), in Pflanzen auf trockenem Boden, frißt die imneren, noch unausgebildeteu Blätter. Legt vor der Verpuppung unter und über sich aus zernagten Rohrteilen eine schräge Scheidewand an. Die Ausflugsöffnung bleibt durch die dünne Epidermis nach außen geschlossen.

Puppe aufrecht im Stengel, gestreckt, walzig, hellbraun, mit langem Kopffortsatz. Puppenruhe 6 bis 7 Wochen.

Non. gem. ab. nigricans Stgr.

Leib und Flügel schwärzlichbraun, der Nierenfleck ganz verloschen.

Nonagria cannae Ochsh. (Fig. 188).

Fühler hellbraun, ohen weiß. Kopf, Thorax und Flügeloberseite heim ơ rötlichbraun, beim $q$ hellgelblich graubraun. Hinterleib bei beiden Geschlechtern etwas heller als der Thorax. Vorderflügel breit, mit steilem Außenrand und scharfer Spitze, Oberseite

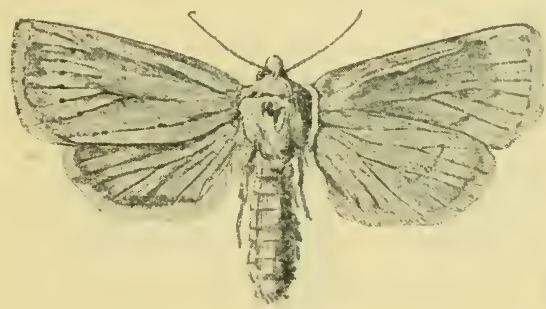

Fig. 1\&8. Nonagria cannae Ochsb. Vergr. 11/2.

einfarbig graubraun, nur auf der Mitte am Zellenende eine meist ganz diffuse, oft kaum merkliche Gruppe schwarzer Schuppen. Hinter der Mitte auf den Adern eine Querreihe schwarzer Punkte. Saunteil meist etwas dınkler, Saunlinie schwarz, Saumschuppen wie die Flügelgrundfarbe. Hinterflügel etwas dunkler als die Vorderflügel, einfarbig oder mit ganz schwach angedeuteter dunkler Bogenlinie. Unterseite bein of rötlichbraun, beim $q$ heller oder dunkler graubraun, ohne Zeichnung. Flügelspannung $32(\delta)-42($ ( ) $) \mathrm{mm}$. August-September. Ganz Deutschland, selten.

Raupe: Kopf gelblichbraun, Nacken- und Afterschild grünlichweiß oder gelblich. Körper dünn und schlank, schmutzig gelbgriin mit feinen schwarzen Warzenpunkten und schwarz gerandeten Stigmen. Länge bis $60 \mathrm{~mm}$. Herbst-Juli im Stengel des Pohrkolbens (Typha) und Igelkolbens (Sparganium), auch in Simsen (Scirpus), bevorzugt Pflanzen mit dünnem Stengel. Verpupjung in der frischen oder vorjälırigen Pflanze.

Puppe aufrecht im Stengel, unmittelbar unter der Ausflugsöfnung, rotbraun mit hellerer Unterseite, walzig, mit rorgestrecktem kegelförmigen Kopffortsatz. Vorletztes Segment mit einem stumpfen Höcker, Hinterende mit melıreren kleinen Spitzen. 


\section{Nonagria neurica $\mathrm{Hb}$.}

Fühler hellbraun, oben weißlich, Halskragen weiß gesäumt. Kopf, Thorax und Hinterleib graubraun, Hinterleib etwas heller. Vorderflügel breit, Oberseite gelblich graubraun, rohrfarben mit undeutlicher schwärzlicher, in einzelne Flecke aufgelöster Mittellängsstrieme, in welche auf der hinteren Mittelader einige weiße Flecke eingestreut sind. Hinter der Mitte eine bogenförmige Querreihe schwarzer Aderpunkte. Außenrand mit strichförmigen schwärzlichen Saumflecken zwischen den Adern, Saumschuppen von der Flügelgrundfarbe. Hinterflügel etwas heller als die Vorderflügel, mit hellgrauer Basis und undeutlichen dunklen Saumflecken. Unterseite hell gelblich graubraun, ohne Zeichnung, nur mit undentlicher Bogenlinie. Flügelspannung $30 \mathrm{~mm}$. Juli - August, Nord- und Westdentschland, in Rohrbeständen, selten.

Raupe: Kopf dunkelbraun, Nacken- und Afterschild gelbbraun mit dunkelbrauner Punktierung. Körper schmutzig weißlich bis grau mit 3 undeutlichen, dorsalen, hellgrauen Längslinien und 2 dorsalen Reihen sehr feiner, schwarzer, borstentragender Warzenpunkte, je 4 auf jedem Segment und schwarzen Stigmen. Länge bis $40 \mathrm{~mm}$. Herbst-Mai oder Anfang Juni in Rohrstengeln (Phragmites), erwachsen nur in den frischen Sprossen. Verpuppung im unteren Teil des Stengels oder in vorjährigen Stengeln.

Puppe mit dem Kopf abwärts über der Ausflugsöffnung, walzig, hellbraun, mit kielförmigem Kopffortsatz und zahlreichen, hakenförmig gekrümmten Borsten an Hinterende. Puppenruhe 6 bis 7 Wochen.

\section{Nonagria dissolnta Tr. var. arundineta Schmidt (Fig. 189).}

Ähnlich $N$. neurica. Körper robuster, Halskragen einfarbig, Vorderflügel schlanker, Oberseite dunkler, graubraun mit rötlichem oder gelblichem Anflug, die schwärzliche Längsstrieme stärker, die

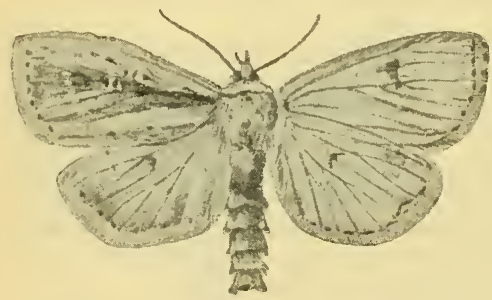

Fig. 189. Nonagria dissoluta Tr. var. arundineta Schmidt. Vergr. $1^{1 / 2}$. weißen Flecke schärfer, Nierenfleck meist deutlich sichtbar. Hinter der gebogenen Punktreihe auf den Adern zuweilen kleine weiße Fleckchen. Unterseite in beiden Flügelpaaren mit deutlichem dunklen Discocellularfleck. Die Saumpunkte ziemlich scharf. Flügelspannung $30-35 \mathrm{~mm}$. August - September, in dichten Rohrbeständen, sehr selten. (Hauptform in Deutschland ausgestorben.)

Raupe: Kopf dunkelbraun, Nacken- und Afterschild graubraun mit je 4 größeren und mehreren kleineren braunen Wärzchen. Körper schmutzig weiß mit hell rötlichem Rücken. 2. und 3. Segment mit je einer Querreihe feiner schwarzer Warzenpunkte, aufden folgenden Segmenten je 4 gleiche Warzenpunkte, je 3 um die weißen, schwarz gesäumten Stigmen und einige sehr feine auf der Außenseite der Afterfüsse. Länge bis $40 \mathrm{~mm}$. Herbst-Juni, in 
Rohrstengeln (Phragmites). Verpuppung im unteren Teil des Stengels.

Puppe gestreckt, walzig, hellbraun. Verhalten wie bei neurica.

Nonagria typhae Thunb. (Fig. 190).

Fühler hell- bis dunkelbraun. Kopf, Thorax und Beine dunkel rötlichbraun oder mehr grau, Hinterleib hell gelblich graubraun. Vorderflügel schlank mit abgeschrägtem Außenrand und ziemlich scharfer Spitze, Oberseite dunkel graubraun mit leichtem rötlichen Anflug, die Adern, besonders hinter der Flügelmitte, weiß, begleitet von unbestimmten schwärzlichen Schuppenstreifen. Am Vorderrand hinter der Mitte 4 weiße Punkte. Hinter der Flügelmitte eine schräge Querreihe schwarzer Punkte auf den Adern, weiter saumwärts eine Parallelreihe keilförmiger schwarzer Zwischenflecke. Längs des Saumes kleine halbkreisförmige schwarze Zwischenflecke. Saumschuppen von der Flügelgrundfarbe, innen eine dunkle Saumlinie bildend. Hinterflügel hell gelblich graubraun mit dunkel graubraunem Außenrand und schwärzlicher Saumlinie. Saumschuppen hell. Unterseite der Vorderflügel dunkel graubraun mit unscharfem Discocellularfleck, an der Spitze und am Außenrand weißlichgrau, Adern

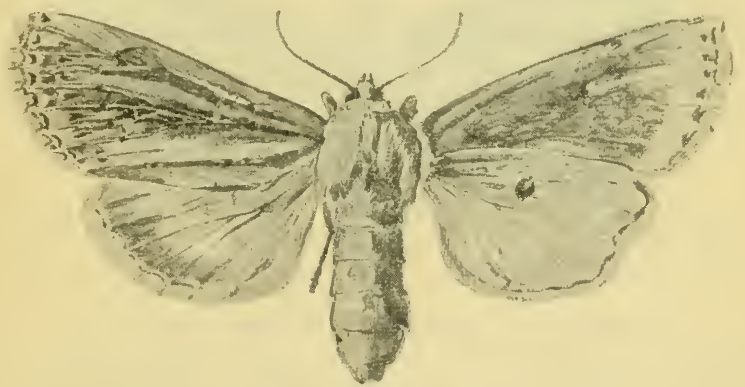

Fig. 190. Nonagria typhae Thunb. Vergr. 11/2.

hinter der Mitte weißlich. Hinterflügel hell, nur am Vorder-und Außenrand dunkler, mit scharfem schwärzlichen Discocellularfleck: beide Flügel mit halbkreisförmigen schwärzlichen Saumflecken und hellen Saumschuppen. Flügelspannung 43-53 mm. August-September, stellenweise häufig.

Raupe: Kopf, Nacken- und Afterschild dunkelbraun. Körper glänzend, schmutzig fleischfarben mit 3 dorsalen hellen Längsstreifen und schwarzen Stigmen. Unterseite schmutzig weiß. Länge bis $70 \mathrm{~mm}$. Herbst-Anfang August im Stengel des hreitblättrigen Rohrkolbens (Typha latifolia L.), vorzugsweise in Pflanzen, die im Wasser stehen.

Puppe mit dem Kopf abwärts über der Ausflugsöffnung, langgestreckt, walzig, hellbraun, mit kurzem stumpfen Kopffortsatz und 8 hakenförmig gekrümmten Borsten an dem abgerundeten Hinterende.

Nonagria typhae ab. fraterna $\mathrm{Tr}$.

Oberseite der Vorderflügel einfarbig dunkel rotbraun oder schwarzbraun mit sehr stark oder ganz reduzierter Zeichnung. Raupe blaugrün mit gelblichem Kopf. 
Nonagria sparganii Esp. (Fig. 191).

Fühler hellbraun, oben weißlich. Kopf, Thorax und Beine rötlich oder gelblichbraun, Hinterleib hell graubraun. Vorderflügel schlank mit steilem Außenrand und ziemlich scharfer Spitze, Oberseite beim ơ rötlich gelbbraun, beim $q$ mehr graubraun mit zerstreuten sch wärzlichen Schuppen, die längs der vorderen und hinteren Mittelader und der von ihnen ausgehenden Adern sich oft stärker anhäufen, so daß diese Partien schwärzlich erscheinen und in der Zelle und über der Ader 2 eine breite hellere Längsstrieme bleibt. Beim $q$ an der Wurzel der Adern 3-5 ein ziemlich scharfer schwarzer Fleck. Hinter der Mitte eine stark einwärts gebogene, oft recht undeutliche Querreihe schwarzer Punkte auf den Adern, am Saum eine Reihe schwarzer Zwischenflecke. Saumschuppen wie die Flügelgrundfarbe. Hinterflügel etwas heller als die Vorderflügel, ohne Zeichnung, mit unscharfen, dunklen Saumfleckchen. Unterseite in der Grundfärbung wie die Oberseite, Vorderflügel auf

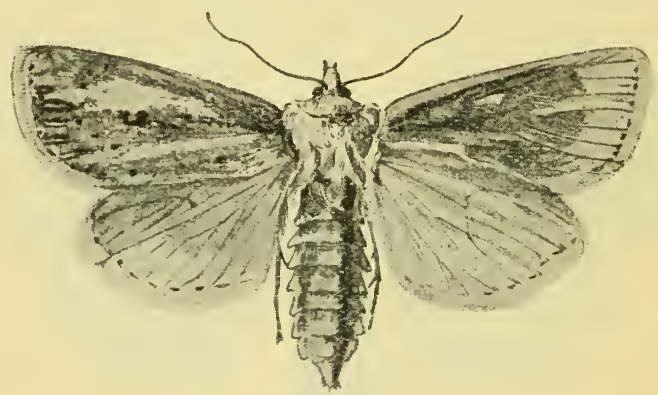

Fig. 191. Nonagria sparganii Esp. Vergr. 12/3.

der Mitte mehr oder weniger ausgedehnt schwärzlich, Innenrand des Hinterflügels blaß bräunlichgelb. Beide Flügel mit schwärz-

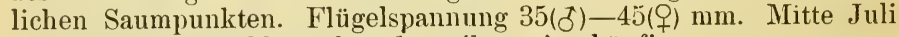
-September, Norddeutschland, stellenweise häufig.

Raupe: Kopf gelblichbraun, Nacken- und Afterschild glänzend grïn. Körper glänzend lichtgrün mit 4 dorsalen dunkleren Längslinien und schwarzbraunen Stigmen, Länge bis $60 \mathrm{~mm}$. HerbstJuli, im breitblättrigen Rohrkolben (Typha latifolia L.), auch in Igelkolben (Sparganium) und Rohr (Phragmites), bevorzugt Pflanzen, die nicht unmittelbar im Wasser stehen. Verwandlung in einer oben und unten zugesponnenen Hölllung.

Puppe aufrecht im Stengel unter der Ausflugsöffnung, rotbraun, schlank, walzig mit kurzem Kopffortsatz.

\section{Coenobia Steph.}

Verwandt mit Nonagria, aber wesentlich kleiner, mit schlankem zarten Körper. Augen nackt. Stirnplatte vorn zugespitzt. Fühler kurz und gleichmäßig gewimpert. Taster nicht aufgebogen, etwas hängend. Beine anliegend beschuppt. Geäder wie bei Nonagria.

Eine deutsche Art. 


\section{Coenobia rufa $\mathrm{Hew}$.}

Fühler gelblichbraun. Kopf und Thorax hell graubraun, Hinterleib lang und schlank, hell gelblichgrün, glänzend. Vorderflügel ziemlich schlank mit gerundeter Spitze, Oberseite glänzend graubraun, heller oder dunkler, mit rötlichem, leicht kupferfarbigem Anflug; hinter der Nitte eine schräge Querreihe feiner schwärzlicher Punkte auf den Adern, die Adern von den Punkten bis zum Saum etwas dunkler als der Flügelgrund. Hinterflügel hell gelblichgrau, glänzend, am Außenrand etwas dunkler mit schwärzlicher Saumlinie. Unterseite graubraun mit schmaler schwärzlicher Saumlinie, Hinterflügel an der Basis heller, mit unscharfem dunklen Discocellularfleck. Flügelspannung $21-23 \mathrm{~mm}$. Norddeutschland, Pommern, Sachsen, fliegt im Juli zwischen Rohr. Selten.

Raupe: sehr ähnlich der von Nonagria dissoluta var. arundineta, aber bedeutend kleiner. Kopf, Nacken und Afterschild glänzend braın. Körper weißlich mit zart rötlichem Rücken und 2 Reihen sehr feiner dorsaler schwarzer Warzenpunkte, je 4 auf jedem Segment und einer feinen schwärzlichen Seitenlinie. Herbst - Juni, in den Stengeln von Binsen ( $\mathrm{J}$ uncus lampocarpus Ehrh.).

$\mathrm{Puppe}$ aufrecht im Stengel, langgestreckt, hellbraun, mit kurzem Kopffortsatz und 2 Borsten am Hinterende.

Calamia Hb. (Fig. 192.)

Augen nackt. Stirn ohne Fortsatz, mit dichter abstehender Behaarung. Fühler des $\delta$ bei lutosa lang und pinselartig, bei phragmitidis kurz und gleichmäßig gewimpert. Taster aufgebogen, bis zur Stirn reichend, mit kurz zylindrischem Endglied. Thorax glatt behaart mit ziemlich undeutlichem vorderen Haar-

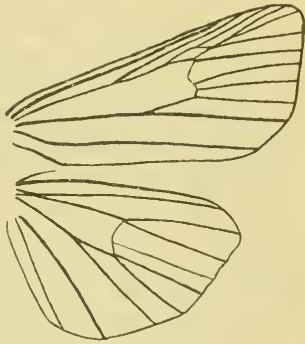

Fig. 192. Calamia phragmitidis $\mathrm{Hb}$. Geäder. schopf. Spitze der Vorderflügel etwas vorgezogen, ziemlich scharf.

Raupen lang, walzig, mit großem kugeligen Kopf und feinen, dunklen, borstentragenden Wärzchen, in Rohr. Puppen mit hakenförmigen Borsten an dem algerundeten Hinterende.

2 deutsche Arten.

Artenübersicht.

\section{Imagines.}

Vorderflügel lang und schmal, hellbraun oder rötlich graubraun mit einer Querreihe schwarzer Punkte, größere Art von $45-50 \mathrm{~mm}$ Spannweite.

C. Iutosa. Vorderflügel kurz und breit, hell oder dunkler graubraun ohne Zeichnung, kleinere Art von 30-35 mm Spannweite.

C. phragmitidis.

Raupen.

Fleischfarben mit braunem Kopf, in Rohrwurzeln. Weißlich mit schwarzem Kopf, in Rohrstengeln.

Süßwasserfauna von Deutschland. Heft 8.

C. lutosat. C. phragmitidis. 


\section{Calamia lutosa $\mathrm{Hb}$.}

Fühler hellbraun oder grau. Kopf und Thorax hellbraun, rötlich graubraun oder hell bräunlichgrau, Hinterleib ähnlich, aber immer etwas heller. Vorderflügel lang und schmal, Oberseite stets von der Farbe des Thorax, mit gleichfarbigen Saumschuppen, zerstreuten schwarzen Schuppen und schmaler heller Saumlinie; hinter der Mitte eine stark gebogene Querreihe schwarzer Aderpunkte, welche sich bei hellgefärbten Stücken auf den Hinterflügel fortsetzen kann. Hinterflügel heller als der Torderflügel, gelblich graubraun oder grau. Unterseite gefärbt wie die Oberseite, mit undeutlichen schwärzlichen Saumpunkten zwischen den Adern, heller Saumlinie und zerstreuten schwärzlichen Schuppen, die gewöhnlich auf der Mitte der Vorderflügel stärker angehäuft sind und hier einen deutlichen Discocellularfleck bilden. Flügelspannung 45 bis $50 \mathrm{~mm}$. August-Oktoler in Rohrbeständen oder auch entfernt von solchen, am Rand von Gehölzen; selten.

Eier klein, kugelig, weißlichgelb, in Gelegen von 5-30 Stück unter den umgeschlagenen Rändern der Teichrohrblätter, mit einer gelatineartigen Schicht überzogen.

Raupe: Kopf braun, Nacken und Afterschild bräunlichgelb, durch eine helle Mittellinie geteilt. Körper bräunlich fleischfarben mit 4 sehr feinen schwarzen Warzenpunkten auf jedem Segment und einer schwärzlichen, an den Einschnitten unterbrochenen dorsalen Mittellängsstrieme auf den Hinterleibssegmenten, die auf jedem Segment von einer gleichfarbigen Querlinie gekreuzt wird. Stigmen weiß mit schwarzer Umrandung. Länge bis $60 \mathrm{~mm}$. April-Juli in den Wurzeln des Rohres (Phragmites) in außerhalb des Wassers stehenden Pflanzen, oft bis über $1 \mathrm{~m}$ tief in der Erde, bringt die befallenen Pflanzen zum Absterben. Verpuppung in der Erde dicht unter der Oberfläche oder in herumliegenden Rohrstücken in einem leichten Gespinst oder ohme solches.

Puppe gelbbraun, am stumpfen Hinterende mit 2 längeren und zwei kürzeren hakenartig gekrümmten Borsten.

\section{Calamia phragmitidis $\mathrm{Hb}$.}

Fühler und Taster gelblichbraun. Kopf und Thorax weißlich graugelb. Hinterleib und Beine etwas dunkler, graubraun. Vorderflügel kurz und breit, mit abgeschrägten Außenrand, Oberseite ganz hell bis dunkel graubraun, am Außenrand stets am dunkelsten, Saumschuppen braun oder rotbraun; ganz ohne Zeichnung, an der Basis zuweilen mit grünlichem Anflng oder die Adern schwach weißlich. Hinterflügel wie die Vorderflügel, mit helleren Saumschuppen. Unterseite wie oben, mit schmaler dunkler Saumlinie, Vorderflügel auf der Nitte dınkler. Flügelspannung $30-35 \mathrm{~mm}$. Juli, zerstreut und selten.

Raupe: Kopf und Afterschild glänzend schwarz, Nackenschild braun mit breiten schwarzen Seitenrändern. Körper schmutzig weiß mit einem großen, unbestimmten, bramvioletten seitlichen Fleck auf jedem Segment, mit schwärzlicher, an den Einschnitten unterbrochener dorsaler Mittellängsstrieme und 4 feinen schwarzen Warzenpunkten auf jedem Segment. Stigmen schwarz. Länge bis $40 \mathrm{~mm}$. Mai an sumpfigen Stellen in den jungen Stengeln des Rohrs (Phragmites), zunächst in der Wurzel unter der Wasser- 
oberfläche, zuweilen mehrere Fub tief im Wasser, später oben im Stengel, ist sehr gefräßig und wächst sehr schnell. Die befallenen Pflanzen kenntlich an ihren verwelkten Spitzen und an einer Öffnung in dem bewohnten Internodium. Verpuppung an der Erdoberfläche oder in Rohrstoppeln.

Puppenruhe 4 Wochen. Ausschlïpfen nur in den späten Abendstunden oder nachts.

\section{Tapinostola Led.}

Kleine Arten mit schlankem zarten Körper und langen Vorderflügeln, den Nonagrien ähnlich. Augen nackt. Stirn ohne Fortsatz, abstehend behaart. Fühler beim ot kurz und dicht gewimpert. Taster vorgestreckt, ganz schwach aufgebogen, unten lang abstehend behaart, mit zylindrischem Endglied. Vorderflügel mit geradem Vorderrand und scharfer, spitzwinkliger Spitze. Geäder wie bèi Calamia. Schenkel und Schienen mit langen äußeren Haarfahnen.

Raupen spindelförmig, an den Wurzeln von Gräsern.

6 deutsche Arten, davon 2 am Wasser.

\section{Artenübersicht.}

\section{Imagines.}

Vorderflügel ohne Zeichnung, Unterseite gelblich. T. Hellmanni. Vorderflügel mit einer Querreihe schwarzer Punkte, Unterseite rötlich.

T. fulva.

\section{Raupen.}

Gelblichweiß mit rötlichem Rücken, in Schilf, Verpuppung in der Erde.

T. Hellmanni.

Gelblichweiß mit 2 rötlichen Rückenstreifen, in Glyceria und Carex, Verpuppung in der Futterpflanze.

T. fulva.

\section{Tapinostola Hellmanni Eversm.}

Fühler hellbraun, oben weißlich. Kopf, Thorax und Hinterleib hell graubraun oder der Hinterleil) etwas heller, mehr gelblichgrau. Oberseite der Vorderflügel hell graubraun mit rötlichem Anflug oder durch schwärzliche Schuppen schmutzig braun erscheinend, ohne Zeichnung, mit gleichfarbigen Saumschuppen und schmaler dunkler Saumlinie. Hinterflïgel etwas heller. Unterseite graubraun oder mehr gelblich, ungezeichnet oder mit ganz undeutlicher mittlerer Bogenlinie. Flügelspannung $25 \mathrm{~mm}$. Juli-August, Norddeutschland, selten.

E i kugelig, glänzend weiß.

Raupe: Kopf glänzend hellbraun, vorn mit einem seitlichen schwarzen Fleckchen; Nacken- und Afterschild bräunlichgelb, weniger glänzend. Körper schmutzig gelblichweiß mit schwach rötlichem Rücken und hellerer Unterseite, Stigmen schwarz. Länge bis $30 \mathrm{~mm}$. August-Ende Juni an sumpfigen Stellen in Schilf (Calamagrostis epigeios Roth) im unteren Teil des Stengels, von außen bemerkbar durch das gelbe Herzblatt. Verpuppung in der Erde in einem leichten Gespinst.

Puppe blaßgelblich. Puppenruhe 3-4 Wochen. 
T. Hellm. ab. saturata Stgr.

Oberseite der Vorderflügel ganz dunkelbraun.

Tapinostola fulva $\mathrm{Hb}$.

Fühler hellbraun. Kopf und Thorax hell rötlich graubraun, Hinterleib heller, mehr graugelb. Oberseite der Vorderflügel gelblichrot oder hell rötlich graubraun mit gleichfarbigen Saumschuppen und einer meist sehr undeutlichen schrägen Querreihe feiner schwarzer Aderpunkte hinter der Mitte. Hinterflügel hell graubraun. Unterseite in beiden Flügelpaaren hell rötlich graubraun, auf der Mitte der Vorderflügel dunkler. Flügelspannung $25 \mathrm{~mm}$. August-September, Norddentschland.

Raupe kurz, in der Nitte am breitesten, hart und steif. Kopf braun, mit hellen Fleckchen und weißer Gabelzeichmung. Nackenschild gelb mit braunem Vorderrand und einer mittleren und 2 seitlichen Vertiefungen. Afterschild glänzend gelb oder braun, hinten in 2 braune oder schwarze Zähnchen auslaufend. Körper schmutzig gelblichweiß mit 2 unscharfen, verschwommenen rötlichen Rückenstreifen und 4 sehr feinen schwärzlichen, borstentragenden Warzenpunkten auf jedem Segment, zwischen denselben einzelne Gruppen von sehr kurzen parallelen Längsstreifen. Stigmen schwarz, in einer unterbrochenen schwärzlichen Linie. Länge bis $30 \mathrm{~mm}$. Herbst Juni. In Sumpfgräsern [Wasserschwaden (Glyceria aquatica Wahlenb.), Sumpfsegge (Carex acutiformis Ehrh.)] dicht über der Wurzel, Verpuppung im oberen Teil des Stengels nahe bei den abgestorbenen Herzblättern zwischen lose zusammengesponnenen zernagten Pflanzenteilen.

Puppe gelbrot, mit vorragendem Kopf, Hinterende abgerundet, mit Dornen.

\section{T. fulv. ab concolor $\mathrm{Tutt}$.}

Einfarbig hell gelblichgrau. Norddeutschland.

\section{Senta Steph. (Fig. 193).}

Augen nackt. Stirn gewölbt, mit glatter anliegender Beschuppung. Fühler sehr kurz und gleichmäßig dicht gewimpert. Taster sanft aufgebogen, bis zur Stirn reichend, mit anliegender Beschuppung und ziemlich langem Endglied. Thorax glatt behaart, mit schwachem vorderen Haarschopf. Vorderflügel langgestreckt, mit gleichmäßig gebogenem Vorder- und Hinterrand und scharfer rechtwinkliger Spitze. Ader 3 und 4 im Hinterflïgel aus dem unteren Zellenende, 6 und 7 kurz gestielt.

Raupen schlank, dorsoventral etwas abgeplattet, dünn und zerstreut behaart, mit feinen Wärzchen. In Teichrohr.

Fig. 193. Senta maritima Tausch. mit feinen Wärzchen.
Geäder.

Senta maritima Tausch.

Fühler hellbraun, oben weißlich. Kopf, Thorax und Beine graubraun, Hinterleib heller, gelblichgrau, schlank. Vorderflügel 
schlank, mit scharfer Spitze, Außenrand zunächst senkrecht, an der Ader 3 nach innen umbiegend; Oberseite graubraun, zwischen den beiden Mitteladern und am Außenrand mehr gelblichbraun. Ringund Nierenfleck durch einige weiße Fleckchen, welche einen unvollkommenen Ring bilden, angedeutet. Hinter der Mitte eine schräge Querreihe feiner schwarzer Punkte auf den Adern, Außenrand mit schwarzen Saumpunkten. Saumschuppen graubraun. Hinterflügel weißgrau mit feiner dunkler Saumlinie. Unterseite der Vorderflügel hell oder dunkler graubraun, der Hinterflügel weißlich mit dunklerem Vorder- und Außenrand, in beiden Flügelpaaren mit scharfem schwärzlichen Discocellularfleck und dunkler Bogenlinie, welche sich im Hinterflügel in schwärzliche Punkte auflöst, sowie dunklen Saumpunkten. Flïgelspannung 30-35 mm. Juni-Juli, zwischen Rolır. Stark variabel.

Raupe: Kopf oben etwas eingeschnitten, glänzend schwarzbraun, Nackenschild kurz, halhkreisförmig, glänzend braun. Körper graugelblich mit rötlichem oder bläulichem Anflug. Auf dem Rücken eine feine weißliche, an den Einschnitten unterbrochene Mittellängslinie, begleitet von 2 feinen weißlichen Nebenlinien, auf der Seite ein feiner weißlicher, darunter ein schwärzlicher Seitenstreif. Körper bedeckt mit zerstreuten, feinen, schwarzen Warzenpunkten und feinen hellen Härchen. Stigmen schwarz. Länge bis $40 \mathrm{~mm}$. Spätsommer - Mai in Rohr (Phragmites), tagsüber in Rohrstoppeln verborgen, führt eine nächtliche Lebensweise und lebt räuberisch von anderen im Rohr vorkommenden Insekten, selbst von Raupen und Puppen. Verpuppung in zugesponnenen Rohrstoppeln in einem leichten Gespinst.

Puppe schlank und dünn, hellbraun mit gelblicher Unterseite, Hinterende stumpf mit 2 längeren und 4 kürzeren Borsten.

S. mar. ab. hipunctata Hew. (Fig. 194).

Im Vorderflügel an Stelle des Ring- und Nierenfleckes 2 scharfe, runde, schwarze Flecke, welche auch auf der Unterseite sichtbar

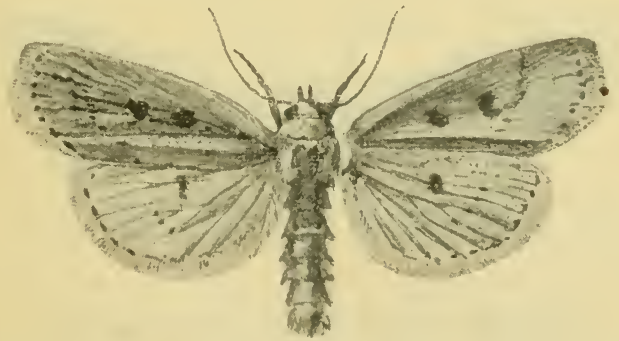

Fig. 194. Senta maritima Tausch. ab. bipunctata Hew. Vergr. 12/s.

sind; an der Basis ein kurzer, schwacher Längsstrich, hinter der Punktreihe ein schwarzer Wisch. Saumpunkte scharf, schwarz. Discocellularfleck im Hinterflügel auch auf der Oberseite. 
S. mar. ab. wismariensis $\mathrm{Schmidt}$.

Vorderflügel mit schwarzer, außen verbreiterter Mittellängsstrieme, in der die beiden schwarzen, schmal weiß umrandeten Flecke liegen.

\section{S. mar. ab. nigricostata Stgr.}

Vorderflügel mit breitem schwarzen Vorderrand. Pommern.

S. mar. ab. nigrostriata Stgr.

Vorderflügel mit zahlreichen, schmalen, schwarzen Längsstrichen.

\section{Meliana $\mathrm{Curt.}$}

Verwandt mit Senta. Augen behaart. Endglied der Taster sehr kurz, stummelförmig. Thorax ohne Haarschopf. Hinterleib beim o mit breitem Afterbüschel, beim o spitz. Vorderflügel mit scharfer vorgezogener Spitze und abgeschrägtem Außenrand. Geäder wie bei Senta.

Raupe gestreckt, walzig, an Vorder- und Hinterende etwas verjüngt, in Rohr. Puppe schlank, walzig, mit 4 Dornen am abgerundeten Hinterende.

Nur eine Art.

Meliana flammea Curt (Fig. 195).

Fühler hellbraun. Kopf, Thorax und Beine rötlich graubraun, Hinterleib heller, grau. Oberseite der Vorderflügel von der Farbe des Thorax, einfarbig, auf der Mitte etwas dunkler, hinter der Mitte mit einer dem Außenrand parallelen Querreihe feiner schwarzer Punkte auf den Adern und mit schwarzen Sammpunkten; die beiden Punktreihen zuweilen ganz verloschen. Adern längs des Vorderrandes und hinter der Punktreihe weißlich. Saumschuppen wie die Flügelgrundfärbung. Hinterflügel hell grauhraun mit etwas helleren Saumschuppen. Unterseite in beiden Flügeln wie die Grundfärbung der Oberseite, ohne Zeichnung, nur mit kleinen schwärzlichen Saumpunkten. Flïgelspannung $35 \mathrm{~mm}$. Mitte Mai-Anfang Juni, in Rohrbeständen, selten. ơ fliegt nur an warmen dunklen Abenden.

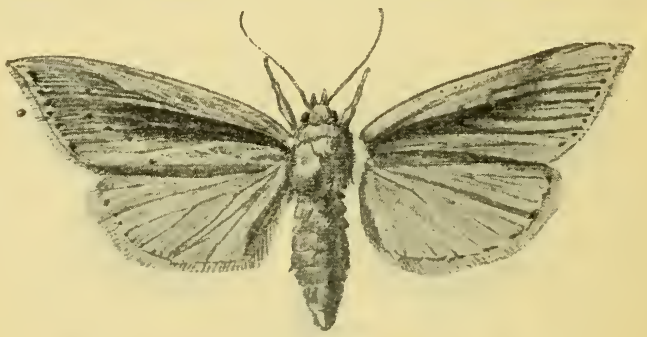

Fig. 195. Meliana flammea Curt. Vergr. $13 / 4$.

Raupe: Kopf bräunlichgelb, Nacken- und Afterschild hellbraun. Körper gelblich mit zerstreuten feinen schwarzen Warzenpunkten und 3 weißlichen Rückenlinien, die mittlere undeutlich und dunkel gesäumt, die seitlichen an den Einschnitten unterbrochen. Stigmen schwarz umrandet, in einer hellen Seitenstrieme. 
Länge bis $40 \mathrm{~mm}$. Sommer - Herbst in Rohr (Phragmites). Verpuppung im September oder Oktober zwischen 2 dünnen gesponnenen Scheidewänden.

Puppe schwarzbraun, im Winter in Rohrstoppeln.

- Leucania Ochsh. (Fig. 196).

Augen behaart. Fühler borstenförmig, beim ot mit gleichmäßiger sehr kurzer Wimperung und jederseits einer kurzen feinen Borste am Ende jedes Gliedes. Taster wie bei Meliana. Rüssel kräftig. Thorax mit glatter anliegender $\mathrm{Be}-$ haarung, bei manchen Arten hinter dem Halskragen mit einem kleinen aufgerichteten Haarschopf. Hinterleib schmal kegelförmig, beim $\delta$ abgestumpft, beim $q$ spitz. Vorderflügel gegen die Spitze verbreitert, Spitze rechtwinklig oder nur wenig vorgezogen, Saum ganzrandig. Saum der Hinterflügel an der Ader 5 etwas eingebuchtet; Ader 3 und 4 ans dem unteren, 6 und 7 aus dem oberen

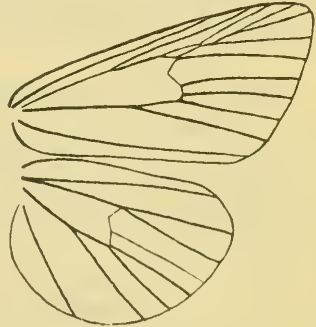

Fig. 196. Leucania. Geäder. Zellenende.

Raupen spindelförmig mit kleinem Kopf, nackt, schmutzig gelb oder weißlich mit helleren und dunkleren Längsstreifen und schwarzen Warzenpunkten. Tagsüler versteckt, die am Wasser lebenden Arten gern in Rohrstückchen und Rohrstoppeln verborgen, an Rohr, Schilf und Sumpfgräsern.

Puppen schlank, mit Borsten oder Dornen am Hinterende. Zahlreiche deutsche Arten, davon 6 am Wasser oder auf Sumpfboden.

\section{Arten übersicht.}

\section{Imagines.}

1. Vorderflügel mit schwarzem Wurzelstrich und schwarzen Längsstrichen zwischen den Adern hinter der Mitte. 2. Vorderflügel ohne scharfe schwarze Striche. 3.

2. Vorderflügel mit scharfem, $\boldsymbol{-}$-förmigem weißen Fleck auf der Mitte, Wurzelstrich kurz.

L. 1 album.

Vorderflügel ohne solchen Fleck, Wurzelstrich lang.

L. comma.

3. Vorderflügel mit einzelnen schwarzen Punkten oder einer Punktreihe.

Vorderflügel ohne schwarze Punkte, auf der ganzen Fläche zwischen den Adern mit zerstreuten schwarzen Schuppen bedeckt.

L. impudens.

4. Vorderflügel mit 3 einzelnen schwarzen Punkten am unteren Zellenende und auf der Nitte der Ader 2 und 5.

5 .

Vorderflügel mit einer schrägen Bogenreihe schwarzer Punkte.

5. Unterseite bräunlich, Discocellularflecke undeutlich.

I. obsoleta.

Unterseite weiß, Discocellularflecke scharf, schwarz.

L. impura.

I. straminea 


\section{Raupen.}

1. Auf der Rückenmitte mit einer oder mehreren dunklen Längsstriemen, mit weißlichen Längslinien oder ohne solche. 2.

Rückenmitte hell, mit 3 weißlichen Längslinien, die seitlichen außen von einer schwärzlichen Linie begleitet, an Rohr und Seggen.

2. Nur eine mittlere dunkle Längsstrieme.

3 schwarze Längsstriemen, die mittlere durch eine weiße Längslinie geteilt.

L. impudens.

3.

Vit einer oder mehreren weißlichen dorsalen Längslinien Hellgrau mit dunkler Rückenstrieme, ohne helle Längslinien, an Rohr.

L. obsoleta.

4. Mit einer weißlichen Mittellängslinie in der dunklen Rückenstrieme, an Rohr und Seggen.

L. impura.

Mit 5 weißlichen Längslinien, die mittlere in der dunklen Strieme, an Rohr.

5. Rötlichbraun mit braunem Kopf, an Gräsern.

Hell gelblichbraun mit grünlichgrauem Kopf, an Gräsern.

L. straminea.

L. comma.

L. I album.

\section{Leucania 1 album (L.) (Fig. 197.)}

Fühler schwärzlich graubraun. Körper hell graubraun, Halskragen mit 2 schwärzlichen Querbinden, Schulterdecken mit einzelnen schwarzen Schuppen. Vorderflügel oberseits gelblichgrau mit dunkel graubraunen, von der Wurzel bis zur Spitze reichenden,

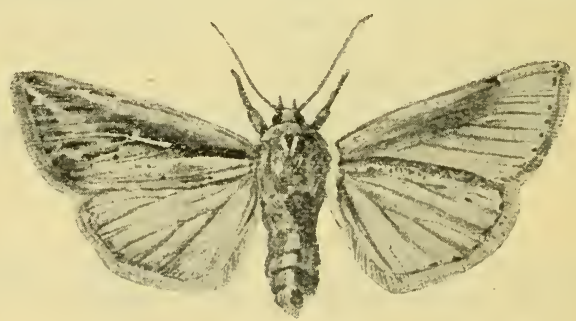

Fig. 197. Leucania l album (L.). Vergr. 12/3.

auf der Mitte verbreiterten Mittellängsschatten und ebenso gefärbtem Saum. Nahe der Wurzel am Hinterrand des Mittelschattens ein schwarzer Längsstrich. Zwischen den Adern 2 und 3 längs der hinteren Mittelader ein scharfer weißer Strich, welcher am Zellenende rechtwinklig nach oben umbiegt und so die Form eines $\lrcorner$ annimmt. Adern hinter der Flügelmitte weiß, besonders deutlich 3 und 4. Außenrand mit heller Saumlinie und schwarzen Saumpunkten zwischen den Adern. Hinterflügel von der Grundfarbe der Vorderflügel, an der Wurzel heller, Saum und Adern dunkel graubraun. Unterseite der Vorderflügel glänzend gelblichgrün mit schwarzen Saumpunkten und schwach angedeuteter, am Vorderrand mit einem schärferen schwärzlichen Fleck beginnender Bogenlinie. Hinterflügel glänzend hellgrau mit zerstreuten dunkelbraunen Adern am Vorderrand und Saum und schwarzen Saumpunkten. An der Stelle der Bogenlinie undeutliche schwärzliche Punkte auf den Adern. Flügelspannung $35 \mathrm{~mm}$. Mai-Juni und Ende August-Oktober, nicht selten. 
Raupe (Fig. 178): Kopf glänzend grünlichgrau. Körper hell gelblichbraun mit 3 dorsalen schwärzlichen Längsstriemen, die mittlere durch eine weißliche Linie geteilt, die seitlichen oben hell gesäumt; zwischen den Längsstriemen jederseits eine Reihe schwarzer, einzeln auf den Segmenten stehender Warzenpunkte. Über den schwarzen Stigmen 2 schwärzlichgraue Seitenstreifen, unter denselben auf jedem Segment einige schwarze Punkte. Länge bis $40 \mathrm{~mm}$. Auf nassen Wiesen an Gräsern. 2 Generationen, HerbstFrühjahr und Juni-Juli. Verpuppung in einem leichten, mit Erde und Pflanzenteilen verwebten Gespinst.

Puppe kurz und dick, hellbraun mit hellen Einschnitten.

\section{Leucania comma (L.).}

Fühler bräunlich, oben hellgrau. Körper hell graubraun, Kopf meist etwas dunkler, Halskragen mit schwärzlicher Querbinde. Unterseite des Hinterleibs rötlichbraun. Oberseite der Vorderflügel hell graubraun mit dunkleren Längsschatten zwischen den Adern. Vorderrand und Adern weißlich, besonders scharf die hintere Mittelader; hinter derselben ein scharfer schwarzer Längsstrich von der Wurzel bis zum Zellenende, ferner hinter der Mitte zwischen den Adern melır oder weniger deutliche schwarze Längsstriche. Vor dem unteren Zellenende ein scharfer schwarzer Punkt. Außenrand und Saumschuppen am dunkelsten, meist etwas rötlich; zwischen den Adern schwarze Saumpunkte, die schwarzen Längsstreifen zuweilen bis $\mathrm{zu}$ diesen verlängert. Hinterflügel heller oder dunkler graubraun mit heller Wurzel und hellen Saumschuppen. Unterseite rötlich graubraun, heller oder dunkler, Hinterflügel am Innenrand grau mit dunkleren Adern. Flügelspannung $35-40 \mathrm{~mm}$. Ende Nai_Juli und Ende August - Oktober.

Raupe: Kopf braun mit schwärzlichen Striemen; Nackenschild schwarz mit 3 weißen Linien, von denen sich die mittlere als feine Längslinie über den ganzen Rücken fortsetzt. Körper heller oder dunkler rötlichbraur mit zerstreuten schwarzen Punkten, 3 dorsalen schwarzen Längslinien, die mittlere durch die weiße Mittellinie geteilt. Seiten heller, Stigmen schwarz, in einer schwärzlichen Längsstrieme. Unterseite gelblicligrau. Länge bis $50 \mathrm{~mm}$. Auf nassen Wiesen an Gräsern, besonders Schwingelgras (Festuca). Verpuppung an der Erde in einem leichten, mit Erde und Graswurzeln verwebten Gespinst. 2 Generationen.

Puppe wie bei Leuc. $l$ album.

\section{Lencania impudens $\mathrm{Hb}$.}

Fühler hellbraun, oben weißlich grau. Kopf und Thorax hell graubraun mit rötlichem Anflug. Hinterleib oben heller, mehr grau, Unterseite und Beine dunkler. Oberseite des Vorderflügels hell rötlich graubraun mit weißlichen Adern und über die ganze Fläche zwischen den Adern zerstreuten schwarzen Schuppen. Zwischen den Adern ferner unbestimmte dunkle Längsstreifen, welche gegen den Saum breiter und deutlicher werden. Hinterflügel dunkel graubraun mit helleren, rötlichen Saumschuppen. Unterseite hell rötlich, wie die Oberseite des Yorderflügels mit schwarzen Schuppen bestreut; Vorderflügel auf der Mitte breit verdunkelt. Hinterflügel 
zuweilen mit undeutlichem Discocellularfleck. Flügelspannung 35-40 mm. Juni-Juli. Mehr in Süddeutschland, besonders in den Alpen.

Raupe: Kopf gelbbraun mit schwärzlichen Punkten und 2 ebensolchen nach hinten divergierenden Striemen; Nackenschild glänzend braun mit 3 weißlichen Linien. Körper gelblichweiß mit 3 dorsalen weißen Längslinien, die mittlere zwischen 2 Reihen zu je 1 Paar auf jedem Segment stehender schwarzer Warzenpunkte, die äußeren auf der Innenseite von einer schwarzen Längslinie begleitet. Seitlich 3 weitere feine weißliche Längslinien. Stigmen schwarz, in einer grauen Längslinie. Länge bis $50 \mathrm{~mm}$. Herbst - Mai, an sumpfigen Stellen in Rohr (Phragmites) und Seggen (Carex). Verpuppung an der Erdoberfläche.

Puppe hell rotbraun, schlank.

\section{Leucania obsoleta $\mathrm{Hb}$.}

Fühler braun, oben hellgrau. Kopf und Thorax gelblich graubraun, Hinterleib etwas heller, mehr grau. Oberseite der Vorderflügel von der Farbe des Thorax, mit weißlichen Adern und gelblichen feinen dunklen Längslinien wie bei $L$. impura. Hinter der Mitte eine vom Vorderrand zur Mitte des Hinterrandes ziehende schräge Bogenreihe schwarzer Aderpunkte. Außenrand mit feinen schwarzen Saumpunkten. Hinterflügel weißgrau mit ebensolchen Saumschuppen, Adern und Außenrand dunkelbraun, am Saum einige schwärzliche Punkte. Unterseite im Vorder- und Hinterflïgel weißlichgran, am Vorderrand mehr gelblich mit zerstreuten schwärzlichen Schuppen, mit deutlichem dunklen Discocellularfleck und schwarzen Saumpunkten; Vorderflügel auf der Nitte verdunkelt. Flügelspannung $34-40 \mathrm{~mm}$. Ende Mai-Juli.

Raupe: Kopf, Nacken- und Afterschild graubraun. Körper in der Jugend grün, erwachsen hellgrau mit dunklerer Rückenlängslinie. Stigmen schwarz. Länge bis $50 \mathrm{~mm}$. Herbst-Anfang Mai, an Teichen und sumpfigen Stellen, an Rohr (Phragmites), tagsiiber in Rohrstoppeln oder abgebrochenen hohlen Stïcken. Spinnt sich am unteren Ende von Rohrstengeln oder in Stoppeln ein und überwintert daselbst von September bis Mai in einem Gespinst. Verpuppung Anfang Mai.

Puppe braun mit 4 feinen Borsten und 2 Dornen am Hinterende.

\section{Lencania impura $\mathrm{Hb}$.}

Fühler hellbraun, oben weißlich. Körper gelblich oder bräunlich grau, Kopf und Thorax etwas dunkler. Oberseite der Vorderflügel hell gelblichgrau mit weißlichen Adern und zahlreichen feinen, helleren oder dunkleren braunen Längslinien. Vor dem unteren Zellenende sowie auf der Mitte der Adern 2 und 5 je ein scharfer schwarzer Punkt. Am Innenrand einzelne schwarze Schuppen. Außenrand mit feinen schwarzen Saumpunkten. Hinterflügel graubraun mit hellerer Basis und weißlichen Saumschuppen. Unterseite der Vorderflügel gelblichgrau, die Mitte schwärzlich und oft mit deutlichem rötlichen Anflug, Außenrand mit schwarzen Saumpunkten. Hinterflügel hellgrau, glänzend, mit zerstreuten schwärzlichen Schuppen am Vorder- und Außenrand und mit schwarzen 
Saumpunkten; zuweilen die Discocellularader verdunkelt und die Bogenlinie durch dunkle Flecke auf den Adern markiert. Flügelspannung 30-35 mm. Ende Mai-Juni und Juli-August.

Raupe: Kopf hellbraun mit schwärzlichen Längsstrichen und dunkelbraunem Hinterrand. Körper schmutzig gelblich mit breiter dunklerer Rückenstrieme; in derselben eine weißliche Mittellängslinie zwischen 2 Reihen schwarzer Warzenpunkte, je 4 auf jedem Segment. Stigmen schwarz, in einer graubraunen Längsstrieme. Länge bis $50 \mathrm{~mm}$. Am Wasser, an Rohr (Phragmites) und Seggen (Carex). Verpuppung in der Erde. '2 Generationen.

Puppe schlank, hell rotbraun mit 2 Dornen am Hinterende.

\section{Leucania straminea $\mathrm{Tr}$.}

Fühler hellbraun, oben weißlichgrau. Körper hell gelblich graubraun, Hinterleib an der Basis weißlich. Halskragen mit 2 feinen bramen Querbinden. Oberseite der Vorderflügel gelblichgrau mit weißlichen Adern und zahlreichen hell graubraunen Längslinien, hinter der hinteren Mittelader mit einem ebensolchen breiteren Längsschatten. Vor dem unteren Zellenende sowie auf der Mitte der Ader 2 und 5 je ein zuweilen undentlicher schwarzer Punkt. Außenrand mit feinen scharfen schwarzen Saumpunkten. Hinterflügel weiß mit leichtem bräunlichen Anflug und einigen unscharfen schwärzlichen Saumpunkten. An der Stelle der Bogenlinie einige schwärzliche Aderpunkte. Unterseite weiß, im Vorderflügel und am Vorderrand des Hinterflügels leicht gelblich mit zerstreuten schwärzlichen Schuppen; beide Flügel mit scharfem schwärzlichen DiscoceHularfleck und scharfen schwarzen Saumpunkten. Flügelspannung 35-40 mm. Juli.

Raupe: Kopf hellbraun. Körper in der Jugend lederfarbig mit bläulichgraıer Rückenlängslinie, erwachsen matt strohfarben mit feinen schwärzlichen Punkten besät, mit 5 weißen Längslinien, die mittlere in einer breiten dunklen Rückenstrieme. Stigmen schwarz. Unterseite bläulichgrau. Länge bis $50 \mathrm{~mm}$. Herbst Ende Mai oder Juni an Rohr (Phragmites), tagsüber in Rohrstoppeln, überwintert halberwachsen.

Puppe langgestreckt, braun, $\delta$ am abgerundeten Hinterende mit 4 längeren, $Q$ mit 4 kurzen Dornen. Puppenruhe 4 Wochen.

\section{Erastriinae.}

Kleinere Arten mit glatter anliegender Beschuppung und kleinen Haarschöpfen auf dê̂ Hinterleib. Augen nackt. Fühler gewimpert und beborstet. Taster leicht aufgebogen, anliegend beschuppt. Schienen ungedornt. Vorderflügel breit, dreieckig, mit ziemlich scharfer Spitze.

Raupen 14 füßig.

\section{Erastria Ochsh. (Fig. 198).}

Ziemlich kleine Arten mit schlankem Körper und breiten dreieckigen Vorderflügeln. Augen nackt. Fühler beim $\delta$ kurz und dicht gewimpert mit einer längeren Borste jederseits an jedem Segment. Taster mäßig aufgebogen, anliegend beschuppt nit kurzem 
cylindrischen Endglied. Stirn, Thorax und Hinterleib breit und anliegend beschuppt, hinterer Schopf am Thorax vorhanden. Zelle

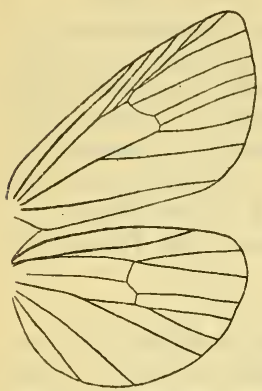

Fig. 198. Erastria uncula Clerck. Geäder. im Vorderflügel mit dem hinteren Ende weiter nach außen reichend als mit dem vorderen, Anhangszelle klein. Ader $8 \mathrm{im}$ Hinterflügel an dar Basis eine kurze Strecke mit der vorderen Mittelader verschmolzen. Raupen 14 füßig, die Füße des 7. Segmentes verkümmert, dünn und schlank, nackt. An Gräsern und niederen Pflanzen.

6 deutsche Arten, davon 2 am Wasser.

\section{Artenübersicht.}

Vorderflügel dunkel olivenbraun mit 2 scharfen weißen Querbinden.

Er. argentula.

Vorderflïgel schwarzbraun mit breiter heller Vorderrandbinde und gebogenem zapfenförmigen Mittelfleck.

Er. uncula.

Erastria argentula Hb. (Fig. 199).

Fühler dunkelbraun, oben graugelb. Kopf und Thorax mit graugelb und dunkel olivenfarben gemischter Beschuppung, Halskragen mit weißem Saum, Schulterdecken und Thorax am Hinterende ebenfalls weiß. Beine graubraun. Beschuppung des Hinterleibs grau und olivenfarben vermischt. Oberseite der Vorderflügel

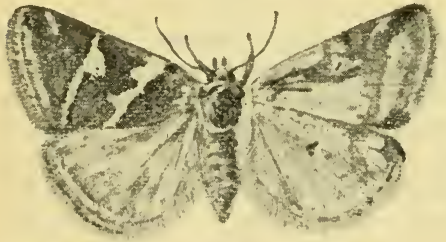

Fig. 199. Erastria argentula Hb. Verg!: 2. dunkel olivenbraun mit 2 vom Vorderrand bis zum Innenrand schräg nach außen ziehenden weißen, undeutlich schwarz gesäunten Querbinden, die innere am Vorder- und Hinterrand der Zelle mit je einem zapfenartigen Vorsprung, die änßere in der Gegend des Nierenfleckes mit einer bauchigen Vorwölbung. Vor der Spitze ein kleiner weißer Strich, vor dem Saum eine gerade weiße Strieme. Saumschuppen weiß und dunkelbraun gemischt. Hinterflügel graubraun mit hellerer Basis. Saumschuppen grau mit dunkelbrauner Linie längs des Saumes. Unterseite graubraun mit gelblichem Grundton, im Vorderflügel die Zeichnung der Oberseite schwach angedentet, Hinterflïgel mit dentlichem schwarzbraunen Discocellularfleck. Flügelspannung $20-23 \mathrm{~mm}$. Mai Juni, zerstreut und nicht häufig.

Raupe: Kopf bräınlichgrün. Körper lebhaft grün mit dunkler dorsaler Mittellängslinie, seitlich eine weiße und unter dieser eine gelbe Längslinie, in welcher die roten Stigmen stehen. Länge bis $30 \mathrm{~mm}$. August und September auf sumpfigen Wiesen an Cyperaceen (Cyperus und Carex), Verpuppung an der Erde oder zwischen Grashalmen in einem leichten Gespinst.

Puppe klein, kolbig, hellbraun. 
Erastria uncula Clerck (Fig. 200).

Fühler, Kopf und Thorax dunkelbraun, Beine und Hinterleib graubraun. Vorderflügel oben mit einer breiten, von der Basis bis zur Spitze reichenden gelblich grauen, vorn mehr bräunlichen Vorderrandbinde, an welche auf der Flïgelmitte ein großer, schräg nach außen gerichteter zapfenförmiger, gebogener weißer Fleck mit dunklerem Kern anschließt. Basalwärts von diesem am Hinterrand der hellen Binde ebenfalls ein gegen die Binde verschwimmender weißer Fleck. Der Saumteil wird von einer innen weißen, außen graubraunen Binde eingenommen. Saumlinie schwarzbraun, Saum-

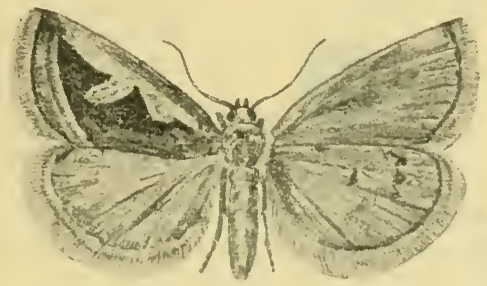

Fig. 200. Erastria uncula Clerck. Vergr. 2.

schuppen graubraun. Flügelmitte tief dunkel schwarzbraun, gegen den Hinterrand heller. Hinterflügel dunkel graubraun mit helleren Saumschuppen. Unterseite dunkel granbraun mit gelblich grauem Grundton. Saumlinie schwarzbraun, Hinterflügel etwas heller als die Vorderflügel, mit dunklem Discocellularfleck und dunkler Bogenlinie. Flügelspannung 20-23 mm. Mai-Juni, häufig an sumpfigen Stellen.

Raupe gleicht der von Er. argentula. Stigmen rotbraun, in der gelben Seitenlinie. Länge bis $30 \mathrm{~mm}$. Juni-Juli, an Riedgräsern (Carex und Cyperus). Verpuppung an der Erde in einem mit Erde und Pflanzenteilen vermischten Gespinst.

Puppe kurz, dick, braungrün.

\section{Plusiinae.}

Augen von einem Kŕranz langer Wimperhaare umgeben. Fühler gewimpert. Taster steil aufgebogen, dicht beschuppt, zuweilen verlängert. Körper kräftig, dicht und lang behaart, mit sehr breitem hinteren Haarschopf am Thorax und geschopftem Hinterleib. Schienen ungedornt. Vorderflügel breit, mit scharfer Spitze, meist mit lebhaft metallglänzenden Flecken.

Raupen 12 füßig.

\section{Plusia (Fig. 201 u. 202).}

Mittelgroße, kräftig gebaute Arten mit dreieckigen, meist lehhaft mit silber- oder goldglänzenden Flecken gezeichneten Vorderflügeln. Augen nackt, von einem Kranz langer dünner Wimperhaare umgeben. Stirn mit abstehender, zu einzelnen dichten Büscheln geordneter Behaarung. Fühler kurz gewimpert. Taster steil aufgebogen, bis zum Scheitel reichend oder stark verlängert, dicht abstehend 
beschuppt. Endglied verschieden geformt. Thorax mit stark entwickeltem hinteren Haarschopf, Hinterleil ebenfalls geschopft. Vorderflïgel breit mit scharfer Spitze, Anhangszelle klein, Ader 8 und 9 langgestielt, 9 in die Spitze. Ader 8 im Hinterflügel die vordere

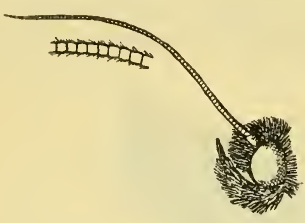

Fig. 201.

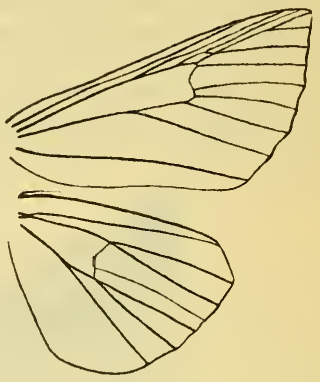

Fig. 202.

Fig. 201 u. 202. Plusia festucae Hb. Kopf und Geäder.

Mittelader nur ganz kurz berührend; Ader 3 und 4 aus dem unteren, 6 und 7 aus dem oberen Zellenende.

Raupen 12 füßig, mit verjüngtem Vorder- und verdicktem Hinterende, meist an niederen Pflanzen. Zahlreiche deutsche Arten, davon eine am Wasser.

\section{Plusia festucae Hb. (Fig. 203).}

Fühler hellbraun. Stirn gelb beschuppt, auf der Mitte hellrot untermischt. Taster, Thorax und Beine braunrot, Hinterleib oben graugelb, unten braunrot. Oberseite der Vorderflügel von lebhaft rötlich goldbrauner Grundfarbe; an der Basis ein schwach goldglänzender leicht braun überdeckter Vorderrandfleck, welcher bis

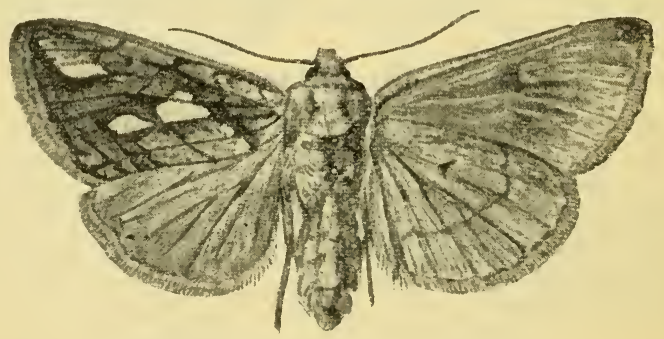

Fig. 203. Plusia festucae Hb. Vergr. ca. 2.

$\mathrm{zu}$ einer subbasalen, dicht hinter dem Vorderrand nach innen umbiegenden dunkelhraunen Querlinie reicht. Auf der Flügelmitte über der Ader 1 b 2 scharfe silber- oder schwach goldglänzende Tropfenflecke, der äußere kleiner. Hinter diesen beiden Flecken ist die Grundfarbe ebenfalls silberglänzend, aber außer dem inneren Rand mit Braun überdeckt. Ein ähnlicher, etwas größerer Silber- 
fleck vor der Spitze, gegen diese allmählich verstreichend, innen von einer dunklen schrägen Querlinie begrenzt. Hinter den weißen Flecken eine mehr oder weniger deutliche dunkle Wellenlinie, dicht vor dem Saum eine dunkle Querlinie. Saumschuppen rötlich braun. Hinterflügel dunkel graubraun mit hellerer Basis und rötlichen Saumschuppen. Unterseite lebhaft rotbraun oder mehr graubraun, Vorderflügel auf der Mitte schwärzlich, Hinterflügel an der Basis heller, mit dunklem Discocellularfleck und dunkler Bogenlinie, welche im Vorderflïgel nur am Vorderrand deutlich ist. Flügelspannung 33-38 mm. Juli und September, verbreitet, nicht selten.

Raupe: Kopf bräunlichgrau. Körper lebhaft grïn mit dunkelgrüner weiß eingefaßter dorsaler Mittellängslinie, einer schmalen gelben Querbinde am Vorderrande jedes Segments und mehreren feinen seitlichen gelben Längslinien. Über den Füßen eine weiße, oben dunkelgrün gesäumte Längsstrieme. Länge bis $50 \mathrm{~mm}$. Herbst - Nai oder Anfang Juni und Juli-August, stets auf nassem, sumpfigem Boden an Ried- und Schwingelgras (Carex und Festuca), Wasserschwaden (Gly ceria aquatica Wahlenb. und fluitans L.), Rohr (Phragmites), breitblättrigem Rohrkolben (Typha latifolia L.), Igelkolben (Sparganium ramosum Huds.). Verpuppung zwischen einem zusammengebogenen Blatt der Nahrungspflanze in einem dünnen hellgrauen Gespinst. Bewegt sich ähnlich wie die Spannerraupen, im Bogen.

Puppe hellgrün oder gelblich mit schwarzbraunem Rücken. Puppenruhe 3 Wochen.

\section{Herminiinae.}

Kileinere, zart gebaute Arten mit stark verlängerten Tastern und Beinen. Augen nackt. Fühler beim đ̛ häufig lang gefiedert. Taster vorgestreckt oder leicht aufgebogen. Vorderschienen beim ¿ zuweilen mit langem Haarbüschel. Kïorper glatt anliegend beschuppt. Vorderflügel dreieckig oder verlängert, mit scharfer Spitze, 12 oder 11 Adern, mit oder ohne Anhangszelle.

\section{Gattungsübersicht.}

Taster vorgestreckt, alstehend behaart, Vorderflügel mit 12 Adern und kleiner Anhangszelle.

Herminia. Taster leicht aufgebogen, anliegend beschuppt, Vorderflügel mit 11 Adern, ohne Anhangszelle.

Tholomiges.

\section{Herminia (Fig. 204 u. 205).}

Augen nackt. Stirn etwas abstehend behaart. Fühler beim $\delta$ mit langen gewimperten Fiederästen, beim $q$ dicht gewimpert, mit einer längeren Borste an jeder Seite jedes Gliedes. Taster sehr stark verlängert, das 2. Glied besonders lang, vorgestreckt, seitlich stark zusammengedruickt und oberseits lang abstehend behaart, 3. Glied kürzer, spitz, etwas aufgebogen. Thorax und Hinterleib glatt anliegend beschuppt. Vorderschienen des $\delta$ mit langem basalen Haarbüschel. Vorderflügel mit scharfer, leicht vorgezogener Spitze, die Adern 7, $8+9$ und 10 aus dem Ende der sehr kleinen 
Anhangszelle; im Hinterflügel die Adern 3 und 4 sowie 6 und 7 kurz gestielt.

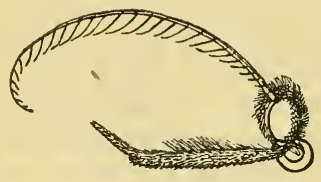

Fig. 204.

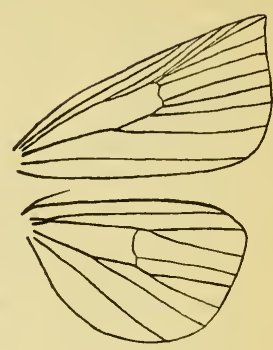

Fig. 205.

Fig. 204 u. 205. Herminia cribrumalis Hb. Kopf $\left(\sigma^{\prime}\right)$ und Geäder.

Raupen 16 füßig, leicht spindelförmig, mit kleinem kugeligen Kopf und zerstreuten feinen borstentragenden Wärzchen. An niederen Pflanzen und Gräsern.

4 deutsche Arten, davon eine am Wasser.

Herminia cribrumalis Hb. (Fig. 206).

- Körper und Flügel gelblichgrau, Vorderflügel oben mit zerstreuten dunkelbraunen Schuppen, einem scharfen schwarzen Punkt vor dem Zellenende und hinter der Mitte 2 Querreihen schwarz-

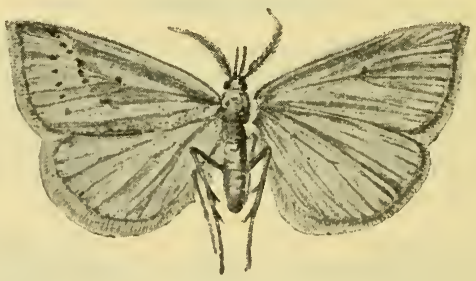

Fig. 206. Herminia cribrumalis $\mathrm{Hb}$. ठ大 Vergr. ca. 2.

brauner Punkte zwischen den Adern, beide Reihen am Vorderrand vor der Spitze beginnend, vorn genähert, hinten divergierend, die innere stark einwärts gebogen, die äußere steil. Hinterflügel wie die Vorderflügel, mit undeutlichem dunklen Discocellularpunkt, sonst ohne Zeichnung. Unterseite etwas dunkler als die Oberseite, dichter mit braunen Schuppen bestreut, in beiden Flügeln mit deutlichem dunklen Discocellularfleck. Flügelspannung $24-28 \mathrm{~mm}$. Juni-Juli in Sumpfgegenden.

Raupe graubraun mit feiner ockergelber Sprenkelung und dunkler, weißlich gesäumter dorsaler Mittellängslinie sowie schwarzen, hell umrandeten Warzenpunkten. Seiten heller, gelblich, Stigmen schwarz. Länge bis $30 \mathrm{~mm}$. Herbst-Mai an sumpfigen Stellen zwischen Rohr an Sumpfgräsern. Verpuppung zwischen lose zusammengesponnenem Moos oder Grashalmen. 
Puppe schwarzbraun mit hellbraunen Einschnitten und zahlreichen Häkchen am Hinterende.

\section{Tholomiges Led. (Fig. 207 u. 208).}

Kleine zart gebaute Art mit schlanken aufgelogenen Tastern und langen schmalen Flügeln. Augen nackt. Stirn sehr breit, glatt anliegend heschuppt. Fühler mit kurzen, am Ende etwas erweiterten

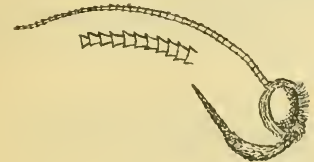

Fig. 207 .

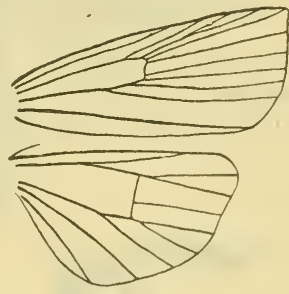

Fig. 208.

Fig. 207 u. 208. Tholomiges turfosalis Wocke. Kopf und Geäder.

Gliedern. Taster verlängert, anliegend beschuppt, sanft aufgebogen, mit dünnem spitzen Endglied. Thorax und Hinterleib glatt anliegend beschuppt. Vorderflügel mit scharfer rechtwinkliger Spitze, olne Anhangszelle, Ader 7 aus dem Zellenende, 8 mit 9 langgestielt, 10 fehlt.

Entwicklung unbekannt.

Eine deutsche Art.

Tholomiges turfosalis Wocke (Fig. 209).

Fühler dunkelbraun; Körper gelblich oder dunkler graubraun. Stirn, Halskragen und Schulterdecken zuweilen hellgrau. Vorderflügel oberseits graubraun oder heller mit gelblichem Grundton, mit schwarzem Discocellularfleck und mehreren zuweilen undeutlichen schwärzlichen Querbinden, die 1. hinter der Basis, die 2. auf der Mitte, hinter dem Discocellularfleck nach außen zum Vorderrand abbiegend oder zu dem Discocellularfleck selbst führend und

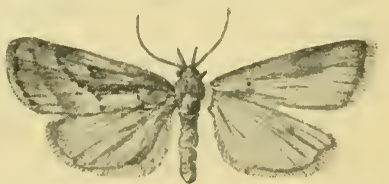

Fig. 209. Tholomiges turfosalis Wocke. Vergr. 21/2. von dem vorderen Teil getrennt; eine 3 . weniger scharfe Binde beginnt an der Spitze und führt schräg einwärts zum Hinterrand. Außenrand mit meist scharfen, getrennten oder zusammenflieRenden Saumflecken. Hinterflügel und Unterseite einfarbig graubraun. Flügelspannung $14-15 \mathrm{~mm}$. Juni, Norddeutschland, Schlesien, in Sumpfgegenden.

\section{Cossidae, Holzbohrer.}

Große oder mittelgroße Arten mit dicht behaartem langgestreckten Körper und kleinem Kopf. Fühler kurz, beim ơ lang gefiedert, Augen nackt, Ocellen fehlen. 'Taster klein, Rüssel fehlt. 
Beine kurz. dicht behaart, Schenkel und Schienen gleich lang. Schienenendsporne klein. Flügel gestreckt, mit gerundeter Spitze, Vorderflügel mit 2, Hinterflügel mit 3 Innenrandadern.

Raupen nackt, mit einzelnen kurzen Borsten, 16 füßig mit Kranzfüßen, mit starken Mandibelı, im Innern von Bäumen und anderen Pflanzen.

Puppen mit dorsalen Dornenquerreihen am Hinterleib.

Phragmatoecia Newm. (Fig. 210 u. 211).

Fühler beim ơ lang, beim of kurz gefiedert, Taster kurz, stummelförmig, hängend. Stirn und Gesicht lang abstehend behaart. Körper mit dichter, etwas zottiger Behaarung, Hinterleih

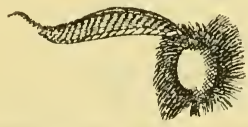

Fig. 210.

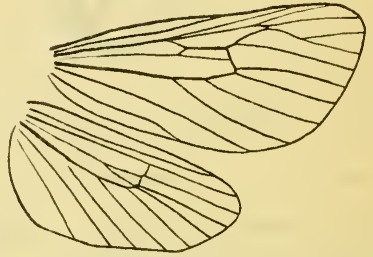

Fig. 211.

Fig. 210 u. 211. Phragmatoecıa castaneae (Hb.) ठั Kopf und Geäder.

beim $\delta$ doppelt, heim $q$ etwa 3 bis 4 mal so lang wie der Thorax. Flügel beim $q$ länger und schlanker als beim $\delta$. Zelle im Vorderflïgel durch 2 miteinander quer verbundene Längsadern geteilt, daher vierteilig. Ader 4 und 5 getrennt aus dem unteren, 7 + 8 und 9 getremnt aus dem oberen Zellenende. Tordere Mittelader des Hinterflügels frei, übrige Adern einzeln und weit getremnt aus der Zelle, nur 4 und 5 stark genähert. Zelle durch eine Gabelader längsgeteilt.

Raupe langgestreckt, dünn, walzig, unter Wasser an der Wurzel des Rohrs.

Puppe langgestreckt, walzig, mit dorsalen Querreihen kleiner, rückwärts gerichteter Dornen.

\section{Phragmatoecia castaneae (Hb.) (Fig. 212).}

Körper und Flügel beim ơ gelblichbraun, beim $q$ bräunlichgrau. Oberseite der Vorderflügel mehr oder weniger dicht mit dunkleren Schuppen bestreut, über der Ader $1 \mathrm{~b}$ eine Längsreihe schwärzlicher Fleckchen. Sammschuppen beim ơ mit schwärzlichen Punkten an den Aderendigungen. Hinterflügel etwas heller als die Vorderflügel. Unterseite ebenfalls etwas heller, ohme Zeichmung. Flïgelsyannung o $35-40 \mathrm{~mm}$, ᄋ $40-50 \mathrm{~mm}$.

Stellenweise, am Rhein, Schlesien, Pommern, selten.

Ei lang oval, fast walzig, glänzend weißlichgrau.

Raupe: Kopf und Nackenschild braun. Körper schmutzig gelblich, mit ¿Q Querreihen dümner schwarzer Borstenhaare auf jedem Segment, Rücken verloschen rotbraun mit weißlıcher Mittellängs- 
linie. Stigmen schwarz. Länge bis $60 \mathrm{~mm}$. Im Stengel des Rohrs (Phragmites) nahe der Wurzel unter Wasser, überwintert daselhst

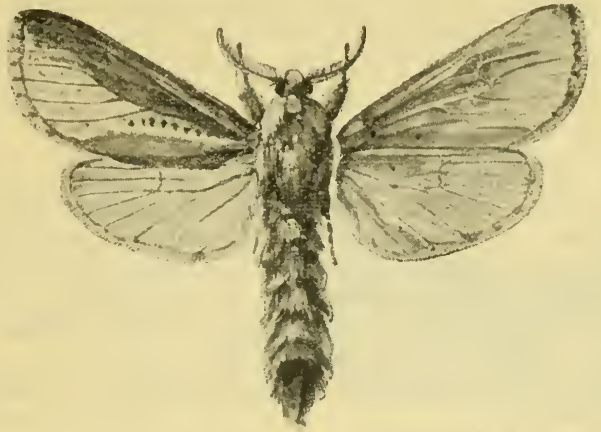

Fig. 212. Phragmatoecia castaneae (Hb.) ठ์.

zweimal und geht dann höher hinauf. Verpuppung im Mai in dem zugesponnenen Schaft in einem weißen, seidenglänzenden Gespinst. P up p dunkelbraun, mit kurzen, etwas helleren Flügelscheiden.

\section{Pyralididae, Zünsler.}

Kleinere oder mittelgroße Arten mit schlankem Körper und langen dünnen Beinen. Augen nackt. Ocellen meist vorhanden. Fühler bortenförmig, bei beiden Geschlechtern meist verschieden, beim đ̊ länger, oder stärker gefiedert als beim ${ }_{+}$, zuweilen gezähnt. Rüssel meist kräftig entwickelt. Labialtaster verschieden, bei einigen Gruppen selı lang. Maxillartaster gewöhnlich gut ausgebildet. Vorderflügel gewöhnlich dreieckig, zuweilen lang und schmal, mit 12 oder 11 Adern; Zelle ungeteilt, Ader 4 und 5 dicht zusammen oder gestielt aus dem hinteren Zellenende, 9 ans 8 oder 7 , selten fehlend. Hinterflügel stets mit Haftborste und 3 Innenrandadern, ohme eingeschobene Zelle, Ader 4 und 5 wie im Vorderflïgel, 8 mit 7 eine Strecke versclımolzen oder dicht daneben verlaufend. behaart.

Raupen schlank, 16 füßig, mit Kranzfüßen, dünn und kurz

Die Pyralididen umfassen in den Nymphulnen (Hydrocampinen) die einzige Lepidopterengruppe, deren Raupen im Wasser leben und teilweise Kíiemenfäden besitzen. Hierher gehört anch Acentropus nivers, der einzige deutsche Schmetterling, dessen $q$ auch als Imago im Wasser leht. Zwei Gattungen der Crambinen und die kleine Gruppe der Schoenobiinen sind nur Anwohner des Wassers.

\section{Übersicht über die am Wasser vorkommenden Unterfamilien.}

1. Labialtaster meist stark verlängert, dick heschuppt und vorgestreckt; Ader $10 \mathrm{im}$ Vorderflügel stets frei.

a) Hintere Mittelader im Vorderflügel oben lang behaart. 
b) Hintere Mittelader im Vorderflügel oben nicht behaart.

Schoenobiinae.

2. Labialtaster nie auffällig verlängert, dünn, etwas anfgebogen, Ader $10 \mathrm{im}$ Vorderflügel mit 8 und 9 gestielt, oder die Taster klein, hängend und Ader $10 \mathrm{im}$ Vorderflügel frei.

Nymphulinae.

\section{Crambinae.}

Arten mit stark verlängerten, dick beschuppten Labialtastern, gut entwickelten pinselförmig behaarten Maxillartastern, gestreckten schmalen, beim $\approx$ und of häufig verschieden geformten Vorderflügeln und sehr breiten Hinterflïgeln mit oben langbehaarter hinterer Mittelader. Ocellen vorhanden oder fehlend. Fühler bei $\delta$ und ㅇ meist einfach. Rüssel klein oder fehlend. Zelle im Hinterflügel offen. Ader 7 mit 8 lang gestielt.

Raupen schlank, dünn behaart, an Gräsern. Verpuppung in einem Kokon.

Am Wasser 2 Gattungen.

\section{Gattungsübersicht.}

Ader 7 im Vorderflügel mit 8 und 9 langgestielt, 11 frei.

Ader 7 im Vorderflügel frei, 11 in die Costalader.

Calamotropha.

Chilo.

Calamotropha Zell. (Fig. 213 u. 214).

Stirn vorstehend, gewölbt, Ocellen fehlen. Fühler geißelförmig, Glieder gegen die Spitze am Ende unbedentend erweitert. Maxillar-

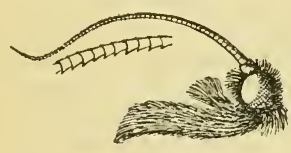

Fig. 213.

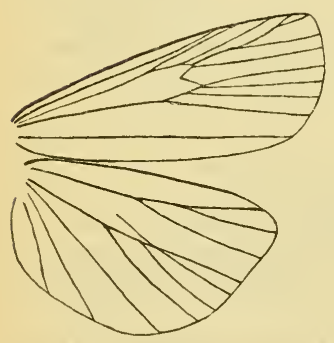

Fig. 214.

Fig. 213 u. 214. Calamotropha paludella (Hb.). Kopf und Geäder.

bildend. Ader 3 und 4 kurz, 7 und 8 ziemlich lang gestielt. dicht beschuppt, am Ende locker und etwas abstehend behaart. Labialtaster pinselartig, bis etwas über die Hälfte der Maxillartaster reichend. Hinterleib lang und schlank, den Analwinkel der Hinterflügel weit überragend. Beine kräftig und gedrungen, Vorderhüften wenig kürzer als die Schenkel, Vorder-, Mittel- und Hinterschienen $=1 / 2,1 / 1$ und $1 \frac{1}{2}$ der Schenkellänge. Sporne der Hinterschienen kräftig, die vorderen knapp hinter der Mitte. Vorderflügel verhältnismäßig breit, mit rechtwinkliger, ziemlich scharfer Spitze. Außenrand zunächst gerade und steil, dann an der Ader 3 nach innen umbiegend. Ader 4 und 5 dicht beieinander aus dem unteren, 6 und $7+8$ +9 gemeinsam aus dem oberen Zellenende, 10 kurz vor dem Zellenende, 11 ziemlich kurz und steil. Hinterflügel etwas kürzer als die Vorderflügel, breit, halbkreisförmig, Vorderrand gerade.

Außen- und Innenrand einen Halbkreis taster von ungefähr dreifacher Kopflänge, Eine deutsche Art. 
Calamotropha paludella Hb. (Fig. 215).

Fühler gelhlichbraun, oben weiß. Taster grauweiß, außen mit zahllreichen bräunlichen Schuppen. Körper gelblichgrau oder weißgrau. Oberseite der Vorderflügel gelblich graubraun, staubfarben, heller oder dunkler, zuweilen fast rein weiß, mit einem schwärzlichen Fleck vor dem Zellenende und 2 meist ziemlich undeutlichen Querreihen schwarzbrauner Punkte, die innere aus 3 oder 4 Punkten bestehend, die einen mit dem Scheitel auswärts gekehrten rechten Winkel bilden und von denen meist nur der in der Zelle liegende Scheitelfleck deutlich ist; die 2. hinter der Mitte, am Vorderrand beginnend, zunächst auswärts gerichtet, dann in scharfem Winkel umbiegend und einwärts zum Hinterrand ziehend. Hinterflügel weiß mit leicht gebräuntem Saum. Unterseite im Vorderflügel

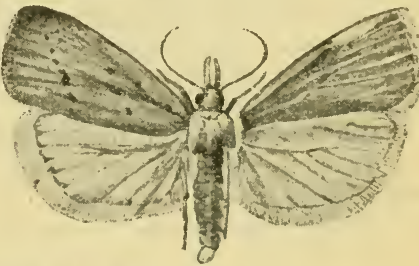

Fig. 215. Calamotropha paludella (Hb.). Vergr. $11 / 2$. graulraun, an der Basis etwas heller, die Adern hinter der Mitte weißlich, im Hinterflügel weiß mit gebräuntem Vorderrand und Saum. Flügelspannung $23-30 \mathrm{~mm}$. Juli-August, Norddeutschland, in Sumpfgegenden.

Raupe weißlich, glänzend, mit durchscheinender Rückenlinie; zn beiden Seiten derselben eine Reihe grauer Flecke, je 2 auf jeder Segmentseite, die vorderen kleiner als die hinteren. Kopf klein, bräunlich mit dunklerer Mundpartie. Neben den schwarzen Stigmen ebenfalls je ein grauer Fleck. Länge bis $25 \mathrm{~mm}$. Mai-Juni oder Anfang Juli in den äußeren breiten Blättern abgestorbener Pflanzen des loreitblättrigen Rohrkolbens (Typha latifolia L.), miniert einen langgestreckten geraden Gang bis zur Wurzel, immer in demselben Blatt, steigt erwachsen wieder aufwärts und verpuppt sich im oberen ausgesponnenen Teil des Ganges nach Anlegung eines bis zur äußersten dünnen Hautschicht der Pflanze geführten horizontalen Ganges, welcher als Ausflugsöffnung dient.

Puppe aufrecht im Fraßgang, lehmgelb.

Chilo Zincken (Fig. 216 u. 217).

Stirn vortretend, gewölbt, mit einem hornigen Vorsprung. Ocellen sehr klein. Fühler beim o* wenig länger als beim $q, 2 / 3$ bis $3 / 4$ der Flügellänge erreichend, kurz gewinpert. Labialtaster sehr lang, vorgestreckt, dicht beschuppt und seitlich zusammengedrïckt. Maxillartaster kurz, pinselförmig. Hinterleib die Hinterflügel beim o wenig, heim 오 ziemlich weit überragend, beim q

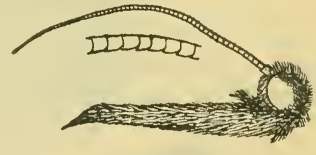

Fig. 216.

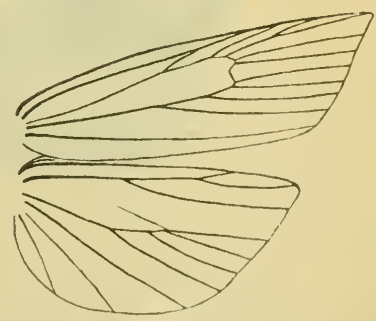

Fig. 217.

Fig. 216 u. 217. Chilo phragmitellus (Hb.), Kopf ( $(\delta)$ und Geäder $(f)$. 
ohne Afterbüschel. Beine lang und kräftig, Vorder-, Mittel- und Hinterschienen $2 / 3,1 / 1$ und $1 \frac{1}{2}$ der Schenkellänge; vordere Sporne der Hinterschienen hinter der Mitte. Vorderflügel beim $\delta^{2} 2_{2}^{1}$, beim o $3 \mathrm{mal}$ so lang wie breit, Spitze beim ơ abgerundet oder etwas vortretend, Außenrand steil und gerundet. Spitze beim of scharf, Außenrand gerade, mehr oder weniger stark abgeschrägt. Hinterflügel wenig kürzer als der Vorderflügel, breit, halbkreisförmig, Außenrand beim or mehr gerundet, beim of mehr gerade. Ader 4 und 5 im Vorderflügel getrennt aus dem unteren, 6 und 7 getrennt aus dem oberen Zellenende, 8 und 9 lang gestielt, 8 in die Spitze, 11 ziemlich steil in die Costalader. Hintere Nittelader im Hinterflügel oben lang behaart, Ader 4 und 5 zusammen aus dem unteren Zellenende, 7 in die Spitze, mit 8 lang gestielt. und dick.

Raupen mit Rückenwarzen, in Sumpfgräsern. Puppe kurz

2 deutsche Arten.

Artenübersicht.

Imagines.

Vorderflügel olıne helle Zeichnung, mit schwarzem Fleck am Zellenende.

Ch. phragmitellus.

Vorderflügel mit weißer Zeichnung, hellem Vorderrand, mindestens aber mit einem weißen Fleck am Zellenende.

Ch. cicatricellus.

Raupen.

Gelblich oder grünlich mit 5 rotbraunen Längsstreifen, in Rohr.

Schmutzig weiß mit rötlichem Rïcken, in Simsen.

Ch. phragmitellus.

Ch. cicatricellus.

Chilo phragmitellus (Hb.) (Fig. 218).

§. Fühler, Taster, Kopf und Thorax hellbraun bis schwarzbraun. Hinterleib hell graubraun. Spitze der Vorderflügel ziemlich scharf, etwas vorgezogen. Oberseite hellbraun bis tief schwarz-

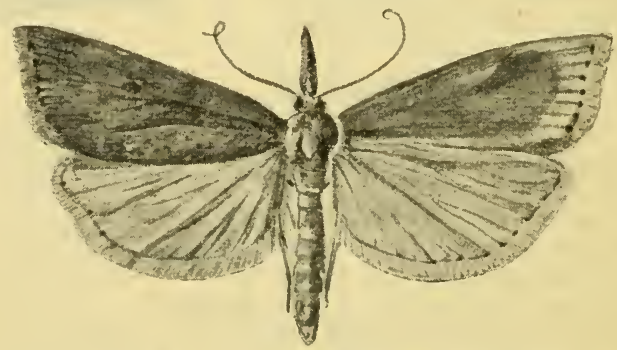

Fig. 218. Chilo phragmitellus ( $\mathrm{Hb}$ b.) o'. Vergr. $1^{2} / 3$.

braun, stets mit der Thoraxfärbung übereinstimmend, mit schwarzem Punkt am oberen Zellenende, hinter der Mitte mit feinen dunklen Längsstriemen zwischen den Adern, welche mit schwarzen Saumpunkten enden. Hinterflügel hell graubraun mit weißlichem Grund- 
ton. Unterseite graubraun mit schwarzen Saumpunkten, im Hinterflïgel heller. Fliigelspannung ca. $30 \mathrm{~mm}$.

o. Kopf und Thorax lebhaft ockerbraun oder fast graugell, bastfarben, Hinterleil, gelblich graubraun. Oberseite der Vorderflügel stets mit der Thoraxfärbung übereinstimmend, mit sehr feinen schwarzen Saumpuukten; der schwarze Fleck am oberen Zellenende zuweilen undeutlich. Hintere Flügelhälfte zuweilen dünn mit schwarzen Schuppen bestreut. Hinterflügel oben und unten weif Unterseite der Vorderflügel gelblichgrau. Flügelspannung $33-38$ m Ende Juli-Ende August, vorwiegend in Norddeutschland.

Raupe schlank, nackt, weißlich gelb oder grünlich mit 5 rotbraumen Längsstreifen. Kopf und Nackenschild gelbbraun. Raupe Herbst-Juni in Rohrstengeln (Phragmites), wächst sehr langsam, frißt die inneren Zellenschichten. Die bewohnten Pflanzen äußerlich nicht verändert. Raupe gewöhnlich ïher dem Wasserspiegel, dringt aber auch bis zur Wrurzel vor. Verpuppt sich in den vorjährigen Pflanzen dicht über dem Wasserspiegel olne Gespinst, nur oben und unten durch eine Gespinstdecke abgeschlossen. Ausflugsöffnung von der äußeren Haut der Pflanze bedeckt.

Prippe aufrecht im Stengel, schlank, braun, mit nasenförmiger Erhöhung am Kopf und stumpfem, mit kurzen Zälınchen bewehrtem Hinterende. Ruht 4 Wochen oder überwintert zum zweitenmal.

Chilo cicatricellus (Hb.) (Fig. 219).

б. Fühler dunkelbraun bis schwarzbraun. Taster, Kopf und Thorax graugelb, grau, graubraun bis schwarzbraun. Hinterleib heller oder dunkler graubraun, Spitze der Vorderflügel abgerundet. Oberseite wie der Thorax varierend zwischen graugelb und tief schwarzbraun, stets mit dem Thorax übereinstimmend. Auch in der Zeichnung etwas variabel. Bei dunklen Stücken ist meist der

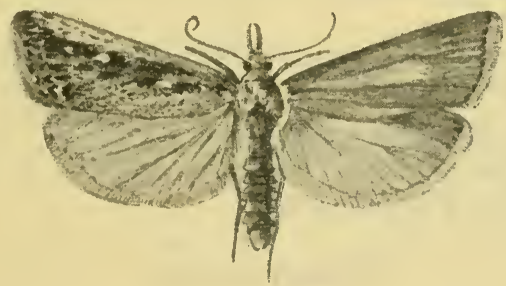

Fig. 219. Chilo cicatricellus (Hb.) o. Vergr. $1 \frac{1}{3}$.

ganze Flïgel mehr oder weniger dicht mit weißlichen sehuppen hestreut. Vielfach ist eine breite helle, ron der Wurzel his zur Spitze reichende Vorderrandbinde vorhanden. Längs der vorderen Mittelader ein gegen die Spitze verbreiterter dunkler Längsschatten, zuweilen sehr scharf, oder auch fast ganz fehlend, in demselhen am Zellenende ein weißer Fleck und ein kleinerer weißer Fleck linter der Mitte. Längs der hinteren Mittelader ebenfalls ein von der Wurzel ausgehender schwarzer Längsstrahl, in welchen ein weißer Fleck eingeschaltet ist. Vor dem Saum eine weiße quere Zackenbinde, gewöhnlich in einzelne Bogen aufgelöst, von welchen kurze weiße Striche gegen den Saum ausstrahlen. Schwarze Saum- 
punkte deutlich. Hinterflügel weiß mit grauem Vorder- und Außenrand. Unterseite graubraun bis schwarzbraun, Wurzel und Innenrand der Hinterflügel weiß. Spitzenhälfte des Vorderrandes im Vorderflügel hell, zwischen den Adern weißliche, bis zum Saum reichende Längsstriche. Flügelspannung 23-26 mm.

ㅇ. Kopf und Thorax gelblichbraun bis dunkel graubraun, Hinterleib graubraun. Oberseite der Vorderflügel hellbraun bis tief schwarzbraun, bei dunklen Stiicken stets etwas dunkler als der Thorax, häufig nit breitem, scharf abgesetztem weißlichen Vorderrand. Die weißen Flecke wie beim J, aber of sehr undeutlich oder ganz fehlend, nur der Fleck am Zellenende stets wenigstens angedentet. Hinterflügel weiß, Vorder- und Außenrand zuweilen leicht gebräunt. Unterseite der Vorderflügel graubraun, Vorderrand gegen die Spitze weißlich, Hinterflïgel weiß. Flügelspannung 30-37 mm. Anfang Juli-Mitte Augnst. Hauptsächlich in Norddeutschland.

Raupe schlank, schmutzig weiß, mit rötlichem Rï̈cken und einer besonders auf den mittleren Segmenten dentlichen durchscheinenden dunkleren, oft blutroten unterbrochenen Rückenlängsstrieme. Kopf gelb mit brauner Winkelzeichnung; Nackenschild gelb, am Hinterrand mit 6 im Halbkreis stehenden schwarzen Punkten; die beiden nächsten Seginente etwas breiter als die übrigen, oben mit mehreren verschieden großen glänzenden Warzen besetzt; auf den folgenden Segmenten je 4 sehr kleine schwarze Rückenpunkte auf ähnlichen, breiten, bräunlich glänzenden Warzenflecken. Afterschild bräunlich gelb. Herbst-Juni oder Anfang Juli, in den untersten Stengelteilen der Seesimse (Scirpus lacuster L.), oft zahlreich in einer Pflanze, die bewolnten Pflanzen Aurch lebhaft gelbe Färbung der oberen Stengelhälfte erkennbar. Verpuppung ohne Gespinst in der etwas erweiterten Stengelröhre, etwa $2 \mathrm{~cm}$ unter der ovalen, mit einer dünnen Haut verschlossenen Ausflugsöffnung.

Puppe braun mit schwärzlichen Flügelscheiden, Kiopf mit Eshnabelförmiger Spitze, Hinterleibssegmente mit je einem Kranz kleiner Dörnchen, welche auf dem letzten Segment am stärksten sind. Hinterende breit und stumpf, hinten mit einem, an den Seiten mit mehreren kleinen Zähnchen. Puppenruhe kaum 8 Tage, die Hülle bleibt im Lager zurïck.

\section{Schoenobiinae.}

Ziemlich große derbe Arten mit langem schlanken Körper, sehr langen Beinen und langgestreckten schmalen, bei $\delta$ und o verschieden geformten Vorderflügeln. Ocellen vorhanden, klein. Fühler beim ơ wesentlich länger als beim $q$ und gewimpert. Labialtaster stark verlängert oder auch kurz. Maxillartaster gut ausgebildet, pinselförmig. Rüssel klein oder fehlend. Zelle der Hinterflügel mehr oder weniger deutlich geschlossen, hintere Mittelader oben nicht behaart, Ader 7 und 8 gestielt.

Raupen schlank, in Rohr und Sumpfgräsern. Puppe schmal und schlank.

3 deutsche Gattungen. 


\section{Gattungsübersicht.}

1. Labialtaster wenig länger als der Kopof, dünn. Labiaitaster stark verlängert, dicht beschmppt.

2. Ader $10 \mathrm{im}$ Vorderflügel frei aus der Zelle. Ader $10 \mathrm{im}$ Vorderflügel mit $8+9$ gestielt.

Scirpopliaga.

2.

Schoenobius.

Donacaula.

\section{Scirpophaga Tr. (Fig. 220 u. 221 ).}

Stirn flach, beim ot etwas schmäler als beim ․ Fühler dïnn, geibelförmig, kurz gewimpert, bein o etwas länger als die Ilälfte des Vorderflïgels, beim $q$ nur lialb so lang wie beim $\sigma^{*}$. I Labialtaster so lang wie der Kopf, gerade vorgestreckt und zugespitzt. Maxillartaster kurz, stummelförmig. o mit dichtem wolligen, abgestutzten Afterbüschel. Beine lang und kräftig, mit verlängerten Hüften; Vorder-, Mittel- und Hinterschienen $=1 / 2,1 / 1$ und $2 / 1$ der Schenkellänge. Sporne der Hinterschienen dick und kräftig, die vorderen hinter der Mitte. Vorderflügel des of $2 \frac{1}{2}$, des $q 3 \mathrm{mal}$ so lang wie breit, Hinterflügel breit, mit stark gerundetem Außen- und Innenrand; Spitze des Vorderflügels gerundet, Außenrand beim $\delta$ ziemlich steil, beim $ᄋ$ mehr abgeschrägt. Zelle im Vorderflügel bis ïber die Mitte reichend, Ader 4 von 3 doppelt so weit getrennt als von 5 ; 6 und 7 ziemlich weit getrennt, 7. $8+9$ und 10 einander genähert, $8+9$ lang gestielt, in die

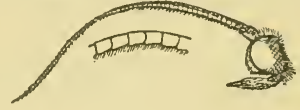

Fig. 220.

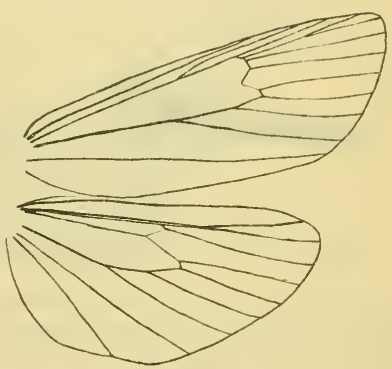

Fig. 221.

Fig. 220 u. 121. Scirpophaga praelata Scop. Kopf und Geäder. Flügelspitze, 10 einzeln aus dem oberen Zellenende, 11 erst ziemlich steil, dann sehr schräg verlanfend. Zelle in Hinterflügel oben bis zur Mitte, unten etwas weiter reichend; Ader 3 in der Mitte zwischen 2 und 4,4 von 3 etwa 3 mal so weit entfernt wie von 5 ; 6 frei aus der Zelle, 7 ebenso, dann eine Strecke dicht an 8.

Eine deutsche Art.

\section{Scirpophaga praelata Scop.}

б kleiner und schlanker als das o. Körper und Flügel glänzend weiß, ohne Zeichnung. Beine ausgedehnt dunkelbramn, Tarsen dunkelbraun mit weißen Gliedspitzen. Vorderflïgel ohen etwas dunkler als die Hinterflïgel, mit grauem oder bräunlichem Anflug. Vorderflügel und Vorderrand der Hinterflügel beim $\sigma$ unten stark gebräunt. Flügelspannung $31\left(\sigma^{\prime}\right)-4 \vec{r}($ q $) \mathrm{mm}$. Juli-August.

Eier an die Futterpflanze (Seesimse, Scirpus lacuster L.) abgelegt, mit der weißen Afterwolle des o l hedeckt.

Raupe lederbraun, nackt, mit hellbraunem Kopf und mit vorstehenden Hinterfüßen, welche auch an der Puppe sichtbar sind. Länge bis $35 \mathrm{~mm}$. Raupe Herbst-Juni in den Stengeln von Scir- 
pus lacuster L. Bohrt sich als junge Raupe in den oberen Teil der Pflanze ein und fribt einen Kanal bis auf die Wurzel, in welche sie aber nicht eindringt; erweitert den Raum über der Wurzel und steigt wieder aufwärts. Verpuppung unter dem Wasserspiegel in einem Gespinst nach Anlegung einer bis auf die äußerste Stengelhaut gehenden Ausflugsöffnung iiber dem Wasser.

Puppe weiß, äußerst dïnnhäntig und ganz durchscheinend.

\section{Schoenobius Dup. (Fig. 222 u. 223).}

Stirn breit, flach gewöllt. Fühler des of fast doppelt so lang wie beim $ᄋ$ und gewimpert. Labialtaster sehr lang und kräftig, vorgestreckt, seitlich zusammengedrückt; Maxillartaster kurz, den ersteren aufliegend, etwa so lang wie der Kopf. Hinterleib langgestreckt, den Analwinkel der Hinterflügel mit mehr als der Hälfte seiner Länge überragend, beim ㅇ mit dichtem wolligen Afterbüschel. Beine wie bei Scirpophaga, Vorder-, Mittel- und Hinterschienen

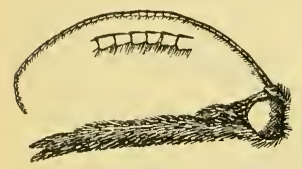

Fig. 222.

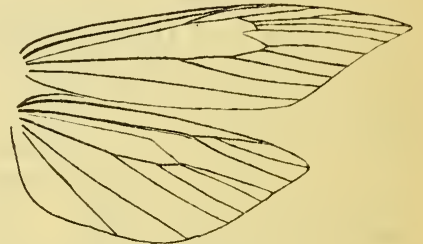

Fig. 223.

Fig. 222 u. 223. Schoenobius forficellus Thunb. Kopf (ठ') und Geäder (ㅇ).

$1 / 2,1 / 1$ und $2 / 1$ der Schenkellänge. Vorderflügel beim of ziemlich breit mit abgerundeter Spitze und steilem geschwungenen Außenrand, beim $Q$ schmäler und länger, mit sehr scharfer vorgezogener Spitze und stark abgeschrägtem, leicht ausgehöhltem Außenrand. Hinterflügel beim of breit, halbkreisförmig, beim o die Spitze ziemlich scharf, der Außenrand mehr abgeschrägt und gerade.

\section{Artenübersicht.}

\section{Imagines.}

\section{¿ Vorderflügel mit zahlreichen schwarzen Flecken.}

\section{Sch. gigantellus}

Vorderflügel mit einer schrägen dunklen Querbinde von der Spitze zum Innenrand.

sich. forficellus.

ㅇ Vorderflügel ockergelb, Spannweite $35-40 \mathrm{~mm}$. Sch. gigantellus.

Vorderflügel heller oder dunkler gelblichbram, Spannweite 30 $-35 \mathrm{~mm}$.

Sch. forficellus.

Raupen.

Lelimgelb, Kopf und Nackenschild gelblichbraun, in Rohr.

sch. gigantellus.

Graugrün, Kopf und Nackenschild schwarz, in Wasserschwaden und Segge.

Sch. forficellus.

Schoenobius gigantellus Schiff (Fig. 224).

o. Fühler schwarzbraun, Taster und Körper graubraun, Hinterleib glänzend. Oberseite der Vorderflügel hell graubraun mit un- 
bestimmtem schwarzbraunen, gegen die Spitze verbreiterten Längsschatten, zerstrenten schwarzbramen Fleckchen und ebensolehen Sammpunkten an den Aderendigungen. Hinterflügel graubraun mit weißlicher Wurzel, schwarzbraunen Saumpunkten und einer unscharfen dunklen (inerbinde hinter der Mitte. Unterseite gratoraun mit schwarzhramen Sammpunkten. Hinterflügel an der Wurzel zuweilen ausgedehnt weißlich. Flügelspannung 25-30 mm.

†. Fühler, Taster und Körper gelblichgrau. Oberseite der Vorderflügel lebhaft ockerfarben mit einem schwärzlichen Punkt am unteren Zellenende und auf Ader 1 und undeutlichen dunklen Sampunkten. Hinterflügel weiß. Unterseite der Vorderflügel hell gelhlichgran, glänzend, der Hinterflügel weiß mit gelblichgranem Vorderrand. Flügelspannung $35-40 \mathrm{~mm}$. Juni-August, hauptsächlich in Norddeutschland, selten.

Raupe lehmgelb mit grauschimmernden Querfalten; wird bei der Zucht olivengrün. Kopf klein und spitz, glänzend gelblichhraun, vorn und hinten dunkler. Nackenschild von der Farbe des Kopfes. Thoraxsegmente verbreitert. Stigmen sehr klein, braun.

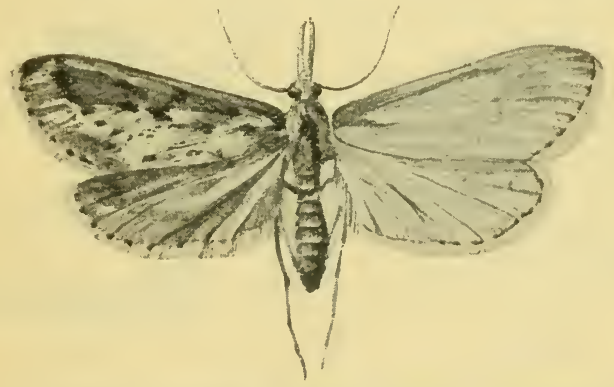

Fig. 224. Sihoenobius gigantellus Schiff. d. Vergr. 2.

Mai-Juni, vereinzelt noch Ende August in den jungen Trieben des Rohrs ('Pragmites commun is Trin.). Die befallenen Pflanzen verwelken und brechen dicht über oder unter dem Wasserspiegel ab. Die Raupe geht durch die Scheidewände bis in die Wurzel, die inneren Zellenschichten abfressend, und häuft ilre Exkremente im oberen Teil des Rohrstumpfes an, verläßt den ausgefressenen Stengel, indem sie das Stück, in welchem sie sich befindet, oben und unten durchbeißt, an beiden Enden zuspinnt und sich darin an eine neue Pflanze treiben läßt; kriecht an dieser ein Stïck hinauf, die Wohmröhre mitziehend, welche sie dann mit einem Ende, oft senkrecht abstehend, festspimnt, worauf sie sich in den frischen Stengel einbohrt; kann zweimal überwintern. Verpuppung in einem röhrenförmigen durchsichtigen Gespinst, welches bis zu der darüber befindlichen, mit einer häutigen Gespinstkappe verschlossenen Ausflugsöffnung geführt wird. Öffnung zuweilen unter dem Wasserspiegel. Die Zucht ist seh" schwierig.

Puppe zylindrisch, glatt, strohgell, mit sehr zarter durehscheinender Hülle. Hinterbeinscheiden bis zum vorletzten Segment reichend. 


\section{Schoenobius forficellus Thunb. (Fig. 225).}

o. Fühler braun, Kopf und Thorax gelblichbraun, Aufenseite der Taster und Beine dunkler. Hinterleib oben gelblich graubraun, unten gran. Oberseite der Vorderflügel variierend zwischen hell gelblichgrau und graubraun, mit einem zuweilen sehr deutlichen, zuweilen ganz fehlenden, von der Wurzel bis zur Spitze reichenden schwarzbraunen Längsschatten und einer schrägen, von der Spitze bis zum Imnenrand ziehenden, unscharfen schwarzbraunen Querbinde. Am unteren Zellenende ein scharfer, auf der Ader 1 zwei weniger scharfe schwarze Flecke; Außenrand mit schwarzen Saumpunkten an den Aderendigungen, Saumschuppen gelblichgrau. Hinterflügel weißlich, Vorderrand und Saum mehr oder weniger ausgedehnt braun, mit schwarzen Saumpunkten und einer umbestimmten dunklen Querbinde hinter der Mitte. Unterseite graubraun mit helleren Saumschuppen und schwarzen Saumpunkten. Die schrägen Querbinden schwach angedeutet. Wurzel der Hinterflügel weißlich. Flügelspannung 22-28 mm. Mitte Juni-A ugust, liäufiger als gigantellus.

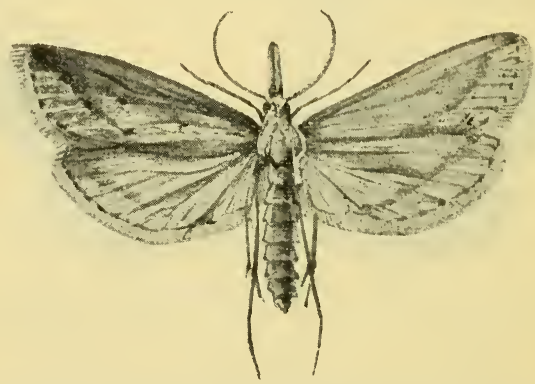

Fig. 225. Schoenobius forficellus Thunb. o'. Vergr. $13 / 4$.

․ Oberseite der Vorderflïgel heller oder dunkler gelblich braun, Längsschatten undeutlich oder fehlend, nur der schwärzliche Punkt am unteren Zellenende deutlich. Hinterflügel weiß mit leichtem gelblichen Anflug. Unterseite der Vorderflügel hell gelblichbraun, der Hinterflügel weißlich. Flïgelspannung $30-35 \mathrm{~mm}$.

Raupe ähnlich der von Sch. gigantellus, auch in der Lebensweise; graugrün, glanzlos, mit dunkelgrüner Rückenlinie und weißlichem Hinterende. Kopf schwarz mit heller Winkelzeichnung, Nackenschild mit schwarzem, durch eine feine weiße Linie geteilten Fleck. Auf dem Afterschild 2 halbkreisförmige, mit der hohlen Seite einander zugekehrte Zeichnungen. Herbst-Mai oder Anfang Juni in Carex-Arten und in Wasserschwaden (Glyceria aquatica Wahlenb.). Wandert wie gigantellus, bei Carex in einem zusammengerollten Blatt, bei Glyceria in einem Stengelstïck, aus dem sie mit dem Vorderende hervorragt. Verpuppung im Stengel der Futterpflanze in einem langen, röhrenartigen, weißen und zähen Gespinst, das bis zu der zugesponnenen Ausflugsöffnung reicht; etwas über der Mitte des Gespinstes eine lederartige Kappe, welche von dem Falter durchbrochen wird. 
Puppe zylindrisch, sehr zart, gelblichweiß oder hellbraun mit dunkler Rückenlinie, braunen Augen, langen Flügelscheiden und bis zum Endsegment reichenden Ilinterbeinscheiden. Die Stigmen bilden stark vortretende hellbrame Wärzchen.

\section{Donacaula Meyr. (Fig. 226 u. 227).}

Nahe verwandt mit Schoenobizis. Fühler des ơ etwas länger als die Hülfte der Vorderflügel, gewimpert. Taster wie bei Schoenobius, ebenso der Flügelschnitt. Ader 4 und $5 \mathrm{im}$ Vorderflügel aus dem unteren, $8+9+10$ aus dem oberen Zellende, 8 in die Spitze, ? und 10 nahe zusammen in den Vorderrand; 11 ziemlich steil, zuweilen mit der Costalader anastomosierend. Im Hinterflügel Ader 4 und 5 aus dem unteren, 6 aus dem oberen Zellenende, 7 mit 8 lang gestielt.

Nur eine deutsche Art.

Donacaula mucronella Schiff.

Fühler, Taster, Kopf und Thorax braun, Hinterleib heller, granbraun. Oberseite der Vorderflügel graubraun mit dunklerem Mittellängsschatten und breitem hellgrauen Vorderrand. Außenrand mit schwärzlichen Saumpunkten an den Aderendigungen.

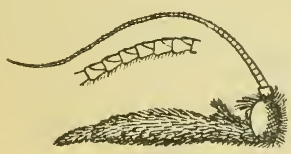

Fig. 226.

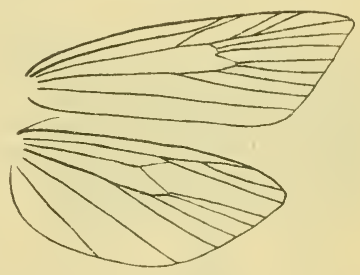

Fig. 227.

Fig. 226 u. 227. Donacaula mucronella Schiff. $\sigma^{\prime}$. Kopf und Geäder.

IIinterflügel heller, Wurzel und Innenrand weißlich, Aufenrand mit feinen schwarzen Saumpunkten. Unterseite graubraun mit schwarzen Saumpunkten, Innenrand der Hinterflïgel weißlich. Flïgelspannung $25 \mathrm{~mm}$.

Raupe braun, mit gelblichem Kopf, in Rohr (Plıragmites) und Segge (Carex), überwintert in der Nährpflanze.

\section{Nymphulinae (Hydrocampinae).}

Mittelgroße, zart gebaute Arten mit schlankem Körper, sehr langen Beinen, besonders stark verlängerten Vorderbeinen und ziemlich breiten, gerundet dreieckigen Vorderflügeln (Acentropus mit kürzeren Beinen und schmalen Vorderflügeln, $q$ ungeflügelt). Ocellen vorhanden oder fehlend. Fühler beim o' nur schwach gewimpert, einfach. oder mit am Ende erweiterten Gliedern. Labialtaster nicht verlängert, vorgestreckt mit leicht aufgehogenem kurzen spitzen Endglied oder hängend. Naxillartaster vorhanden oder fehlend. Rüissel vorhanden. Nittelzelle der Hinterflügel geschlossen, Ader 7 und 8 lang gestielt, hintere Hittelader oben nicht hehaart. 
Raupen in Wasser an Wasserpflanzen, in Gehäusen oder Röhren aus zusammengesponnenen Blattstücken, bei Paraponyx mit langen Kiemenfäden. Verpuppung im Wasser in einem dichten Gespinst.

4 deutsche Gattungen.

\section{Gattungsübersicht.}

I. Labialtaster vorgestreckt oder auch gebogen, Maxillartaster vorhanden; größere, in beiden Geschlechtern geflïgelte Arten.

1. Fühler einfach.

2. Fühlerglieder, besonders beim ơ, am Ende erweitert.

Nymphula.

a) Maxillartaster gut entwickelt, wenig kürzer als die Labialtaster, Ocellen vorhanden.

b) Maxillartaster klein, stummelförmig, Ocellen fehlen.

Cataclysta.

II. Labialtaster hängend, Maxillartaster fehlen; kleine Art, $q$ stummelflügelig.

Acentropus.

\section{Nymphula Schrk. (Hydrocampa Aut.).}

(Fig. 228 u. 229).

Stirn flach und breit, Ocellen deutlich, aber von der dichten Beschuppung verdeckt; Fühler fadenförmig, einfach, beim ơ sehr kurz und dicht gewimpert. Naxillartaster aufwärts gebogen, dünn, 1. und 2. Glied unten lang abstehend, 3. Glied anliegend, beschuppt, Labialtaster etwas kürzer, dünn. Hinterleib lang und schlank, den Analwinkel der Hinterflügel weit überragend, beim o mit terminalem Haarbüschel. Beine lang. Vorderhüften stark verlängert, so lang wie die Schenkel, Vorderschienen $1 / 2$ der Schenkellänge, am Ende verdickt, Vordertarsen länger als Schenkel und Schiene zusammen. Mittelschienen wenig, Hinterschienen heträchtlich länger

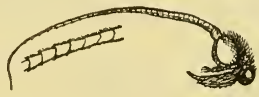

Fig. 228.

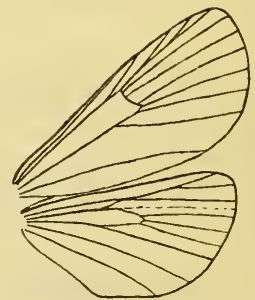

Fig. 229.

Fig. 228 u. 229. Nymphula stagnata Don. Kopf und Geäder.

als die Schenkel. Vorderflügel etwas mehr als doppelt so lang wie breit, mit deutlichem, abgerundetem Vorderwinkel, Außenrand ziemlich steil, leicht geschwungen, Hinterwinkel hreit algerundet. Ader $8+9+10$ aus dem oberen Zellenende. Hinterflügel breit, Vorderund Analwinkel abgerundet, Ader 6 kurz hinter der Zellenmitte entspringend, anastomosiert mit $7+8$.

3 deutsche Arten. 


\section{Artenübersicht.}

Imagines.

1. Flügel mit scharfen dunkelbraunen Binden und breitem zusammenhängenden Saumband.

2. Flügel mit hellerer unscharfer Zeichnung. Saumband aus 2 getrennten Linien gebildet. N. rivulalis.

2. Discocellularfleck im Vorderflügel dunkellraun. N. stagnata. Discocellularfleck im Vorderflügel hellbraun mit dunkler Umrandung.

N. nymplaeata.

Ranpen.

Dunkelgelb bis olivenfarben, nur an Igelkolben.

N. stagnata. Hell olivenbramn mit dunklen Einschnitten und 3 dorsalen dunklen Längslinien, an verschiedenen Wasserpflanzen. N. nymphtaeata.

\section{Nymphula rivulalis Dup. (Fig. 230).}

Weiß, Fühler und Innenseite der Vorderbeine braun. Zeichnung wie bei stagnata, aber weniger scharf und oft nur schwach ansgebildet. Discocellularfleck im Vorderflügel dunkel unrandet, ohne dunklen Kern, die äußere Doppelbinde in beiden Flügeln mit einigen zackenartigen Fortsätzen gegen den Außenrand. Im Hinter-

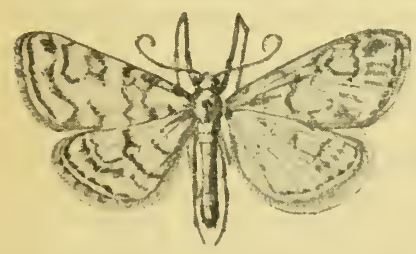

Fig. 230.

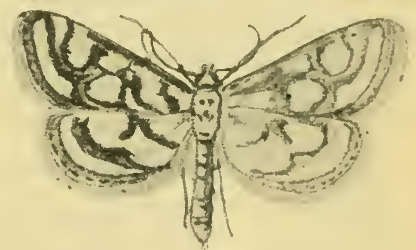

Fig. 231.

Fig. 230. Nymphula rivulalis Dup. Vergr. 2.

Fig. 231. Nymphula stagnata Don. Vergr. ca. 2.

flügel außer der subbasalen und der üußeren Binde eine durchgehende Mittelbinde. Saum mit schmaler brauner Saumlinie, davor eine leichtgezackte dunkelbranne Linie. Zeichnung der Unterseite unscharf. Flügelspannung $17-19 \mathrm{~mm}$. Juni - September, hesonders an hochrandigen Wiesengräben. Nordostdeutschland, nicht häıfig.

Entwicklung unbekannt.

\section{Nymphula stagnata Don. (Fig. 231).}

Weiß, Fühler bräunlich, Taster mit braunem Rücken und brauner Spitze, Beine teilweise braun, Hinterleib mit melur oder weniger deutlichen braunen Rückenflecken. Flügel weiß mit dunkelbranner Zeichnung. Vorderflïgel: Vorderrand his jenseits der Mitte hraun, nahe der Basis eine einfache schräge Querbinde, vor der Mitte eine vom Hinterrand ausgehende Doppelbinde, hinter der Mitte eine zweite, gegen den Vorderrand gegalselte Doppelbinde, der innere Ast mit der ersten Doppelbinde auf der hinteren IIittelader verbunden und über den schwarzlramnen Discocellularfleck laufend. 
Beide Doppelbinden schließen 3 runde weiße Flecke ein. Außenrand mit goldbramem Saumband. Hinterflügel: eine subbasale Querbinde, am Vorderrand mit einem schräg nach anßen gerichteten Anhang. Hinter der Mitte eine wellenförmige Doppellinde. Saumband wie im Vorderflügel. Zeichnung der Unterseite wie oben, aber blaß und unscharf. Flügelspannung 20-22 mm. Juni-Juli. Häufig an stehenden Gewässern, Flußufern, Seen.

Ei er oval, halbdurchsichtig mit gestreifter Oberfläche, Ende Juli zu größeren Gruppen vereinigt an die Unterseite schwimmender Blätter des Igelkolbens (Sparganium simplex Huds. und ramosum Huds.) abgelegt.

Raupe zunächst farblos und durchsichtig mit schwarzem Kopf und Nackenschild, dann graubraun oder olivenfarben, Kopf und Nackenschild hellbraun, vor der Überwinterung wieder durchsichtig. Kopf klein und flach, 3. Thoraxsegment am breitesten. Körper der erwachsenen Raupe dunkelgelb bis olivenfarben mit braun gerandeten Stigmenl. Länge 20-25 mm. Raupe Anfang August bis Oktober minierend in den Blättern des Igelkolbens, daselbst bis Mitte April überwinternd, dann bis Nitte Mai oder Juni in einem aus 2 mit den Rändern zusammengesponmenen Blättern gebildeten Sack dicht unter dem Wasserspiegel, die Blattränder benagend und ausfressend, bei Sparg. ramosum die Blätter skelettierend. Verrät sich durch die schwärzlichen Fraßstellen. Verwandlung in einem langen weißen, mit Blattstücken umhüllten und an einem schwimmenden Blatt festgesponnenen Cocon.

Pu p p e schlank, lebhaft dunkelgelb, Hinterende in einen ventralwärts gebogenen Haken auslaufend.

\section{Nymphula nymphaeata L. (Fig. 232).}

Körper weißlich (q) oder vorwiegend bräunlich (ठ). Flügel weiß, die braune Zeichnung wie hei stagnata, aber ansgedehnter, die Binden breiter. Discocellularfleck hellbraun mit dunkler Um-

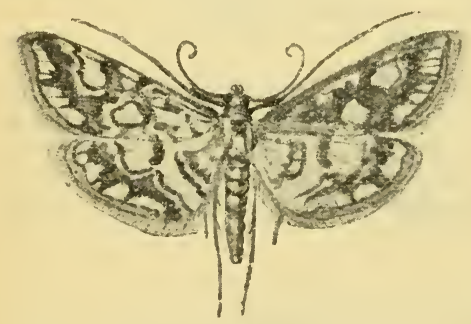

Fig. 232. Nymphula nymphaeata L. Vergr. 2.

Eier kurz oval, flach, dunkelgelb. randung. Die äußere Doppelbinde sendet im Vorder- und Hinterflügel einzelne zackige Fortsätze gegen das goldbraune Saumband. Zeichnung auf der Unterseite nicht heller als oben. Trennung der Doppelbinden weniger scharf. Basale Binde im Hinterflügel ebenfalls doppelt, von dem schrägen Vorderrandfleck deutlich getrennt. Flügelspannung $21-26 \mathrm{~mm}$. Juni-August, mit N. stagnata. Häufig.

Raupe gedrungen, in der Mitte am breitesten, vorn und hinten verjüngt. Köorper glänzend, in der Jugend grün, später auf dem Rücken hell olivenbraun mit dunkleren Einschnitten und 3 dunklen Längslinien, unten heller; Kopf sehr klein, olivenbraun, mit dunkler Mundpartie und dunklem Hinterrand, Nackenschild hell olivenbraun, glänzend, vorn und hinten schmal schwarz gesäumt, nit mittlerem schwarzbraunen, durch eine helle Linie ge- 
teilten Querfleck. Stigmen dunkelbraun gerandet. Länge bis $25 \mathrm{~mm}$, $\Varangle$ größer als $\delta$. Herbst-Mai oder Mitte Juni an der weißen und gelben Wasserrose (Nymphaea alba L., Nuphar luteum L.), Froschbiß (Hydrocharis morsus ranae L.), Laichkraut (Pota= mogeton natans L. und polygonifolius Pourr.), Wasserstern (Callitriche). Wasserlinse (Lemna), Igelkolben (Sparganium). Schneidet aus einem Blatt der Nahrungspflanze ein elliptisches Stück heraus und spinnt es mit dem Rand auf ein anderes Blatt fest, benutzt den innen ausgesponnenen Raum als Wohnung, von hier aus das Blatt benagend. Das aufgesponnene Blattstïck stirbt ab und wird braun, woran die Anwesenheit der Raupe zu erkennen ist. Bietet ein Blatt keine Nahrung mehr, so schneidet sie den Boden des sackförmigen Wohnraums heraus und läßt sich in diesem an eine frische Pflanze treiben, wo sie einen neuen Wohnraum anlegt. Verläßt Anfang November das Wasser mit ihrer Wohnung und spinnt diese an einer Pflanze fest zum Überwintern. Verpuppung ebenfalls über der Wasseroberfläche zwischen 2 zusammengesponnenen Blättern.

Puppe dunkelbraun, Flïgelscheiden und Unterseite lebhaft hellbraun; Hinterende stumpf, warzenförmig, mit einigen kleinen Borsten.

\section{Paraponyx Hb. (Fig. 233).}

Stirn breit, Ocellen sehr klein, von der Beschuppung verdeckt. Fühler fadenförmig, die Gliedenden, besonders beim ठे, verbreitert, die Glieder daher im Umriß dreieckig, der ganze Fühler perlschnurähnlich erscheinend. Labialtaster stärker gebogen als bei Nymphula, Maxillartaster kürzer. Hinterleib wie bei Nymphula. Vorderhüften etwas kürzer als die Schenkel und doppelt so breit, Vorderschienen etwa $2 / 3$ der Schenkellänge, Vordertarsus etwas kürzer als Schenkel und Schiene zu-

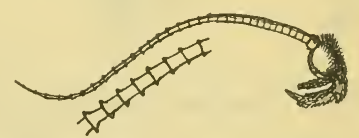

Fig. 233. Paraponyx stratiotata L. Kopf. sammen. Mittel und Hinterhüften kurz. Mittelschienen etwas länger als die Schenkel, Hinterschienen doppelt so lang, die vorderen Sporne auf der Schienenmitte. Flügel länger und schmäler als bei Nymphula, Vorderflügel etwa $2 \frac{1}{2}$ mal länger als breit, Vorderwinkel abgerundet, Außenrand gleichmäßig geschwungen, Hinterflügel mit etwas kürzerem Innenrand und daher schmäler als bei Nymphula, Außenrand mehr abgekürzt. Geäder wesentlich wie kei Nymphula, Gabel der Ader'n 7 und 8 im Vorderflügel kürzer, 4 und 5 im Hinterflügel nicht getrennt. Die Zeichnung besteht aus dem scharfen Discocellularfleck und einer breiten, oft unvollständigen braunen Mittelbinde. 2 deutsche Arten.

Artenübersicht.

Imagines.

Discocellularfleck im Vorderflügel schwarzbraun mit weißem Kern.

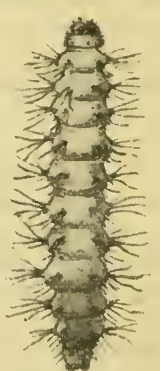

Fig. 234. Paraponyx stratiotata $\mathrm{L}$. Raupe.

Vergr. $1 \frac{1}{2}$. 
Discocellularfleck im Vorderflügel aus 2 getrennten dunkelbraunen Punkten gebildet.

P. nivalis.

Paraponyx stratiotata L. (Fig. 235).

Körper vorwiegend weiß bis vorwiegend hellbräunlich. Saum der Vorderflügel steil. $\delta$. Grundfarbe der Flügel weiß, Vorderflügel mit leichter bräunlichgelber Tönung oder ausgedehnt hellbraun, nit einem undeutlichen subbasalen, meist nur in 2 Flecken angedeuteten, dunkelbraunen Querstrich und einer breiten braunen Querbinde auf der Flügelmitte, innen unscharf, außen scharf begrenzt und stark geschwungen sowie mit einem Streifen der weißen Grundfarbe gesäumt. Discocellularfleck scharf, schwarzbraun mit weißem Kern. Zwischen der Mittelbinde und den Saum eine weitere, viel blassere Binde. Längs des Saumes eine schmale bräunliche Linie, Saumschuppen blaßbräunlich. Hinterflügel weiß, mit einer auf der Flügelmitte unterbrochenen und auf der vorderen Hälfte nach außen verschobenen dunkelbraunen Querbinde; längs des Saumes eine schmale braune Linie, Saum-

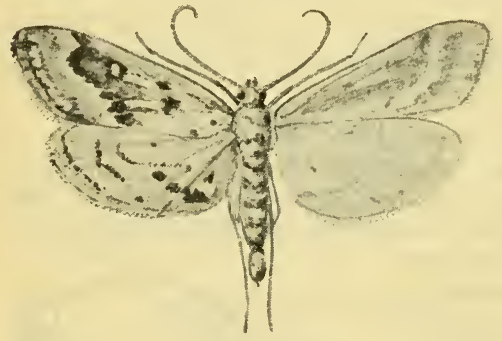

Fig. 235. Paraponyx stratiotata L. $\delta$. Vergr. $21 / 2$. schuppen weiß mit kleinen braunen Flecken zwischen den Adern. Unterseite weiß mit ganz leichtem bräunlichgelben Anflug, die Binden nur sehr undeutlich.

ㅇ. Vorderflügel hellbraun, Binden wie beim ơ, aber aus der dunkleren Grundfarbe nur wenig hervortretend. Discocellularfleck deutlich, mit hellem Kern. Hinterflügel weiß mit braunem Anflug, Querbinde deutlich, wenig unterbrochen, außerdem Spuren einer basalen Querbinde. Unterseite ausgedehnt bräunlich. Flügelspannung 18(ठ) 26(O) $\mathrm{mm}$. Ende Juli-September, an Gewässern.

Eier oval, grün, an schwimmende Blattstücke abgelegt.

Raupe (Fig. 234) vorn und hinten etwas verjüngt, jederseits vom 2. Segment an mit 3 Längsreihen langer, dünner, büschelweise von gemeinsamem Stamm ausgehender Kiemenfäden. Körper etwas durchscheinend, hellgrünlich, olivenfarben oder gelb. Kopf sehr klein, braun, Mundpartie und Hinterrand schwarzbraun. Kiemenfäden grauweiß, Stigmen sehr klein, schwarz. Länge bis $25 \mathrm{~mm}$. Herbst-Juni an Krebsschere (Stratiotes aloides L.), Wassernuß (Trapa natans L.), Wasserstern (Callitriche), in einem aus 2 Blattstücken zusammengesponnenen Gehäuse. Führt in kurzen Zwischenräumen mit dem Körper in dorsoventraler Richtung heftig schlagende Bewegungen aus, jedenfalls zur Beförderung der Kiemenatmung, wobei das Hinterende unbeweglich bleibt. Die jungen laupen fressen nur die Oberflächenschicht der Blätter, während die älteren große runde Stïcke herausfressen. Überwintert bis April ruhend zwischen den Blättern der Futterpflanze. Verpuppung unter Wasser zwischen 2 oder 3 Blattstïcken in länglichem, weißem, wasserdichtem Gespinst.

Puppe kegelförmig, glatt, zuerst gelb mit braınen Augen, dann die Flügelscheiden dunkel graubraun, Thorax hellbraun, Hinter- 
leib weißlich fleischfarben mit hellbraunen Querstreifen. Stigmen orangebraun, schwarz umrandet. Hinterende stumpf, am Kopf 2 schwarze Härchen. Puppenruhe 4 Wochen.

Paraponyx nivalis Schiff.

Saum der Vorderflügel stark algeschrägt, weiß. Vorderflügel mit 3 bramen Querbinden, die basale nahe dem Vorderrand in einem dunkelbraunen Punkt endigend, die mittlere vom Vorderrand bis zur Ader 2 stark geschwungen, den aus 2 scharfen dunkelbraunen Punkten bestehenden Discocellularfleck umfassend, die äußere blasser, dem Saum parallel, auf den Adern mit gegen den Rand vorgezogenen Spitzen. Längs des Saumes eine feine braune Linie, Saumschuppen bräunlich. Hinterflügel mit einer mittleren und einer distalen Querbinde. Zeichnung der Unterseite blaß und undeutlich, Discocellularfleck des Vorderflügels sichtbar. Flügelspannung 20-21 mm. Juni-Juli, in Bayern (Alpen), selten.

Entwicklung unbekannt.

\section{Cataclysta $\mathrm{Hb}$. (Fig. 236).}

Stirn flach, so breit wie die Augen. Ocellen fehlen. Fühlerglieder am Ende verbreitert, beim o etwas stärker als beim $q$, mit dreiseitigem Umriß. Labialtaster stark aufwärts gebogen, anliegend beschuppt, 3. Glied sehr dünn. Maxillartaster sehr kurz, stummelförmig. Hinterleib wie bei Nymphula. Vorderschenkel doppelt so lang wie die am Ende erweiterte Schiene, Tarsus so lang wie Schenkel und Schiene zusammen. Schenkel und Schiene der Mittelbeine von gleicher Länge, Hinterschiene fast doppelt so lang wie der Schenkel, vordere Sporne auf der

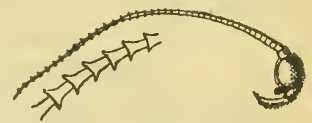

Fig. 236. Cataclysta lemnato L. Kopf. Mitte. Vorderflügel schlank, ca. $2^{1} / 2$ mal länger als breit, Hinterflügel mit schwach gebogenem Vorderrand und breit gerundetem Innenrand. Geäder wie bei Nymphula.

Die Zeichnung besteht aus braunen Querstreifen, einem dunklen Discocellularfleck im Vorderflügel und einem scharfen schwarzen Saumband mit einer Reihe weißer Punkte im Hinterflügel.

\section{Cataclysta lemnata L. (Fig. 237).}

ऽ. Körper und Flügel weiß, Fühler braun, Taster weiß mit sch warzem Endglied, Beine teilweise braun. Vorderflügel mit kleinem braunen Discocellularfleck und braunem Saumband sowie mit Andeutung einer braunen Subbasal- und Submarginalbinde. Hinterflügel mit scharfem dunkelbraunen Zellenfleck, einer breiten, subbasalen, vom Innenrand bis in die Zelle reichenden Zackenbinde und mehreren unregelmäßigen braunen Linien hinter der Mitte. Randpartie bräunlichgelb mit tiefschwarzem Saumband, das eine Reihe kleiner silberweißer Flecke einschließt. Unterseite olne scharfe Zeichnung, Vorderflügel braun, Hinterflügel weiß mit dunklem Zellenfleck und undeutlicher brauner Mittelbinde. Saumband von oben etwas durchscheinend.

ㅇ. Körper ausgedehnt braun. Vorderflügel braun mit unscharfer dunklerer Zeichnung, welche die Subbasalbinde, den Disco- 
cellularfleck und die Submarginalbinde erkenmen läßt; außerhalb der letzteren von der Spitze bis nahe zum Innenwinkel eine weißliche Linie, welche wie beim o das braune Saumband einschließt. Hinterflügel weiß, Zeichnung schärfer als beim đ’, Basal-

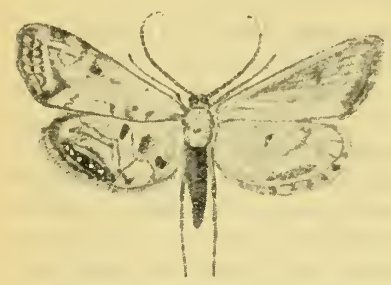

Fig. 237. Cataclysta lemnata L. Vergr. $2^{1 / 2}$. binde breiter, außen von einer feinen Linie begleitet, hinter der Mitte eine gezackte Doppelbinde. Unterseite der Vorderflügel braun, der Hinterflügel vorwiegend weif mit Andeutung derselben Zeichnung wie oben. Flügelspannung $16\left(\delta^{\circ}\right)-22(+) \mathrm{mm}$. Ende MaiAugust, wahrscheinlich in 2 Generationen. Häufig an stehenden Gewässern.

Raupe glatt mit einzelnen Härchen, olivenfarben mit braunen und schwärzlichen Strichen. Kopf klein, gelblich, Nackenschild dunkler. Stigmen sehr klein. Herbst-Mai, hauptsächlich an der Unterseite von Wasserlinsen (Lemna), Verpuppung Anfang Mai in einem aus Wasserlinsen oder anderen Pflanzenstücken verfertigten, innen weiß ausgesponnenen, sackartigen Gehäuse.

Puppe schlank, schwarzbraun, mit vorstehenden Knöpfchen am Hinterende. Puppenruhe 2 Wochen.

\section{Acentropus Curt. (Fig. 238 u. 239).}

Stirn flach gewölbt, etwas breiter als die Augen. Ocellen fehlen. Fühler ungefähr von der Länge des Körpers, ziemlich dick. Glieder kurz, so lang wie breit. Labialtaster dick, abwärts gebogen, Maxillartaster fehlen. Körper glatt und anliegend beschuppt. Vorderhüften verlängert und verdickt, fast so lang wie die Schenkel, Schienen kürzer als die letzteren; Mittelschienen ebenso lang wie die Schenkel, Hinterschienen länger, mit äußerst kurzen Spornen. Flügel nur

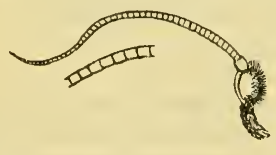

Fig. 238.

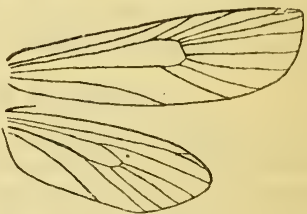

Fig. 239.

Fig. 238 u. 239. Acentropus niveus Oliv. ठ․ Kopf und Geäder.

beim ơ, halbdurchsichtig, dünn beschuppt und ohne Zeichnung, lang und schmal, Vorderflügel 3-4 mal so lang wie breit, mit abgerundeter Spitze und stark abgeschrigtem, in flachem Bogen in den Innenrand übergehendem Anßenrand. Hinterflügel 2-3mal so lang wie breit. Flügel des $q$ rudimentär, stummelförmig. Zelle bis über die Flïgelmitte reichend. Ader 4 und 5 stark genähert, 6 und 7 getrennt, $\$+9$ mit langem gemeinsamen Basalstïck und sehr 
kurzer Gabel, 8 in die Spitze, 10 und 11 frei aus der Zelle, schräg in den Vorderand. Im Hinterflügel 4 und 5 getrennt aus dem Zellenende, 6 eine Strecke vor dem Zellenende entspringend, frei, 7 und 8 erst liurz vor der Spitze getrennt.

\section{Acentropus nivens Oliv. (Fig. 240 u. 241).}

Körper bräunlichgełb mit weißgrauer, beim of mehr bräunlicher Beschuppung. Flügel des ơ durchscheinend, milchig grauweiß beschuppt, die Hinterflügel heller als die Vorderflügel. Flügelspannung des of $11-17 \mathrm{~mm}$. Nai-Juni und September.

O stets im Wasser. Begattung an der Oberfläche.

Eier in Klumpen oder flachen scheibenförmigenGelegen in einer Gallerthülle an die Nahrungspflanzen alygelegt. Eiruhe ca. 3 Wochen.

Raupen zunächst grünlichgelb mit hellbraunem, dunkel gerandetem Kopf und Nackenschild, später weißlich-

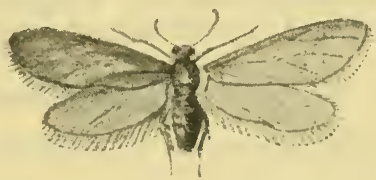

Fig. 240.

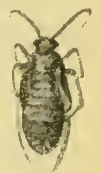

Fig. 241.

Fig. 240 u. 241. Acentropus niveus Oliv, ठ u. ․ Vergr. '2. gell, durchscheinend. Am 1. Hinterleibsring am breitesten, vorn und hinten schmäler. Mit unregelmäßigen Längsreihen kleiner borstentragender Hautwarzen. 9 Stigmenpaare, keine Kiemenfäden. In ca. 6 Wochen erwachsen, 12-14 mm lang.

2 Generationen. Raupen September-Mai und Juli-August im Wasser, besonders an verschiedenen Laichkrautarten (Pot a mo g e to n), auch an Wassemuß (Trapa natans L.), Tansendblatt (Myriophyllnm), Zanichellie (Zanichellia), Seegras (Zostera), in der ersten Woche in Innern der Pflanze, damn außen an den Blättern, in einem röhrenförmigen Gehäuse aus Blattstücken, oft in beträchtlicher Tiefe, bis zu $3 \mathrm{~m}$. Verpuppung in einem aus Blattstücken neu verfertigten Gehäuse, welches mit dem grauweißen luftgefüllten Cocon verwebt und an der Nahrungspflanze befestigt ist.

Puppe stets unter Wasser, mit dem Kopf alowärts im Cocon, hell gelblichbraun mit dorsalen Querstrichen und hellerer Unterseite. Kopf mit 3 Paar zum Öffnen des Gehäuses dienenden Dornen. Ilinterende stumpf, vorletztes und letztes Segment mit Chitinhäkchen zur Befestigung im Cocon. of P'uppen kleiner und schlanker als die ‥ Puppenruhe ca. 25 Tage.

\section{Tortricidae, Wickler.}

Kileinere Arten, stets unter Nittelgröße, mit verhältnismäßig kräftigem Körper, mäßig langen Beinen und gerundet viereckigen, in der Ruhe flach dachförmig gehaltenen Vorderflügeln. Angen nackt; Ocellen vorhanden. Fühler fadenförmig, häufig gewimpert, selten bein $\delta$ gezähnt oder gekämmt. Rüssel meist kräftig entwickelt. Maxillartaster fehlen. Labialtaster gut entwickelt, aufgebogen oder vorgestreckt, anliegend oder abstehend beschuppt, selten verlängert, mit kurzem Endglied. Vorderflügel groß und breit, trapezförmig, selten melır dreieckig, mit steilem Außenrand 
und 12 getrennten Adern, selten 7 und 8 gestielt. Hinterflügel breit, gerundet, stets mit Haftborsten und 3 Innenrandadern, im Geäder wechselnd; hintere Mittelader bei einer Gruppe oben lang behaart.

Raupen walzig, an Kopf und Hinterende etwas verjüngt, 16 füßig, mit Kranzfüßen, mit stark chitinisiertem Nacken - und Afterschild und feinen, paarweise geordneten, borstentragenden Punktwärzchen. Zwischen aufgewickelten und versponnenen Blättern, in Blüten und Früchten, in Pflanzenstengeln und Wurzeln usw.

Puppen mit spitzem oder stumpfem Hinterende, am Hinterleil, mit dorsalen Querreihen spitzer Dornen und ventralen Dornwärzchen oder mit Häkchen am Hinterende.

Von der sehr artenreichen Familie kommt nur eine Gattung mit 2 deutschen Arten ständig am Wasser vor.

\section{Epibleminae.}

Hintere Mittelader der Hinterflügel oben lang behaart.

$$
\text { Bactra Steph. (Fig. } 242 \text { u. 243). }
$$

Stirn abstehend beschuppt. Fühler gewimpert. Taster vorn verbreitert und glatt abgeschnitten, dicht beschuppt. Thorax glatt

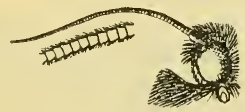

Fig. 242.

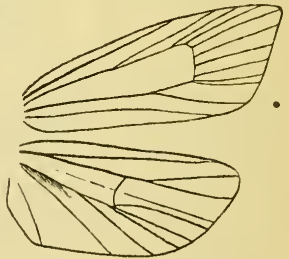

Fig. 213.

Fig. 242 u. 243. Bactra lanceolana Hb. Kopf und Geäder.

beschuppt. Hinterschienen des of ohne Haarpinsel. Ader 3, 4 und 5 der Hinterflügel dicht beieinander aus dem unteren, Ader 6 und 7 gestielt, aus dem oberen Zellenende.

Raupen in Sumpfgräsern.

2 deutsche Arten.

Artenübersicht.

Imagines.

Vorderflügel mit feiner dunkler Strichelung am Vorderrand und einem dunklen mittleren aus einzelnen Flecken gebildeten Längsstrahl.

B. lanceolana. Vorderflügel mit fleckiger, aus unterbrochenen, breiten dunklen Querbinden bestehender Zeichnung.

B. furfurana.

Raupen.

Weißlich, Kopf und Nackenschild schwarz. Grünlich, Kopf schwarz, Nackenschild braun.

B. lanceolana.

B. furfurana. 
Bactra lanceolana $\mathrm{Hb}$. (Fig. 244).

Fühler dunkelbraun, Kopf, Thorax und Hinterleib graubraun. Vorderflügel in der Grundfärbung und Zeichnung variabel, meist hellgrau bis gelblich oder bräunlich grau, mit zuweilen stark zurïcktretender schwarzlorauner Zeichnung. Vorderrand mit schräger dunkler Strichelung. Die Hauptzeichnung besteht aus einem dunklen Wisch oder Fleck auf der hinteren Mittelader, einem winkelförmigem Fleck am Zellenende und einem Strich an der Spitze; schwach gezeichnete Tiere zeigen nur einen kleinen Fleck am Zellende und an der Spitze; zuweilen zieht ein dunkler Längsschatten von der Wurzel bis zur Spitze. Hintere Flïgelhälfte und Außenrand mit unregelmäßigen dınklen Punkten und Linien. Hinterflügel bräunlich grau, heller oder dunkler. Unterseite des Vorderflügels dunkel graubraun, Vorderrand gegen die Spitze und Saumschuppen heller, der Hinterflügel heller, mehr grau. Flügelspannung $12\left(0^{\circ}\right)-15(q) \mathrm{mm}$. Ganz Europa, in Deutschland Mai-Juni und August-September, stellenweise sehr häufig.

Raupe in der Jugend lebhaft grün, später schmutzig weiß mit grünlichem oder rötlichem Anflug; Kopf und Nackenschild schwarz, Afterschild braun. April-Mai und Juli-August im unteren Stengel von Binse (Juncus ef fusus L.) und;Cypergras (Cy perus longus L).

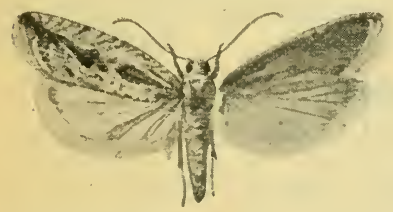

Fig. 241. Bactra lanceolana Hb. Vergr. 4.

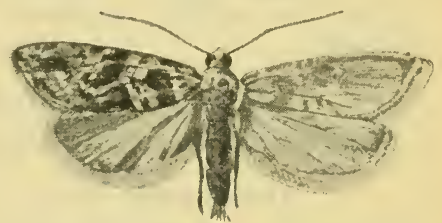

Fig. 245. Bactra furfurana Hew. Vergr. 4.

Bactra furfurana $\mathrm{Hew}$. (Fig. 245).

Fühler dunkelbraun, Kopf und Thorax gelblich, grau oder braun, Hinterleib bräunlich grau. Oberseite der Vorderflügel weißlich oder gelblich grau, beim of mit schwarzbrauner, beim of mit hellbrauner fleckiger Zeichnung, bestehend aus einer basalen Querbinde, welche den Vorderrand frei läßt, einer breiten gebrochenen Mittelbinde und einem Wisch an der Spitze. Zeichnung wie bei lanceolana ziemlich variabel. Außerdem am Vorder- und Innenrand unregelmäßige dunkle Flecke. Hinterflügel bräunlich grau, ebenso die Unterseite. Flügelspannung $12\left(\delta^{\circ}\right)-19(+) \mathrm{mm}$. Mai-Juli zerstreut und seltener als lanceolana.

Raupe hell grünlich, Kopf schwarz mit weißem Längsstrich, Nacken- und Afterschild braun. April-Mai und Juli im Stengel von Binse (Juncus effusus L.) und Seesimse (Scirpus lacustris L.).

\section{Tineidae. Schaben, Motten.}

Meist kleine zarte Formen mit schmalen spitzen Flügeln und langen kräftigen Hinterbeinen. Ocellen vorhanden oder fehlend, Fühler fadenförmig, mit verlängertem walzigen, zuweilen sehr auffällig gebildeten Basalglied. Rüssel vorhanden oder fehlend. Maxillartaster oft vorhanden, Labialtaster meist sehr lang und dünn, auf- 
gebogen, zuweilen kurz und längend. Hinterschienen mit kräftigen langen Spornen, zuweilen außerdem mit langen steifen Borsten. Flügelgeäder vollständig oder rudimentär, Ader 7 und 8 im Hinterflügel, wenn beide vorhanden, stets getrennt.

Raupen meist 16 füßig, selten 14 oder 18 füßig, mit Kranzfüßen, zuweilen fußlos, mit verschiedener Lebensweise.

Äußerst artenreiche Familie mit zahlreichen Untergruppen, von denen aber nur wenige Anwohner des Wassers sind.

\section{Übersicht über die am Wasser vorkommenden Unterfamilien.}

I. Labialtaster lang und dünn, aufgebogen; Maxillartaster fehlen. 1. Fühlerglied nicht auffällig gebildet, Hinterschienen ohne lange Borsten.

1. Flügel breit, Vorderflügel mit rechtwinkliger Spitze und steilem Außenrand, ziemlich große Art.

2. Flïgel schmal und spitz, kleine zarte Arten.

a) Hinterflügel linear, ohne Zelle, mit nur 2 Adern.

b) Hinterflügel mit Zelle, Geäder normal. Laverninae. Cosmopteryginae.
Laverninae. II. Labialtaster kurz, hängend; Maxillartaster vorhanden. 1. Fühlerglied sehr auffällig vergrößert, Hinterschienen mit langen steifen Borsten.

Nepticulinae.

\section{Orthotaeliinae.}

Mit den Merkmalen der einzigen Gattung

Orthotaelia Steph. (Fig. 246 u. 247).

Stirn und Scheitel mit dichter. etwas abstehender Behaarung. Ocellen fehlen. Fühler wenig länger als die Hälfte der Vorder-

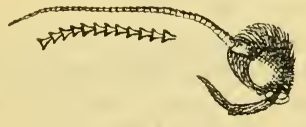

Fig. 246.
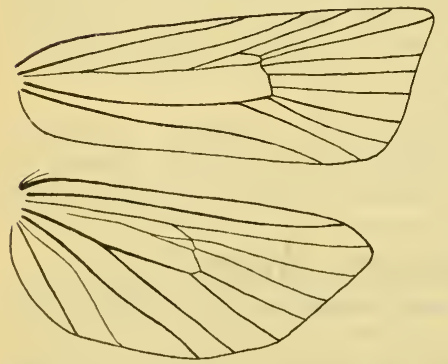

Fig. 247.

Fig. 246 u. 247. Orthotaelia sparganella Thunb. Kopf und Geäder. flügel, Basalglied wenig verdickt, Geißelglieder am vorderen Ende etwas erweitert. Taster lang und dünn, aufgebogen, bis zum Sicheitel reichend, anliegend beschuppt. Rüssel sehr kurz. Hinterleib langgestreckt, mit melır als der Hälfte über den Analwinkel der Hinterflügel hinausreichend.

Vorderflügel etwa $2 \frac{1}{2}$ mal so lang wie breit. Vorder- und Innenrand bis zum Saum fast parallel, Außenrand fast senkrecht, gerade. Ader 3 und 4 stark genähert aus dem unteren, 9 aus dem oberen Zellenende, alle Adern außer 3 und 4 deutlich getrennt nnd einzeln aus der Zelle. Oberer Teil der Zelle durch eine in der Verlängerung von Ader 6 verlaufende Längsader abgeteilt. Hinterflügel breit, halbkreisförmig, alle Aderı einzeln, Ader 3 und 4 getrennt aus 
dem unteren Zellenende, 5 von 4 mehr als doppelt so weit entfernt als von 6. Beine lang und robust, Vorder-; Mittel- und Hinterschienen $1 / 2,1 / 1$ und $11 / 2$ der Schenkellänge.

Eine deutsche Art.

Orthotaelia sparganella Thun b. (Fig. 248).

Fühler gelblichbraun. Kopf und Thorax, Vorder- und Mittelbeine lebhaft rost- oder ockerbraun, Hinterleib und Hinterbcine hell bräunlichgraı. Vorderflügel oberseits von der Farbe des Thorax, zuweilen etwas dunkler oder auch heller, melır olivenfarben mit mehr oder weniger deutlichem, dunkleren, rötlich purpurbraunen, gegen den Saum bis zum Vorder- und Hinterwinkel sich verbreiternden Mittellängsschatten. Beim ơ meist am Zellenende ein schwärzlicher Fleck, in der Zelle, längs der Ader 1 und vor dem Saum einige oft sehr undeutliche schwärzliche Punkte. Hinterflügel glänzend, hellgrau mit leichtem bräunlichen Anflug. Unterseite einfarbig hell bräunlichgrau, im Hinterflügel heller. Flïgelspannung 20-28 mm. JuliAugust.

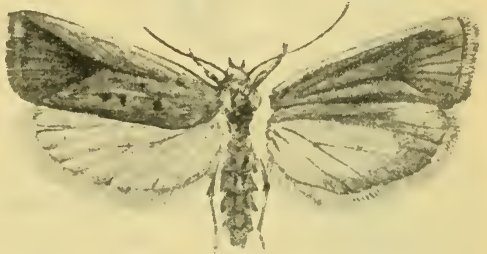

Fig. 248. Orthotaelia sparganella Thumb. Vergr. 2.

R a u p e schlank, blaßgrün mit rötlichgrauer Rüickenlängsstrieme. Kopf braun, Nackenschild graubraun mit dunklerem Seitenrand; Afterschild breit, flach vertieft mit erhabenen Rändern, hinten in 2 gespreizte Zähnchen auslaufend. Vorn auf den beiden ersten Segmenten Querreihen kräftiger schwarzer Warzenpunkte. Herbst - Juni (auch im August beobachtet) in verschiedenen Wasserpflanzen: Wasserschwertlilie (Iris pseudacorus L., auch in I. germanica L.), Rohrkolben (Typha angustifolia L.), Igelkolben (Sparganium ramosum Huds., Sp. simplex Huds.), Wasserschwaden (Glyceria aquatica Wahlenb.), Simse (Scirpus lacustris L.). In der Jugend in jungen Blättern, später in Stengel ïber der Wurzel in einer Röhre. Von außen bemerkbar durch die abgestorbenen Herzblätter. Oft in großer Zahl an einem Ort. Verpuppung in der Wohnpflanze.

$\mathrm{Puppe}$ zylindrisch, am Hinterende fast breiter als vorn, blaßgelblich mit bräunlichem Vorderende. Tasterscheiden abstehend, gekrümmt, die mittleren lang, nach hinten divergierend, die seitlichen kurz, stumpf. An den Einschnitten eine dichte Querreihe spitzer, rïckwärts gekehrter Dörnchen, Hinterende in 2 divergierende Spitzen auslaufend.

\section{Cosmopteryginae.}

Kleine zarte Arten mit auffälig schmalen und spitzen, sehr lang befransten Flügeln. Yorderflügel mit lehhaft metallglänzenধler Zeichnung. Hinterflïgel linear, mit 2 einfachen ddern. Rüssel klein; Maxillartaster fehlen; Labialtaster sehr lang und dünı, sichelförmig aufgebogen.

Eine deutsche Gattung. 


\section{Cosmopteryx Hb. (Fig. 249 и. 250).}

Stirn stark vortretend, hoch gewölbt. Ocellen fehlen. Fühler gekerbt, etwas külzer als der Vorderflügel, Basalglied verlängert und am Ende verdickt. Taster sehr lang und dünn, sichelförmig aufgebogen, mit der Spitze den Scheitel überragend; 2. Glied fast so lang wie das Endglied, am Ende etwas verdickt. Hinterschienen von doppelter Länge der Schenkel, Sporne sehr lang und kräftig, die vorderen auf der Mitte. Vorderflügel etwa sechsmal so lang

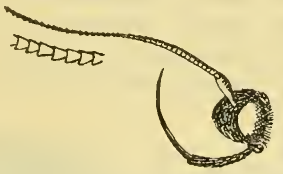

Fig. 249.

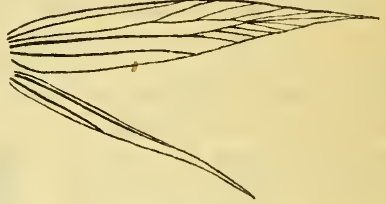

Fig. 250.

Fig. 249 u. 250. Cosmopteryx lienigiella Zell. Kopf und Geäder.

wie breit, mit sehr scharfer feiner Spitze. Zelle schmal und sehr spitz, Ader 2-5 in ziemlich gleichen Abständen aus der Zelle in den Hinterrand, Ader 7 aus dem Zellenende in die Flügelspitze mündend, mit 6 und 8 kurz gestielt; Ader 9 kurz vor dem Zellenende, 11 ungefähr auf der Zellenmitte, 10 in der Mitte zwischen beiden. Hinterflügel linienartig schmal mit sehr langen Saumhaaren und nur 2 deutlichen Adern, je eine in dem Vorder- und Innenrand.

Raupen in Blättern minierend.

\section{Artenübersicht.}

\section{Imagines.}

Vorderflügel hell graubraun mit 2 silberglänzenden schwarzgepunkteten Querbinden.

C. lienigiella. Vorderflügel schwarzbraun mit ockergelber goldgesäumter Querbinde.

C. scribaïella.

Cosmopteryx lienigiella Zell. (Fig. 251).

Kopf und Thorax gelblich graubraun mit 2 seitlichen und einer mittleren weißen Längslinie. Fühler schwarzbraun, Taster

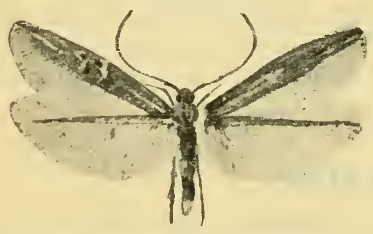

Fig. 251. Cosmopteryx lienigiella Zell. Vergr. 3. anßen schwarzbraun, innen weiß beschuppt. Beine hell graubraun, teilweise weißlich. Vorderflügel oberseits gelblich graubraun, mit 3 von der Basis bis zur Mitte reichenden, weißen Längslinien am Vorderrand, auf der Mitte und am Innenrand, sowie einigen kurzen Linien zwischen denselben. Hinter der Mitte und am Ende des 2. Drittels je eine silber- oder etwas goldglänzende Querbinde, die innere mit einem schwarzen Fleck vorn an der Außenseite, die äußere mit einigen kleinen schwarzen Fleckchen an der Innenseite. Von jen- 
seits der äuferen Binde bis zur Flügelspitze ein weißer Mittellängsstrich. Saumhaare hell graubraun. Hinterflügel graubraun, weißlich glänzend. Saumhare etwas dunkler als im Vorderflügel. Unterseite der Flügel dunkelbraun mit weißem Glanz. Hinterleil) oberseits dunkelbraun mit sehr schmalen, an den Seiten zu großen Flecken erweiterten weißen Hinterrandsäumen. Unterseite glänzend weiß. Flügelspannung 9-12 mm. Juni-Juli, an Rohr.

Raupe (Fig. 252) hellweißlich, rosa, durchscheinend, mit schwarzem Kopf und zuweilen bindenartigen dunkleren (Querstreifen auf den vorderen Segmenthälften. Am 2. Segment am breitesten, nach hinten allmählich verschmälert. Länge $8-10 \mathrm{~mm}$. HerbstFrühjahr minierend in den Blättern des Rohrs (Phragmites) an der Blattoberseite. Wechselt von Blatt zu Blatt. Minen flach, als große, lange, grangrüne oder weißliche Flecke erscheinend. Exkremente am unteren Ende der Mine angesammelt, selten aus derselben entfernt. Überwintert in der Mine in einem zähen, halbdurchsichtigen Cocon innerhalb eines großen ovalen, ausgesponnenen Raumes. Verpuppung im Frühjahr.

\section{Cosmopteryx scribaïella Zell.}

Körper tief schwarzbraun, Kopf, Thorax und Beine mit lebhaft goldglänzenden Flecken. Unterseite des Hinterleibs in ganzer Ausdehnung goldglänzend. Fühler schwarz, mit weißer Spitze und 2 weißen Ringen vor derselben. Taster schwarz, innen weißlich. Vorderflügel tief schwarzbraun, auf der Mitte eine breite, lebhaft ockergelbe, hinten verschmälerte Quer-

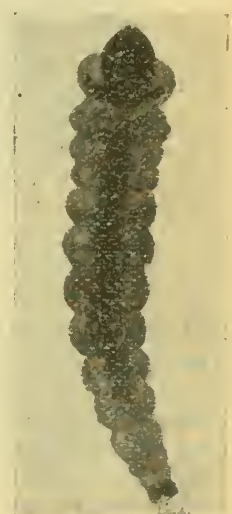

Fig. 252. Cosmopte. ry.x lienigiella Zell. Raupe. Vergr. 6. Nach Stainton. binde, beiderseits von goldglänzenden Binden eingefaßt; an der Basis ein langgestreckter, breiter, goldglänzender Fleck, vor der Spitze ein silberweißer Längsstrich. Hinterflügel heller als die Vorderflügel, mehr graubraun, einfarbig. Unterseite dunkelgraubraun, im Vorderflügel.stark glänzend. Flügelspannung 9-11 $\mathrm{mm}$.

Mit der vorigen Art.

Raupe ebenfalls in Phragmites, oft 2 oder 3 in einem Blatt, ähnlich der von $C$. lienigiella, auch in der Minenbildung. Verpuppung in der Mine.

\section{Laverninae.}

Ziemlich kleine Arten mit schmalen spitzen Flügeln. Kopf anliegend beschuppt oder behaart. Ocellen meist fehlend. Riüssel vorhanden. Naxillartaster fehlen, Labialtaster lang und dünn, sichelförmig aufgebogen. Zelle in beiden Flügeln vorhanden

Raupen nackt, meist im Innern von Pflanzen, im Stengel oder in Blättern minierend.

Limnaecia Staint. (Fig. 253 u. 254).

Stirn vortretend, stark gewölbt. Fülller dünn, so lang wie der Leib, beim $\delta$ etwas länger, Basalglied verlängert und am Ende er- 
weitert, $4 \mathrm{mal}$ so lang wie dick, Geißelglieder kurz, am Ende verbreitert. Taster sehr lang, dünn, sichelförmig, Endglied den Scheitel weit üb erragend, dümn und spitz, etwa doppelt so lang wie das etwas dickere anliegend beschuppte Mittelglied. Beine kräftig, Vorder-, Mittel- und Hinterschienen $=1 / 2,1 / 1$ und $2 / 1$ der Schenkellänge, Hinterschienen oben lang behaart, Sporne kräftig, die vorderen auf der Schienenmitte. Vorderflügel schmal lanzettlich mit scharfer

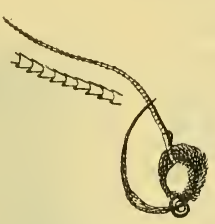

Fig. 253.

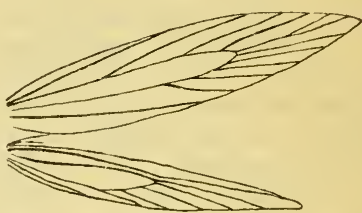

Fig. 254.

Fig. 253 и. 254. Limnaecia phragmitella Staint. Kopf und Geäder.

Spitze, 5 mal so breit wie lang, Saumhaare am Hinterrand so lang wie die Breite. Ader 2 auf der Flügelmitte, $2-5$ in ziemlich gleichen Abständen, 6 aus dem Zellenende, $7+8$ lang gestielt, die ïl)rigen Adern einzeln. Hinterflügel halb so breit und wenig kürzer als der Vorderflügel. Saumhaare an der Basis doppelt so lang wie die Flïgelbreite, Zelle bis zur Mitte reichend, Ader 5 und 6 aus dem Zellenende, alle Adern einzeln. Innterleib des ठे mit kräftiger stark behaarter Haltezange.

Einzige deutsche Art:

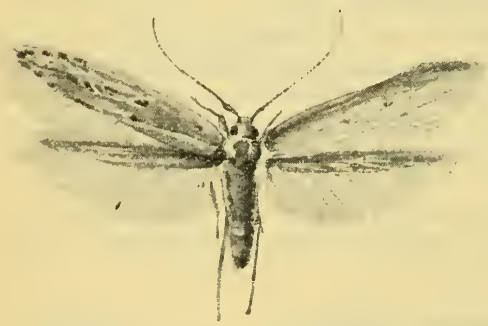

Fig. 255. Limnaecia phragmitella staint. Vergr. $21 / 2$.

\section{Limnaecia phragmitella}

Staint. (Fig. 255).

Körper und Flügel hell graubraun, von der Farle trockenen Schilfes. Hinterflügel etwas heller, grau, glänzend. Saumlhaare lang, gelblichgrau. Vorderflügel oberseits mit einer unbestimmten schwärzlichen

Längslinie auf der Mitte, von welcher gewölnnlich die beiden Endpunkte deutlicher und weißlich umran-

det sind. An den Aderendigungen unscharfe schwärzliche Punkte. Unterseite wie oben, ohne Zeichnung. Flïgelspannung 14(ठ) bis 21(さ) $\mathrm{mm}$. Juni-August, zerstreut.

Raupe (Fig. 256) breit und flach, gelblichweiß mit 3 hell graubraunen Rückenlinien und ebensolcher Seitenlinie. Kopf glänzend gelbbraun mit dunklerem Hinterrand; Nackenschild etwas dunkler als der Kopf, mit hellem Mittelfleck. Länge bis $12 \mathrm{~mm}$. August -April in den Kolben des breitblättrigen Rohrkolbens (Typha 
latifolia L.), wächst langsam, zuweilen in großer Zahl, bis zu 30, in einem Kolben. Die befallenen Kolben eigentümlich zerfetzt und

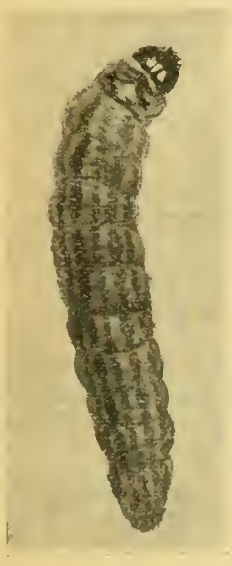

Fig. 256.

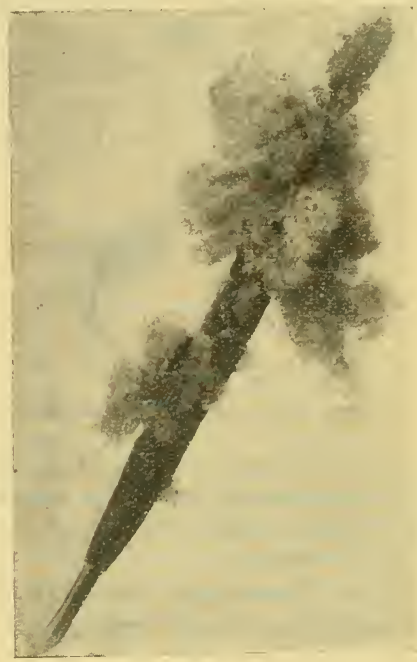

Fig. 257.

Fig. 256. Limnaecia phragmitella Staint, Raupe. Vergr. 5. Nach Stainton. Fig. 25\%. Rohrkulben, durch Raupen von Limnaecia phragmitella zerfressen. Nach Stainton.

zerrissen, so daß der flaumige, flockige Inhalt heransquillt (Fig. 25ॅ). Verpuppung im Kolben in einem dicht mit Flam unkleicleten Gespinst.

\section{Nepticulinae.}

Sehr kleine, äußerst zarte Arten mit lang behaarten, spitzen Flïgeln. Kopf abstehend behaart. Ocellen fehlen. Fühler mit auffällig stark vergrößertem plattenförmigen Basalglied. Riüssel fehlt. Maxillartaster vorhanden, mehrgliedrig, dünn, fadenförmig. Labialtaster hängend. Geäder rudimentär, Zelle der Vorderflitgel fehlend oder sehr kurz, Hinterflügel stets ohne Zelle. Hinterschienen mit langen steifen Borsten.

Raupen 18füßig, in Pflanzenstengeln und Blättern minierend.

Mehrere Gattungen, davon eine am Wasser.

Opostega Zell. (Fig. 258 u. 259).

Stirn und Scheitel abstehend beschuppt. Fühler so lang wie der Vorderflügel oder wenig kürzer, Basalglied stark vergrößert, blattfürmig, gewölht, die Höhlıng nach außen gekehrt; Geißel cinfach. Lahialtaster kurz und dick, hängend, Naxillartaster länger 
und schlanker, mehrgliedrig. Vorderhüften stark verbreitert, so lang wie der Schenkel. Schienen und Metatarsen der Hinterbeine mit dichter langer stachliger Beborstung, ebenso die Mittelschienen, aber viel schwächer. Hinterschienensporne groß und kräftig, die vorderen vor der Mitte. Vorderflügel etwa dreimal so lang wie breit, zugespitzt, mit 4 unverzweigten Längsadern; Costalader sehr

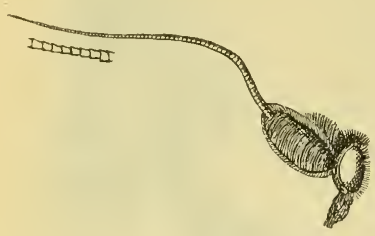

Fig. 258.

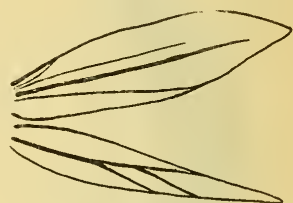

Fig. 259.

Fig. 258 и. 259. Opostega auritella Hb. Kopf und Geäder.

kurz, vordere und hintere Mittelader vor der Spitze endigend. Hinterflügel schmal und spitz mit langen dichten Saumhaaren und einer kräftigen Längsader mit 1 Ast in dem Vorder- und 2 Ästen in dem Innenrand.

Kleine schneeweiße braungefleckte Motten. Am Wasser 2 Arten. Entwicklung wenig bekannt.

\section{Artenübersicht.}

\section{Imagines.}

Vorderflügel mit deutlichem braunen Vorder- und Innenrandfleck, Spannweite 9-11 mm.

Op. auritella.

Vorder- und Innenrandfleck im Vorderflügel klein, undeutlich,

Spannweite $7-8 \mathrm{~mm}$. Op. crepusculella.

Opostega auritella $\mathrm{H}$ b. (Fig. 260).

Kopf und Thorax sowie Basalglied der Fühler weiß beschuppt. Fühllergeißel hell gelblichbraun. Beine braun. Hinterleib dunkel-

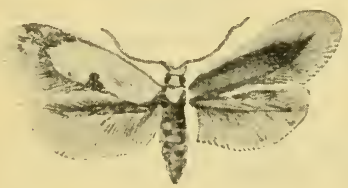

Fig. 260. Opostega auritella $\mathrm{Hb}$. Vergr. 3. braun. Oberseite der Vorderflügel schneeweiß mit graubraunen weiß untermischten Saumhaaren, einem braunen Fleck in der Mitte des Innenrandes und einem gleichen langgestreckten Fleck an der Spitze. Unterseite und die Hinterflügel ganz einfarbig graubraun. Flügelspannung 9-11 mm. Juni-Juli, Norddeutschland, an sumpfigen Stellen stellenweise-sehr häufig, fliegt in den frühen Abendstunden.

Raupe hellgrün, minierend im Stengel der Sumpfdotterblume (Caltha palustris L.). Verpuppung in einem festen weißen Gespinst. 


\section{Opostega crepusculella Z ell.}

Fühler, Kopf und Thorax wie bei auritella. Hinterleib oberseits dunkelbraun, unten hellgrau. Vorderflügel schneeweif mit 2 schmalen gebogenen schrägen hellbraunen Querlinien an der Spitze und einem zuweilen fehlenden kleinen Fleck in der Mitte des Vorder- und Innenrandes. Saumhaare weiß. Hinterflïgel weiß, Saumhare hellbräunlich. Unterseite leicht bräunlichgrau. Flügelspannung $7-8 \mathrm{~mm}$. Juni--Anfang August, ganz Deutschland an Teichen und schilfreichen Grähen, auf feuchten Wiesen.

Entwicklung unbekannt. 


\section{Register.}

\begin{tabular}{|c|c|c|c|c|c|c|c|c|c|}
\hline \multirow{2}{*}{$\begin{array}{c}\text { Acentropus } \\
\text { niveus. }\end{array}$} & \multicolumn{4}{|r|}{ Seite } & \multirow[b]{2}{*}{ Cataclysta } & \multicolumn{4}{|r|}{ Seite } \\
\hline & & & & 148 & & & & & 117 \\
\hline Ameletus & . & & & 2 & ptilum & & & & 19,3 \\
\hline & & & & 21 & lut & & . & & \\
\hline mur & & & & 75 & tum & & . & & \\
\hline & & & & & $\mathrm{Chi}$ & . & - & & \\
\hline . & . & . & & 150 & & & · & & \\
\hline & . & & & 151 & lus & & 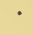 & & \\
\hline la. & . & & & . 151 & & & & & \\
\hline e & 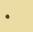 & & & 15 & $\mathrm{Chl}$ & & : & & 19, \\
\hline & 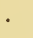 & & & 15,32 & & & • & & \\
\hline & . & & & 16,18 & 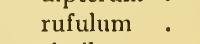 & & & & \\
\hline & . & & & 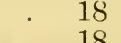 & & & & & \\
\hline & · & & - & & $\mathrm{Cl}_{1}$ & & & & 46, \\
\hline & - & & & i6, 1 & . & & * & & 51,8 \\
\hline & & & & . 17 & $\mathrm{ca}$ & & . & & 50, \\
\hline & . & & & 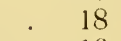 & & 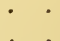 & • & & \\
\hline & . & & . & & . & & - & & \\
\hline & & & & & s. & & & & \\
\hline & - & & & 17 & & & & & \\
\hline & & & & 17,1 & & & & & \\
\hline & & & & & & & & & \\
\hline & . & & 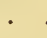 & & pes & & & & 12 , \\
\hline & . & & 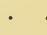 & 14,3 & & 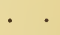 & & & \\
\hline & . & & . & 1 & $\mathrm{Co}$ & . & & & \\
\hline h & 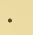 & & . & & & & . & & \\
\hline $\mathrm{h}$ & . & & . & & ryg & & & & \\
\hline & . & & 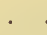 & & ery $x$ & 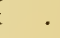 & - & & \\
\hline al & . & & 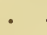 & 113 & & . & & & \\
\hline & - & & . & . 1 & & 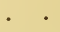 & . & & \\
\hline & & & . & & & - . & - & & \\
\hline oph & & & . & 13 & Crambinae & 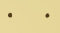 & - & & \\
\hline & & & & -100 & & & & & \\
\hline ap & - & & & 55,88 & & & & & \\
\hline & - & & - & & $\begin{array}{l}\text { ryg } \\
\text { ryx }\end{array}$ & & & & \\
\hline & - & & . & 55, & & & • & & \\
\hline & . & & . & & & & & . & \\
\hline pygmaca. & . & & & & mucronclla & & & & \\
\hline
\end{tabular}




\begin{tabular}{|c|c|c|c|c|c|c|}
\hline & & - & & & & \\
\hline us & . & $\bullet$ & - & . & $\cdot$ & 26 , \\
\hline $\mathrm{im}$ & . & . & - & . & - & \\
\hline & . & . & - & . & 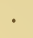 & \\
\hline & . & . & . & . & . & \\
\hline is & . & . & & . & . & \\
\hline & . & . & & . & - & \\
\hline & . & . & - & 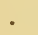 & . & \\
\hline is & & . & . & - & . & 22 , \\
\hline ilis & . & . & 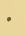 & . & . & \\
\hline era & . & . & 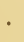 & . & 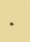 & \\
\hline . & . & - & . & 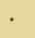 & - & \\
\hline ps & . & . & 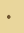 & - & 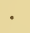 & \\
\hline . & . & . & . & - & . & \\
\hline & & . & . & . & . & \\
\hline erel & $11 \mathrm{a}$ & & . & . & . & 14 \\
\hline . & & • & . & . & . & \\
\hline erel & & dae & & . & . & \\
\hline rid & & & . & . & . & \\
\hline erid & ae & & . & . & . & \\
\hline $\min$ & ae & & . & . & . & . 15 \\
\hline a & . & . & . & . & . & \\
\hline & . & . & . & . & . & \\
\hline . & . & . & . & . & • & \\
\hline in a & & & . & . & . & \\
\hline $\ln l e$ & $\mathrm{bi}$ & & & . & • & 12, \\
\hline . . & - & . & - & . & - & \\
\hline lauta. & - & . & . & . & . & \\
\hline leuca & & 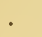 & . & & . & \\
\hline I a d & . & . & . & . & . & . \\
\hline & • & . & & . & & . 1 \\
\hline $\mathrm{nae}$ & & . & & . & . & \\
\hline $\mathrm{pha}$ & & . & & & & . \\
\hline gma & & & & & & . 1 \\
\hline gma & & var. & & & & 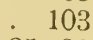 \\
\hline nia & & & & . & & 25,3 \\
\hline ns. & & . & - & . & & \\
\hline . & & . & & & & \\
\hline ennis & & & & • & ${ }^{\circ}$ & \\
\hline ea. & & & & & & \\
\hline ia. & & & & & . & \\
\hline & & & & & & \\
\hline in a & & & & & & 1 \\
\hline$y$ & & & & & & • \\
\hline $\mathrm{p}$ & & e & & & & \\
\hline cia & & & & . & & \\
\hline & & & & & & \\
\hline pet: & & & & . & & . 1 \\
\hline & & & & ${ }^{\circ}$ & & \\
\hline & & & & & & \\
\hline $\mathrm{y}$ & & & & & & 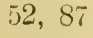 \\
\hline
\end{tabular}

Seite

Is op tery $x$

apicalis

Burmeisteri

neglecta

53, 88

serricornis

54

torrentium

53

tripunctata

54,88

54,88

I averninae

155

Lepidoptera.

96

Lep tophlebia

10,31

cincta

11

marginata

10

Meyeri

12

submarginata . . . . 11

Leptophlebiidae . . 10

Leucania . . . . . . 119

comma . . . . . . 121

impudens . . . . . . 121

impura

122

1 album

120

obsoleta

122

straminea . . . . . . 123

Leucaniinae . . . . 105

Leuctra . . . . 63,91

albida . . . . . 66

Braueri . . . . . 64

cingulata . . . . . 65

cylindrica . . . . . 63

digitata . . . . . 66

geniculata . . . . 64

hippopus . . . . . 68

inermis . . . . 68

Klapáleki . . . . 66

nigra . . . . . . 67, 92

prima . . . . . 69, 92

Leuctridae . . . . 60

Limnaecia . . . . 155

phragmitella . . . . 156

Marthamea . . . . . 45

Meliana . . . . 118

flammea . . . . 118

Miana . . . . . 101

ophiogramma . . . . 121

ophiogramma var. maerens 102

Nemura . . . . . 70, 92

avicularis . . . . . 79

borealis . . . . . 77

brevistyla . . . . . 75

cambrica . . . . . 80

cinerea . . . . 76, 95 


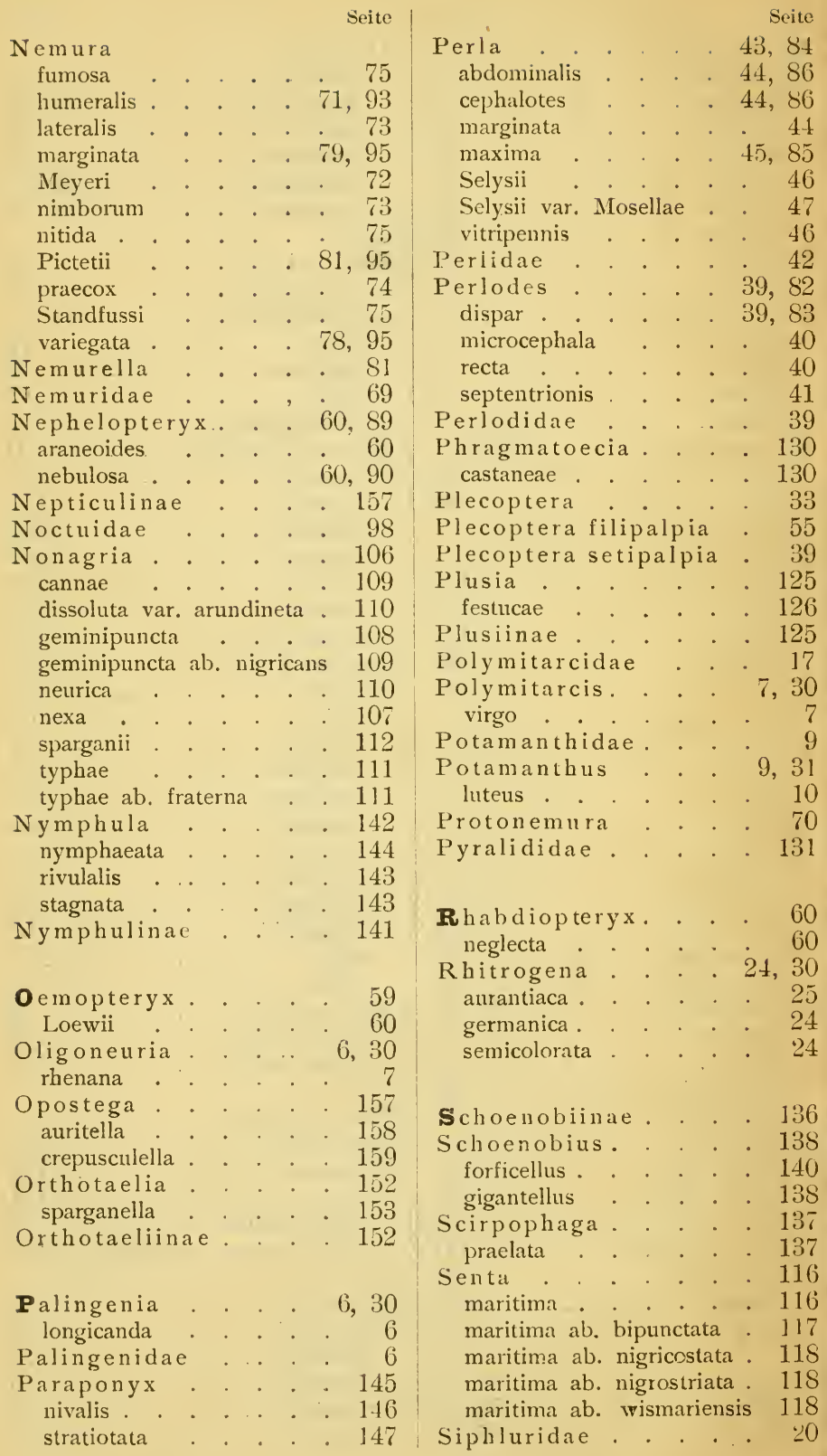


Seite

Seite

Siphlurus . . . . . 21, 32 armatus . . . . . 22

lacustris . . . . . . 22

Taeniopterygidae. . . 56 Taeniopteryx trifasciata. . . . 57, 58 Tapinostola . . . . 115 fulva . . . . . 116 Taeniopteryx . . . 57,90 Braueri . . . 57,91 Kempnyi . . . . . 57 monilicornis . . . 57 Risi . . . . . . 59 fulva ab. concolor . . 116 Hellmanni . . . . 115 Hellmanni ab. saturata . 116 Tholomiges . . . . . 129 turfosalis . . . . . 129 Tineidae . . . . 151 seticornis . . . 59, 91 Tortricidae . . . 149 


SMITHSONIAN INSTITUTION LIBRARIES nhent OL482.G2K63 Ephemerida, Plecoptera, Lepidoptera, 